Universidade de São Paulo

Faculdade de Filosofia, Ciências e Letras de Ribeirão Preto

Departamento de Química

Programa de Pós-Graduação em Química

\title{
Polímeros de coordenação à base de cobalto(II) e N,N'-bis(4-piridil)-1,4,5,8-naftaleno diimida como ligante e suas propriedades estruturais, espectroscópicas e fotoelétricas
}

Evandro Castaldelli

Tese apresentada à Faculdade de Filosofia, Ciências e Letras de Ribeirão Preto da Universidade de São Paulo, como parte das exigências para a obtenção do título de Doutor em Ciências, Área: Química

Ribeirão Preto - SP 
Universidade de São Paulo

Faculdade de Filosofia, Ciências e Letras de Ribeirão Preto

Departamento de Química

Programa de Pós-Graduação em Química

Polímeros de coordenação à base de cobalto(II) $\mathrm{e}$ $N, N$ '-bis(4-piridil)-1,4,5,8-naftaleno diimida como ligante e suas propriedades estruturais, espectroscópicas e fotoelétricas

Evandro Castaldelli

Orientador: Grégoire Jean-François Demets

Ribeirão Preto - SP 


\section{FICHA CATALOGRÁFICA}

Castaldelli, Evandro

Polímeros de coordenação à base de cobalto(II) e $N, N^{\prime}$-bis(4-piridil)-

1,4,5,8-naftaleno diimida como ligante e suas propriedades estruturais, espectroscópicas e fotoelétricas. Ribeirão Preto, 2015.

115 p. : il. ; $30 \mathrm{~cm}$

Tese de Doutorado, apresentada à Faculdade de Filosofia, Ciências e Letras de Ribeirão Preto/USP - Área de concentração: Química. Orientador: Demets, Grégoire Jean-François.

1. Naftaleno Diimidas 2. Polímeros de coordenação 3. Metal-organic frameworks 4. Dispositivos eletrônicos 


\section{Folha de Aprovação}

\section{Evandro Castaldelli}

"Polímeros de coordenação à base de cobalto(II) e $N, N^{\prime}$-bis(4-piridil)-1,4,5,8-naftaleno diimida como ligante e suas propriedades estruturais, espectroscópicas e fotoelétricas"

Aprovado em: Ribeirão Preto, de de

Prof. Dr. Instituição:

Assinatura:

Prof. Dr. Instituição: Assinatura:

Prof. Dr. Instituição: Assinatura:

Prof. Dr. Instituição: Assinatura:

Prof. Dr. Grégoire Jean-François Demets (Orientador) Instituição: Faculdade de Filosofia, Ciências e Letras de Ribeirão Preto Assinatura: 
The secret of getting ahead is getting started. - Mark Twain 


\section{Dedicatórias}

Aos meus pais Luiz e Maria Aos meus irmãos Priscila e Lucas

A minha namorada Juliana 


\section{Agradecimentos}

- Ao meu orientador, Prof. Dr. Grégoire Jean-François Demets, pela oportunidade e confiança depositados em mim;

- Ao Prof. Dr. S. Ravi P. Silva, por me receber e orientar no período que estive trabalhando em seu grupo de pesquisa no Advanced Technology Institute da University of Surrey, Reino Unido;

- Ao Prof. Richard I. Walton e Dr. Guy Clarkson, University of Warwick, pela solução da estrutura de monocristal do MOF-CoNDI-py-2 e excelentes discussões científicas;

- Ao Dr. Kostis Michelakis e ao Dr. Dave Cox pela fundamental ajuda na preparação dos dispositivos eletrônicos do MOF-CoNDI-py-2;

- Ao Dr. Chris Mills, University of Surrey, pela ajuda com os ajustes dos mecanismos de condutividade do MOF-CoNDI-py-2;

- Ao Prof. Jerome Chauvin e ao Prof. Jean-Claude Moutet, Université de Grenoble, pelas análises de eletroquímica do MOF-CoNDI-py-2;

- À Prof. ${ }^{a}$ Juliana Fonseca de Lima, pelo carinho imenso e preciosas discussões científicas. Por me incentivar nos momentos mais difíceis e ajudar a comemorar todas as vitórias;

- Ao Prof. Osvaldo Antonio Serra, que sempre acolheu e colaborou de maneira fundamental para a realização deste trabalho;

- Ao Prof. Sérgio Emanuel Galembeck, Prof. Ricardo Vessecchi Lourenço, e ao Renato Orenha, pela ajuda com os cálculos teóricos e eventuais degustações de café e cervejas locais;

- Ao Prof. Amando Ito e ao Prof. louri Borissevitch, e ao Dr. Gustavo Parra, o Pudim, pelas análises de absorção, fluorescência e tempo de vida de emissão da NDI-py;

- Ao Prof. Luiz Alberto Beraldo de Moraes, pela análise de massas da NDI-py;

- Ao Prof. Koiti Araki, pela disposição e pelas análises de reflectância difusa;

- À Prof. ${ }^{a}$ Sofia Nikolaou pelas análises de fluorescência e discussões sobre complexos, além das excelentes considerações em meu exame de qualificação;

- À Bruna e Natacha, por auxiliarem nas análises de fluorescência;

- Ao Prof. José Maurício Caiut, pelas importantíssimas discussões em meu exame de qualificação;

- Aos amigos John, Imalka, Simon e Thomas, por toda ajuda e turismo de pubs durante a estadia na Inglaterra;

- Aos técnicos Vinícius, Rodrigo e Lourivaldo pelo cuidado nas análises;

- Aos grandes amigos Flávio Xicó e PC Fô pelos memoráveis churrascos, discussões científicas e os constantes "só vamos tomar uma";

- Aos amigos de laboratório, principalmente o Francisco Caixa pelas colaborações;

- À FAPESP, pelo suporte e auxílio financeiro concedido nos projetos de Doutorado 2011/22379-6 e de estágio no exterior, 2012/09719-5;

- Dedico esta linha para todos que, por descuido, tenha porventura esquecido de mencionar;

- E todos aqueles que de alguma forma me ajudaram nesta caminhada, muito obrigado. 


\section{Resumo}

Polímeros de coordenação têm atraído a atenção de pesquisadores na última década por conta de sua incrível versatilidade e virtualmente infinito número de possibilidades de combinação de ligantes orgânicos e centros metálicos. Estes compostos normalmente herdam as características magnéticas, eletrônicas e espectroscópicas de seus componentes base. Entretanto, apesar do crescente número de trabalhos na área, ainda são raros os polímeros de coordenação que apresentem condutividade elétrica. Para este fim, utilizou-se a $N, N^{\prime}$-bis(4-piridil)-1,4,5,8-naftaleno diimida, ou $\mathrm{NDI}$-py, que pertence a uma classe de compostos rígidos, planares, quimicamente e termicamente estáveis e que já foram extensamente estudados por suas propriedades fotoeletroquímicas e semicondução do tipo $n$. O primeiro polímero de coordenação sintetizado, MOF-CoNDI-py-1, indicou ser um polímero linear, de estrutura 1D. O segundo, MOF-CoNDI-py-2, que conta com ácido tereftálico como ligante suporte, é um sólido cristalino com cela unitária monoclínica pertencente ao grupo espacial C2/c, determinado por difração de raios- $X$ de monocristal. A rede apresenta um arranjo trinuclear de íons $\mathrm{Co}$ (II) alto spin com coordenados em uma geometria de octaedro distorcido, enquanto os ligantes NDI-py se encontram em um arranjo paralelo na estrutura, em distâncias apropriadas para transferência eletrônica. Com o auxílio de cálculo teóricos a nível de DFT, foi realizado um estudo aprofundado dos espectros eletrônicos e vibracionais, com atribuição das transições observadas, tanto para o MOF-CoNDI-py2 quanto para o ligante NDI-py livre. A rede de coordenação absorve em toda a região do espectro eletrônico analisada, de $200 \mathrm{~nm}$ a $2500 \mathrm{~nm}$, além de apresentar luminescência com característica do ligante. Dispositivos eletrônicos fabricados com um cristal do MOF-CoNDI-py-2 revelaram condutividades da ordem de $7,9 \times 10^{-3} \mathrm{~S} \mathrm{~cm}^{-1}$, a maior já observada para um MOF. Além de elevada, a condutividade elétrica dos cristais demonstrou-se altamente anisotrópica, sendo significativamente menos condutor em algumas direções. Os perfis de corrente versus voltagem foram analisados em termos de mecanismos de condutividade, sendo melhores descritos por um mecanismo limitado pelo eletrodo to tipo Space-Charge Limited Current, concordando com a proposta de condutividade através dos planos de NDI-py na rede. A condutividade dos cristais também é fortemente dependente de luz, apresentando fotocondução quando irradiado por um laser vermelho, de $632 \mathrm{~nm}$, enquanto apresenta um comportamento fotorresistivo frente a uma fonte de luz branca. Estes resultados, combinados, trazem um MOF em uma estrutura incomum e com elevada condutividade elétrica, modulada por luz, em medidas diretas de corrente. Não existem exemplos conhecidos de MOFs na literatura com estas características. 


\begin{abstract}
Coordination polymers have been a major topic in materials science during the past decade, thanks to their versatility and virtually infinite possible combinations between metal centers and organic ligands. These coordination polymers usually inherit the properties of their components, such as magnetic, spectroscopic and electronic characteristics. However, despite the increasing number of research papers in this topic, it is still hard to find coordination polymers featuring electronic conductivity. To achieve that, we used a naphthalene diimide derivative, $N, N^{\prime}$-bis(4-pyridyl)-1,4,5,8naphthalene diimide or NDI-py, which belongs to a class of rigid, planar, thermally and chemically stable compounds, extensively studied due to their photoelectrochemical properties and their $n$-type semiconductivity. The first coordination polymer synthesised, MOF-CoNDI-py-1, was an amorphous linear polymer, with a 1D structure. Based on these observations, MOF-CoNDI-py-2 was synthesised by using terephthalic acid as a supporting ligand, and it is a crystalline solid which its monoclinic unit cell belongs to a $\mathrm{C} 2 / \mathrm{c}$ space group, as determined by single crystal $\mathrm{X}$-ray diffraction. This network features a trinuclear high-spin $\mathrm{Co}(\mathrm{II})$ unit, and each metal ion sits on a distorted octahedra coordination geometry, while the NDI-py ligands sit in a parallel arrangement, with distances suitable for electronic transfers. A detailed study of their vibrational and electronic spectra, supported by DFT calculations, was performed, as well as a full description and assignment of the observed bands. MOF-CoNDI-py-2 absorbs in the whole studied spectral region, from $200 \mathrm{~nm}$ to $2500 \mathrm{~nm}$, while it also features a ligand-centered emission spectrum. Electronic devices built around its crystals revealed electric conductivities of $7.9 \times 10^{-3} \mathrm{~S} \mathrm{~cm}^{-1}$, which is, to the best of our knowledge, the highest for a MOF to this date. This conductivity is also highly anisotropic, being significantly less conductive in certain directions. The current versus voltage profiles were analysed in terms of known conduction mechanisms, with best fits when using an electrode-limited Space-Charge Limited Current mechanism, in agreement with the proposition that this conductivity happens through the NDI-py stacking planes. Additionally, this mechanism is influenced by an external light source, being a photoconductor with a red laser, $632 \mathrm{~nm}$, and a photoresistor with a white light. Combined, these results bring a light-modulated, highly conductive MOF material with an unusual structure. As far as we know, there are no similar MOFs in the literature, which makes MOF-CoNDI-py-2 one of a kind.
\end{abstract}




\section{Sumário}

Resumo ................................... i

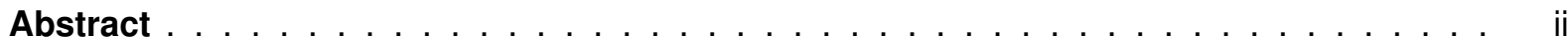

Apresentação da Tese . . . . . . . . . . . . . . . . . . . . . . . . . . . . . . V v

Acrônimos, Siglas, Símbolos e Abreviaturas . . . . . . . . . . . . . . . . . . . . . vi

1 Introdução 1

1.1 Polímeros de coordenação . . . . . . . . . . . . . . . . . . . . . . . . . . . . 2

1.1 .1 Geral . . . . . . . . . . . . . . . . . . . . . . . . . . . . 2

1.1.2 Nomenclatura e terminologia . . . . . . . . . . . . . . . . . . . . 4

1.1.3 Métodos de síntese . . . . . . . . . . . . . . . . . . . . . . 4 4

1.1 .4 Aplicações . . . . . . . . . . . . . . . . . . . . . . . . . . . . 6

1.2 Naftaleno diimidas . . . . . . . . . . . . . . . . . . . . . . . . . . . . . . 8

1.2 .1 Geral . . . . . . . . . . . . . . . . . . . . . . . . . . 8

1.2 .2 Métodos de síntese . . . . . . . . . . . . . . . . . . . . . . . . . 10

1.2 .3 Aplicações . . . . . . . . . . . . . . . . . . . . . . . . . . . . . . . . . 11

1.3 Polímeros de coordenação contendo NDls . . . . . . . . . . . . . . . . . . . . . . . . . . . 14

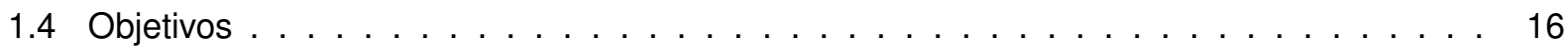

2 Parte Experimental $\quad 17$

2.1 Reagentes utilizados . . . . . . . . . . . . . . . . . . . . . . . . . . . . . . 17

2.2 Síntese da NDI-py . . . . . . . . . . . . . . . . . . . . . . . . . . . . . . . . . . . . 18

2.3 Síntese do MOF-CoNDI-py-1 . . . . . . . . . . . . . . . . . . . . . . . . . . . . . . . . 19

2.4 Síntese do MOF-CoNDI-py-2 . . . . . . . . . . . . . . . . . . . . . . . . . . . . . . . . 20

2.5 Técnicas de caracterização . . . . . . . . . . . . . . . . . . . . . . . . . . . . . . . . 21

2.5.1 Espectroscopia eletrônica . . . . . . . . . . . . . . . . . . . . . . . . . . 21

2.5.2 Análise termogravimétrica . . . . . . . . . . . . . . . . . . . . . . . . . 21

2.5.3 Difração de raios-X e estrutura de monocristal . . . . . . . . . . . . . . . . . . . . 21

2.5.4 Dispositivos eletrônicos . . . . . . . . . . . . . . . . . . . . . . . . . 21

2.5 .5 Eletroquímica . . . . . . . . . . . . . . . . . . . . . . 23

2.5 .6 Luminescência . . . . . . . . . . . . . . . . . . . . . . . . . . . . . . 23

2.5.7 Espectrometria de massas . . . . . . . . . . . . . . . . . . . . . . . . . . . . . 24

2.5.8 Espectroscopia vibracional . . . . . . . . . . . . . . . . . . . . . . . . . 24

2.5 .9 Microscopia óptica . . . . . . . . . . . . . . . . . . . . . . . . . . . . . . . . . . . 24

2.5.10 Microscopia eletrônica de varredura . . . . . . . . . . . . . . . . . . . . . . . . 24

2.5.11 Ressonância magnética nuclear . . . . . . . . . . . . . . . . . . . . . . . . . . 24

2.5.12 Ressonância paramagnética eletrônica . . . . . . . . . . . . . . . . . . . . . . . 24

2.6 Cálculos teóricos . . . . . . . . . . . . . . . . . . . . . . . . . . 25

3 Resultados e Discussão 27

3.1 NDl-py . . . . . . . . . . . . . . . . . . . . . . . . . . . . . . . 27

3.1.1 Ressonância magnética nuclear . . . . . . . . . . . . . . . . . . . . . . 27

3.1.2 Espectrometria de massas ... . . . . . . . . . . . . . . . . . . . 32 
3.1.3 Espectroscopia vibracional . . . . . . . . . . . . . . . . . . . . . . 33

3.1 .4 Espectroscopia eletrônica . . . . . . . . . . . . . . . . . . . . . . 35

3.1 .5 Luminescência . . . . . . . . . . . . . . . . . . . . . . . . . . 38

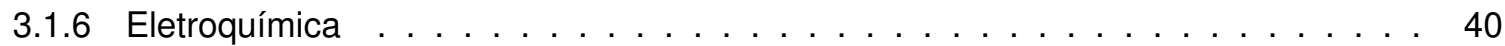

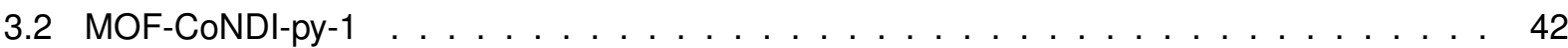

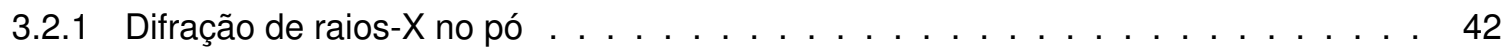

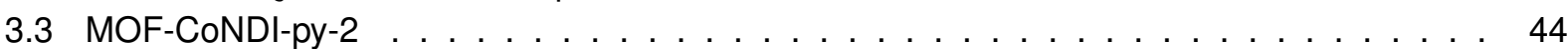

3.3.1 Microscopia óptica e eletrônica . . . . . . . . . . . . . . . . . . 44

3.3.2 Difração de raios-X e estrutura de monocristal . . . . . . . . . . . . . . . . 46

3.3.3 Método de Ligação-Valência . . . . . . . . . . . . . . . . . . 50

3.3 .4 Análise térmica . . . . . . . . . . . . . . . . . . . . . . . . . . . 51

3.3.5 Espectroscopia vibracional . . . . . . . . . . . . . . . . . . 53

3.3.6 Ressonância paramagnética eletrônica . . . . . . . . . . . . . . . . 55

3.3 .7 Eletroquímica . . . . . . . . . . . . . . . . . . . . . 55

3.3.8 Espectro eletrônico e níveis de energia . . . . . . . . . . . . . . . 58

3.3.9 Fluorescência e tempo de vida emissão . . . . . . . . . . . . . . . . . . . . . 64

3.3.10 Dispositivos eletrônicos . . . . . . . . . . . . . . . . . . . . . 66

4 Conclusões e Perspectivas $\quad 74$

$\begin{array}{ll}\text { Bibliografia } & 77\end{array}$

$\begin{array}{ll}\text { A1. Lista de figuras } & 80\end{array}$

A2. Lista de tabelas $\quad 82$

$\begin{array}{ll}\text { A3. FTIR do íon tereftalato } & 83\end{array}$

$\begin{array}{ll}\text { A4. Tabela de caracteres do grupo } D_{2 h} & 84\end{array}$

A5. Tabela de caracteres do grupo $\mathrm{C}_{i} \quad 85$

$\begin{array}{ll}\text { A6. Produção bibliográfica } & 87\end{array}$

$\begin{array}{ll}\text { A7. Súmula curricular } & 96\end{array}$

$\begin{array}{lr}\text { A8. Índice remissivo } & 98\end{array}$

$\begin{array}{ll}\text { A9. Propriedades dos reagentes utilizados } & 100\end{array}$ 


\section{Apresentação da Tese}

Este trabalho foi realizado em diferentes etapas. A síntese e a maioria das caracterizações do ligante e polímeros de coordenação aqui discutidos foram realizados no Departamento de Química da Faculdade de Filosofia, Ciências e Letras de Ribeirão, Universidade de São Paulo - a atual sede do trabalho, financiado pela FAPESP. Os dispositivos eletrônicos e demais caracterizações elétricas foram realizadas no Advanced Technology Institute da University of Surrey, Reino Unido, sob orientação do Prof. Dr. S. Ravi P. Silva, durante um estágio de doze meses com bolsa FAPESP do tipo BEPE por lá realizado. A estrutura de monocristal foi resolvida em parceria com o Prof. Richard I. Walton e o Dr. Guy Clarkson, ambos da University of Warwick, Reino Unido. Os Prof. Jean-Claude Moutet e Prof. Jerome Chauvin da Université de Grenoble, França, colaboraram para as caracterizações eletroquímicas e magnéticas do polímero de coordenação.

Este trabalho não seria possível sem a colaboração e parceria de inúmeras pessoas, de diferentes partes do mundo, e o autor é imensamente grato à oportunidade e ajuda de todos.

Evandro Castaldelli 


\section{Acrônimos, Siglas, Símbolos e Abreviaturas}

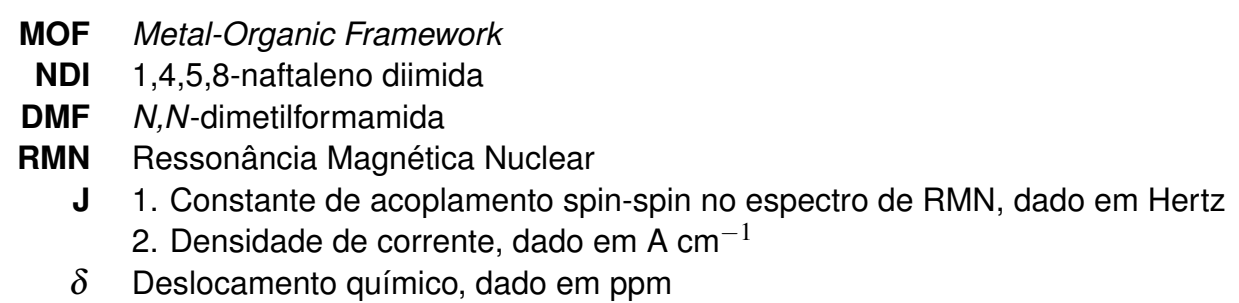

FTIR Fourier Transform Infrared Spectroscopy - Espectroscopia de absorção de luz na região do infravermelho com transformada de Fourier

$v \quad$ Número de onda, dado $\mathrm{em}^{-1}$

$\lambda$ Comprimento de onda

$\lambda_{\text {ex }}$ Comprimento de onda de excitação

$\lambda_{e m} \quad$ Comprimento de onda de emissão

$\lambda_{\max }$ Comprimento de onda máximo

TpA Ácido Tereftálico

TGA Thermogravimetric Analysis - Análise Termogravimétrica

DTG Derivative Thermogravimetric Analysis - Análise Termogravimétrica Derivativa

PECVD Plasma-Enhanced Chemical Vapour Deposition

FIB Focused lon Beam

SHE Standard Hidrogen Electrode - eletrodo padrão de hidrogênio

$\phi \quad$ Diâmetro, dado em metros

A Área, dada em metros quadrados

CME Cavity Microelectrode - microeletrodo de cavidade

Dept135 Distortionless Enhancement by Polarization Transfer, em um ângulo de $135^{\circ}$

HMBC Heteronuclear Multiple Bond Correlation - técnica de RMN 2D que correlaciona os sinais dos átomos de carbono e hidrogênio

DFT Density Functional Theory

TD-DFT Time-Dependant Density Functional Theory

B3LYP Becke, three parameter, Lee-Yang-Parr

NIST National Institute of Standards and Technology

GIAO Gauge-Including Atomic Orbitals - método para simulação de RMN

TMS Tetrametilsilano, $\mathrm{Si}(\mathrm{Me})_{4}$

u.a. Unidades arbitrárias

HOMO Highest Occupied Molecular Orbital

LUMO Lowest Unoccupied Molecular Orbital

Fc Ferroceno

WE Working Electrode - eletrodo de trabalho

CE Counter Electrode - eletrodo auxiliar

RE Reference Electrode - eletrodo de referência

GCE Glassy Carbon Electrode - eletrodo de carbono vítreo

$v$ Velocidade de varredura eletroquímica, dada em $\mathrm{V} \mathrm{s}^{-1}$

$\mathbf{E}_{g} \quad$ Band-gap óptico

SCE Saturated Calomel Electrode - eletrodo de calomelano saturado

UV-Vis Região do espectro luminoso do ultravioleta e do visível, entre $190 \mathrm{~nm}$ e $800 \mathrm{~nm}$.

Vis-NIR Região do espectro luminoso do visível e do infravermelho próximo, entre 400 nm e 2500 $\mathrm{nm}$.

MLCT Metal-to-Ligand Charge Transfer - Transferência de carga metal-ligante

FX Fenda de excitação

FM Fenda de emissão

LMCT Ligand-to-Metal Charge Transfer - transferência de carga do ligante para o metal

SCLC Space-Charge Limited Current - corrente limitada por carga espacial

PF Poole-Frenkel

FN Fowler-Nordheim 


\section{Capítulo 1}

\section{Introdução}

$\mathrm{N}$

a última década, o desenvolvimento e uso de novos sistemas eletrônicos e dispositivos como células solares, sensores, computadores e dispositivos lógicos em geral, se acentuou juntamente com a busca por novos materiais que apresentem novas características ou que sejam alternativas mais econômicas ou sustentáveis que as soluções já existentes. Classicamente, firmou-se o desenvolvimento de sistemas eletrônicos baseados em silício e, mais recentemente, na substituição do silício por materiais orgânicos que, em geral, possuem menor custo de produção e flexibilidade de aplicações, favorecendo a produção em massa.

Concomitantemente ao desenvolvimento de dispositivos eletrônicos, uma classe de compostos atraiu o interesse da comunidade científica. Por conta de sua estrutura organizada e diversidade de propriedades possíveis, os Polímeros de Coordenação e Metal-Organic-Frameworks, ou MOFs, pertencentes à uma classe de materiais híbridos orgânico-inorgânico surgiram como uma atraente alternativa para um grande número de aplicações, desde estocagem e purificação de gases, até catálise heterogênea e aplicações na área da saúde.

Interessantemente, essas duas linhas de pesquisa começaram a convergir em um interesse mútuo. A transição ocorreu de forma um tanto natural visto que ambas geralmente empregam e acontecem em institutos de pesquisa multidisciplinares, uma vez que necessitam de uma gama de conhecimentos nas mais diversas áreas, como por exemplo síntese orgânica, caracterização estrutural de sólidos, espectroscopia e fabricação de dispositivos eletrônicos. Esta ampla necessidade tem um efeito bastante positivo em termos de colaborações entre as diversas áreas do conhecimento, fato derivado da dificuldade que apenas um grupo de pesquisa teria em desenvolver um projeto desta magnitude isoladamente. 


\section{$-1.1-$}

\section{Polímeros de coordenação}

§ 1.1.1. Geral - Compostos porosos têm atraído a atenção da comunidade científica, como químicos e físicos, por conta do interesse na criação de poros nanométricos e o estudo dos novos fenômenos nestas estruturas. Há também um interesse comercial na aplicabilidade destes materiais em processos de separação, estocagem e catálise heterogênea. Estes compostos são completamente regulares, possuem alta porosidade, uma estrutura ordenada altamente modelável e, além disso, a síntese destes compostos ocorre em condições moderadas. A escolha de uma determinada combinação de unidades moleculares discretas leva à formação de uma rede estendida, que é o chamado processo de produção bottom-up - síntese de uma estrutura maior a partir de unidade menores, exato oposto de técnicas top-down como a fotolitografia. A integridade estrutural das unidades que compõem a rede é mantida através de reações que permitem o uso dessas unidades como módulos na associação de estruturas estendidas. $^{1}$

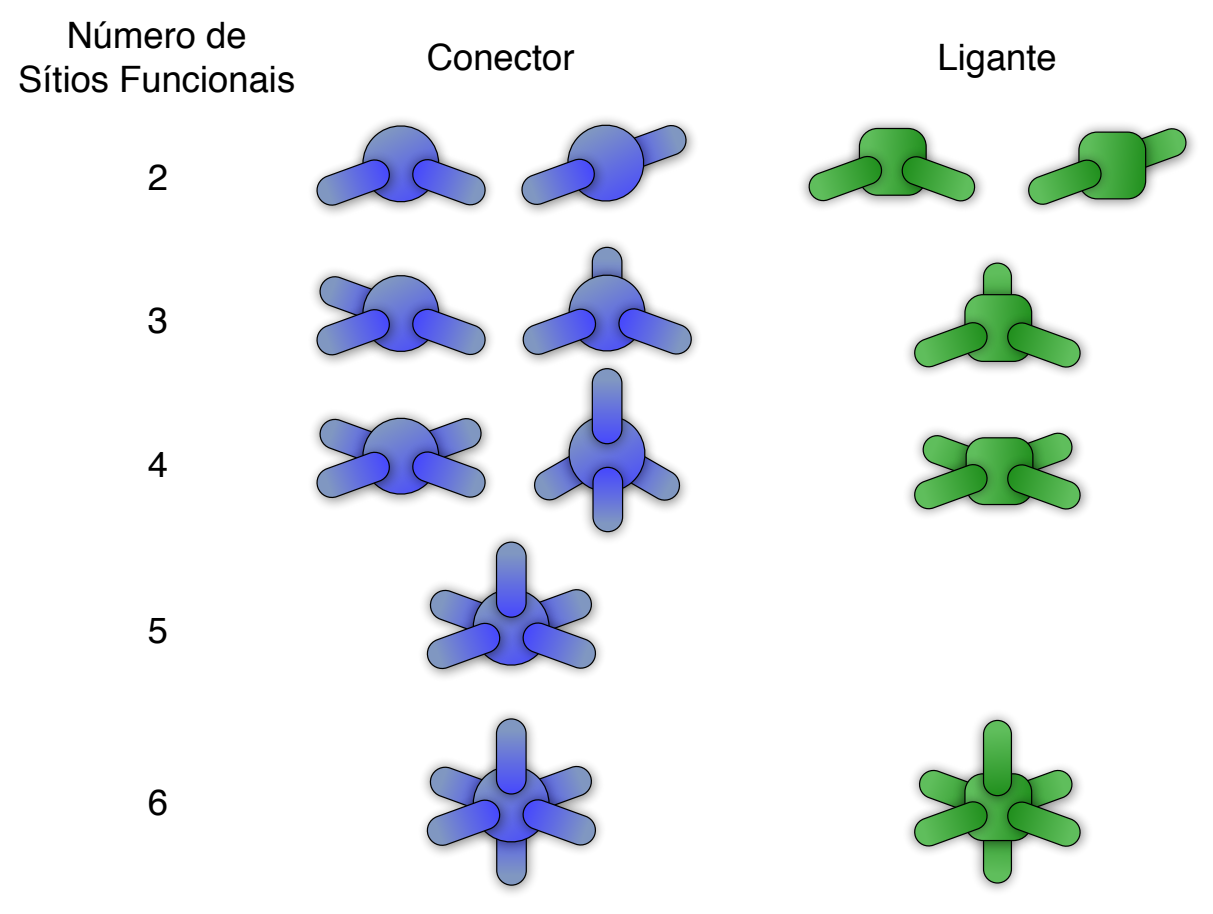

Figura 1.1: Estruturas básicas representativas para a formação de polímeros de coordenação.

Os polímeros de coordenação contém dois componentes centrais: conectores e ligantes, como mostra a Figura 1.1. Esses componentes são definidos como reagentes de partida com os quais a estrutura principal é formada. Além desses, ainda existem componentes auxiliares como unidades hóspede e contra-íons. As características importantes dos conectores e ligantes são o número e orientação de 
seus pontos de coordenação, isto é, número e geometria de coordenação. Para este fim, íons de metais de transição são geralmente empregados como conectores versáteis. Dependendo de que metal se trata e de seu estado de oxidação, os números de coordenação podem variar de 2 a 7, dando origem à muitas geometrias, que podem ser linear, na forma de $\mathrm{Y}$ ou $\mathrm{T}$, tetraédrica, quadrada-planar, piramidal de base quadrada, bipirâmide trigonal, octaédrica, trigonal prismática, bipirâmide pentagonal, e suas vertentes distorcidas. Por exemplo, os íons $\mathrm{Ag}\left(\mathrm{I}^{2}\right.$ e $\mathrm{Cu}(\mathrm{I})^{1}$ de configuração eletrônica $\mathrm{d}^{10}$ possuem vários números de coordenação e geometrias que podem ser modelados através de uma mudança nas condições de reação, como solventes, contra-íons e ligantes. Como se pode concluir então, o centro metálico é determinante na orientação da estrutura a ser formada, pois ele carrega consigo uma geometria específica e, quando há mais de uma possível geometria de coordenação, pode-se alterar as condições do sistema para que uma delas seja preferencial, sendo possível portanto arranjar o sistema de maneira relativamente simples. Por outro lado, os ligantes oferecem uma vasta variedade de sítios e forças de ligação nas várias direções, como também pode ser visto na Figura 1.1. Haletos são os ligantes mais simples e de menor dimensão, podendo gerar estruturas quasi-1D de valência mista ligando centros metálicos (cadeias do tipo $M X)$ com fórmula geral $\left\{\left[\mathrm{M}^{\mathrm{II}}(\mathrm{AA})_{2}\right]\left[\mathrm{M}^{\mathrm{IV}}(\mathrm{AA})_{2} \mathrm{X}_{2}\right] \cdot 4 \mathrm{Y}\right\}_{n} \cdot{ }^{(\mathrm{a}), 3}$

Redes quadradas dão um exemplo particularmente simples e comumente reportado de uma rede metal-orgânica previsível. Esse tipo de polímero de coordenação é baseado geralmente no uso de complexos 1:2 (metal:ligante) com ligantes bifuncionais. O ligante 9,10-bis(4-piridil)antraceno na presença de $\mathrm{Ni}\left(\mathrm{NO}_{3}\right)_{2}$ forma uma rede 2D interpenetrada na presença de benzeno ${ }^{4}$, como o exemplo da Figura 1.2a, e similarmente para cobalto com ligantes bipiridínicos ${ }^{5}$, como na Figura 1.2b.

A síntese de materiais porosos que apresentam quiralidade é de particular interesse pois tais polímeros de coordenação poderiam ser utilizados em catálise heterogênea assimétrica ou separações enantiosseletivas. Estes materiais podem ser sintetizados explorando compostos orgânicos quiriais puros, isto é, onde apenas um enantiômero está presente; ou com redes helicoidais. A quiralidade inerente dessas arquiteturas advém principalmente da disposição espacial particular obtida que da presença de centros quirais propriamente ditos. ${ }^{6-8}$

Além das propriedades já exemplificadas, um dos maiores atrativos dos polímeros de coordenação reside nas inúmeras possibilidades de combinações entre os centros metálicos e os ligantes, uma vez que a estrutura resultante carregará consigo as propriedades físico-químicas dos metais e dos ligantes que as compõe.

\footnotetext{
(a) $\mathrm{M}(\mathrm{II})-\mathrm{M}(\mathrm{IV})=\mathrm{Pt}(\mathrm{II})-\mathrm{Pt}(\mathrm{IV}), \mathrm{Pd}(\mathrm{II})-\mathrm{Pd}(\mathrm{IV}), \mathrm{Ni}(\mathrm{II})-\mathrm{Pt}(\mathrm{IV}), \mathrm{Pd}(\mathrm{II})-\mathrm{Pt}(\mathrm{IV}), \mathrm{Cu}(\mathrm{II})-\mathrm{Pt}(\mathrm{IV}) ; \mathrm{X}=\mathrm{Cl}^{-}, \mathrm{Br}^{-}, \mathrm{I}^{-}$e haletos mistos; $\mathrm{AA}=$ etilenodiamina, 1,2-diamino-ciclohexano, etc.; $\mathrm{Y}=\mathrm{ClO}_{4}^{-}, \mathrm{BF}_{4}^{-}$, halidas, etc.
} 


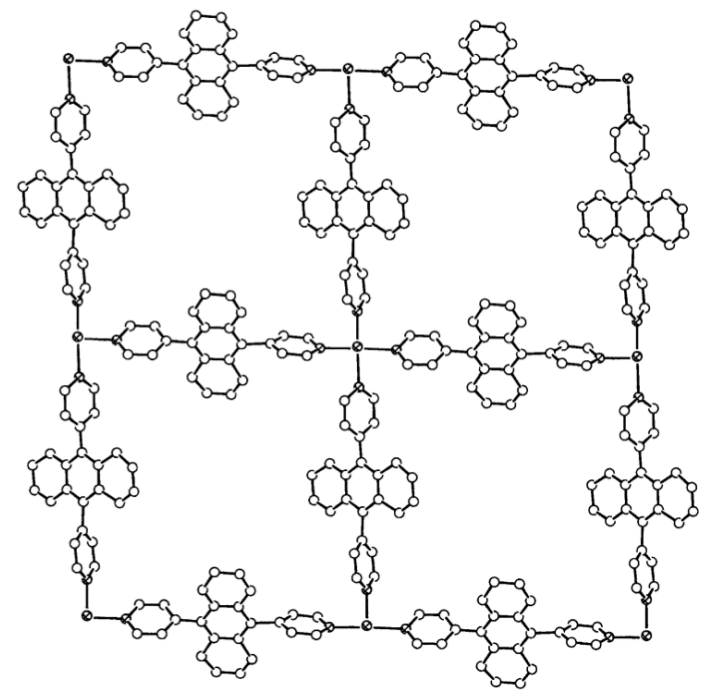

(a) $\left\{\left[\mathrm{Ni}\{9,10 \text {-bis(4-piridil)antraceno }\}_{2}\left(\mathrm{H}_{2} \mathrm{O}\right)_{2}\right] \cdot \mathrm{NO}_{3}\right\}_{n} \cdot{ }^{4}$

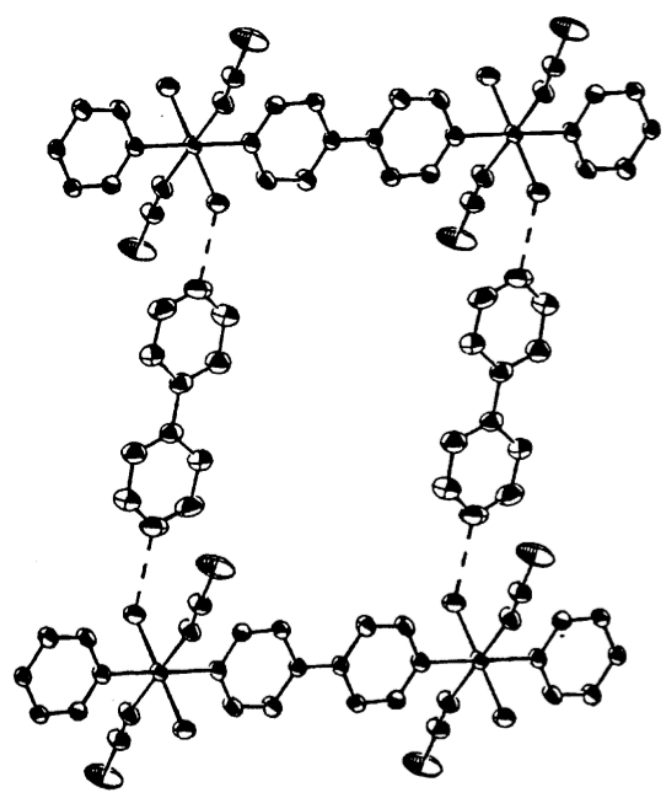

(b) $\left\{\left[\mathrm{Co}(\mathrm{NCS})_{2}\left(4,4^{\prime}-\mathrm{bpy}\right)\left(\mathrm{H}_{2} \mathrm{O}\right)_{2}\right] \cdot 4,4^{\prime}-\mathrm{bpy}\right\}_{n} \cdot{ }^{5}$

Figura 1.2: Exemplos de polímeros de coordenação propostos por BIRADHA e LU.

$\S$ 1.1.2. Nomenclatura e terminologia - Por muitos anos a nomenclatura das redes de coordenação esteve sujeita, em grande parte, aos conceitos subjetivos de cada autor, pois não haviam regras ou recomendações apropriadas até recentemente. Os termos "polimero de coordenação", "rede de coordenação", "metal-organic framework" e "organic-inorganic frameworks" podiam ser encontrados na literatura com os mesmos significados, o que causava uma certa confusão e inconsistência entre os diversos artigos. Um trabalho começado pela IUPAC em 2009 e finalizado em 2013 afim de normatizar a nomenclatura destes compostos sugere que o termo polímero de coordenação seja o descritor geral e que deve ser sempre acompanhado da dimensionalidade da estrutura. Dessa forma, as redes lineares devem ser descritas como polímero de coordenação 1D, por exemplo, com a mesma lógica a ser aplicada às redes bidimensionais e tridimensionais. Nestas regras, o termo MOF passa a ser uma subclasse dos polímeros de coordenação $2 D$ e $3 D$, porém somente quando estes compostos apresentarem porosidade intrínseca. $^{9}$

§ 1.1.3. Métodos de síntese - De maneira geral, a síntese dos polímeros de coordenação consiste na reação de um sal de um metal com os ligantes, em uma determinada razão molar. Existem inúmeras maneiras empregadas para se permitir a coordenação entre os compostos e a formação do material de interesse, e alguns exemplos serão discutidos a seguir.

A rota sintética mais empregada para os polímeros de coordenação é a hidrotermal ou solvotermal, que consiste no aquecimento da solução que contem os reagentes em um reator, composto de um 
frasco de Teflon ${ }^{\circledR}$ dentro de uma carcaça de aço inox, que se fecha de forma a permitir sínteses em pressões mais elevadas. Como fonte de calor, emprega-se comumente um forno convencional ou, mais recentemente, um forno de micro-ondas. ${ }^{10,11}$

Alternativamente, pode-se empregar a síntese por difusão lenta dos reagentes, de modo que se permita uma lenta difusão dos ligantes e centros metálicos. Em contrapartida, este tipo de síntese requer maiores tempos de reação, da ordem de sete dias ou mais. ${ }^{12}$

Apesar de pouco usual, também é possível utilizar uma rota eletroquímica. Esta técnica consiste de uma célula em um arranjo de dois eletrodos na qual o cátodo e o ânodo são placas compostas pelo metal de interesse - como cobre e zinco, por exemplo -, e o eletrólito de suporte é uma solução que contém o ligante. Como exemplo, MUELLER utilizou um arranjo de dois eletrodos de cobre e uma solução metanólica de ácido benzeno-1,3,5-tricarboxílico aplicando 1,3 A (de 12 a 19 V) por 2,5 $\mathrm{h}^{13}$. Em um outro trabalho, S. ALVES JR realizou a síntese do [Cu(benzeno-1,3-dicarboxilato)-DMF]·2 $\mathrm{H}_{2} \mathrm{O}$ por um método similar, utilizando eletrodos de cobre e $\mathrm{NaNO}_{3} \quad 0,1 \mathrm{~mol} \mathrm{dm}^{-3}$ como eletrólito de suporte, obtendo rendimentos da ordem de $90 \%$ em apenas 8 min de síntese. ${ }^{14}$

Modificações pós-sintéticas têm se mostrado uma abordagem atraente, principalmente quando os ligantes que se tem interesse possam ser volumosos ou apresentem pontos adicionais de coordenação, ou qualquer outra propriedade que possa porventura dificultar ou impossibilitar a formação da rede de coordenação. Como exemplo, BuRRows utilizou um derivado de ácido tereftálico - um ligante bastante comum em MOFs -, que continha um grupo $-\mathrm{NH}_{2}$, para a síntese de um MOF contendo Zn(II) e, após a síntese, realizou reações de condensação para adicionar grupos funcionais de interesse, como mostra a Figura 1.3. ${ }^{15}$<smiles></smiles>

IRMOF-3<smiles></smiles>

1a-d<smiles>[R7]CNc1cc(C(=O)O[R17])ccc1C(=O)O[Z10]</smiles>

2a-d

Scheme 1 (i) RCHO, THF; (ii) $\mathrm{NaBH}_{3} \mathrm{CN}$, THF [R = Me (1a, 2a), Et (1b, 2b), $\left.\operatorname{Pr}(\mathbf{1 c}, \mathbf{2 c}), \mathrm{C}_{7} \mathrm{H}_{15}(\mathbf{1 d}, \mathbf{2 d})\right]$.

Figura 1.3: Esquema da reação de modificação pós-sintética do MOF produzido por BuRRows. ${ }^{15}$ 
§ 1.1.4. Aplicações - As aplicações mais comuns dos polímeros de coordenação são aquelas que exploram suas áreas superficiais, como adsorção, purificação e estocagem de gases, e catálise ${ }^{1}$. Como exemplo, WRIEDT estudou a adsortividade seletiva de gases de um MOF baseado em cobre ${ }^{16}$, e este demonstrou adsorção seletiva de $\mathrm{CO}_{2}$ frente a $\mathrm{N}_{2}$, como mostra a Figura 1.4.

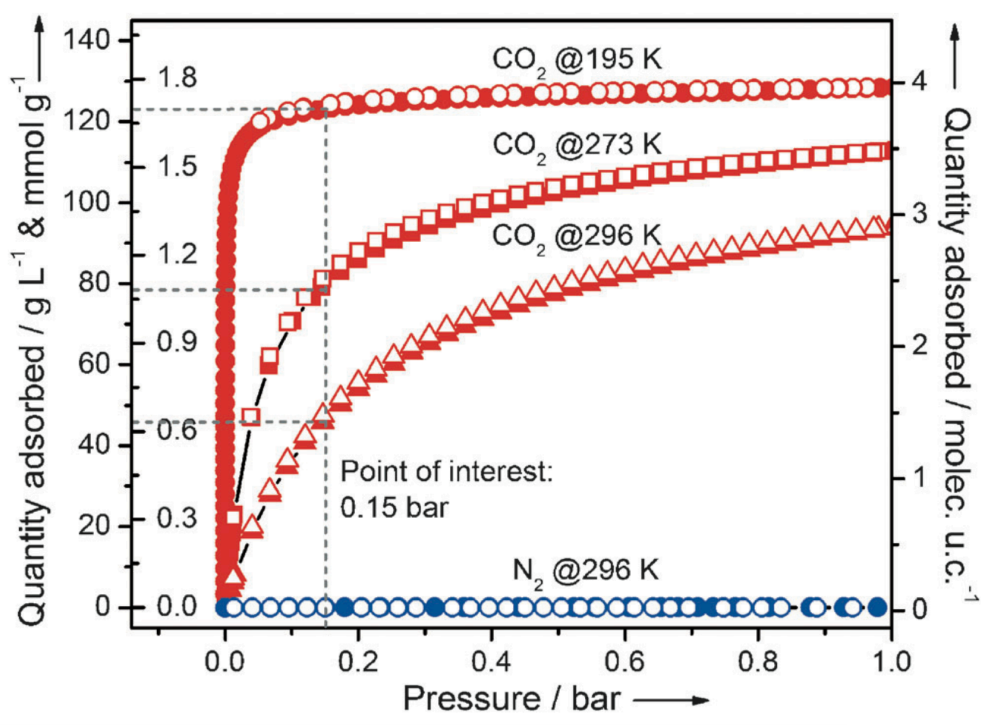

Figura 1.4: Adsortividade seletiva de $\mathrm{CO}_{2}$ frente a $\mathrm{N}_{2}$ do MOF de WRIEDT. ${ }^{16}$.

Por serem classicamente materiais isolantes, pouquíssimos MOFs foram desenvolvidos com o intuito de serem materiais condutores elétricos. Os mais recentes e notáveis são os MOFs desenvolvidos pelo grupo de J. T. HUPP ${ }^{17,18}$, contendo uma naftaleno diimida como ligante e $\mathrm{Zn}($ II) como centro metálico, exibindo atividade redox; e aqueles desenvolvidos pelo grupo de M. DINCǍ, baseados em Mn(II) e Fe(II), e ligantes derivados do ácido 2,5-dihidroxibenzeno-1,4-dicarboxílico, com um exemplo na Figura 1.5a, e apresentaram condutividades da ordem de $10^{-13} \mathrm{~S} \mathrm{~cm}^{-1}$, através de medida indireta ${ }^{19}$, até $10^{-6} \mathrm{~S} \mathrm{~cm}^{-1}$, por medida direta ${ }^{20}$. O polímero de coordenação com a maior condutividade que foi encontrado é o desenvolvido por HUTCHINS, um polímero de coordenação 1D baseado em $\mathrm{Ag}(\mathrm{I})$ e um ligante piridínico monodentado, na Figura 1.5b, com condutividade da ordem de $20 \mathrm{~S} \mathrm{~cm}^{-1}$. Por apresentar uma estrutura 1D, este composto não é classificado como MOF. ${ }^{21}$

É possível também encontrar alguns dispositivos eletrônicos que contenham MOFs em suas estruturas, como por exemplo células solares que incorporam MOFs que são classicamente isolantes. As estruturas são modificadas de forma a conter materiais condutores como perovisktas, $\mathrm{TiO}_{2}$ ou nanotubos de carbono inseridos nos poros da estrutura, de forma que o polímero de coordenação não é um condutor propriamente dito, e serve apenas como suporte para estrutura. Como exemplo, VINOGRADOV sensibilizou um conhecido MOF, MIL-125, que não é condutor, com $\mathrm{TiO}_{2}$ e precursores de perovskitas, 


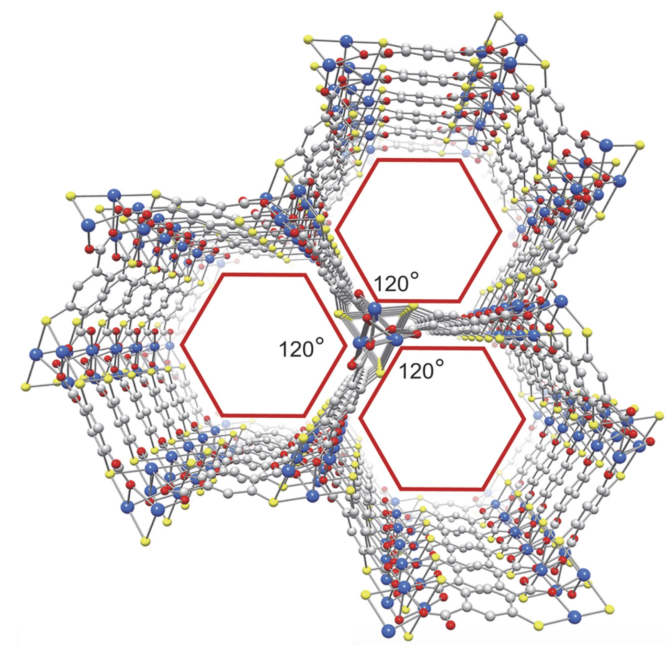

(a) Estrutura do MOF utilizado por M. DINCĂ para obter condutividades da ordem de $10^{-6} \mathrm{~S} \mathrm{~cm}^{-1}{ }^{20}$

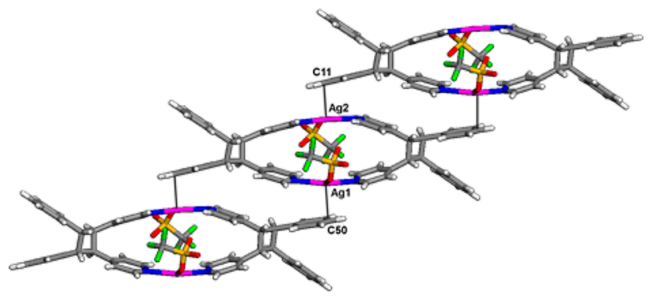

(b) Estrutura do polímero de coordenação utilizado por HUTCHINS para obter condutividades da ordem de $20 \mathrm{~S} \mathrm{~cm}^{-1}{ }^{21}$

Figura 1.5: Estruturas dos polímeros de coordenação condutores de J. T. HUPP e HUTCHINS.

que são materiais classicamente empregados em dispositivos, para construir uma célula solar ${ }^{22}$. Neste caso, o MOF não é o material ativo e sim um suporte para os materiais ativos.

Outra aplicação, obtida pela incorporação das propriedades dos centros metálicos utilizados, é a produção de redes com propriedades luminescentes. Como exemplo, um MOF produzido pelo grupo de S. ALVES JR através da construção sistemática de redes contendo $\mathrm{Eu}^{3+}, \mathrm{Tb}^{3+} \mathrm{e} \mathrm{Gd}^{3+}$, em um material em camadas, exibe emissão de luz branca. ${ }^{23}$ 


\section{Naftaleno diimidas}

§ 1.2.1. Geral - Naftaleno diimidas, ou NDIs, são compostos orgânicos de conjugação estendida, planares, rígidos, capazes de formarem empilhamentos $\pi$, estáveis tanto térmica como quimicamente e que possuem propriedades ópticas e eletrônicas ricas, fatores que as tornam bastante atraentes. Além disso, são facilmente sintetizadas a partir de seus dianidridos naftálicos disponíveis comercialmente, sendo possível obter diimidas substituídas com quaisquer grupos $\mathbf{R}$ de interesse com relativa facilidade, tanto simétrica quanto assimetricamente. Na Figura 1.6 foram representados os principais membros: as 1,4,5,8-naftaleno diimidas, as 3,4,9,10-perileno diimidas e as 1,2,4,5-piromelítico diimidas. As NDIs, em geral, apresentam maior solubilidade nos solventes mais comuns - clorofórmio, tolueno e dimetilformamida, por exemplo - que as perileno diimidas e são mais estáveis e possuem melhores e mais desejáveis características espectrais e eletrônicas que as piromelítico diimidas, em termos de energia e coeficientes de absortividade, e também em termos de estabilidade, além de terem sido mais extensamente estudadas que estas últimas. ${ }^{24-27}$<smiles>[R]n1c(=O)c2cc3c(=O)n([R])c(=O)c3cc2c1=O</smiles>

PyDI<smiles>[R]N1C(=O)c2ccc3c4c(ccc(c24)C1=O)C(=O)N([R])C3=O</smiles>

NDI<smiles>[R]N1C(=O)c2ccc3c4ccc5c6c(ccc(c7ccc(c2c37)C1=O)c64)C(=O)N([R])C5=O</smiles>

PDI

Figura 1.6: Principais diimidas aromáticas - naftaleno (NDI, centro), perileno (PDI, direita) e piromelítico (PyDI, esquerda) diimidas.

Os grupos $\mathbf{R}$ indicados na Figura 1.6 têm papel importante nas propriedades destas imidas, coibindo ou promovendo fenômenos como a agregação em solução e emissão de luz, por exemplo. Substituintes aromáticos são retiradores de elétrons e resultam em NDIs fracamente ou não fluorescentes, enquanto a substituição com grupos alquil promove uma fluorescência branco-azulada, por volta de $400 \mathrm{~nm}$, característica desta classe de compostos. Também é possível a substituição através do esqueleto aromático central, dando origem à compostos extremamente coloridos, condutores e funcionais, de propriedades fotofísicas muito distintas de seus análogos não substituídos. ${ }^{24,28}$ 
De maneira geral, as NDIs apresentam duas características fundamentais em seus espectros eletrônicos: luminescência e progressões vibrônicas, representados na Figura 1.7. O espectro de absorção UV-Vis de uma NDI é, em geral, composto por duas regiões: i) entre aproximadamente $190 \mathrm{~nm}$ e $250 \mathrm{~nm}$, ocorrem transições intensas de natureza $\pi-\pi^{*}$; e ii) entre $300 \mathrm{~nm}$ e $400 \mathrm{~nm}$ aparecem três ou mais bandas em sequência que correspondem às progressões vibrônicas da transição $\pi-\pi^{*}$. Essa progressão vibrônica é originada por acoplamentos das transições eletrônicas com os modos vibracionais em cerca de $1350 \mathrm{~cm}^{-1}$ e $300 \mathrm{~cm}^{-1}$, que são distorções completas do esqueleto central. As absortividades molares são bastante elevadas, da ordem de $10^{4} \mathrm{~L} \mathrm{~mol}^{-1} \mathrm{~cm}^{-1}$. A formação de agregados entre mesmas espécies de diimida ou com diferentes moléculas pode revelar bandas de transferência de carga ou desestruturação das transições $\pi-\pi^{*}$. Naftaleno diimidas dialquil-substituídas, em $\mathrm{CH}_{2} \mathrm{Cl}_{2}$ por exemplo, apresentam bandas de absorção fortes e bem estruturadas abaixo de $400 \mathrm{~nm}$ e um espectro de emissão do tipo espelho com deslocamento de Stokes de apenas $0,05 \mathrm{eV}(\Delta \lambda \approx 7 \mathrm{~nm})$, o que significa que é pequena a diferença entre os estados fundamental e excitado. Além disso, foram observadas emissões do tipo excímero em tolueno. ${ }^{24,29-34}$

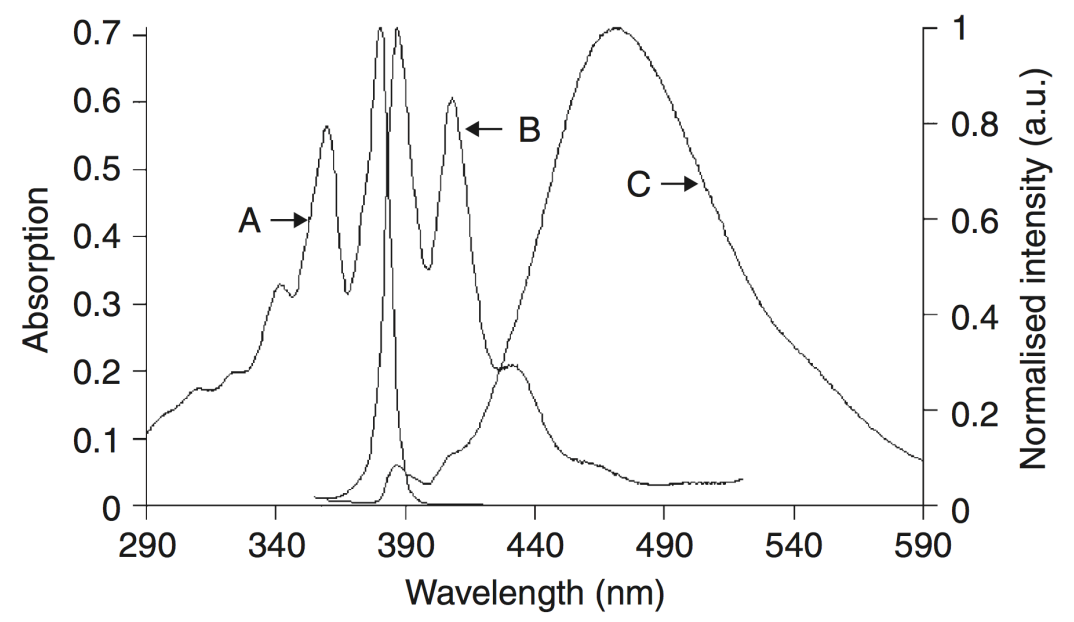

Figura 1.7: Espectros de absorção (A), emissão (B, $\lambda_{e x}=360 \mathrm{~nm}$ ) em $\mathrm{CH}_{2} \mathrm{Cl}_{2}$; e de emissão em tolueno (C) de uma NDI dialquil-substituída, retirado da Referência 29.

As NDIs podem ser facilmente reduzidas tanto quimicamente com um agente redutor, como $\mathrm{NaBH}_{4}$ ou $\mathrm{Na}_{2} \mathrm{~S}_{2} \mathrm{O}_{4}$, quanto eletroquimicamente, e apresentam em geral dois potenciais de redução atribuídos à formação do radical ânion ( $\mathrm{NDI}^{\bullet-}$ ) e do diânion $\left(\mathrm{NDI}^{2-}\right)$, segundo as Equações 1.1 e 1.2. Estes potenciais de redução variam de acordo com os substituintes mas em geral apresentam a primeira redução em $\mathrm{E}_{\text {red }}^{1} \approx-0,5 \mathrm{~V}$ e a segunda redução em $\mathrm{E}_{\text {red }}^{2} \approx-1,0 \mathrm{~V} v \mathrm{SCE}$, que são valores relativamente baixos. Também é conhecido o seu poder foto-oxidativo, que atuam como mediadores nas transferências fotoinduzidas de energia e de elétrons, podendo também ser utilizadas como catalisadores em reações orgânicas fotoassistidas. ${ }^{24,35,36}$ 


$$
\begin{gathered}
\mathrm{NDI}+e^{-} \longrightarrow \mathrm{NDI}^{\bullet-} \\
\mathrm{NDI}^{\bullet-}+e^{-} \longrightarrow \mathrm{NDI}^{2-}
\end{gathered}
$$

Outro fator interessante é que também é possível caracterizar e trabalhar com essas formas reduzidas. Seus espectros de absorção, por exemplo, são compostos por uma série de bandas acima de $450 \mathrm{~nm}$ e no infravermelho próximo ${ }^{29,36}$; e sabe-se que NDls reduzidas apresentam também sinais de EPR altamente estruturados ${ }^{37}$. Em 2000, GosztolA publicou um trabalho interessante sobre as espécies reduzidas de algumas piromelítico, naftaleno e perilenoimidas e a suas diimidas correspondentes. Como característica, o estado excitado dessas espécies são dubletos onde o elétron excitado se encontra em um orbital $\pi^{*}$. No trabalho em questão, esses radicais foram produzidos eletroquimicamente a partir das espécies neutras e foram excitados com lasers pulsados. Os radicais tanto das imidas quanto das diimidas apresentam intensas absorções no visível e bandas mais fracas no infravermelho próximo correspondentes às transições $\mathrm{D}_{0} \rightarrow \mathrm{D}_{n}$, referente à estados dubletos, como consta os espectros na Figura 1.8 apenas para a naftaleno diimida. Os estados excitados dos radicais das imidas resultaram em sua decomposição enquanto suas diimidas correspondentes apresentaram espectros transientes das transições $\mathrm{D}_{1} \rightarrow \mathrm{D}_{n}$ e os tempos de vida de $\mathrm{D}_{1}$, que situam-se todas abaixo de $600 \mathrm{ps}$, aumentam proporcionalmente com a energia de $\mathrm{E}_{00} \cdot{ }^{36}$

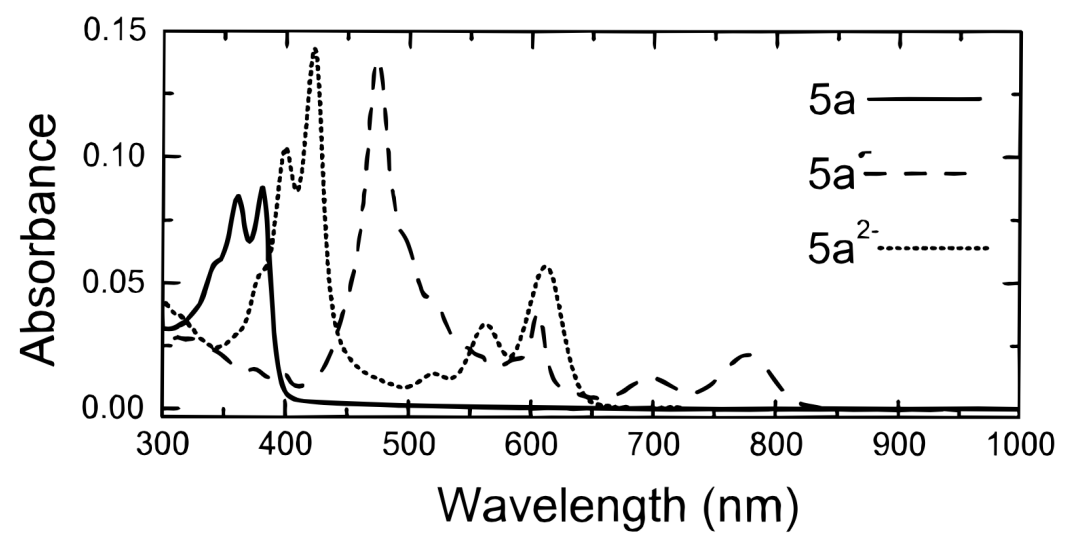

Figura 1.8: Espectros de absorção de uma naftaleno diimida neutra (5a) e suas formas reduzidas, radical ânion $\left(5 a^{\bullet-}\right)$ e diânion $\left(5 \mathrm{a}^{2-}\right)$. Adaptado da Referência 36.

§ 1.2.2. Métodos de síntese - A síntese das naftaleno diimidas consiste da condensação de uma amina primária, $\mathrm{R}-\mathrm{NH}_{2}$, com o diandrido naftálico, e existem algumas diferentes rotas para fazê-lo, como mostra a Figura 1.9. Para a síntese de NDls simétricas há, basicamente, duas rotas empregadas na 


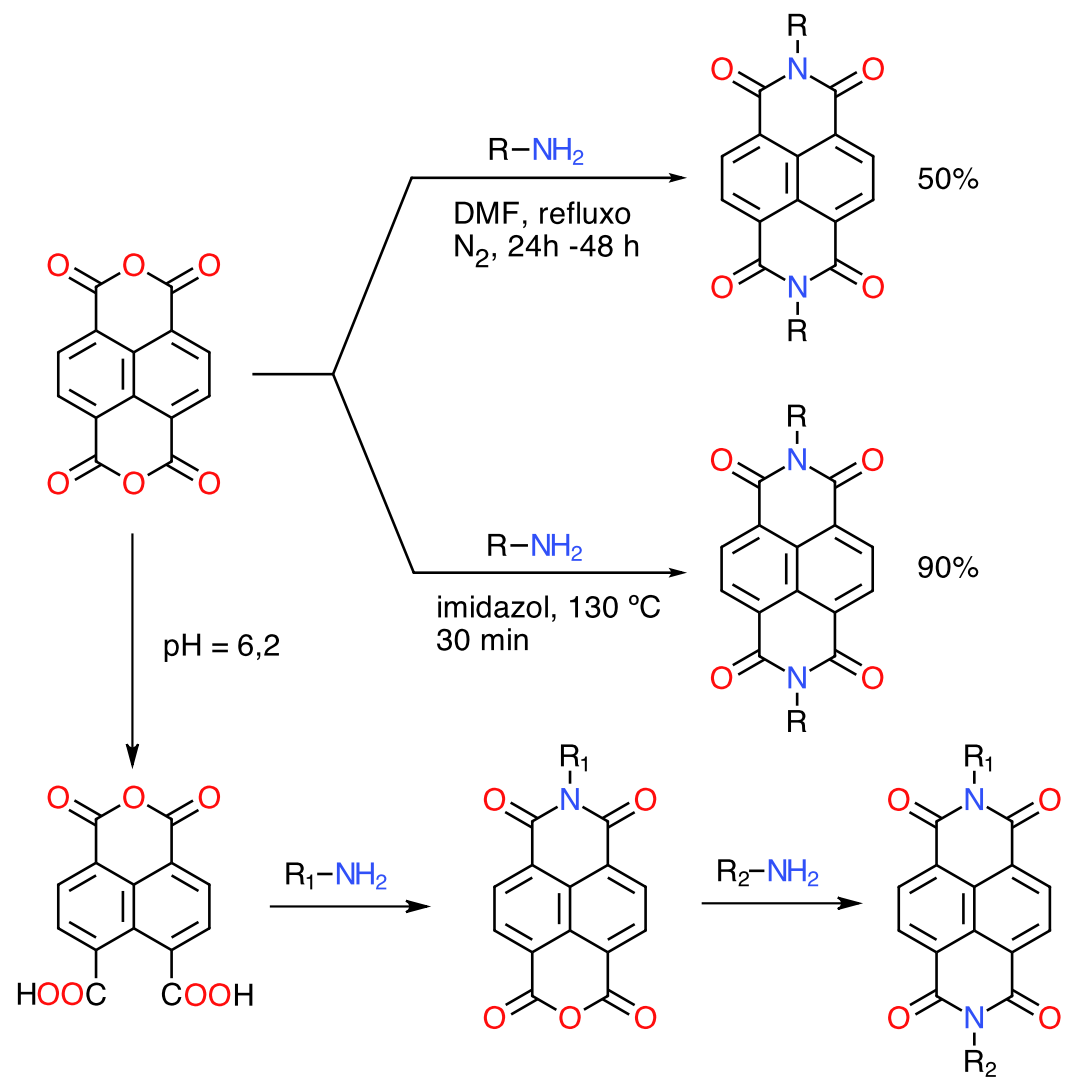

Figura 1.9: Esquemas de síntese de uma naftaleno diimida simétrica e assimétrica.

literatura. A mais popular emprega refluxo em $\mathrm{DMF}^{38} \mathrm{sob}$ atmosfera inerte, com tempos de reação entre $12 \mathrm{~h}$ e $48 \mathrm{~h}$ e rendimentos típicos da ordem de $50 \%$. A segunda rota consiste na substituição de DMF por imidazol fundido ${ }^{39}$, com tempos de reação de 30 min e rendimentos da ordem de $90 \%$. Esta rota em imidazol, além de diminuir drasticamente o tempo de ração, dispensa o uso de uma atmosfera inerte e eleva significativamente o rendimento da reação.

Apesar de não ser o foco deste trabalho, também é possível sintetizar diimidas assimétricas, com dois distintos grupos $\mathbf{R}$ substituintes. Um dos métodos envolve explorar os diferentes valores de pKa que os dois anidridos do precursor apresentam. A abertura dos anidridos em meio aquoso pela adição de $\mathrm{KOH}$, com subsequente ajuste de $\mathrm{pH}$ para 6,2 com $\mathrm{H}_{3} \mathrm{PO}_{4}$ permite que o dianidrido naftálico apresente um dos lados disponíveis para reação com a amina primária, permitindo uma segunda reação com um segundo substituinte. ${ }^{40}$

§ 1.2.3. Aplicações - As diimidas são compostos de potencial aplicação médica e principalmente tecnológica. Diversos sistemas e dispositivos baseados em diimidas têm sido reportados nos últimos anos, tais como aplicações em terapia fotodinâmica ${ }^{41}$, reparação de DNA ${ }^{42}$, transístores de efeito de campo $^{43}$, biossensores ${ }^{44}$, células solares ${ }^{45,46}$, eletrocatálise ${ }^{47}$, entre outros. 
As NDIs podem ser aplicadas no desenvolvimento racional de sistemas supramoleculares para desempenhar funções de mecanismos básicos conhecidos, como a contração de um músculo ou o movimento de um transportador, porém ao nível molecular ${ }^{48,49}$. Estudos de transferência eletrônica fotoinduzida em sistemas do tipo doador-sensibilizador-aceptor (D-P-A) são realizados com o intuito de compreender a fundo como a natureza converte energia solar em substâncias de alta energia intrínseca $^{50}$. O efeito das pontes que ligam os aceptores e doadores exerce no sistema, no que diz respeito ao tempo de vida e eficiência de formação dos estados de cargas separadas, foi estudado por OsUKA. Foram sintetizados complexos do tipo da Figura 1.10b, utilizando uma porfirina de zinco, uma porfirina base-livre e uma naftaleno diimida. Existe um gradiente de energia entre as unidades e o sistema produz um estado de cargas separadas através de uma cascata de transferências de energia e de elétrons quando este é exposto a uma fonte luz de $\lambda=532 \mathrm{~nm}$, o que leva a porfirina de zinco ao seu estado excitado e às subsequentes transferências citadas. ${ }^{51}$

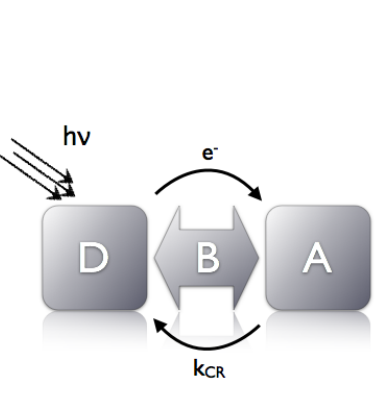

(a) Díade supermolecular.

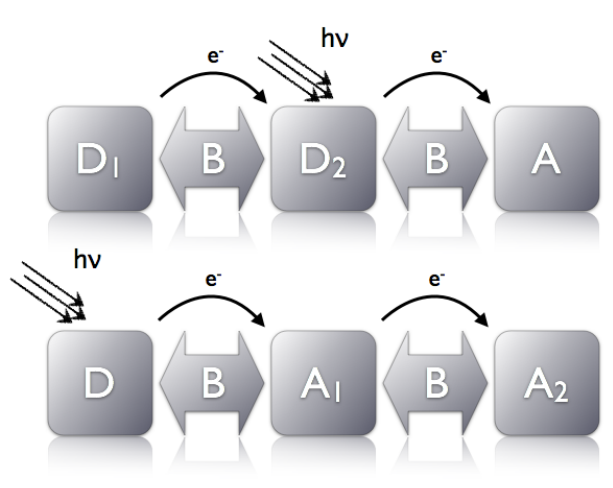

(b) Tríade supermolecular.

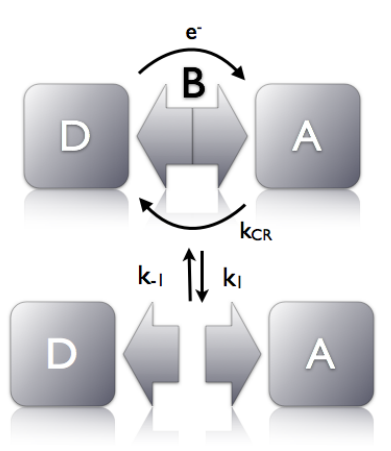

(c) Díade supramolecular.

Figura 1.10: Três abordagens distintas de modelos fotossintéticos artificiais.

Outros sistemas semelhantes ao de OsuKA são possíveis, em que um sistema supramolecular é usado para modificar quimicamente a superfície de um eletrodo para a produção de hidrogênio e oxigênio a partir da água ${ }^{52,53}$. Essa célula fotoeletroquímica desenvolve as semi-reações de um sistema fotossintético em dois eletrodos modificados. Ao contrário de um sistema eletroquímico convencional, o potencial é fornecido pela luz ao invés de uma bateria. Nesses sistemas também é possível utilizar diimidas aromáticas para promover as transferências eletrônicas.

Em um trabalho mostramos a possibilidade de se produzir eletrodos modificados com uma naftaleno diimida de forma simples para obter eletrodos estáveis, duráveis e que fotocatalisam a reação de redução do oxigênio. Um eletrodo de carbono vítreo (GCE) foi modificado com um derivado de NDI, a DC18 da Figura 1.11, e apresentou modestos potenciais de redução $\left(\mathrm{E}_{r e d}^{1}=-0,19 \vee\right.$ e $\left.\mathrm{E}_{r e d}^{2}=-0,69 \vee v \mathrm{Ag} / \mathrm{AgCl}\right)$ 
e maior condutividade quando irradiado por uma fonte de luz branca. ${ }^{47}$

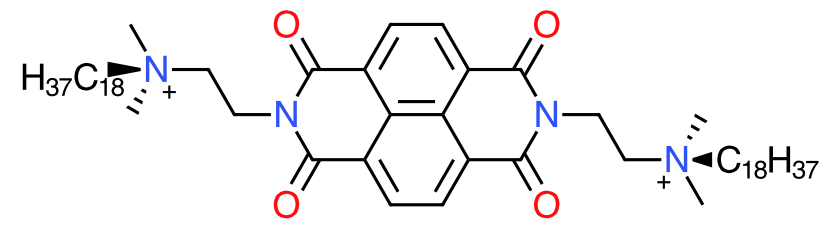

Figura 1.11: Derivado de 1,4,5,8-naftaleno diimida, DC18.

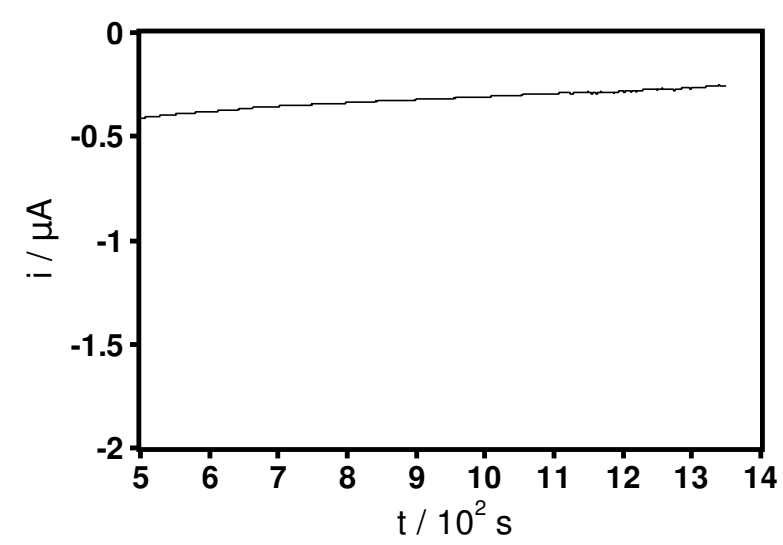

(a) GCE não modificado, $E=-0,67 \mathrm{~V}$.

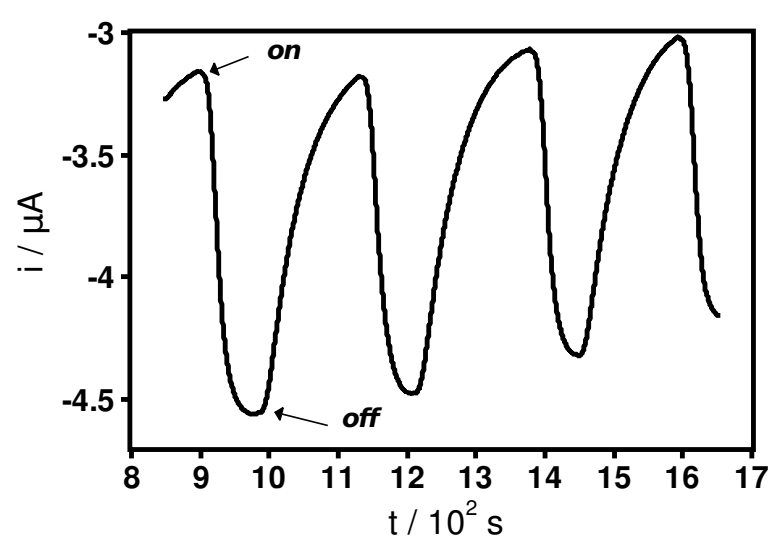

(b) GCE modificado com filme de DC18 em E = -0,67 V, na presença (on) e ausência (off) de uma fonte de luz branca.

Figura 1.12: Ensaios de fotocorrente em um eletrodo de carbono vítreo modificado com um filme de DC18 em um potencial constante de $-0,675 \mathrm{~V} v \mathrm{Ag} / \mathrm{AgCl}$ em uma solução aquosa de $\mathrm{KCl} 0,1 \mathrm{~mol} \mathrm{dm}^{-3}$ saturada de $\mathrm{O}_{2} .{ }^{47}$

A aplicação de NDIs em dispositivos eletrônicos tem produzido bons resultados. Sabe-se que essas diimidas são dos poucos compostos orgânicos do tipo $n$ e, além disso, são bastante estáveis frente à oxidação pelo ar atmosférico, um dos maiores problemas dos dispositivos eletrônicos orgânicos. Transístores de efeito de campo (OFETs) produzidos com um derivado de NDI apresentaram uma das maiores mobilidades de carga $(\mu)$ já observados ${ }^{54}$, com $\mu=6,2 \mathrm{~cm}^{2} \mathrm{~V}^{-1} \mathrm{~s}^{-1}$. A introdução do derivado DC18 como camada de injeção de elétrons em uma estrutura de LED orgânico convencional diminuiu a voltagem de operação em $25 \%$, aumentou o brilho do dispositivo em $350 \%$, além de aumentar a longevidade do LED. ${ }^{55}$

Existem na literatura alguns exemplos de complexos metálicos que utilizam diimidas aromáticas como substituintes em ligantes, como a substituição de ligantes bipiridínicos em complexos de rutênio ${ }^{56-58}$ e similares com centros metálicos de $\mathrm{Cu}(\mathrm{I}), \mathrm{Cu}(\mathrm{II})$ e $\mathrm{Fe}(\mathrm{III})^{59}, \mathrm{Ag}(\mathrm{I})^{60}$ e $\mathrm{Pt}(\mathrm{II})^{61}$, para estudos de transferência eletrônica. Isso nos leva às potenciais aplicações que as NDls podem apresentar em polímeros de coordenação. 


\section{Polímeros de coordenação contendo NDls}

Diimidas aromáticas como as NDIs podem ser utilizadas como ligantes em polímeros de coordenação, gerando estruturas interessantes com propriedades fotoluminescentes e de absorção seletiva de gases, como $\mathrm{CO}_{2}$. A escolha de grupos $\mathbf{R}$ apropriados pode tornar possível que sejam coordenadas com diversos centros metálicos como $\mathrm{Hg}(\mathrm{II}), \mathrm{Zn}(\mathrm{II}), \mathrm{Cd}(\mathrm{II}), \mathrm{Co}(\mathrm{II})$ e $\mathrm{Mn}(\mathrm{II})$ gerando desde estruturas 1D até estruturas de coordenação 2D ou 3D poliméricas com estruturas periódicas bem definidas. ${ }^{8,62,63}$

Um extensivo trabalho sobre a síntese de polímeros de coordenação contendo o ligante $N, N^{\prime}$-bis(3metilpiridil)-1,4,5,8-naftaleno diimida foi realizado por DENG, com diversos centros metálicos - Cd(II), $\mathrm{Hg}(\mathrm{I}), \mathrm{Zn}(\mathrm{II})$ e Co(II) - e condições de síntese, obtendo as variadas estruturas da Figura 1.13, contendo redes 1D, 2D e 3D. Os compostos que continham Cd(II) como centro metálico são luminescentes e exibem emissão característica do ligante NDI, porém em menores intensidades - efeito atribuído à supressão da fluorescência exercida pela coordenação com o metal.

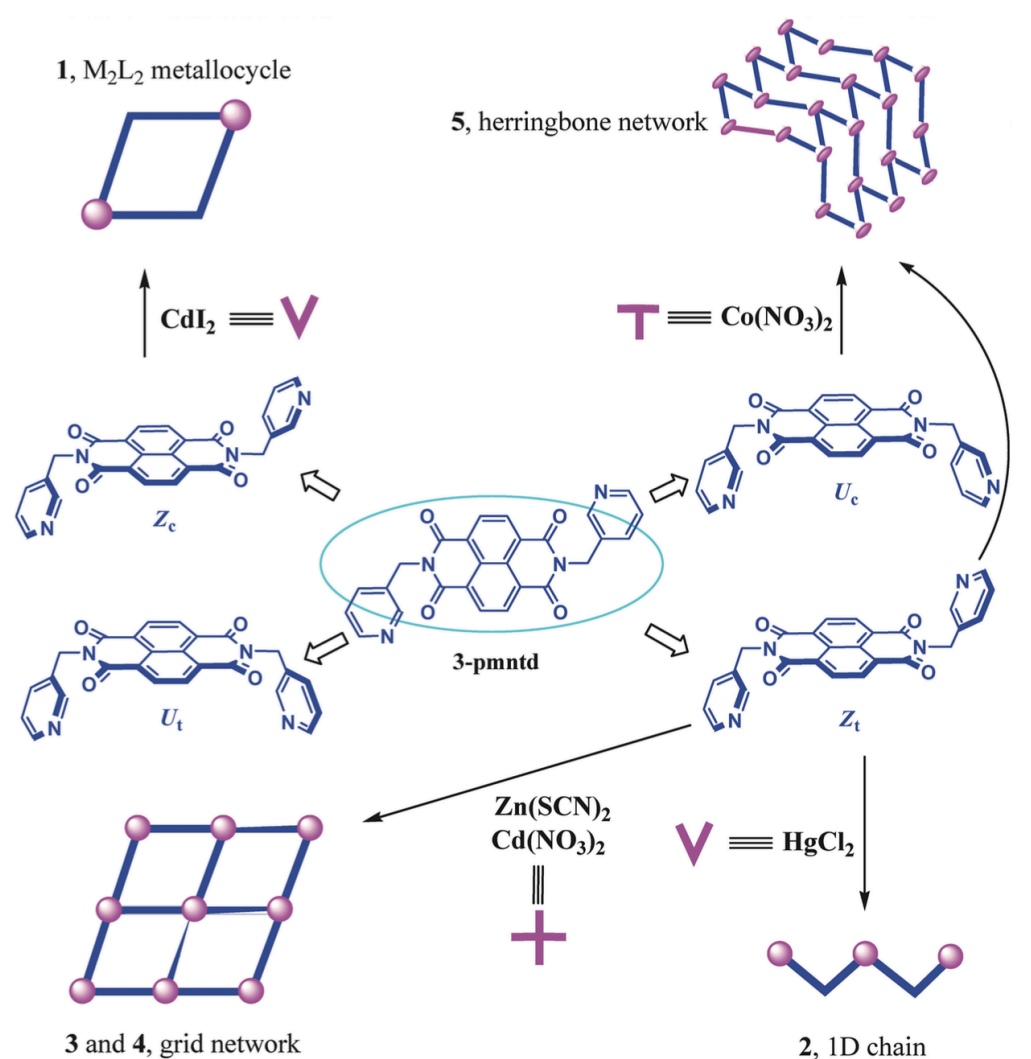

Figura 1.13: Polímeros de coordenação contendo $N, N^{\prime}$-bis(4-metilpiridil)-1,4,5,8-naftaleno diimida como ligante com diferentes centros metálicos. ${ }^{62}$

Em um trabalho semelhante, Lı estudou a diversidade estrutural de polímeros de coordenação que continham piromelítico diimidas com substituintes piridínicos e metais como $\mathrm{Mn}(\mathrm{II}), \mathrm{Cd}(\mathrm{II})$ e $\mathrm{Co}(\mathrm{II})$, com 
redes de estrutura similar as de DENG, e que também apresentaram luminescência naqueles que continham $\operatorname{Cd}(11) .{ }^{63}$

Como já citado, os MOFs desenvolvidos pelo grupo de J. T. HuPP utilizam uma naftaleno diimida como ligante, produzindo as estruturas da Figura 1.14. Estes MOFs utilizam, além da NDI, o centro metálico de $\mathrm{Zn}(\mathrm{II})$ e alguns ligantes dicarboxílicos, como o ácido naftaleno-2,6-dicarboxílico e o ácido bifenil-1,4-dicarboxílico. Estes compostos apresentam elevadas áreas superficiais, da ordem $700 \mathrm{~m}^{2} \mathrm{~g}^{-1}$, e atividade redox - um potencial de redução observado em $-0,7 \vee v s$ ferroceno, atribuído ao ligante NDI. ${ }^{18}$

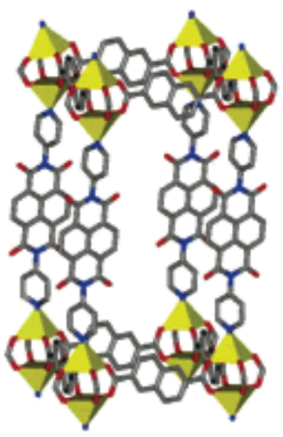

4

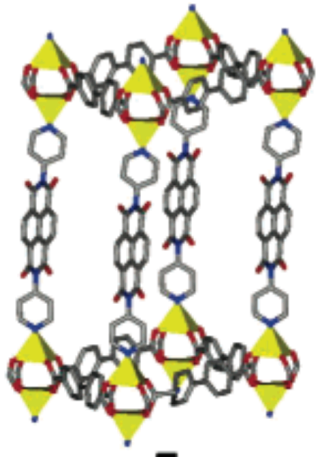

5

Figura 1.14: MOFs contendo NDI como ligante e Zn(II) como centro metálico. O composto 4 utiliza o ácido naftaleno-2,6dicarboxílico e o composto 5 utiliza o ácido bifenil-1,4-dicarboxílico. ${ }^{18}$

Polímeros de coordenação que apresentam fotocromismo foram sintetizados por HAN, baseados em cálcio e uma NDI com ligantes carboxílicos, formando uma rede 3D interpenetrada que apresenta fotocromismo reversível. O MOF formado é amarelo e, quando exposto à luz do sol por alguns minutos, torna-se verde escuro. O sólido retorna a sua coloração amarela depois de dois dias no escuro. ${ }^{64}$

Alguns trabalhos estudam a interação de ânions com a estrutura $\pi$ de derivados de NDI, como a influência do contra-íon na estrutura da rede formada ${ }^{65,66}$, formação de redes coordenadas com polioxometalatos ${ }^{67}$, e formação de estados de cargas separadas em redes contendo clusters de $\left[\mathrm{Mo}_{6} \mathrm{O}_{19}\right]^{2-} .68$ 


\section{Objetivos}

$\mathrm{O}$ objetivo desta tese foi sintetizar um MOF que contenha um derivado de 1,4,5,8-naftaleno diimida como ligante principal, e que fossem capaz de exibir condutividade elétrica e propriedades dependentes da luz, como fotocondutividade, o que ainda é inédito na literatura. Para isso, foi utilizado o derivado $N, N^{\prime}$-bis(4-piridil)-1,4,5,8-naftaleno diimida por conta de seus substituintes piridínicos, que são excelentes pontos de coordenação, além de contribuírem para a conjugação estendida do composto. O centro metálico de escolha foi o íon cobalto(II) por suas conhecidas propriedades magnéticas, labilidade e espectroscopia de seus íons complexos. A rede resultante da combinação deste centro metálico com o ligante derivado de diimida foi caracterizada estruturalmente pela solução de sua estrutura de monocristal, estado de oxidação do centro metálico, atividade eletroquímica, espectroscopia vibracional e eletrônica, e determinação de sua condutividade elétrica. Quando apropriado, os resultados obtidos para o polímero de coordenação foram contrastados com aqueles do ligante livre, afim de determinar mecanismos de funcionamento. 


\section{Parte Experimental}

$\mathrm{E}$

ste capítulo tratará dos detalhes experimentais seguindo a ordem da procedência dos reagentes utilizados, a síntese do ligante de interesse, NDI-py, e a síntese dos polímeros de coordenação estudados, MOF-CoNDI-py-1 e MOF-CoNDI-py-2, respectivamente. Após as descrições de síntese serão detalhados os equipamentos e técnicas de caracterização utilizados.

$$
-2.1-
$$

\section{Reagentes utilizados}

Encontram-se, na Tabela 2.1, os detalhes dos reagentes utilizados.

Tabela 2.1: Detalhes dos reagentes utilizados neste trabalho.

\begin{tabular}{|c|c|c|c|}
\hline Nome & Estrutura & Procedência & Pureza \\
\hline Água ultrapura & $\mathrm{H}_{2} \mathrm{O}$ & Milli-Q & - \\
\hline Acetona & $\mathrm{C}_{3} \mathrm{H}_{6} \mathrm{O}$ & Sigma-Aldrich & $99,5 \%$ \\
\hline Acetonitrila & $\mathrm{MeCN}$ & Sigma-Aldrich & $99,8 \%$ \\
\hline Ácido nítrico & $\mathrm{HNO}_{3}$ & Synth & $65 \%$ \\
\hline Ácido trifluoroacético deuterado & $\mathrm{CF}_{3} \mathrm{COOD}$ & Aldrich & $99,5 \%$ em átomos de $\mathrm{D}$ \\
\hline Ácido tereftálico & & Aldrich & $98 \%$ \\
\hline 4-aminopiridina & & Acros & $98 \%$ \\
\hline Dianidrido 1,4,5,8-naftálico & & Aldrich & $99 \%$ \\
\hline$N, N$-dimetilformamida & $\mathrm{HCON}\left(\mathrm{CH}_{3}\right)_{2}$ & Sigma-Aldrich & $99,8 \%$ \\
\hline Etanol & $\mathrm{CH}_{3} \mathrm{CH}_{2} \mathrm{OH}$ & Synth & $99 \%$ \\
\hline Éter etílico & $\left(\mathrm{CH}_{3} \mathrm{CH}_{2}\right)_{2} \mathrm{O}$ & Synth & $99 \%$ \\
\hline Ferroceno & $\mathrm{Fe}\left(\mathrm{C}_{5} \mathrm{H}_{5}\right)_{2}$ & Aldrich & $98 \%$ \\
\hline Hexafluorofosfato de tetrabutilamônio & $\underset{H}{\left[\mathrm{~N}(\mathrm{n}-\mathrm{Bu})_{4}\right]\left(\mathrm{PF}_{6}\right)}$ & Fluka & $99 \%+$ \\
\hline Imidazol & & Vetec & $99,5 \%$ \\
\hline Nitrato de cobalto(II) hexahidratado & {$\left[\mathrm{Co}\left(\mathrm{H}_{2} \mathrm{O}\right)_{6}\right]\left(\mathrm{NO}_{3}\right)_{2}$} & Synth & $99 \%$ \\
\hline
\end{tabular}




\section{Síntese da NDI-py}

Para a síntese da N,N'-bis(4-piridil)-1,4,5,8-naftaleno diimida, ou NDI-py, empregou-se a rota descrita por BROCHSZTAIN ${ }^{39}$ em 2005, resumida na Figura 2.1. Utilizando uma das sínteses como exemplo, adicionou-se 503,7 mg (1,88 mmol) de dianidrido 1,4,5,8-naftálico (NDA), 543,4 mg (5,77 mmol) de 4aminopiridina e $2 \mathrm{~g}$ de imidazol em um balão de fundo redondo. Ao balão, adicionou-se uma coluna de Vigreux. O sistema foi então imerso em um banho de óleo a $130^{\circ} \mathrm{C}$ por $30 \mathrm{~min}$, sob agitação magnética. Deixou-se a mistura resfriar naturalmente até temperatura ambiente, por cerca de $3 \mathrm{~h}$, adicionou-se $75 \mathrm{~mL}$ de uma mistura $\mathrm{H}_{2} \mathrm{O}: \mathrm{EtOH}: \mathrm{HNO}_{3}(10: 10: 1, \mathrm{v} / \mathrm{v})$, e sonicou-se o sistema final por cerca de 30 min, até total desprendimento do sólido formado ao fundo. Esta suspensão foi mantida em repouso em geladeira, a cerca de $5{ }^{\circ} \mathrm{C}$, e então filtrada a vácuo em papel de filtro quantitativo, lavada com $25 \mathrm{~mL}$ da mesma solução $\mathrm{H}_{2} \mathrm{O}: \mathrm{EtOH}: \mathrm{HNO}_{3}$, água, etanol e dietil éter, nesta ordem, e seco em estufa por $3 \mathrm{~h}$ a $100{ }^{\circ} \mathrm{C}$. Obteve-se $742,1 \mathrm{mg}$ de produto na forma de um sólido bege, resultando em um rendimento de $94 \%$.
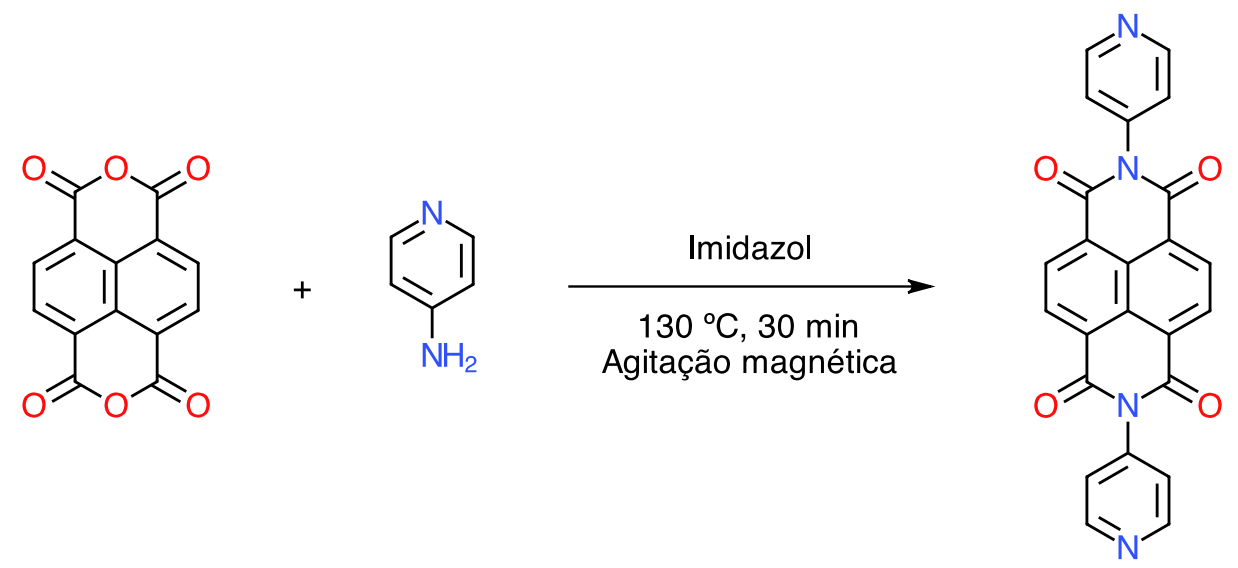

Figura 2.1: Esquema de síntese da $N, N^{\prime}$-bis(4-piridil)-1,4,5,8-naftaleno diimida, ou NDI-py.

Para garantir a pureza do produto, foi realizada a recristalização da NDI-py em DMF. Dissolveu-se todo o sólido em $25 \mathrm{~mL}$ de DMF a $150{ }^{\circ} \mathrm{C}$ e permitiu-se que a solução resfriasse naturalmente até temperatura ambiente, por cerca de $3 \mathrm{~h}$. Ao fim do resfriamento observou-se a formação de cristais espiculados com cerca de $1 \mathrm{~cm}$ cada, de coloração amarelada. Este sólido foi filtrado em papel de filtro quantitativo e lavado exaustivamente com água, etanol e dietil éter, nesta ordem. O sólido obtido foi seco em estufa a $100{ }^{\circ} \mathrm{C}$ por $3 \mathrm{~h}$, com um rendimento de $50 \%$ na recristalização. O rendimento final da síntese, com produto recristalizado, foi de $47 \%$.

Um resumo do resultado das análises estruturais da NDI-py pode ser encontrado a seguir. A discus- 
são detalhada de cada uma delas pode ser encontrada na seção de resultados no Capítulo 3, página 27. NDI-py

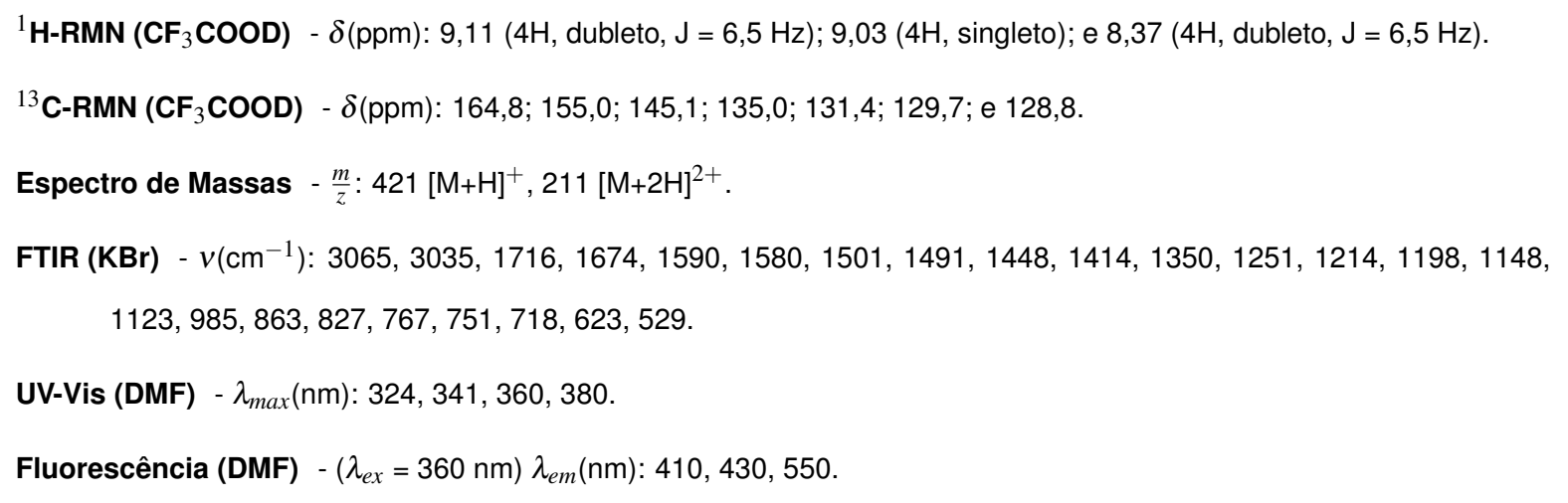

\section{Síntese do MOF-CoNDI-py-1}

A primeira síntese tentada foi uma adaptação da rota descrita por $\mathrm{MA}^{18}$, em 2005, que descreve a síntese solvotermal de um MOF de Zn(II) contendo NDI-py e uma série de outros compostos dicarboxílicos como ligantes. A adaptação da síntese se deu no intuito de, primeiramente, substituir o centro metálico de Zn(II) por Co(II), e também para preencher a esfera de coordenação do metal com ligantes NDI-py. Sendo assim, preparou-se uma solução contendo 50,3 mg (0,120 mmol) de NDI-py em 25,00 mL de DMF, com a ajuda de um balão volumétrico, e esta mistura foi sonicada por $30 \mathrm{~min}$. Transferiu-se $10 \mathrm{~mL}$ (0,048 mmol de NDI-py) desta solução para um frasco de síntese solvotermal ${ }^{(a)}$ Ace Pressure Tube ${ }^{\circledR}$, da Aldrich, aos quais foram adicionados $28,5 \mathrm{mg}(0,098 \mathrm{mmol})$ de $\left[\mathrm{Co}\left(\mathrm{H}_{2} \mathrm{O}\right)_{6}\right]\left(\mathrm{NO}_{3}\right)_{2}$. Este frasco foi aquecido em banho de óleo a $80^{\circ} \mathrm{C}$ por $48 \mathrm{~h}$ sem agitação magnética e, após este período, permitiu-se que a reação resfriasse naturalmente até temperatura ambiente, por cerca de $2 \mathrm{~h}$. Observou-se a formação de um sólido bege, um pouco mais escuro que a NDI-py livre, sem aparência cristalina. Este sólido foi separado por filtração simples e lavado exaustivamente com DMF, água e etanol, nesta ordem.

(a) O frasco consiste de um tubo de vidro de paredes grossas com tampa de Teflon ${ }^{\circledR}$, afixada por borrachas de vedação. 


\section{Síntese do MOF-CoNDI-py-2}

Para a síntese do MOF, dissolveu-se 92,3 mg (0,220 mmol) de NDI-py e 93,4 mg (0,562 mmol) de ácido tereftálico (TpA) em cerca de $30 \mathrm{~mL}$ de DMF sob aquecimento de $100{ }^{\circ} \mathrm{C}$. Após a dissolução completa, a solução foi resfriada naturalmente até temperatura ambiente. Em um frasco diferente, dissolveu-se 155,3 mg $(0,534 \mathrm{mmol})$ de $\left[\mathrm{Co}\left(\mathrm{H}_{2} \mathrm{O}\right)_{6}\right]\left(\mathrm{NO}_{3}\right)_{2}$ em cerca de $10 \mathrm{~mL}$ de DMF. As duas soluções foram misturadas em um frasco de Teflon ${ }^{\circledR}$ e o volume completado para $50 \mathrm{~mL}$ de DMF. Este frasco foi então inserido em uma carcaça de aço inoxidável, completando a montagem. O reator foi acomodado em um forno cerâmico com programação de aquecimento desde a temperatura ambiente, cerca de $30^{\circ} \mathrm{C}$, até $80^{\circ} \mathrm{C}$ a $1^{\circ} \mathrm{C} \mathrm{min}-1$, permanecendo neste patamar por $48 \mathrm{~h}$. A temperatura foi então lentamente diminuída para $50{ }^{\circ} \mathrm{C}$, e assim então permaneceu por mais $24 \mathrm{~h}$. Ao final, o reator foi removido do forno e permitido o resfriamento natural até temperatura ambiente, por cerca de $4 \mathrm{~h}$. Verificou-se a formação de cristais de coloração violeta, razoavelmente grandes e em quantidade, aderidos à superfície do reator. Os cristais foram coletados e lavados exaustivamente com DMF. O rendimento da síntese foi determinado indiretamente baseado na quantidade de ligante NDI-py remanescente na solução-mãe resultante. Como os coeficientes de absortividade molar foram determinados previamente, uma simples determinação de absorção de UV-Vis indicou um rendimento de $49 \%$. 


\section{Técnicas de caracterização}

§ 2.5.1. Espectroscopia eletrônica - As caracterizações por espectroscopia eletrônica da NDI-py foram realizadas a partir de uma solução em DMF em um espectrofotômetro Hewlett-Packard 8453 Diode Array, utilizando uma cubeta de quartzo com $1,00 \mathrm{~cm}$ de caminho óptico. Os gráficos com os espectros obtidos foram gerados no programa SciDavis ${ }^{\circledR} 0.2 .4$ e analisados por desconvolução multipicos utilizando funções gaussianas conforme a Equação 2.1. O ajuste automático fornecido pelo programa, apesar de satisfatório, foi refinado manualmente.

$$
y=y_{0}+\sqrt{\frac{2}{\pi}} \sum_{n=1}^{k} \frac{A_{n}}{w_{n}} e^{-2\left(x-\lambda_{\max }^{n}\right)^{2} / w_{n}^{2}}
$$

Na equação anterior, $A_{n}$ é a área do enésimo pico, $w_{n}$ é a sua largura à meia altura e $\lambda_{\max }^{n}$ o valor de $x$ no máximo deste pico.

Para o MOF-CoNDI-py-2, os espectros eletrônicos foram medidos por reflectância difusa em um espectrofotômetro FieldSpec 3 da Analytical Spectral Devices na região do Vis-NIR, de 350 nm a 2500 nm. Para a região do UV-Vis, de 200 nm a 900 nm, utilizou-se um espectrofotômetro DH-2000-Ball da Ocean Optics. Os dois espectros usaram $\mathrm{MgO}$ como referência e foram corrigidos apenas em relação à linha base.

§ 2.5.2. Análise termogravimétrica - As análises termogravimétricas (TGA) e de temogravimetria derivada (DTG) foram realizadas em um equipamento TA Instruments SDT 2960 Simultaneous DTATGA Thermal Analyst 2100 utilizando atmosfera oxidante, desde a temperatura ambiente até $1000^{\circ} \mathrm{C}$ a $10{ }^{\circ} \mathrm{C} \mathrm{min}^{-1}$.

\section{§ 2.5.3. Difração de raios- $X$ e estrutura de monocristal - Difração de raios- $X$ no pó foram realizadas} em um equipamento Siemens D5005 com uma fonte de Cu usando $\lambda=1,54 \AA$. Os materiais analisados foram secos em estufa a $100^{\circ} \mathrm{C}$ por $3 \mathrm{~h}$. Para a difração de raios- $\mathrm{X}$ de monocristal, cristais apropriados foram montados em um laço de Mitegen e colocados em uma câmera CCD da Bruker-Nonius APEX II de um $\kappa$-goniostato com um ânodo rotativo Bruker-Nonius FR591. Os cristais foram mantidos a $100 \mathrm{~K}$ durante a coleta de dados.

§ 2.5.4. Dispositivos eletrônicos - Os dispositivos eletrônicos foram fabricados por uma combinação de técnicas. Utilizou-se substratos de silício do tipo p, p-Si, sobre os quais foi depositada uma camada 


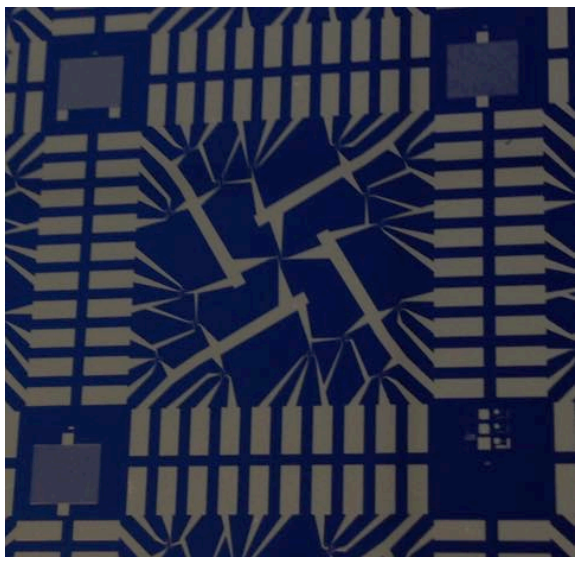

Figura 2.2: Imagem de um dispositivo para a determinação da condutividade elétrica do MOF-CoNDI-py-2.

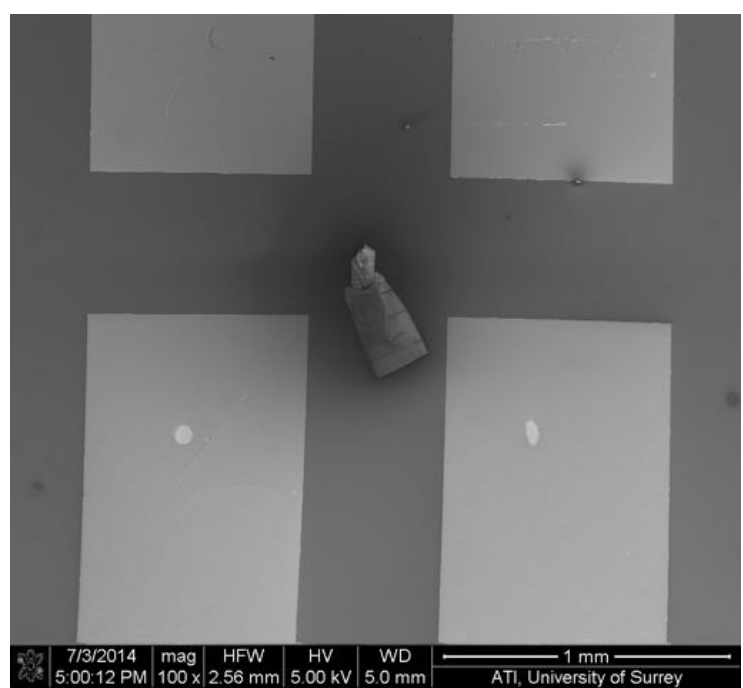

(a) Cristal do MOF-CoNDI-py-2 depositado sobre o dispositivo.

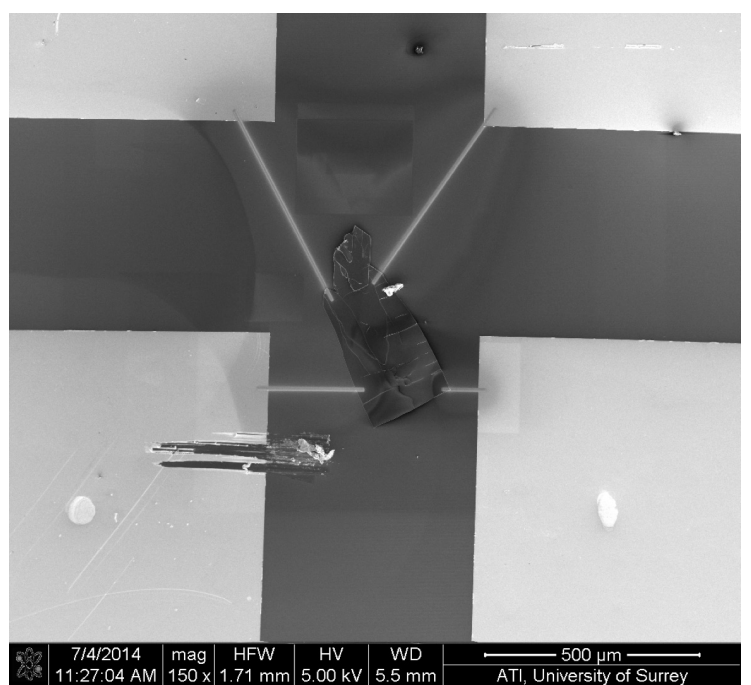

(b) Eletrodos de platina conectando o cristal ao dispositivo.

Figura 2.3: Imagens de um dispostivo do MOF-CoNDI-py-2 antes e após a deposição dos eletrodos de platina.

de $200 \mathrm{~nm}$ de $\mathrm{SiO}_{2}$ por PECVD (deposição de vapor químico auxiliada por plasma). Os eletrodos foram depositados por litografia com o auxílio de uma máscara que continha o padrão desejado. Depositouse uma pré-camada, fina, de Ti para auxiliar na aderência dos eletrodos de Au. A Figura 2.2 traz uma imagem de um desses dispositivos.

Os dispositivos base, após a fabricação, foram limpos em ultrassom em um banho de acetona por 10 min e secos com um fluxo de nitrogênio. Cristais de MOF-CoNDI-py-2 foram depositados através de uma suspensão em acetona, com o auxílio de uma pipeta de Pasteur, conforme a Figura 2.3a. Os cristais do MOF foram então conectados aos eletrodos de Au do dispositivo através de eletrodos de Pt depositados via Focused Ion Beam, FIB, como mostra a Figura 2.3b, utilizando o complexo trimetil(metilciclopentadienil)platina(IV) como fonte de platina. Os dispositivos finalizados foram medidos com um arranjo de dois eletrodos em um equipamento Keithley 2400. 
§ 2.5.5. Eletroquímica - As medidas eletroquímicas da NDI-py foram realizadas em um potenciostato Autolab PGSTAT30 Potentiostat/Galvanostat com uma célula eletroquímica em um arranjo de três eletrodos. Utilizou-se uma solução $10 \mathrm{mmol} \mathrm{dm}{ }^{-3}$ de $\left[\mathrm{N}(\mathrm{n}-\mathrm{Bu})_{4}\right]\left(\mathrm{PF}_{6}\right)$ em DMF como eletrólito de suporte, que foi previamente seco em peneira molecular por sete dias. A concentração do analito foi de $1 \mathrm{mmol} \mathrm{dm}^{-3}$.

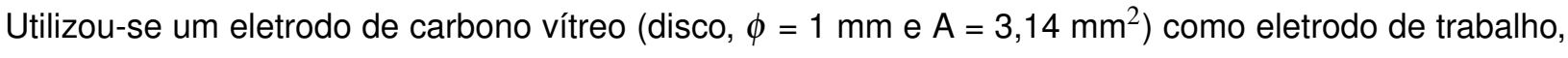
um eletrodo de $\mathrm{Pt}$ (placa, $\mathrm{A}=1,0 \mathrm{~cm}^{2}$ ) como eletrodo auxiliar, e um fio de $\mathrm{Ag}$ como eletrodo de pseudoreferência. Utilizou-se ferroceno $(\mathrm{E}=+0,55 \mathrm{~V} v s \mathrm{SHE})^{69}$ como referência interna e restringiu-se a janela de análise entre $+1 \mathrm{~V}$ e $-1,5 \mathrm{~V}$, começando pela varredura catódica a partir de $0 \mathrm{~V}$.

As medidas de eletroquímica do MOF-CoNDI-py-2 foram realizadas em um potenciostato EG\&G 173 Potentiostat/Galvanostat equipado com um programador universal modelo PAR e um coulombímetro digital modelo PAR, empregando microeletrodos de cavidade (CME) de platina, representados na Figura 2.4. Os cristais do MOF-CoNDI-py-2 foram depositados na cavidade do CME - de diâmetro $\phi=50 \mu \mathrm{m}$, profundidade $\mathrm{d}=25 \mu \mathrm{m}$ e volume $\mathrm{V}=1 \times 10^{-8} \mathrm{~cm}^{3}$ - e montados em uma célula eletroquímica em um arranjo de três eletrodos, com o CME como eletrodo de trabalho, um fio de platina como eletrodo auxiliar, $\mathrm{Ag} \mathrm{AgNO}_{3}\left(10^{-2} \mathrm{~mol} \mathrm{dm}{ }^{-3}\right.$ em MeCN) como referência e $0,1 \mathrm{~mol} \mathrm{dm}{ }^{-3}$ de $\left[\mathrm{N}(\mathrm{n}-\mathrm{Bu})_{4}\right]\left(\mathrm{PF}_{6}\right)$ em MeCN como eletrólito de suporte. Os voltamogramas cíclicos foram impressos diretamente em papel com a ajuda de um plotador $\mathrm{XY}$ e digitalizados em escala.

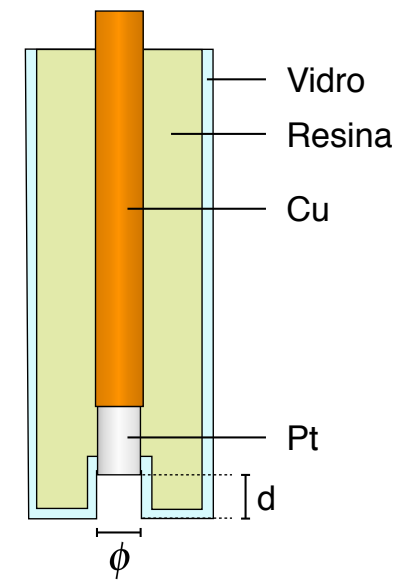

Figura 2.4: Estrutura do microeletrodo de cavidade (CME) utilizado para as medidas de eletroquímica do MOF-CoNDI-py-2.

§ 2.5.6. Luminescência - As análises de emissão de luz da NDI-py foram realizados em um Shimadzu Spectrofluorophotometer RF-5301PC utilizando uma solução em DMF em uma cubeta de quatro faces ópticas de quartzo de 1,00 cm de largura. As análises de emissão de luz no estado sólido, tanto da NDI-py quanto do MOF-CoNDI-py-2, foram realizados em um Horriba-Jobin Yvon SPEX TRIAX 550 FluoroLog 3 com lâmpada de xenônio de 450 W, câmara CCD SPEX Synapse e fotomultiplicadora Ha- 
mamatsu R928P, e as amostras foram acomodadas dentro de um tubo de quartzo de aproximadamente $0,5 \mathrm{~cm}$ de largura.

Os tempos de vida de emissão dos compostos foram obtidos no estado sólido em um sistema PicoQuant MicroTime 200 acompanhado de um microscópio óptico invertido Olympus iX 71 confocal, utilizando um laser para excitação em $\lambda=375 \mathrm{~nm}$ e coletando toda emissão acima de $405 \mathrm{~nm}$.

§ 2.5.7. Espectrometria de massas - A espectrometria de massas da NDI-py foi realizada em um Espectrômetro de Massas Waters Xevo TQ-S com ionizador de electrospray, no modo positivo. As amostras foram dissolvidas em uma mistura $\mathrm{H}_{2} \mathrm{O}: \mathrm{MeOH}(1: 9)$ que também continham ácido fórmico.

§ 2.5.8. Espectroscopia vibracional - Espectros de FTIR foram obtidos em um equipamento Shimadzu IRPrestige-21 Fourier Transform Infrared Spectrophotometer utilizando pastilhas de $\mathrm{KBr}$. Os espectros obtidos foram corrigidos automaticamente para a remoção dos sinais de $\mathrm{H}_{2} \mathrm{O}$ e $\mathrm{CO}_{2}$ atmosféricos e também sofreram ajustes manuais de linha base. As amostras foram secas em estufa a $100^{\circ} \mathrm{C}$ por $3 \mathrm{~h}$ antes das análises.

§ 2.5.9. Microscopia óptica - As imagens de microscopia óptica foram adquiridas com o auxílio de um Microscópio Leica DM2500. Os cristais do MOF-CoNDI-py-2 foram depositados a partir de uma suspensão em DMF sobre uma placa de vidro e o solvente evaporado lentamente a $50^{\circ} \mathrm{C}$.

§ 2.5.10. Microscopia eletrônica de varredura - As imagens de microscopia eletrônica foram registradas em um microscópio Shimadzu SS-550. As amostras foram depositadas no suporte a partir de uma suspensão em acetona.

§ 2.5.11. Ressonância magnética nuclear - Espectros de $\mathrm{RMN}$ de ${ }^{1} \mathrm{H},{ }^{13} \mathrm{C}$, Dept135 e HMBC foram adquiridos em um Bruker DRX-500 a 500 MHz e utilizando ácido trifluoracético deuterado como solvente, sem referência interna.

§ 2.5.12. Ressonância paramagnética eletrônica — As análises de EPR do MOF-CoNDI-py-2 foram realizadas em um Bruker EMX equipado com uma cavidade Bruker ER4116DM, um criostato Oxford Instrument ESR900 e um controlador de temperatura Bruker ER4131VT. As medidas foram feitas utilizando a banda-X em hélio (de $7 \mathrm{~K}$ a $75 \mathrm{~K}$ ) com um frequência de $9,6399 \mathrm{GHz}$ e potência de $6,533 \mathrm{~mW}$. $\mathrm{O}$ fator de atenuação de potência foi de $15 \mathrm{~dB}$ e a amplitude de modulação foi 5G. Não foi utilizada nenhuma referência interna. 


\section{Cálculos teóricos}

Para dar suporte às observações experimentais e extrair informações mais detalhadas de uma série de propriedades dos compostos sintetizados, foram realizados cálculos teóricos a nível de Density Functional Theory (DFT) e Time-Dependant Density Functional Theory (TD-DFT) utilizando o software Gaussian ${ }^{\circledR} 09^{70}$ com o método B3LYP ${ }^{71-74}$ (Becke, three parameter, Lee-Yang-Parr) e as bases de POPLE, 6-31G(d,p), 6-31+G(d,p) ${ }^{75-77}$; e a de DUNNING, cc-pVTZ. ${ }^{78}$

O primeiro passo dos cálculos teóricos foi a determinação da geometria termodinamicamente mais estável, no vácuo. Para a NDI-py, desenhou-se a molécula no programa GaussView ${ }^{\circledR}$ (versão 5.0.8) com uma simetria $D_{2 h}$. Primeiramente a molécula teve sua geometria otimizada via B3LYP/6-31+G(d,p) e em seguida com a base cc-pVTZ ${ }^{(b)}$, utilizando parâmetros ultrafinos de convolução. Em seguida foram determinadas as frequências vibracionais e, pela ausência de frequências negativas, constatou-se tratar de um mínimo de energia sendo, portanto, um estado termodinamicamente estável.

Os espectros de FTIR foram determinados utilizando geometrias otimizadas. O grupo de ponto inicial foi preservado e as vibrações determinadas a 298,15 K e 1 atm, condições padrão do cálculo. As frequências calculadas foram escalonadas por um fator 0,964 de acordo com a orientação do National Institute of Standards and and Technology (NIST). Este fator é dependente do método e base utilizados e visa corrigir diversas diferenças entres os modelos experimental e teórico, como o cálculo da estrutura eletrônica que em geral é feito de maneira aproximada e a superfície da energia potencial não ser harmônica. ${ }^{79}$

As transições eletrônicas verticais, isto é, que não contem nenhum efeito nuclear e térmico, foram determinadas a partir da geometria otimizada da NDI-py em situação de solvatação contínua de DMF. Utilizou-se os mesmos método e base que a para a otimização geométrica, B3LYP e cc-pVTZ.

Os deslocamentos químicos e constantes de acoplamento nos espectros de $\mathrm{RMN}$ de ${ }^{1} \mathrm{H}$ e ${ }^{13} \mathrm{C}$ da NDI-py foram simulados utilizando o método Gauge-Including Atomic Orbitals ${ }^{80}$ (GIAO) com o funcional B3LYP, a base cc-pVTZ e solvatação contínua de ácido acético, com a geometria da molécula otimizada neste solvente. Não estava disponível a parametrização para a solvatação contínua de ácido trifluoroacético, o mesmo que no RMN experimental, e portanto escolheu-se o solvente disponível mais similar; no caso, o ácido acético. Os valores absolutos dos deslocamentos químicos foram representados com referência aos valores de deslocamentos da referência TMS, já disponíveis no banco de dados do programa GaussView. Estes valores são $\delta_{H}^{\mathrm{TMS}}=31,88 \mathrm{ppm}$ e $\delta_{C}^{\mathrm{TMS}}=182,47 \mathrm{ppm}$, determinados via B3LYP

\footnotetext{
(b) Artifício comumente empregando quando se utiliza uma base de elevada demanda computacional, como é o caso.
} 
e 6-311+G(2d,p). No RMN de ${ }^{1} \mathrm{H}$, o efeito da constante de acoplamento $(J)$ calculada foi introduzido sobre o deslocamento químico original utilizando a relação $J=F \Delta \delta$, produto da variação do deslocamento químico $(\Delta \delta)$ e a frequência do equipamento $(F)$. O espectro teórico de RMN de ${ }^{1} \mathrm{H}$ da NDI-py foi convoluído utilizando funções gaussianas com os valores de deslocamento químico calculados, entretanto as áreas e larguras à meia altura dessas gaussianas foram atribuídos arbitrariamente apenas para ilustração. 


\section{Resultados e Discussão}

$\mathrm{N}$

este capítulo, os resultados obtidos serão apresentados e discutidos seguindo uma sequência. Primeiramente serão tratados os resultados do ligante NDI-py, seguido dos resultados do MOFCoNDI-py-1, que por sua vez motivaram a concepção do MOF-CoNDI-py-2.

\section{NDI-py}

§ 3.1.1. Ressonância magnética nuclear - A determinação estrutural da NDI-py foi realizada pela a técnica de Ressonância Magnética Nuclear (RMN). A atribuição dos sinais foi feita com base em efeitos já presumidos ${ }^{81}$ e com a ajuda de cálculos teóricos. O espectro experimental de RMN de ${ }^{1} \mathrm{H}$ da NDI-py pode ser encontrado na Figura 3.1.

A molécula de NDI-py apresenta três ambientes químicos distintos para os átomos de hidrogênio, e cada ambiente deve corresponder a quatro átomos. Os quatro hidrogênios do esqueleto naftalênico central são equivalentes e os substituintes piridínicos apresentam dois hidrogênios equivalentes na posição $\alpha$ ao nitrogênio piridínico, e outros dois na posição $\beta$. Espera-se, portanto, que sejam observados um singleto, referente os hidrogênios centrais, e dois dubletos referentes aos dois ambientes químicos dos hidrogênios piridínicos, e que as integrais dos três sinais sejam equivalentes. De fato, como pode ser conferido na Figura 3.1, é o que se observa experimentalmente.

No espectro experimental, observou-se um dubleto em $\delta=8,37 \mathrm{ppm}(J=6,5 \mathrm{~Hz})$, um singleto em $\delta=9,03$ ppm e outro dubleto em $\delta=9,11(J=6,5 \mathrm{~Hz})$. Por terem o mesmo valor de acoplamento spin-spin, $J$, atribui-se que os sinais em deslocamentos 9,11 ppm e 8,37 ppm estão acoplados e são referentes aos hidrogênios piridínicos, concluindo, portanto, que o singleto central seja referente aos hidrogênios naftalênicos. A atribuição inicial dos sinais é baseada nos efeitos de blindagem esperados 

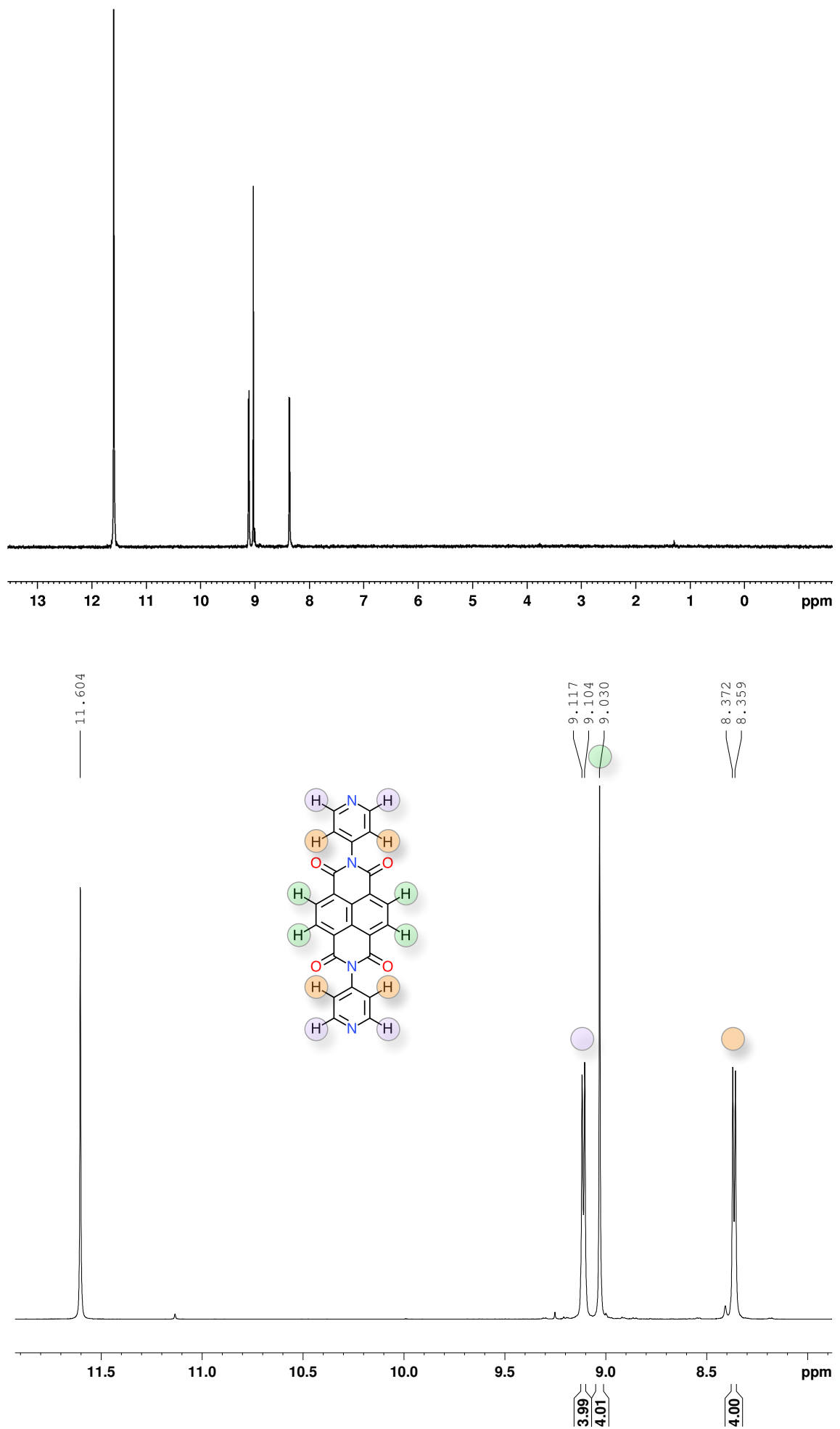

Figura 3.1: Espectros de RMN de ${ }^{1} \mathrm{H}$ da NDI-py em $\mathrm{CF}_{3} \mathrm{COOD}$ a $500 \mathrm{MHz}$, mostrando a região completa (superior) e ampliação dos sinais observados (inferior). 


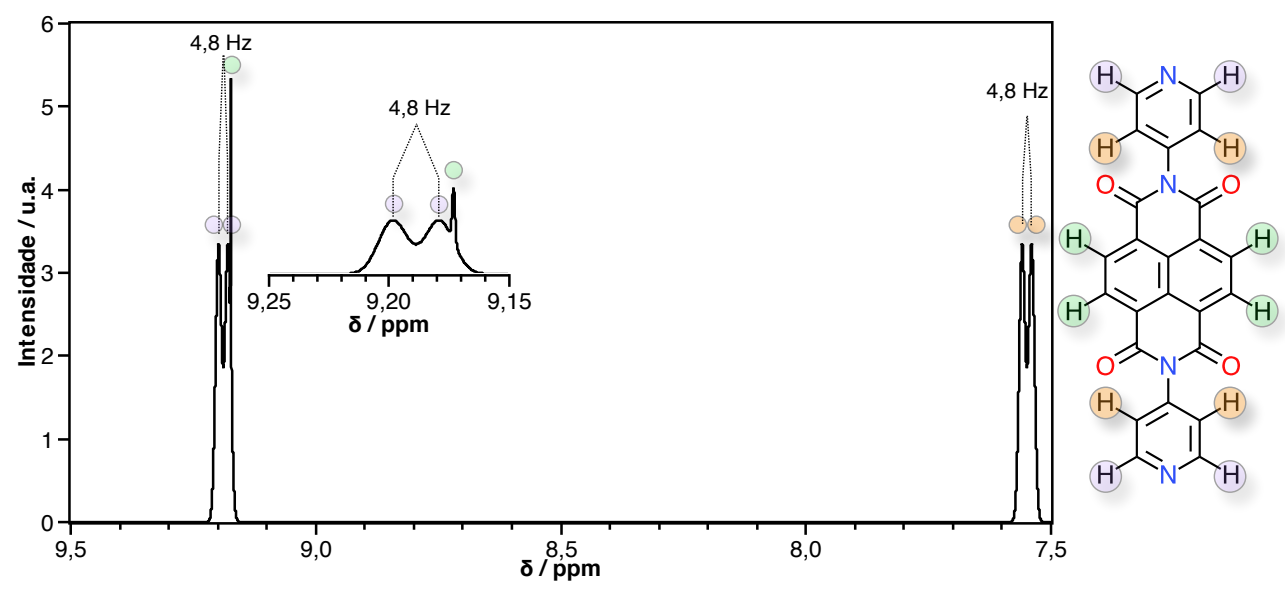

Figura 3.2: Espectro teórico de RMN de ${ }^{1} \mathrm{H}$ da NDI-py em ácido acético e atribuição de seus sinais.

para heteroátomos, como o nitrogênio piridínico.

A influência do campo eletromagnético gerado pelas carbonilas do esqueleto central sobre os hidrogênios piridínicos mais próximos (em $\beta$ ao nitrogênio) foi averiguada por vias teóricas. Havia incerteza sobre a magnitude desta influência que poderia alterar a atribuição dos sinais. O cálculo teórico determinou corretamente três ambientes químicos distintos para os átomos de hidrogênio, de igual degenerescência, isto é, cada sinal é equivalente a quatro átomos de hidrogênio. A atribuição dos sinais obedece a ordem esperada, com os hidrogênios piridínicos em $\alpha$ apresentando o maior deslocamento químico, seguidos por aqueles do esqueleto central e finalmente aqueles em $\beta$ ao nitrogênio piridínico. Os deslocamentos simulados para os dois primeiros casos são bastante satisfatórios, apesar de muito próximos, porém o deslocamento dos últimos foi significativamente subestimado. A constante de acoplamento $(J)$ entre os hidrogênios piridínicos calculada foi de $4,8 \mathrm{~Hz}$, um importante desvio de $26 \%$ do experimental, que apresentou $J=6,5 \mathrm{~Hz}$. No geral, apesar da ligeira discrepância numérica, considera-se que o cálculo tenha sido adequado uma vez que interesse primário era a corroboração da atribuição dos sinais. Na Tabela 3.1, encontra-se a comparação dos dados teóricos e experimentais enquanto na Figura 3.2 é possível encontrar o espectro teórico convoluido do RMN de ${ }^{1} \mathrm{H}$.

Tabela 3.1: Comparação dos dados téorico e experimental para o RMN de ${ }^{1} \mathrm{H}$ da NDI-py.

\begin{tabular}{ccc}
\hline Experimental & Teórico & Desvio \\
\hline$\delta$ (ppm) & & \\
9,11 & 9,19 & $0,9 \%$ \\
9,03 & 9,17 & $1,6 \%$ \\
8,37 & 7,55 & $9,8 \%$ \\
& & \\
$\mathbf{J}(\mathbf{H z})$ & & \\
6,5 & 4,8 & $26,2 \%$ \\
\hline
\end{tabular}

Apesar dos bons resultados na simulação $\mathrm{RMN}$ de ${ }^{1} \mathrm{H}$, os resultados para o ${ }^{13} \mathrm{C}$ são discrepantes do 


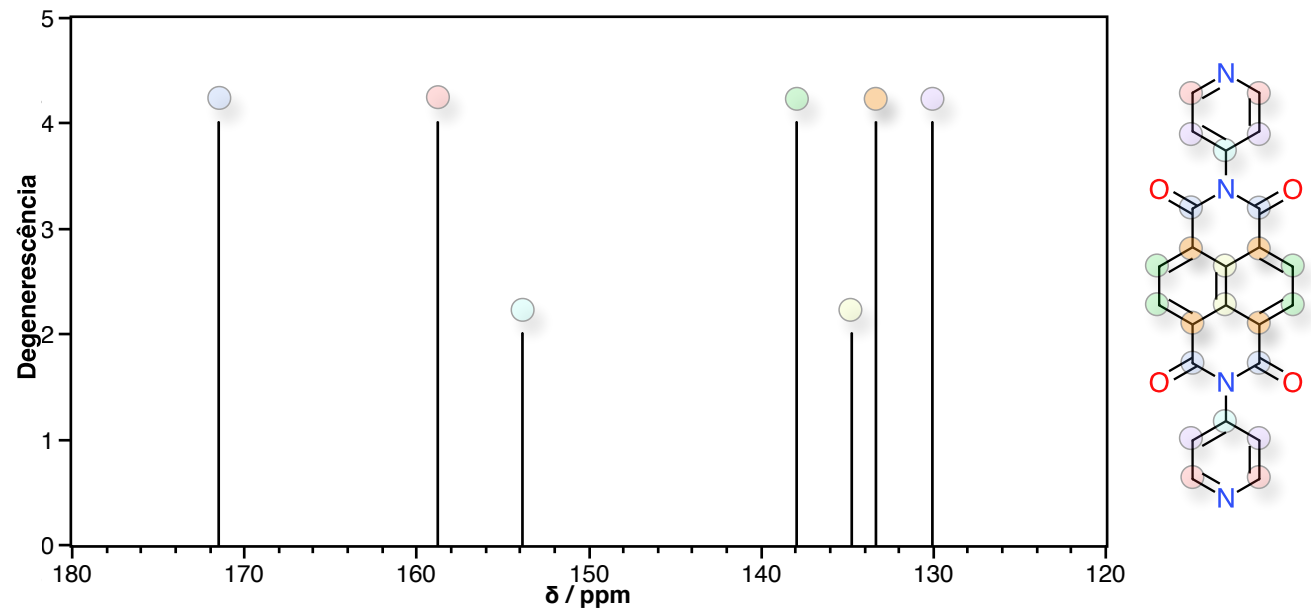

Figura 3.3: Espectro teórico de RMN de ${ }^{13} \mathrm{C}$ da NDI-py em ácido acético e atribuição de seus sinais.

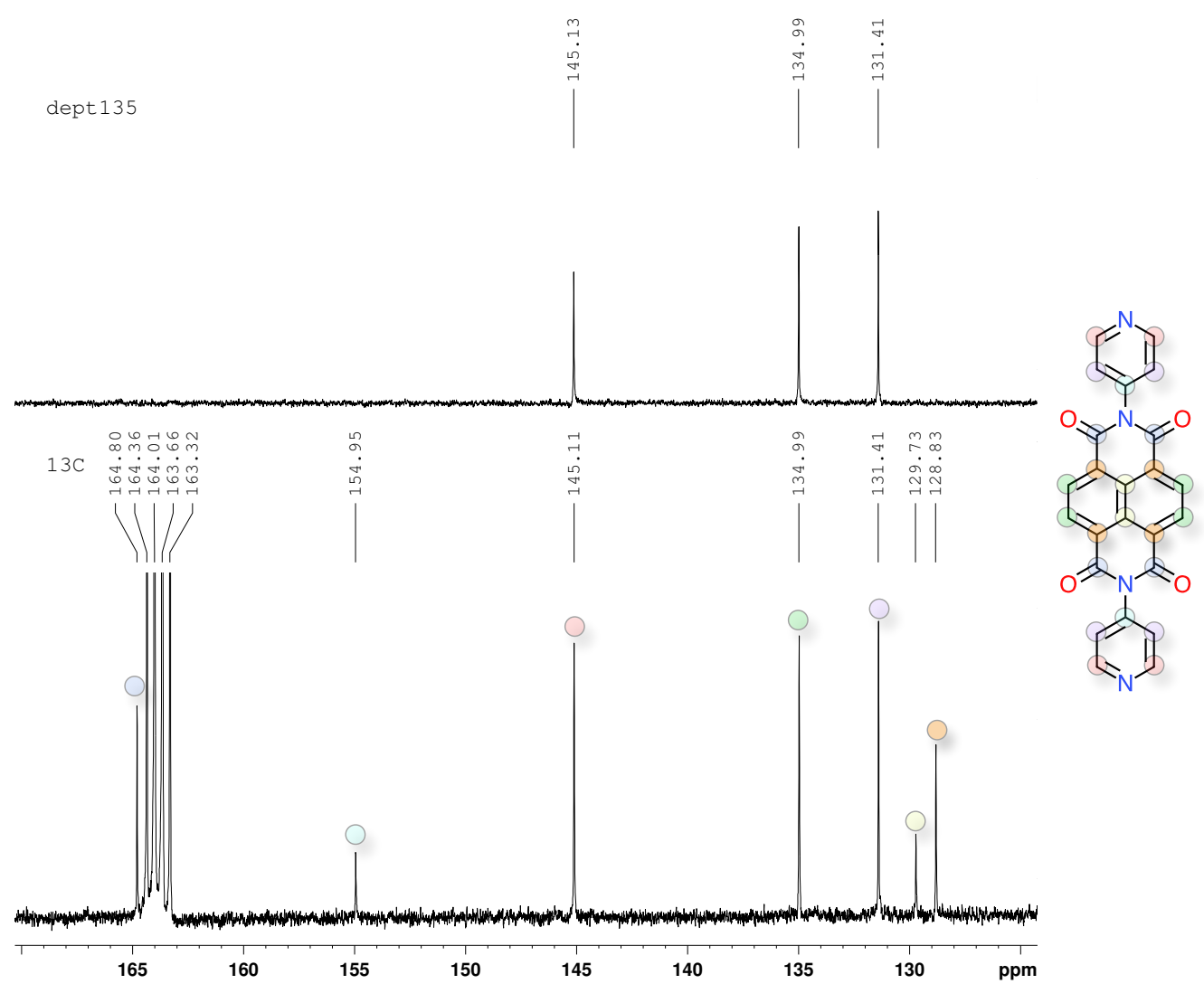

Figura 3.4: Espectros de Dept135 (superior) e de RMN de ${ }^{13} \mathrm{C}$ (inferior) da NDI-py em $\mathrm{CF}_{3} \mathrm{COOD}$ a $500 \mathrm{MHz}$. 
experimental, como pode ser observado nas Figura 3.3 e Figura 3.4.

Os espectros de ${ }^{13} \mathrm{C}$ simulados foram corretos na determinação da região dos valores de deslocamentos químicos porém a atribuição dos sinais diverge do experimental, com principal atenção dada aos deslocamentos dos carbonos mais externos do esqueleto naftalênico, ligados diretamente aos hidrogênios centrais, como evidencia o espectro de RMN através da técnica de Dept135. Para sanar a dúvida da atribuição dos sinais, foi analisado o espectro de RMN bidimensional do tipo HMBC, que correlaciona os sinais de ${ }^{13} \mathrm{C} \mathrm{e}{ }^{1} \mathrm{H}$ acoplados, conforme mostrado na Figura 3.5.

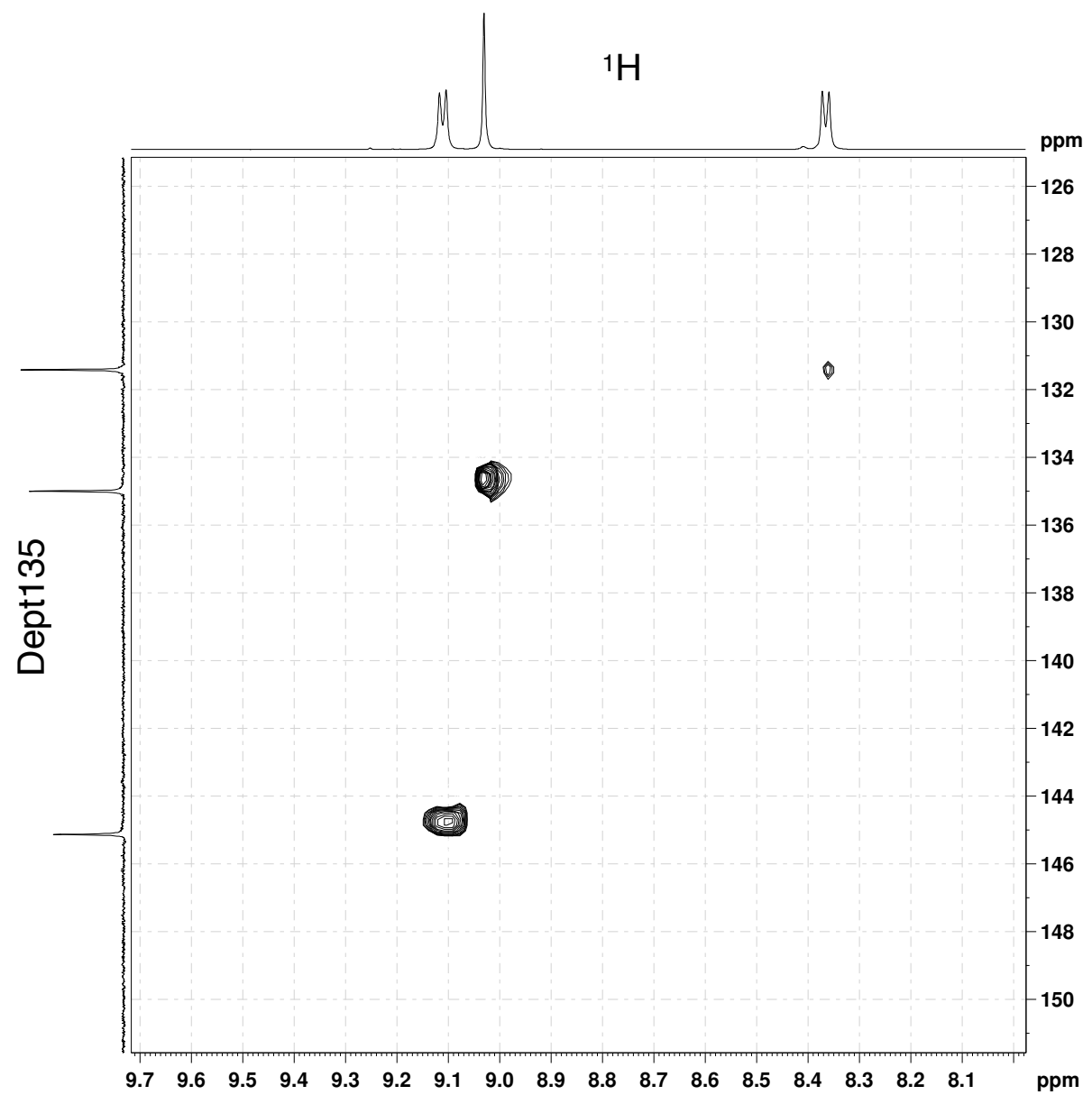

Figura 3.5: Espectro de RMN HMBC da NDI-py em $\mathrm{CF}_{3} \mathrm{COOD}$ a $500 \mathrm{MHz}$.

Com a atribuição prévia dos hidrogênios, é imediata a correlação dos sinais de ${ }^{13} \mathrm{C}$ no espectro de HMBC. As demais atribuições foram baseadas nos efeitos esperados com exceção dos dois carbonos centrais do esqueleto naftalênico, atribuídos ao sinal de 129,73 ppm. Esperava-se que a atribuição fosse oposta, em relação os carbonos atribuídos em 128,83 ppm, pela proximidade com as carbonilas. Entretanto, a atribuição foi baseada na intensidade relativa dos sinais.

Em linhas gerais, os espectros de RMN de ${ }^{1} \mathrm{H},{ }^{13} \mathrm{C}$ e HMBC - bem como suas atribuições de sinais evidenciam a estrutura da NDI-py bem como sua pureza. Os resultados obtidos foram comparados com 
os disponíveis na literatura ${ }^{38}$, havendo uma excelente correspondência entre todos os deslocamentos químicos reportados.

§ 3.1.2. Espectrometria de massas - O objetivo das análises de massas aqui não é detalhar os fragmentos ou tipos de fragmentação e sim, mais objetivamente, comprovar a presença da molécula de interesse. Na Figura 3.6 temos o espectro de massas da NDI-py onde é possível observar os picos referentes ao íon molecular adido de um próton, $[\mathrm{M}+\mathrm{H}]^{+}$, em 421 ; e o íon molecular adido de dois prótons, $[\mathrm{M}+2 \mathrm{H}]^{2+}$, em 211 - fatores decorrentes do tipo de análise. É importante ressaltar que a resolução do equipamento não permite uma relação ótima entre as intensidades dos sinais e, dessa forma, o sinal em 422 é referente ao íon molecular com isótopos de massa superior - como ${ }^{13} \mathrm{C},{ }^{2} \mathrm{H},{ }^{15} \mathrm{~N}$ - adido de um próton, $[(\mathrm{M}+1)+\mathrm{H}]^{+}$. O esperado era que este último tivesse cerca de $20 \%$ da intensidade do sinal do íon molecular, considerando a distribuição dos isótopos presentes.

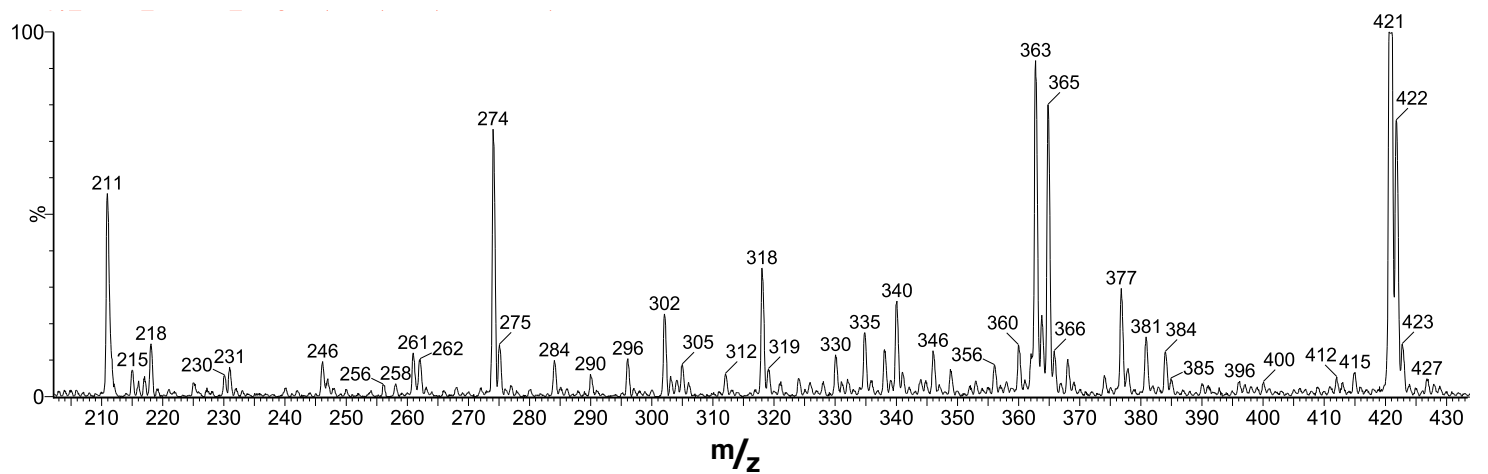

Figura 3.6: Espectro de massas da NDI-py no modo positivo. 
§ 3.1.3. Espectroscopia vibracional — Uma análise de infravermelho com uma completa atribuição de bandas não pôde ser encontrada na literatura. A Tabela 3.2 foi construída com base em cálculos teóricos a nível de DFT e atribuições de bandas de infravermelho de compostos similares ${ }^{82}$. As frequências calculadas foram escalonadas por um fator de 0,964 , conforme recomendado ${ }^{79}$, para levar em consideração a anarmonicidade da superfície de energia potencial e aproximações na estrutura eletrônica calculada. O espectro de FTIR obtido por DFT pode ser comparado com o espectro experimental, como mostra a Figura 3.7.

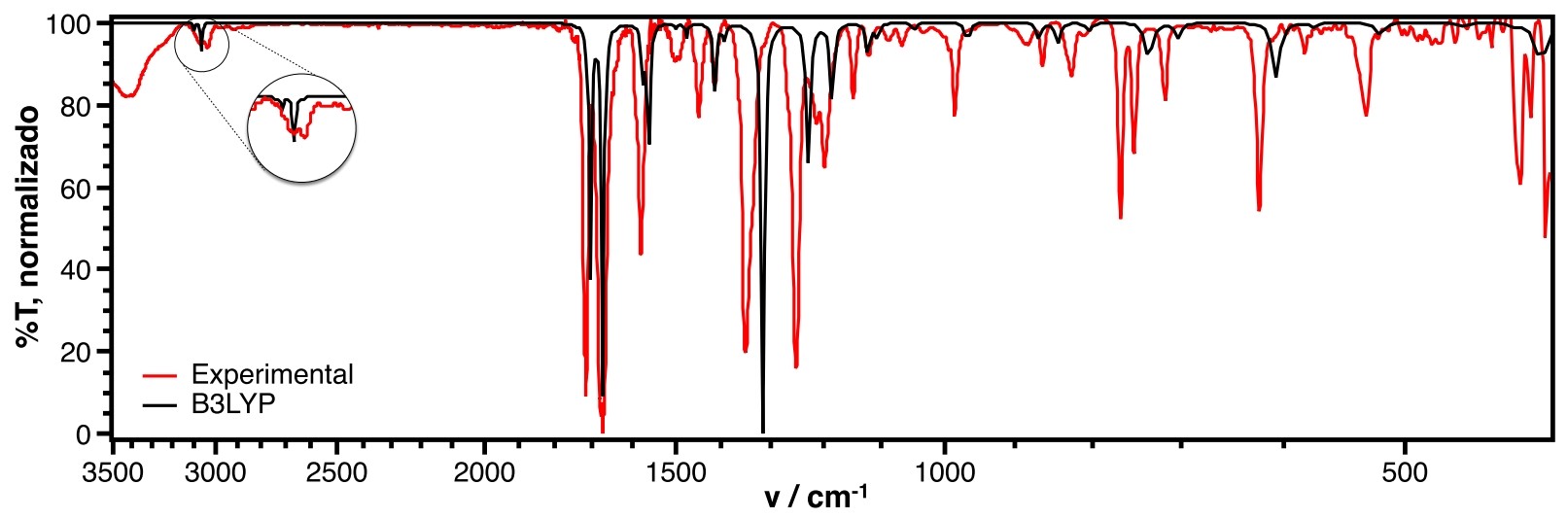

Figura 3.7: Espectros de FTIR teórico, no vácuo, e experimental, em $\mathrm{KBr}$, da NDI-py.

Tabela 3.2: Atribuições das bandas de FTIR da NDI-py baseadas em cálculos DFT e nas referências $82,62,83$ e $84 .^{a}$

\begin{tabular}{|c|c|c|c|c|}
\hline$v\left(\mathbf{c m}^{-1}\right)$ & DFT $\left(\mathbf{c m}^{-1}\right)$ & Desvio & Modo & Atribuição \\
\hline 3065 & 3099 & $1,1 \%$ & $\overline{B_{1 u}}$ & Estiramento Ar-H no plano (py) \\
\hline 3035 & 3063 & $0,9 \%$ & $\mathrm{~B}_{1 \mathrm{u}}$ & Estiramento Ar-H no plano (py) \\
\hline 1716 & 1705 & $0,6 \%$ & $\mathrm{~B}_{3 \mathrm{u}}$ & Estiramento $\mathrm{C}=\mathrm{O}$ \\
\hline 1674 & 1673 & $0,1 \%$ & $\mathrm{~B}_{2 \mathrm{u}}$ & Estiramento $\mathrm{C}=\mathrm{O}$ \\
\hline 1590 & 1576 & $0,9 \%$ & $B_{3 u}$ & Estiramento $\mathrm{C}=\mathrm{C}$ (py) \\
\hline 1580 & 1561 & $1,2 \%$ & $B_{3 u}$ & Estiramento $\mathrm{C}=\mathrm{C}$ (core) \\
\hline 1501 & 1499 & $0,5 \%$ & $\mathrm{~B}_{2 \mathrm{u}}$ & Estiramento $\mathrm{C}=\mathrm{C}(\mathrm{Ar}$, core $)$ \\
\hline 1491 & 1476 & $1,0 \%$ & $\mathrm{~B}_{3 \mathrm{u}}$ & Estiramento $\mathrm{C}=\mathrm{C}(\mathrm{Ar}, \mathrm{py})$ \\
\hline 1448 & 1414 & $2,3 \%$ & $B_{3 u}$ & Dobramento Ar-H no plano (core) \\
\hline 1414 & 1394 & $1,4 \%$ & $\mathrm{~B}_{1 \mathrm{u}}$ & Dobramento Ar-H no plano (py) \\
\hline 1350 & 1315 & $2,6 \%$ & $B_{3 u}$ & Dobramento Ar-H no plano (core) \\
\hline 1251 & 1232 & $1,5 \%$ & $B_{3 u}$ & Dobramento Ar-H no plano (core) \\
\hline 1214 & 1227 & $1,1 \%$ & $\mathrm{~B}_{2 \mathrm{u}}$ & Dobramento Ar-H no plano (core) + respiração $\mathrm{C}=\mathrm{C}$ (core) \\
\hline 1198 & 1185 & $1,1 \%$ & $\mathrm{~B}_{2 \mathrm{u}}$ & Dobramento $\mathrm{Ar}-\mathrm{H}$ no plano (core) + estiramento $\mathrm{C}-\mathrm{N}-\mathrm{C}$ (core, assimétrico) \\
\hline 1148 & 1122 & $2,3 \%$ & $B_{3 u}$ & Dobramento $\mathrm{Ar}-\mathrm{H}$ no plano (core) + estiramento $\mathrm{C}=\mathrm{C}$ (core) \\
\hline 1123 & 1107 & $1,4 \%$ & $\mathrm{~B}_{2 \mathrm{u}}$ & Dobramento Ar-H no plano (core) + estiramento $\mathrm{C}-\mathrm{N}-\mathrm{C}$ (core, assimétrico) \\
\hline 985 & 966 & $1,9 \%$ & $\mathrm{~B}_{2 \mathrm{u}}$ & Dobramento Ar-H no plano (core) + respiração $\mathrm{C}=\mathrm{C}$ (core) \\
\hline 863 & 868 & $0,6 \%$ & $\mathrm{~B}_{1 \mathrm{u}}$ & Dobramento Ar-H fora do plano (core) \\
\hline 827 & 843 & $1,9 \%$ & $\mathrm{~B}_{3 \mathrm{u}}$ & Dobramento C-N-C simétrico (core e py) \\
\hline 767 & 737 & $3,9 \%$ & $\mathrm{~B}_{2 \mathrm{u}}$ & Dobramento Ar-H fora do plano (py) \\
\hline 751 & 734 & $2,3 \%$ & $\mathrm{~B}_{1 \mathrm{u}}$ & Dobramento $\mathrm{C}-\mathrm{N}-\mathrm{C}$ e $\mathrm{Ar}-\mathrm{H}$ fora do plano (core) \\
\hline 718 & 703 & $2,1 \%$ & $\mathrm{~B}_{2 \mathrm{u}}$ & Dobramento Ar-H fora do plano (py) \\
\hline 623 & 608 & $2,4 \%$ & $\mathrm{~B}_{3 \mathrm{u}}$ & Dobramento C-N-C simétrico no plano (core e py) \\
\hline 529 & 519 & $1,9 \%$ & $\mathrm{~B}_{2 \mathrm{u}}$ & Dobramento Ar-H fora do plano (py) \\
\hline
\end{tabular}


O espectro de infravermelho da NDI-py é relativamente simples, haja vista o tamanho da molécula, fator atribuído a sua simetria $D_{2 h}$. Com exceção de poucos modos vibracionais, como os dobramentos C-H dos grupos piridínicos em $3065 \mathrm{~cm}^{-1}$ e $3035 \mathrm{~cm}^{-1}$, a maioria dos modos são compostos, isto é, envolvem mais de um grupo funcional. Naturalmente, como se espera pela tabela de caracteres do grupo de ponto $D_{2 h}$ (veja Apêndice $A 4$, página 84), os modos permitidos são aqueles pertencentes às representações irredutíveis $B_{1 u}, B_{2 u}$ e $B_{3 u}$. As frequências calculadas, utilizadas para as atribuições dos modos, tiveram pequenos desvios das experimentais, com um erro médio de 1,4\%, sendo, portanto, considerados excelentes. Os maiores desvios ocorrem na região chamada de impressão digital, abaixo de $1500 \mathrm{~cm}^{-1}$. Acredita-se que esses desvios sejam originados das limitações do cálculo teórico que, neste caso, considerou a molécula isolada e no vácuo, desconsiderando interações intermoleculares importantes que porventura existam, além dos desvios implícitos no modelo empregado. Não obstante, nota-se também uma banda larga na região de $3500 \mathrm{~cm}^{-1}$ comumente atribuída aos estiramentos $\mathrm{O}-\mathrm{H}$ da água. Como a amostra sofreu tratamento térmico prévio e todos os cuidados foram tomados para diminuir os efeitos da água atmosférica, acredita-se que a NDI-py cristalize com algumas moléculas de solvente em sua rede. 
§ 3.1.4. Espectroscopia eletrônica - As naftaleno diimidas são bastante conhecidas por seus característicos espectros eletrônicos e elevados coeficientes de absortividade molar, que são da ordem de $10^{4} \mathrm{~L} \mathrm{~mol}^{-1} \mathrm{~cm}^{-1}$. No espectro de absorção, observa-se uma transição $\pi \rightarrow \pi^{*}$ entre $300 \mathrm{~nm}$ e $400 \mathrm{~nm}$ juntamente com duas ou mais bandas em maiores energias, de menor intensidade e igualmente espaçadas por cerca de $0,17 \mathrm{eV}$, devido ao acoplamento com os modos vibracionais em aproximadamente $1350 \mathrm{~cm}^{-1}(0,17 \mathrm{eV})$ e $300 \mathrm{~cm}^{-1}$, - distorções completas do esqueleto central ${ }^{32}$. Estes acoplamentos seguem, em geral, uma ordem decrescente de intensidade. Na Figura 3.8 temos uma representação esquemática, baseado na referência 85, da distribuição e contribuição dos níveis eletrônicos e vibracionais dos estados fundamental $\left(\Psi_{0}\right)$ e excitado $\left(\Psi_{1}\right.$ e $\left.\Psi_{2}\right)$ da NDI-py, e a correspondência com seu espectro de absorção UV-Vis em DMF, obtido experimentalmente. Para a construção do esquema, assumiu-se que os estados $\Psi_{0}$ e $\Psi_{1}$ sejam verticais, isto é, envolva mínima variação nas coordenadas nucleares uma vez que esta transição é bastante intensa. O desalinhamento do estado $\Psi_{2}$ segue a mesma lógica, já que a intensidade da transição atribuída é muito menor.

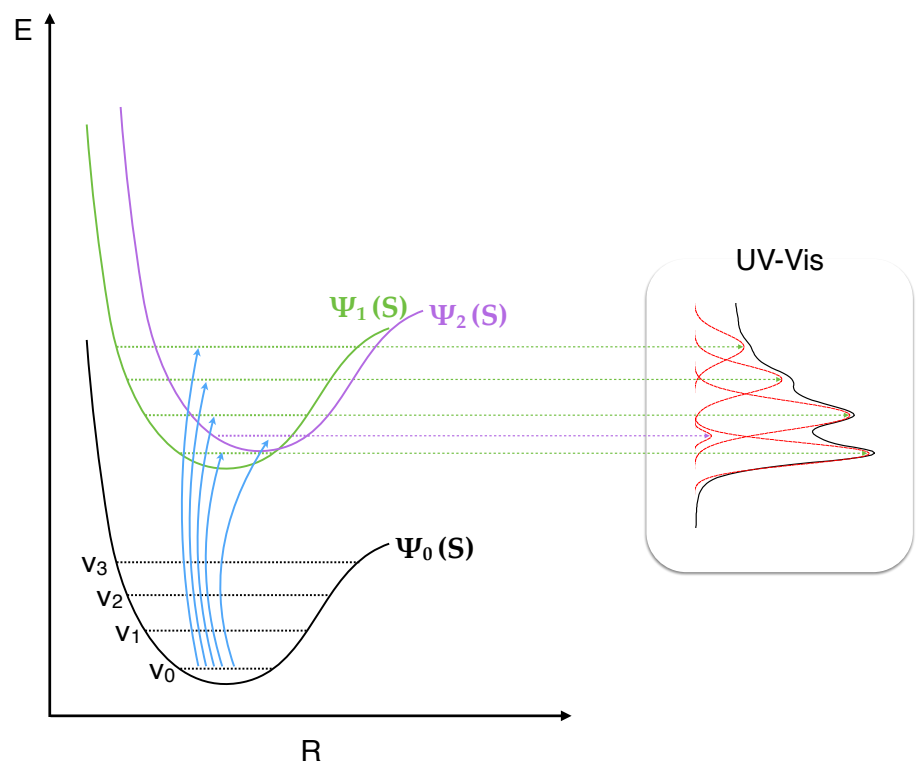

Figura 3.8: Distribuição esquemática dos níveis eletrônicos e vibracionais dos estados singletos da NDI-py bem como a correspondência dos níveis no espectro eletrônico de absorção, obtido experimentalmente a paritr de uma solução em DMF. Supõe-se que os estados $\Psi_{0}$ e $\Psi_{1}$ possuam as mesmas coordenadas nucleares $(\mathbf{R})$, diferentemente do estado $\Psi_{2}$.

Para determinações e comparações mais acuradas, as transições eletrônicas da NDI-py foram calculadas e comparadas com o espectro experimental. A molécula de NDI-py, que pertence ao grupo de ponto $\mathrm{D}_{2 \mathrm{~h}}$, possui um orbital HOMO (Highest Occupied Molecular Orbital) de representação irredutível $\mathrm{A}_{\mathrm{g}}$, no vácuo, em concordância com a literatura ${ }^{32,33}$. O orbital LUMO (Lowest Unoccupied Molecular Orbital) determinado é um $B_{3 g}$ e, dessa forma, a transição HOMO $\rightarrow$ LUMO $\left(A_{g} \rightarrow B_{3 g}\right)$ é proibida por 
Laporte. Interessantemente, quando os efeitos da solvatação de DMF são considerados nos cálculos, não há mudanças na simetria do orbital LUMO todavia o orbital HOMO sofre uma mudança de paridade e se torna um $A_{u}$. Com isso, a transição $H O M O \rightarrow L U M O$ passa a ser permitida e, além disso, é determinada como a transição mais intensa. Não obstante, o valor da energia da transição calculada é bastante próximo ao experimental, com erro menor que $0,01 \mathrm{eV}$. A representação espacial dos orbitais HOMO e LUMO obtidos através dos cálculos são mostrados na Figura 3.9 e os detalhes das transições calculadas estão resumidos na Tabela 3.3

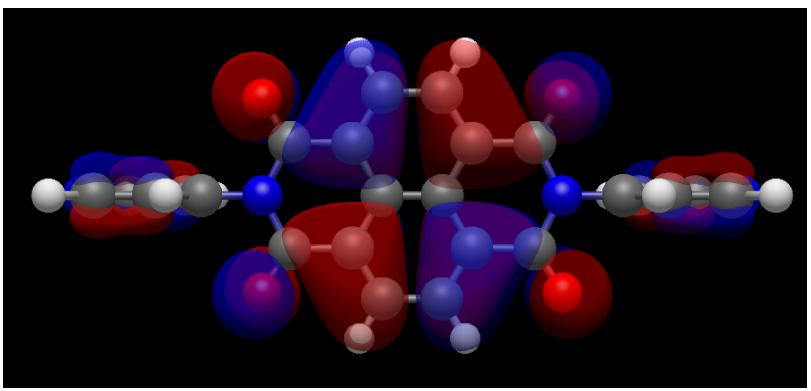

(a) HOMO.

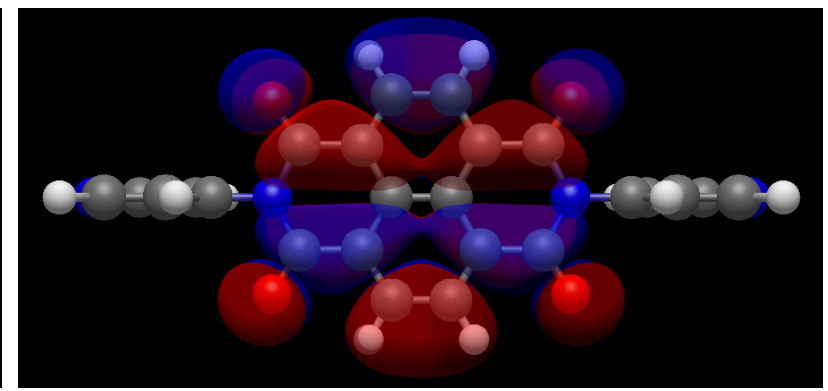

(b) LUMO.

Figura 3.9: Orbitais HOMO e LUMO da NDI-py obtidos por B3LYP/cc-pVTZ em solvatação contínua de DMF.

Tabela 3.3: Transições eletrônicas calculadas para a NDI-py usando B3LYP e cc-pVTZ que possuem $f_{\text {osc }}>0,05$.

\begin{tabular}{|c|c|c|c|c|c|c|}
\hline$\lambda(\mathrm{nm})$ & $E(e V)$ & Operador & $f_{\text {osc }}$ (u.a.) & Orbitais $^{a}$ & Multiplicidade $^{b}$ & Contribuição $\left(c^{2}\right)$ \\
\hline 604,1 & 2,05 & $\mathrm{~B}_{3 \mathrm{u}}$ & 0,0 & $\mathrm{HOMO} \longrightarrow \mathrm{LUMO}$ & $\bar{T}$ & 0,48 \\
\hline 422,1 & 2,94 & $\mathrm{~B}_{2 \mathrm{u}}$ & 0,0 & HOMO-5 $\longrightarrow$ LUMO & $\mathrm{T}$ & 0,49 \\
\hline 379,1 & 3,27 & $B_{3 u}$ & 0,4622 & $\mathrm{HOMO} \longrightarrow \mathrm{LUMO}$ & $\mathrm{S}$ & 0,49 \\
\hline 343,6 & 3,61 & $\mathrm{~B}_{2 \mathrm{u}}$ & 0,0577 & HOMO-5 $\longrightarrow$ LUMO & S & 0,47 \\
\hline 290,0 & 4,28 & $\mathrm{~B}_{2 \mathrm{u}}$ & 0,1086 & HOMO-9 $\longrightarrow$ LUMO & S & 0,47 \\
\hline 232,9 & 5,32 & $\mathrm{~B}_{2 \mathrm{u}}$ & 0,4376 & $\mathrm{HOMO} \longrightarrow \mathrm{LUMO}+2$ & $S$ & 0,41 \\
\hline
\end{tabular}

${ }^{a}$ No caso de contribuições de múltiplos orbitais, escolheu-se os de maior contribuição (c).

${ }^{b} \mathrm{~S}=$ singleto, $\mathrm{T}=$ tripleto.

O espectro de absorção de luz na região do UV-Vis da NDI-py em DMF foi submetido a uma análise de descovolução gaussiana utilizando a Equação 2.1, como mostra a Figura 3.10. Observou-se, na região analisada, que o espectro pôde ser ajustado satisfatoriamente com o uso de cinco gaussianas, cujos parâmetros estão resumidos na Tabela 3.4. Cada componente foi atribuída a uma transição de acordo com sua intensidade e largura, interpretando-se a componente de menor energia, em $380 \mathrm{~nm}$, como a transição HOMO $\rightarrow$ LUMO ou, de maneira mais completa, $S_{0}\left(v_{0}\right) \rightarrow S_{1}\left(v_{0}\right)$. O cálculo determinou esta transição em 379,1 nm - um desvio de 0,2\% em relação ao valor experimental. Esta componente apresenta uma estrutura vibrônica com componentes em $360 \mathrm{~nm}\left(\mathrm{~S}_{0}\left(v_{0}\right) \rightarrow \mathrm{S}_{1}\left(v_{1}\right)\right), 341 \mathrm{~nm}\left(\mathrm{~S}_{0}\left(v_{0}\right) \rightarrow \mathrm{S}_{1}\left(v_{2}\right)\right)$ e $324 \mathrm{~nm}\left(\mathrm{~S}_{0}\left(v_{0}\right) \rightarrow \mathrm{S}_{1}\left(v_{3}\right)\right)$, que foram determinados matematicamente. Essas transições são equivalentes às transições entre os estados $\Psi_{0}$ e $\Psi_{1}$ da Figura 3.8. Importante salientar que, devido à aproximação de 
Born-Oppenheimer, os acoplamentos vibrônicos não foram calculados. Acredita-se que outras componentes de maiores energias e menores intensidades existam porém estejam encobertas por transições mais intensas, como transições $\pi \rightarrow \pi^{*}$ em $\lambda<300 \mathrm{~nm}^{(\mathrm{a})}$. Uma outra componente, de baixa intensidade, foi encontrada em $371 \mathrm{~nm}$ e atribuída a uma segunda transição eletrônica, equivalente ao estado $\Psi_{2}$ da Figura 3.8. O cálculo teórico determinou esta transição em uma maior energia, em 344 nm, um erro significativo. Por conta de sua intensidade, não é possível dizer se esta transição também apresenta acoplamentos vibrônicos.

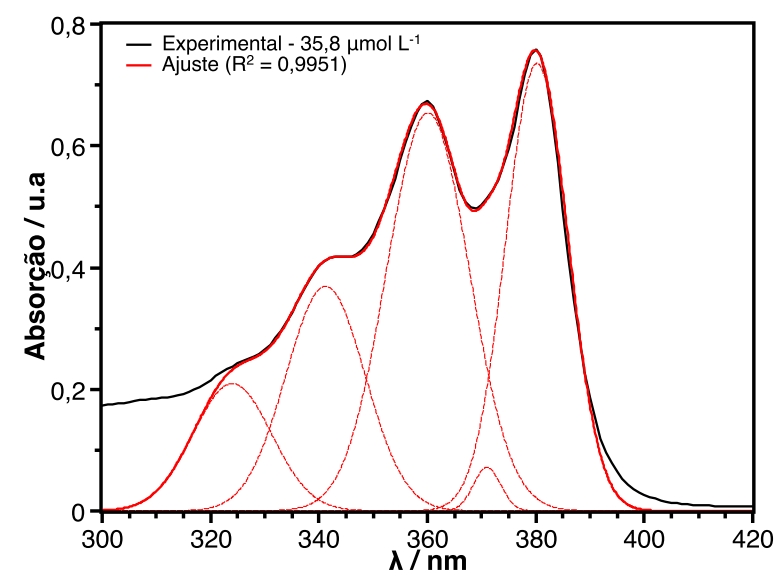

Figura 3.10: Desconvolução gaussiana de um espectro de absorção de luz na região do UV-Vis da NDI-py em DMF.

Tabela 3.4: Parâmetros da desconvolução gaussiana do espectro UV-Vis e coeficientes de absortividade molar da NDI-py em DMF.

\begin{tabular}{ccccl}
\hline$\lambda(\mathbf{n m})$ & $\varepsilon\left(\times \mathbf{1 0}^{4} \mathbf{~}^{\mathbf{~ m o l}^{-1}} \mathbf{c m}^{-1}\right)$ & $\mathbf{w} \mathbf{( n m})^{a}$ & Área (u.a.) & Atribuição \\
\hline 380 & 2,13 & 11,5 & 10,6 & $\mathrm{~S}_{0}\left(v_{0}\right) \rightarrow \mathrm{S}_{1}\left(v_{0}\right)$ \\
371 & - & 5,00 & 0,45 & $\mathrm{~S}_{0}\left(v_{0}\right) \rightarrow \mathrm{S}_{2}\left(v_{0}\right)$ \\
360 & 1,89 & 15,2 & 12,5 & $\mathrm{~S}_{0}\left(v_{0}\right) \rightarrow \mathrm{S}_{1}\left(v_{1}\right)$ \\
341 & 1,16 & 14,6 & 6,75 & $\mathrm{~S}_{0}\left(v_{0}\right) \rightarrow \mathrm{S}_{1}\left(v_{2}\right)$ \\
324 & 0,665 & 14,5 & 3,80 & $\mathrm{~S}_{0}\left(v_{0}\right) \rightarrow \mathrm{S}_{1}\left(v_{3}\right)$ \\
\hline${ }^{a} \mathbf{w}$ é a largura à meia altura. & & &
\end{tabular}

Apesar da discrepância na determinação da segunda transição eletrônica, o cálculo foi bastante preciso na determinação da energia da transição HOMO $\rightarrow$ LUMO. Espera-se que o desvio no cálculo tenha pequeno impacto nos resultados gerais, como o espectro eletrônico, devido à baixa intensidade desta transição.

Os coeficientes de absortividade molar, $\varepsilon$, mostrados na Tabela 3.4, foram determinados através de diluições subsequentes de uma solução da NDI-py em DMF, como na Figura 3.11a. Os coeficientes foram calculados a partir da regressão linear dos máximos das bandas selecionadas, como mostra a Figura 3.11b. Como é possível em compostos com conjugação $\pi$ estendida, verificou-se se haveria a

\footnotetext{
(a) Essas transições não puderam ser explicitamente determinadas por uma limitação experimental, já que o DMF permite a determinação do espectro acima de $270 \mathrm{~nm}$, apenas.
} 


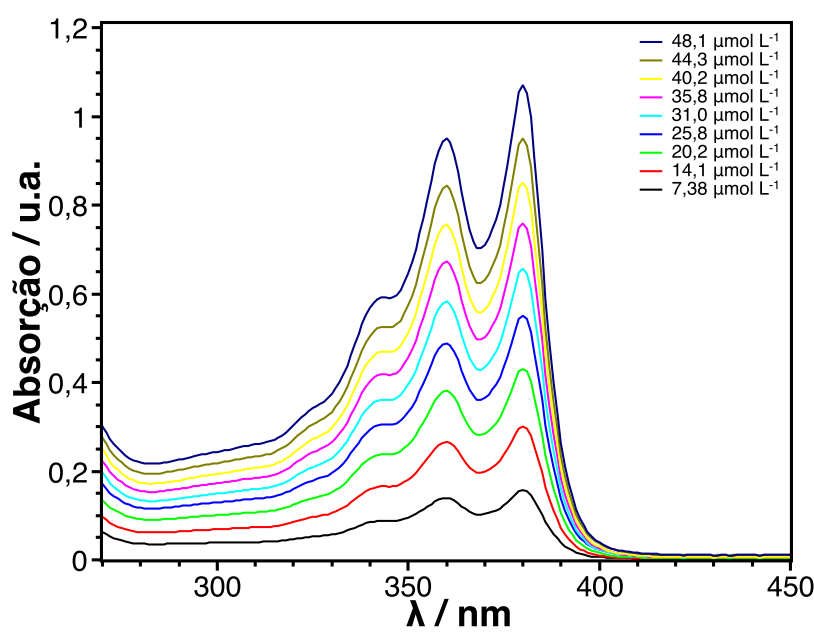

(a) Espectros de absorção em diferentes concentrações.

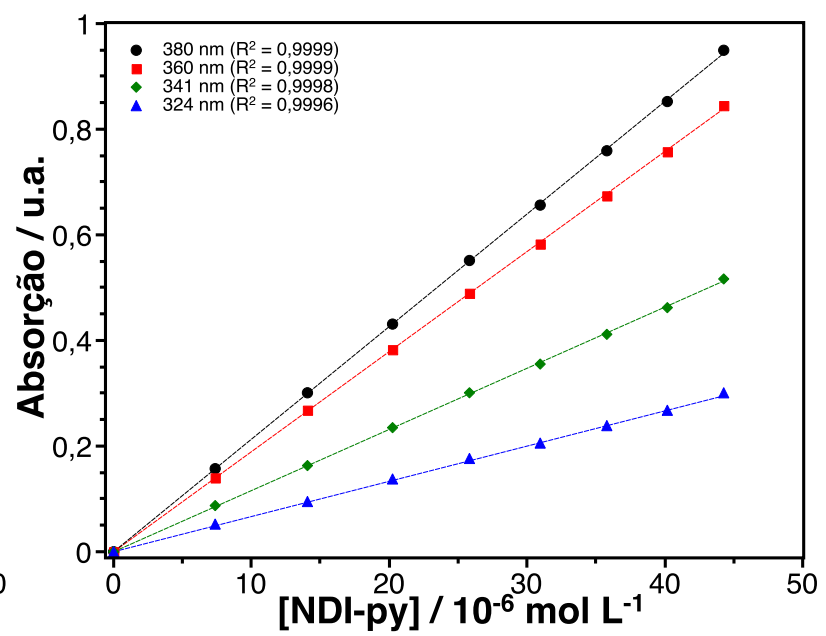

(b) Determinação dos coeficientes de absortividade molar.

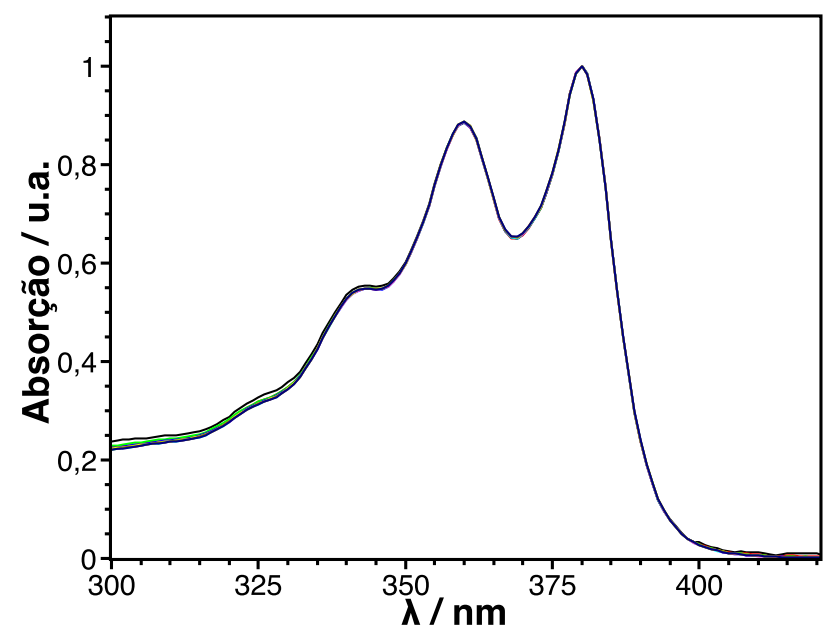

(c) Espectros normalizados e sobrepostos.

Figura 3.11: Espectros de absorção de luz na região do UV-Vis da NDI-py em DMF para a determinação dos coeficientes de absortividade molar.

possibilidade de a NDI-py formar agregados em solução nas concentrações estudadas. Este efeito seria constato através da mudança nas intensidades relativas das bandas ou mudança na forma do espectro. Para tal, os espectros foram normalizados e sobrepostos, como mostra a Figura 3.11c, e foi concluído que a NDI-py não forma agregados nas concentrações estudadas.

§ 3.1.5. Luminescência - As NDIs também são conhecidas por serem fluorescentes e apresentarem, em solventes apropriados - como $\mathrm{CH}_{2} \mathrm{Cl}_{2}$, por exemplo -, bandas estruturadas que se assemelham em muito à imagem espelhada do espectro de absorção, e com deslocamentos de Stokes usualmente inferiores a $0,1 \mathrm{eV}^{24}$. Em geral, o deslocamento de Stokes é proporcional à diferença geométrica e eletrônica que existe entre o estado fundamental e excitado, isto é, os pequenos valores de deslocamento de Stokes que as NDIs apresentam são indicativos que os estados fundamental e excitado destes compostos 


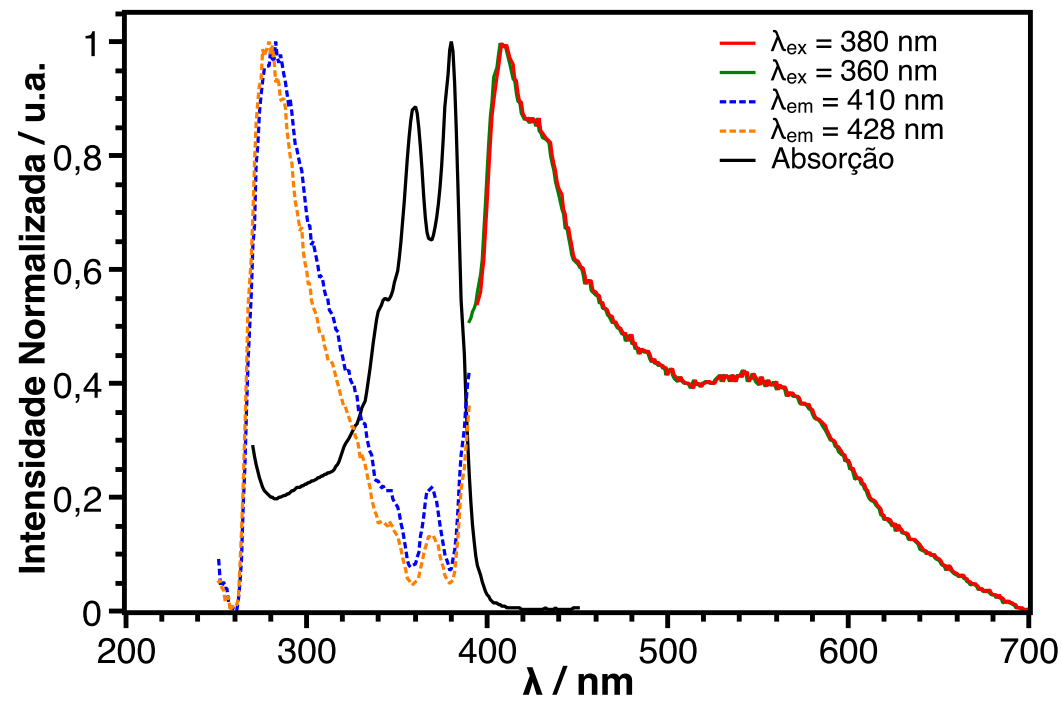

Figura 3.12: Espectros de emissão, excitação e absorção da NDI-py em DMF.

não são muito diferentes.

Na Figura 3.12, temos a comparação dos espectros de absorção, emissão e excitação da NDI-py em DMF. Os espectros de emissão foram registrados excitando as amostras nos dois máximos de menor energia obtidos na desconvolução do espectro de absorção da NDI-py, $\lambda_{e x}=380 \mathrm{~nm}$ e $\lambda_{e x}=360 \mathrm{~nm}$, a saber. Os dois espectros são praticamente idênticos, fato que deriva da discussão anterior de que a banda em 360 nm é um acoplamento vibrônico do estado eletrônico que possui modo vibracional fundamental em $380 \mathrm{~nm}$. Além disso, divergem um pouco da imagem especular do espectro de absorção; tanto pela falta de estruturação das componentes vibrônicas quanto por uma banda bastante larga e mais intensa em $550 \mathrm{~nm}$. Esta banda em $550 \mathrm{~nm}$ foi atribuída à emissões do tipo excímero(b), já observada em sistemas similares ${ }^{29}$. Os espectros de emissão possuem máximo em $410 \mathrm{~nm}$, resultando em um deslocamento de Stokes de cerca de $0,25 \mathrm{eV}(\Delta \lambda=30 \mathrm{~nm})$, razoavelmente elevado para aqueles observados em outras diimidas em solventes como $\mathrm{CH}_{2} \mathrm{Cl}_{2}$. Essa diferença pode ser causada pelo solvente utilizado neste experimento, uma vez que o momento de dipolo e a constante dielétrica do DMF são mais elevados que para o $\mathrm{CH}_{2} \mathrm{Cl}_{2}$, resultando em diferentes estabilizações do estado excitado formado.

Os espectros de excitação divergem consideravelmente do espectro de absorção em solução. Os máximos no espectro de excitação coincidem com vales no espectro de absorção, além de que o máximo observado é de uma banda bastante larga que ocorre em uma região de baixa absortividade no espectro de absorção. Entende-se como consequências dos excímeros formados, indiciados pela existência da banda larga em 550 nm, como já mencionado.

\footnotetext{
(b) Excímero é a formação de um dímero a partir de uma molécula no estado excitado e outra no estado fundamental.
} 
§ 3.1.6. Eletroquímica - A análise eletroquímica da NDI-py foi realizada a partir de uma solução $1 \mathrm{mmol} \mathrm{dm}{ }^{-3}$ em DMF contendo $\left[\mathrm{N}(\mathrm{n}-\mathrm{Bu})_{4}\right]\left(\mathrm{PF}_{6}\right)$ em uma concentração de $10 \mathrm{mmol} \mathrm{dm}{ }^{-3}$, em um arranjo de três eletrodos e a $25 \mathrm{mV} \mathrm{s}^{-1}$. Optou-se por utilizar um eletrodo de pseudo-referência e ferroceno $(F c)$ como referência interna. Esse arranjo facilita a determinação da energia do orbital LUMO uma vez que se utiliza as energias dos orbitais do ferroceno, no vácuo, como referência. No arranjo utilizado, o par $\mathrm{Fc} / \mathrm{Fc}^{+}$apresentou um $\mathrm{E}_{1 / 2}=+0,490 \mathrm{~V}(\Delta \mathrm{E}=125 \mathrm{mV})$ e o voltamograma obtido foi manualmente ajustado, como mostra a Figura 3.13.

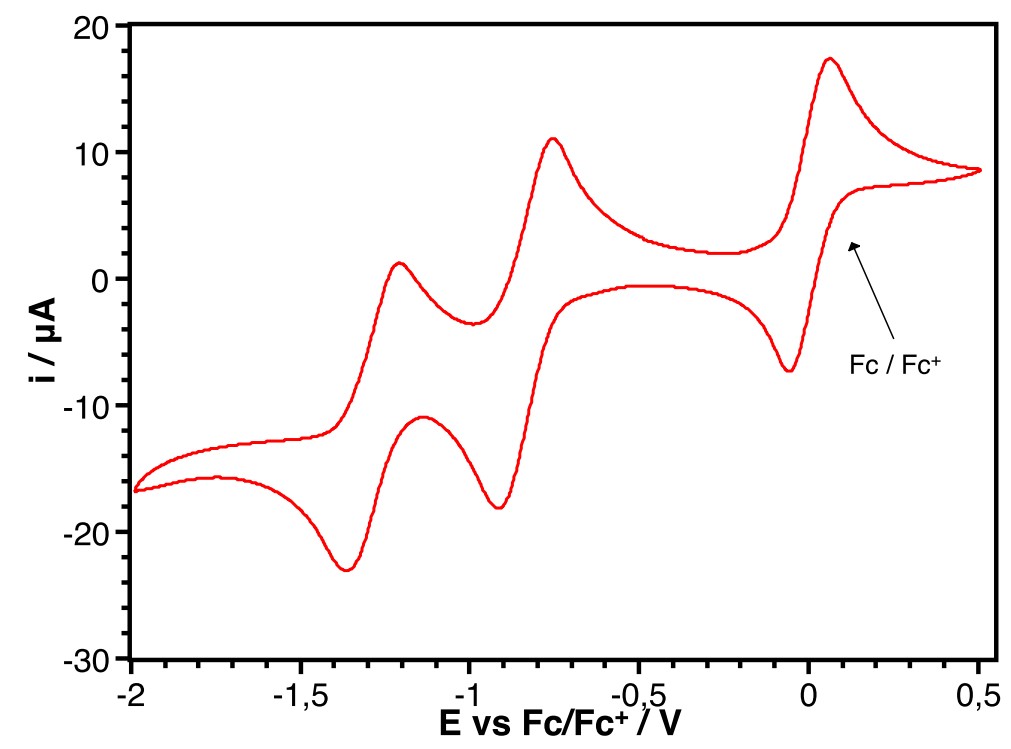

Figura 3.13: Voltamograma cíclico da NDI-py $\left(1 \mathrm{mmol} \mathrm{dm}^{-3}\right)$ em uma solução $10 \mathrm{mmol} \mathrm{dm}{ }^{-3}$ de $\left[\mathrm{N}(\mathrm{n}-\mathrm{Bu})_{4}\right]\left(\mathrm{PF}_{6}\right)$ em DMF, contendo Fc como referência interna. $\mathrm{WE}=\mathrm{GCE}, \mathrm{CE}=\mathrm{Pt}, \mathrm{RE}=\mathrm{Ag}, v=25 \mathrm{mV} \mathrm{s}^{-1}$.

$$
\begin{aligned}
& \mathrm{Fc}^{+}+e^{-} \longrightarrow \mathrm{Fc} \quad E_{1 / 2}=0 \mathrm{~V} \\
& \mathrm{NDI} \text {-py }+e^{-} \longrightarrow \mathrm{NDI}^{-\mathrm{py}^{\bullet}}{ }^{-} \quad E_{1 / 2}=-0,83 \mathrm{~V}, \Delta E=159 \mathrm{mV} \\
& \mathrm{NDI}^{-\mathrm{py}^{\bullet-}}+e^{-} \longrightarrow \mathrm{NDI}^{-\mathrm{py}^{2-}} \quad E_{1 / 2}=-1,29 \mathrm{~V}, \Delta E=159 \mathrm{mV}
\end{aligned}
$$

No voltamograma cíclico, foram observados três processos reversíveis. O primeiro, com $E_{1 / 2}=0 \mathrm{~V}$ $(\Delta \mathrm{E}=125 \mathrm{mV})$, é atribuído ao par ferroceno-ferrocínio $\left(\mathrm{Fc} / \mathrm{Fc}^{+}\right)$, utilizado como referência interna. $\mathrm{O}$ primeiro processo de redução observado ocorre em $\mathrm{E}_{1 / 2}=-0,83 \mathrm{~V}(\Delta \mathrm{E}=159 \mathrm{mV})$ e é atribuído à redução da NDI-py a seu radical ânion, NDI-py ${ }^{\bullet-}$; e a segunda redução, em $E_{1 / 2}=-1,29 \mathrm{~V}(\Delta \mathrm{E}=159 \mathrm{mV})$, é atribuída à formação do diânion, NDI-py ${ }^{2-}$. Essas duas reduções observadas são uma característica eletroquímica bastante importante das naftaleno diimidas e estão de acordo, também nos valores de potenciais observados, com o esperado segundo a literatura ${ }^{24,47}$. Os processos de oxidação, em potenciais 
positivos, não foram observados. Essa é uma limitação experimental já observada previamente. ${ }^{47}$

Com o valor do potencial da primeira redução é possível calcular a energia do orbital LUMO de acordo com a Equação 3.1.

$$
E_{\mathrm{LUMO}}=E_{\mathrm{LUMO}}(\mathrm{Fc})+E_{1 / 2}^{\mathrm{obs}}\left(\mathrm{Fc} / \mathrm{Fc}^{+}\right)+E_{1 / 2}^{\mathrm{obs}}\left(\mathrm{NDI}-\mathrm{py} / \mathrm{NDI}-\mathrm{py}^{\bullet-}\right)
$$

Na equação anterior, $E_{\mathrm{LUMO}}(\mathrm{Fc})$ é a energia do LUMO calculado para o ferroceno no vácuo ${ }^{86}$ - equivalente a -4,8 eV - $E_{1 / 2}^{\mathrm{obs}}\left(\mathrm{Fc} / \mathrm{Fc}^{+}\right)$e $E_{1 / 2}^{\mathrm{obs}}\left(\mathrm{NDI}-\mathrm{py} / \mathrm{NDI}-\mathrm{py}^{\bullet-}\right)$ são os potenciais de meia onda observados para os pares $\mathrm{Fc} / \mathrm{Fc}^{+}$e NDI-py/NDI-py ${ }^{\bullet-}$, respectivamente. Substituindo os valores apropriadamente, é obtido o valor de LUMO = $-3,97 \mathrm{eV}$.

Apesar de não ter sido observado nenhum processo de oxidação na voltametria cíclica, é possível estimar o valor do HOMO a partir do valor de energia do orbital LUMO, calculado previamente, e o valor do band-gap óptico, $E_{g}$, obtido por espectroscopia de absorção na região do UV-Vis. O valor de $E_{g}$ é determinado como o limite da banda de absorção e, para obtê-lo, extrapola-se uma reta neste limite e obtêm-se o valor de energia quando a absorção é zero, conforme a Figura 3.14. A reta ajustada segue a equação $y=7,245 x-22,84 \mathrm{e}$, substituindo para $y=0$, obtemos $E_{g}=3,15 \mathrm{eV}$.

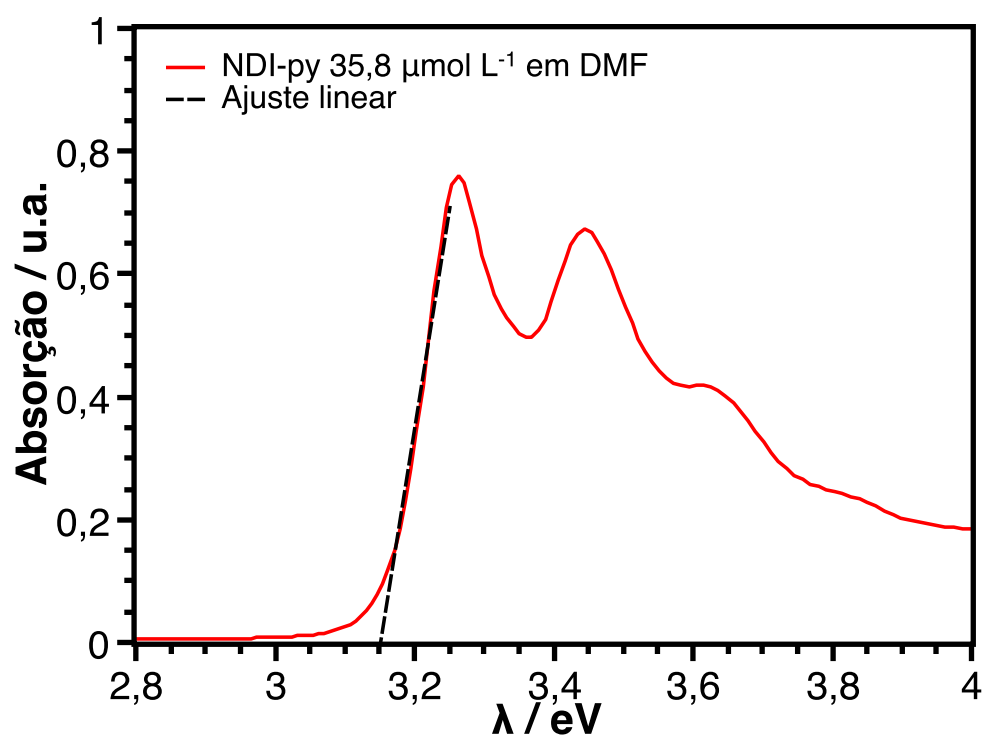

Figura 3.14: Determinação do band-gap óptico $\left(E_{g}\right)$ da NDI-py a partir do UV-Vis em solução.

Com o valor de $E_{g}$, pode-se estimar a energia do HOMO a partir da energia do LUMO através da fórmula LUMO $=\mathrm{HOMO}+E_{g}$. Com os valores previamente obtidos, temos que $\mathrm{HOMO}=-7,12 \mathrm{eV}$. Os valores de HOMO e LUMO calculados estão muito próximos daqueles encontrados na literatura para a NDI-py. ${ }^{87}$ 


\section{MOF-CoNDI-py-1}

§ 3.2.1. Difração de raios-X no pó - Para a determinação da formação de uma estrutura organizada, utilizou-se a difratometria de raios-X no pó, comparando os resultados do MOF-CoNDI-py-1 com os da NDI-py. A comparação foi importante devido à coloração e aspecto muito próximos entre o produto formado e o ligante livre. Como pode ser observado na Figura 3.15, os difratogramas são bastante diferentes tanto em intensidade, número e quantidade de picos observados. A partir do gráfico, observase um pico em $2 \Theta=5,60^{\circ}$ e seus harmônicos em $11,28^{\circ}$ e $16,92^{\circ}$, respectivamente. Utilizando a Lei de Bragg na Equação 3.2.

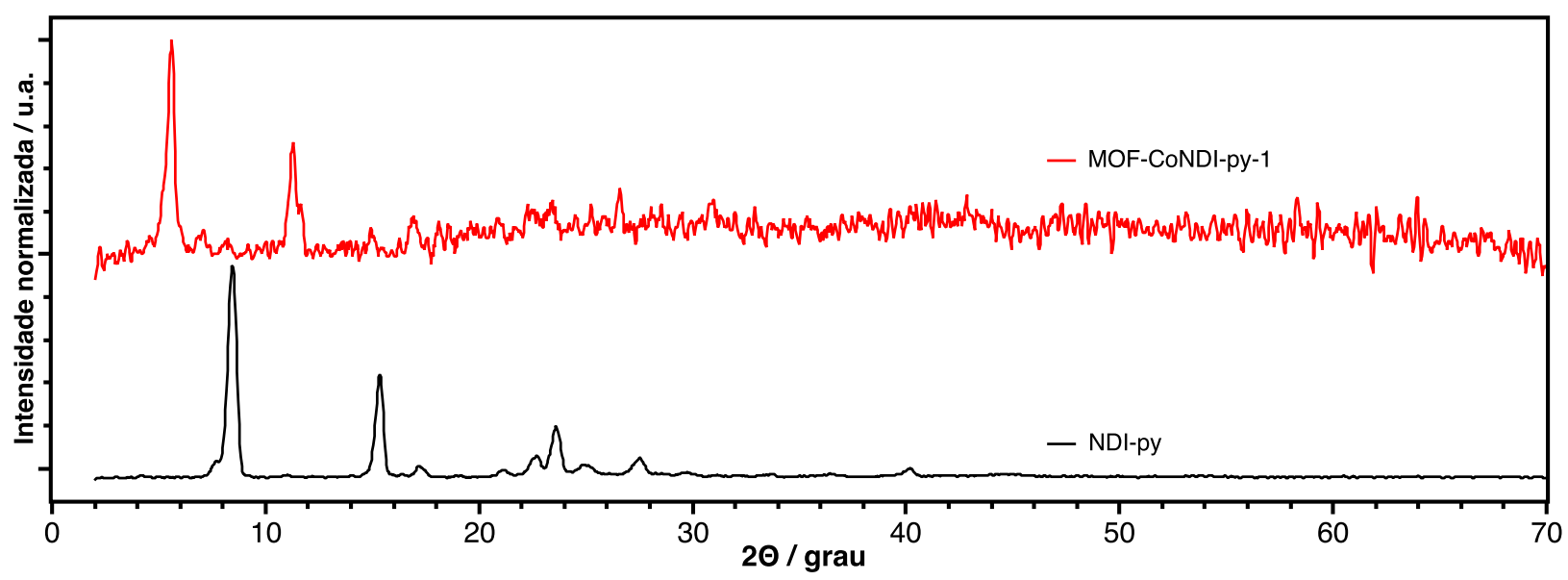

Figura 3.15: Comparação entre os difratogramas de raios-X de pó do MOF-CoNDI-py-1 e NDI-py, usando uma fonte de Cu $(\lambda=1,54056 \AA)$.

$$
n \lambda=2 d \operatorname{sen} \Theta
$$

Na equação anterior, $n$ é um número inteiro, referente ao harmônico, $\lambda$ é o comprimento de onda da fonte utilizada, $d$ é a distância interplanar e $\Theta$ é referente ao ângulo do pico observado no difratograma. Utilizando esta equação obtém-se $d=15,8 \AA$ e, sabendo que a distância entre os nitrogênios piridínicos da NDI-py obtidos por DFT é de 15,56 ̊̊, conclui-se tratar a distância entre dois centros metálicos de cobalto unidos por uma unidade NDI-py coordenada, formando uma estrutura 1D, como na Figura 3.16.

Apesar de a correlação entre morfologia e estrutura cristalina ser delicada, acredita-se que neste caso as imagens de MEV da Figura 3.17 suportem de fato a constatação de o MOF-CoNDI-py-1 ser um polímero 1D, dada a sua morfologia enovelada. Este tipo de morfologia não é esperada para compostos de estrutura 2D ou 3D, por exemplo.

O fortalecimento da hipótese de que o MOF-CoNDI-py-1 seja um polímero 1D motivou a derivação 


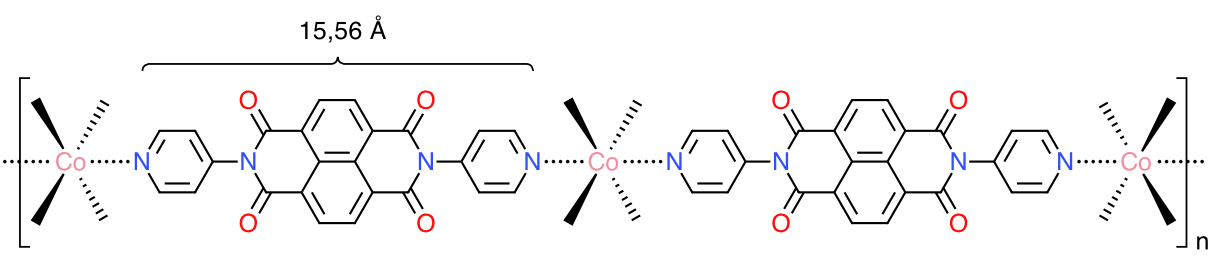

Figura 3.16: Estrutura proposta do MOF-CoNDI-py-1.

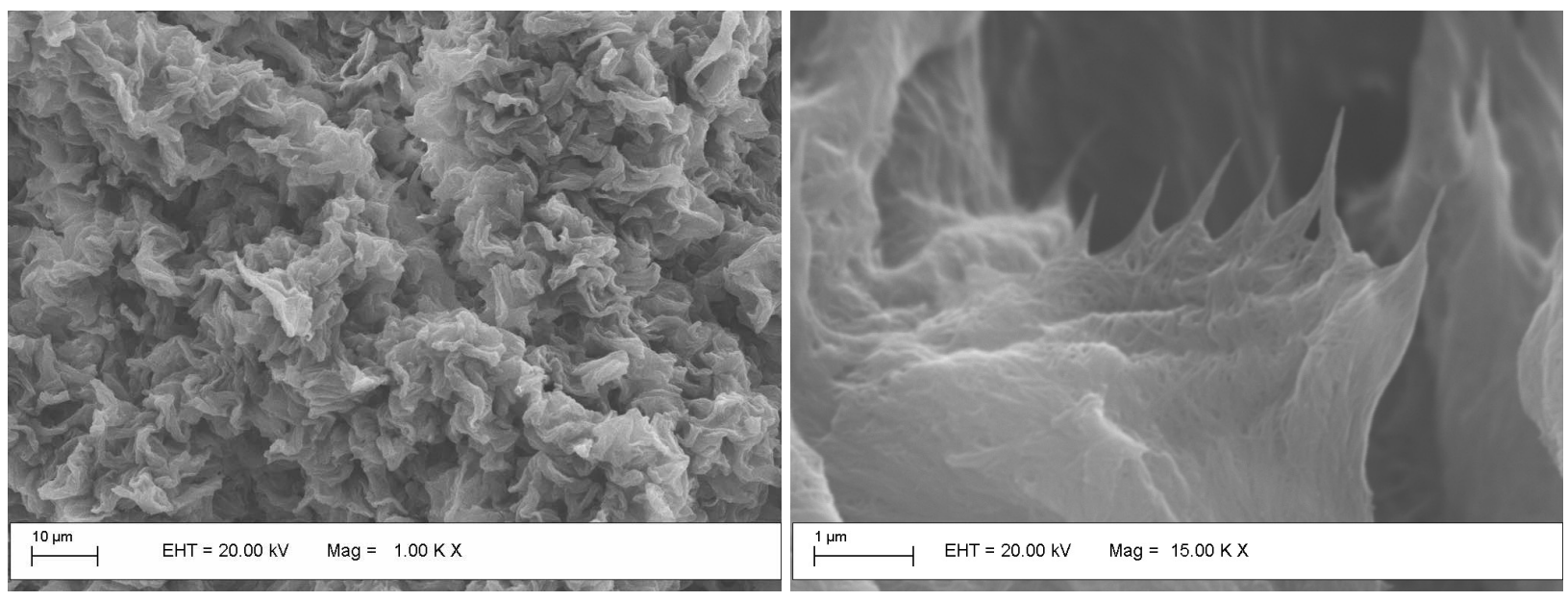

Figura 3.17: Fotomicrografias do MOF-CoNDI-py-1.

da síntese com a introdução de um ligante suporte, afim de que a estrutura cristalina passe para ordens superiores, 2D ou 3D, uma vez que polímeros de coordenação 1D, além de não poderem ser classificados como $\mathrm{MOF}^{9}$, não são interessantes para as aplicações que constam como objetivos deste projeto, entre elas o estudo de propriedades eletrônicas. Dessa forma, optou-se por introduzir o ácido tereftálico (TpA) como ligante suporte, bastante comum em trabalhos envolvendo MOFs, o que deu origem ao MOFCoNDI-py-2. 


\section{MOF-CoNDI-py-2}

Nas seções subsequentes serão apresentados e discutidos os métodos de caracterização empregados para o MOF-CoNDI-py-2, a começar pelas caracterizações estruturais seguidas das caracterizações espectroscópicas e eletrônicas.

§ 3.3.1. Microscopia óptica e eletrônica - Para determinar a morfologia dos cristais do MOF-CoNDIpy-2, foram adquiridas as imagens de microscopia óptica, representada na Figura 3.18, e de microscopia eletrônica de varredura, mostradas na Figura 3.19.

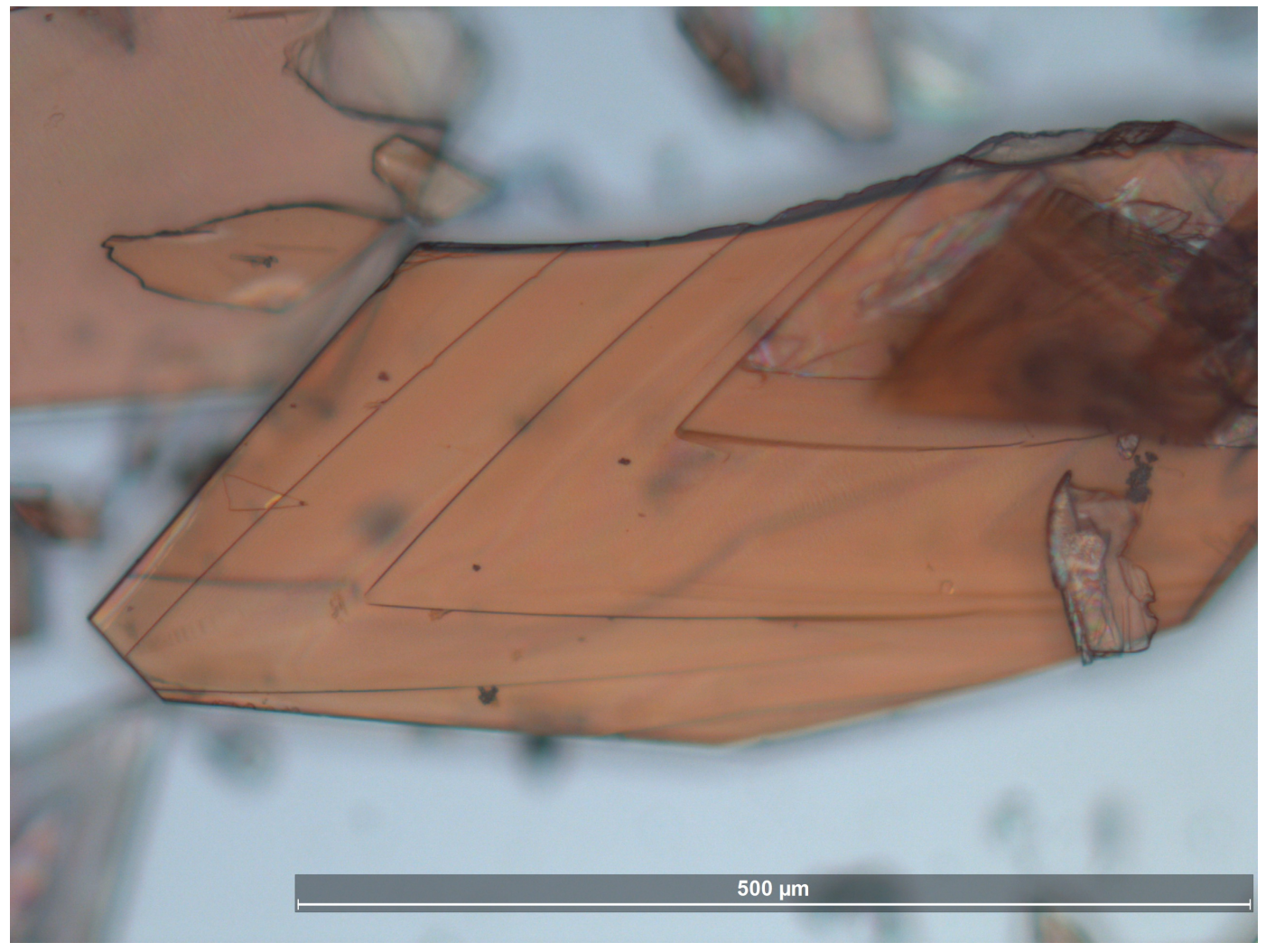

Figura 3.18: Imagens de microscopia óptica do MOF-CoNDI-py-2.

Os cristais apresentam hábito tabular, quase que em uma estrutura 2D. Foi possível observar indicações de planos cristalográficos e padrões periódicos, típico de monocristais. Alguns desses cristais possuíam espessura fina o suficiente para que o feixe de elétrons os atravessasse e fosse possível observar os cristais que estavam por baixo destes. A distribuição de tamanhos dos cristais observada foi relativamente constante, com tamanhos médios da ordem de $500 \mu \mathrm{m}$ e cristais tão longos quanto $3 \mathrm{~mm}$. Alguns cristais apresentaram epitaxia, formando maclas em forma de leque. Não foram observadas estruturas cristalinas diferentes das que são exibidas nas imagens de MEV. 


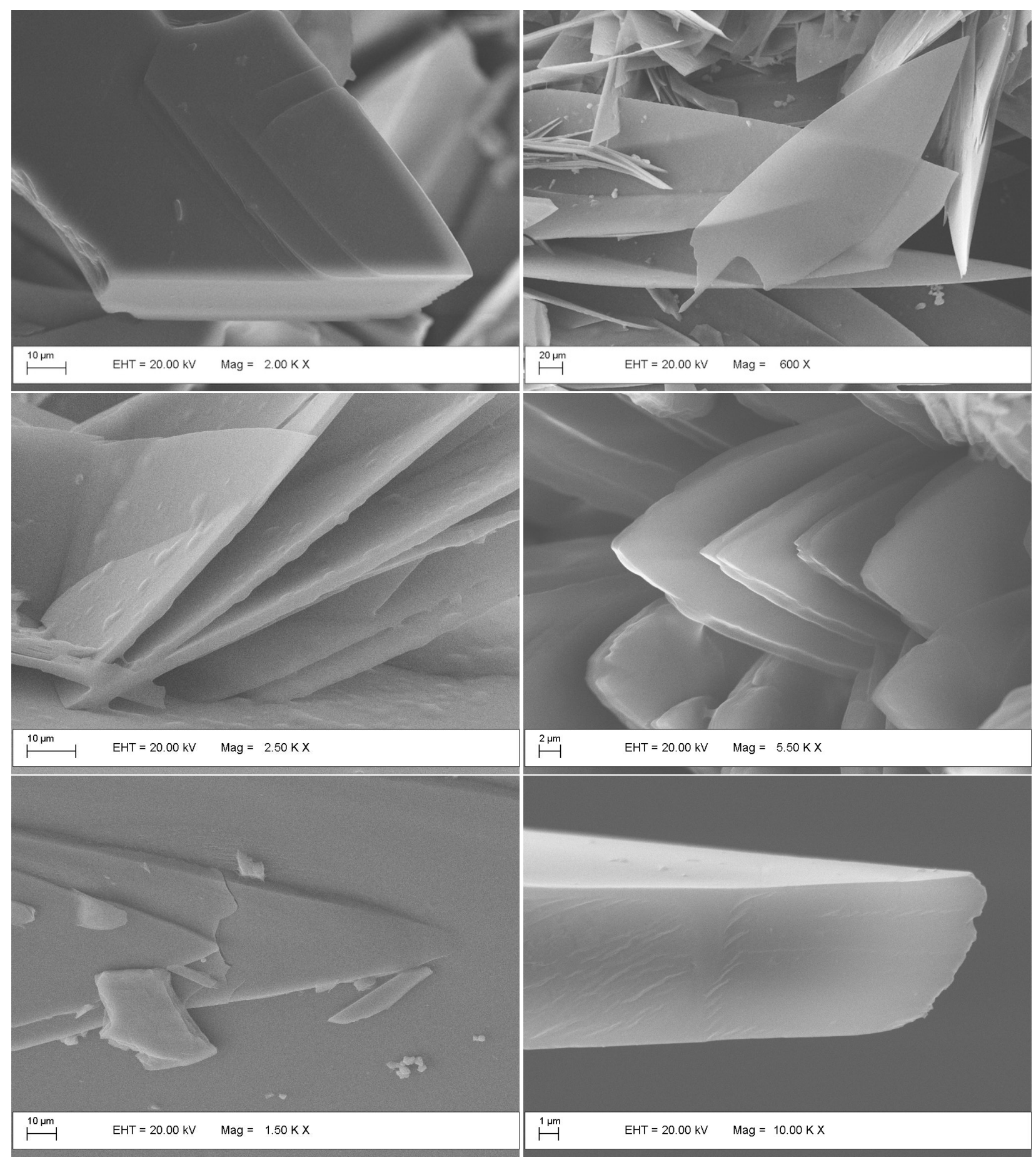

Figura 3.19: Imagens de MEV do MOF-CoNDI-py-2. 
§ 3.3.2. Difração de raios-X e estrutura de monocristal - A estrutura de monocristal do MOFCoNDI-py-2 foi resolvida em parceria com o Prof. Richard I. Walton e o cristalógrafo Dr. Guy Clarkson, ambos da University of Warwick, Reino Unido. Cristais apropriados foram selecionados após a síntese e reservados na solução-mãe. Usando Olex $2^{88}$, a estrutura foi resolvida com o programa ShelXS ${ }^{89}$ empregando Direct Methods e refinada com o pacote SheIXL ${ }^{89}$ e a minimização de mínimos quadrados.

Tabela 3.5: Parâmetros cristalográficos do MOF-CoNDI-py-2.

\begin{tabular}{rl}
\hline Parâmetro & MOF-CoNDI-py-2 \\
\hline Fórmula Empírica & $\mathrm{C}_{27} \mathrm{H}_{19} \mathrm{Co}_{1,5} \mathrm{~N}_{3} \mathrm{O}_{9}$ \\
Massa Molar & $617,83 \mathrm{~g} \mathrm{~mol}^{-1}$ \\
Temperatura de Análise & $100 \mathrm{~K}$ \\
Sistema Cristalino & Monoclínico \\
Grupo Espacial & $\mathrm{C} 2 / \mathrm{c}$ \\
a & $46,903(3) \AA$ \\
b & $9,5709(7) \AA$ \\
$\mathrm{c}$ & $17,9079(13) \AA$ \\
$\alpha$ & $90,00^{\circ}$ \\
$\beta$ & $94,066(3)^{\circ}$ \\
$\gamma$ & $90,00^{\circ}$ \\
Volume da Cela & $8018,69 \AA^{3}$ \\
Z, Z' & 8,0 \\
$\mathrm{R}$ & $11,95 \%$ \\
\hline
\end{tabular}

O cristal é composto de unidades trinucleares de cobalto, unidos por pontes $\mu$-O de íons tereftalato. A unidade assimétrica contem dois átomos de cobalto, denominados $\mathrm{Co}(1)$ e $\mathrm{Co}(2)$. Há também um íon tereftalato completo situado sobre um centro de inversão. A molécula de NDI-py se situa sobre um eixo $\mathrm{C}_{2}$ perpendicular ao plano da molécula. Um molécula de DMF está coordenada ao átomo Co(1) e uma pequena densidade eletrônica foi modelada como $\mathrm{H}_{2} \mathrm{O}$ com uma ocupação de $1 / 4$. Não foram encontrados átomos de hidrogênio para esta molécula entretanto estes foram incluídos na fórmula. A molécula de NDI-py estava bastante desordenada e por isso foi modelada sobre duas posições relacionadas por uma translação do esqueleto central ao longo do eixo $C_{2}$, resultando em ângulos de ligação ligeiramente diferentes entre as piridinas da NDI-py e átomo metálico Co(1). A ocupação dessas duas componentes foi fixada como 50:50. A molécula de DMF coordenada também sofria severa movimentação térmica e diversas restrições foram usadas para ajustar as distâncias de ligação para valores razoáveis, assim como os ângulos de ligação e outros parâmetros térmicos. Os parâmetros da cela unitária estão resumidos na Tabela 3.5. Representações visuais podem ser encontradas nas Figura 3.20 e Figura 3.21.

Este arranjo trinuclear de átomos de cobalto(II), destacado na Figura 3.22, é recorrente em outras estruturas encontradas na literatura de MOFs que contém este centro metálico e ligantes cujos pontos de coordenação são também o átomo de oxigênio ${ }^{90}$. Nessas estruturas também é comum que estes centros metálicos apresentem geometria de coordenação de um octaedro distorcido. Outros compostos 


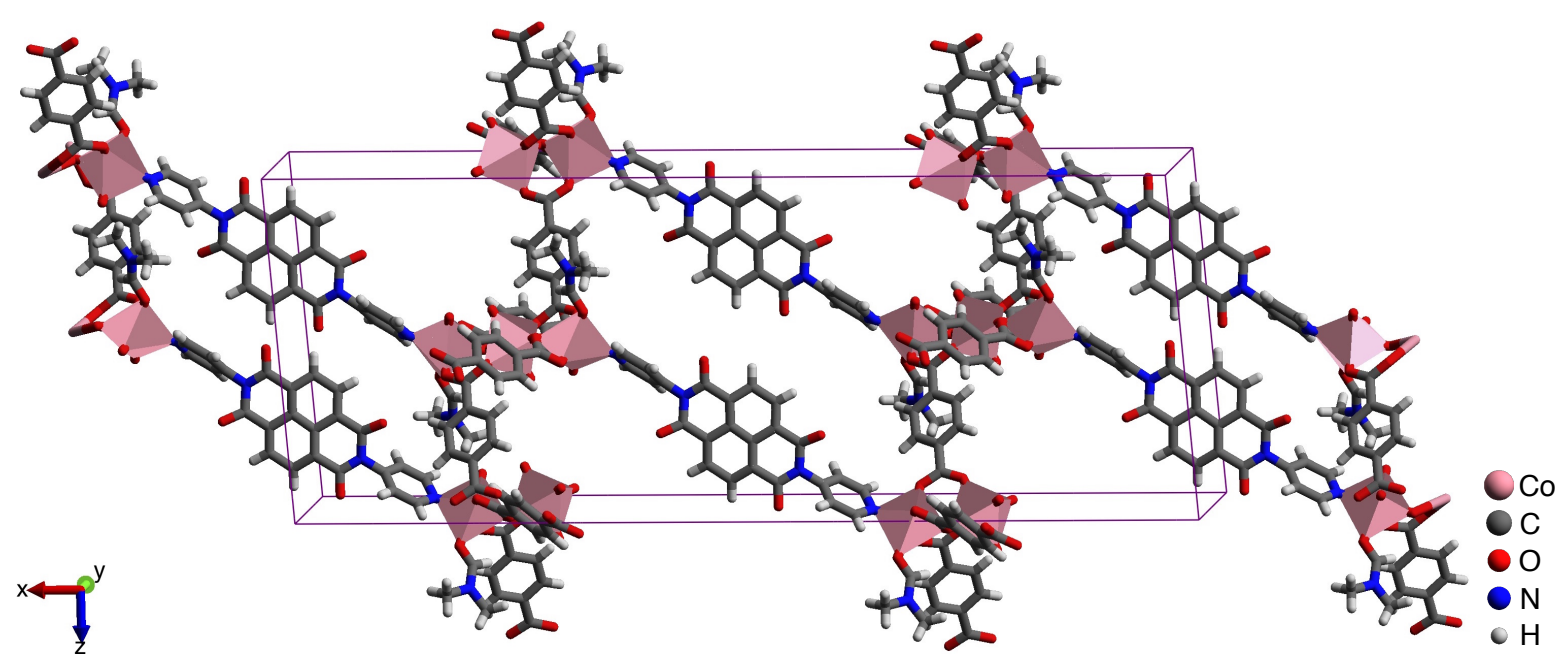

(a) Cela unitária.

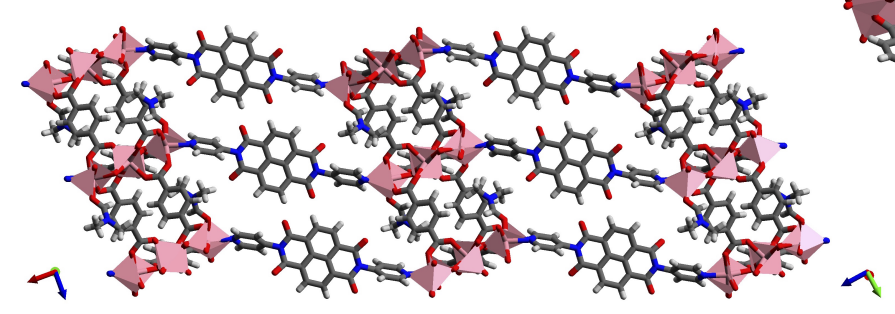

(b) Visão ao longo das moléculas de NDI-py.

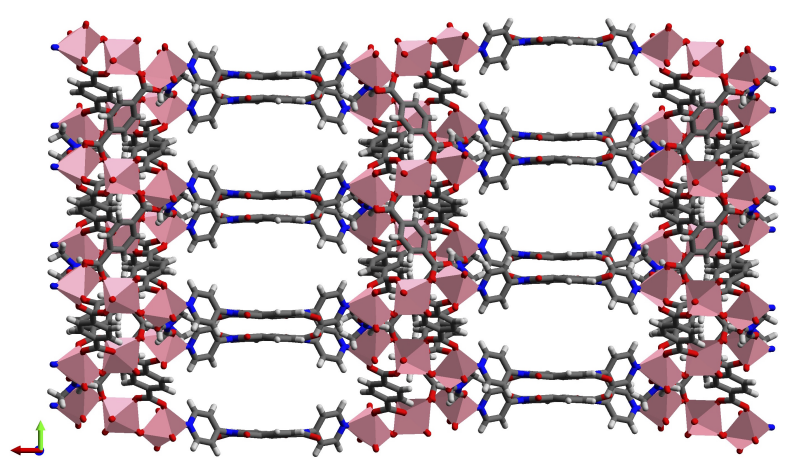

(d) Visão ao longo das moléculas de NDI-py.

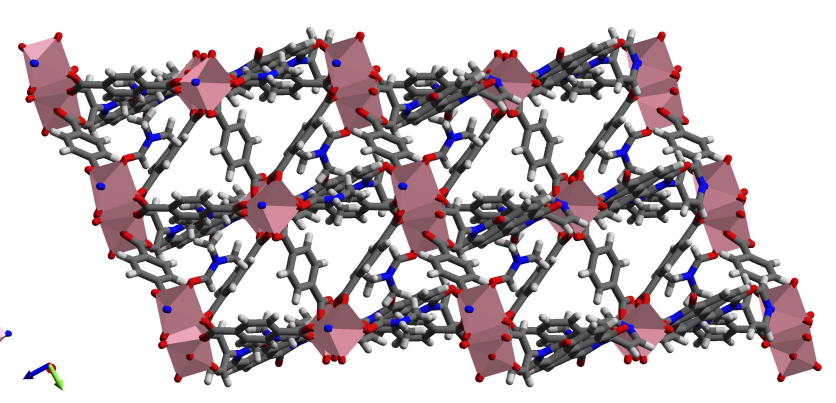

(c) Visão ao longo dos centros metálicos.

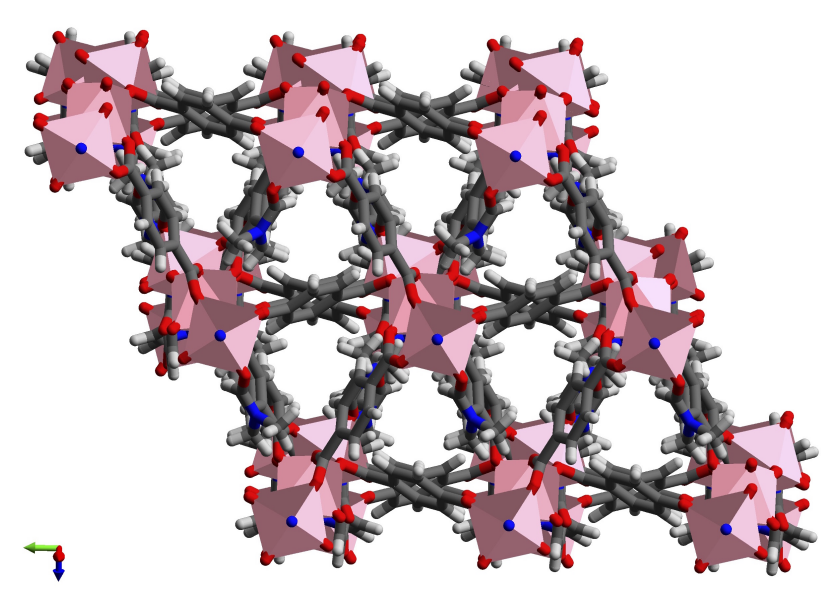

(e) Visão ao longo dos centros metálicos.

Figura 3.20: Estrutura cristalina do MOF-CoNDI-py-2. 

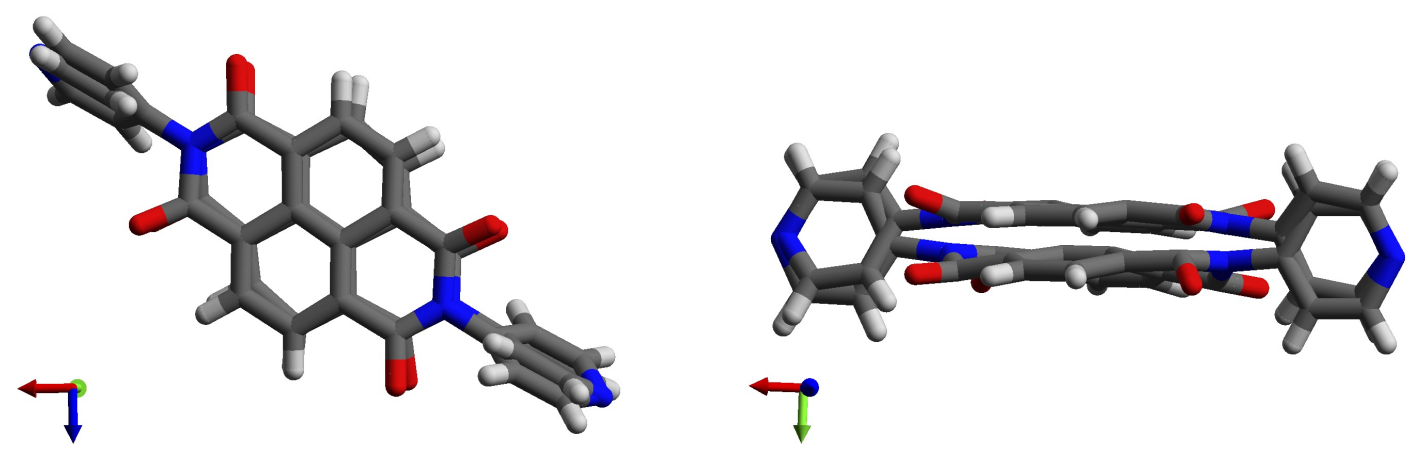

(a) As duas conformações da NDI-py consideradas na estrutura.

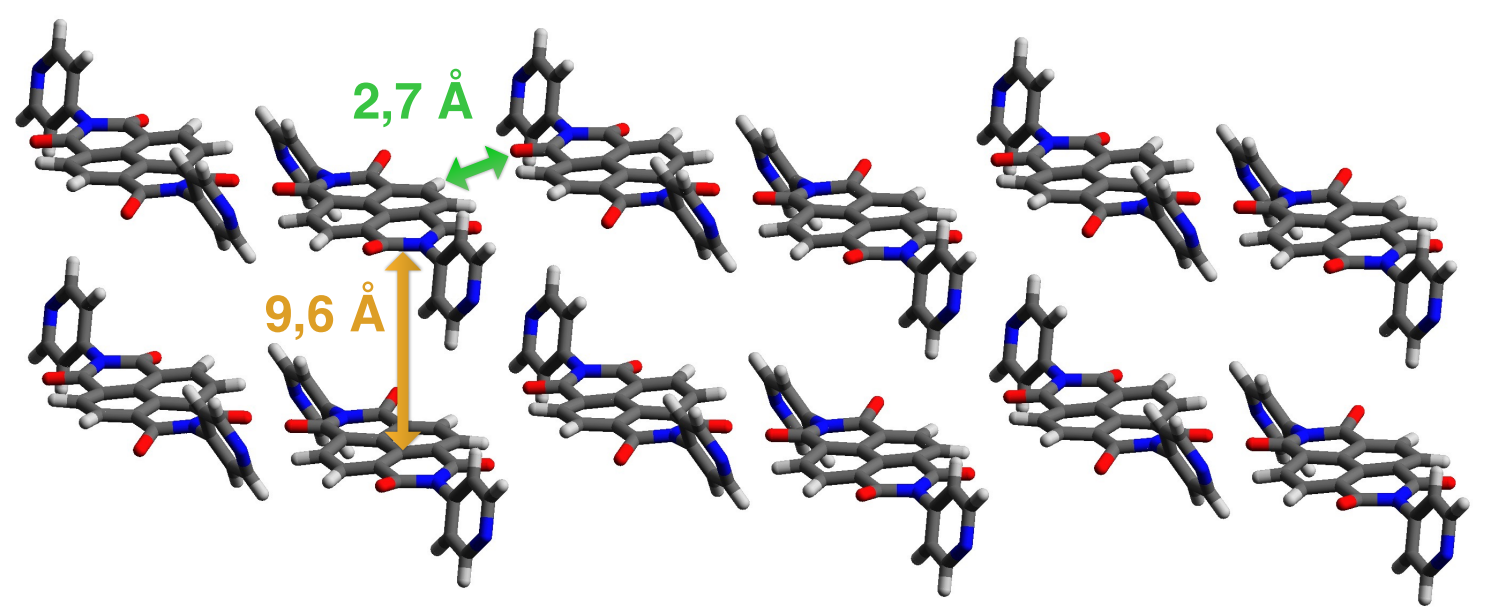

(b) Moléculas de NDI-py e algumas distâncias intermoleculares selecionadas.

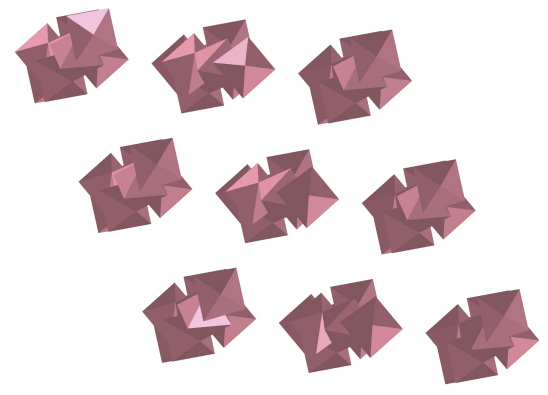

(c) Representação dos átomos de cobalto.

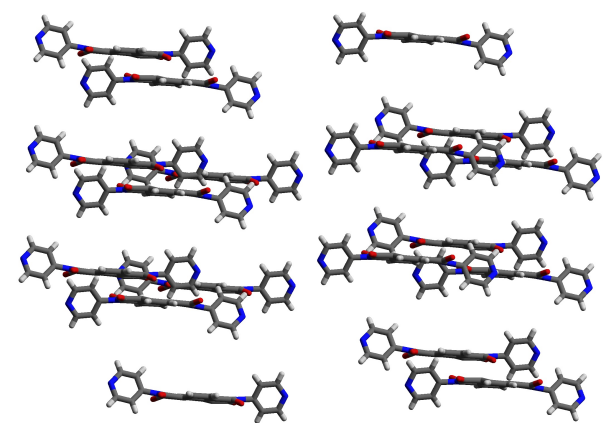

(e) Representação das moléculas de NDI-py.

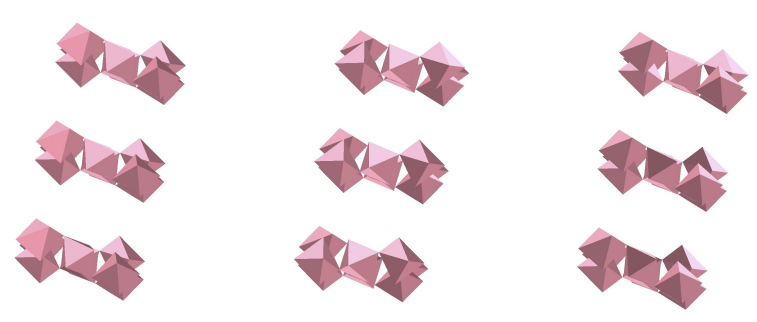

(d) Representação dos átomos de cobalto.
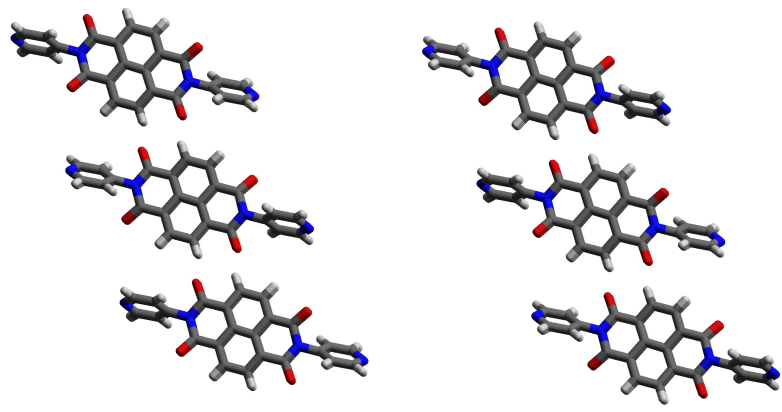

(f) Representação das moléculas de NDI-py.

Figura 3.21: Representação dos centros metálicos e das moléculas de NDI-py no cristal de MOF-CoNDI-py-2. 


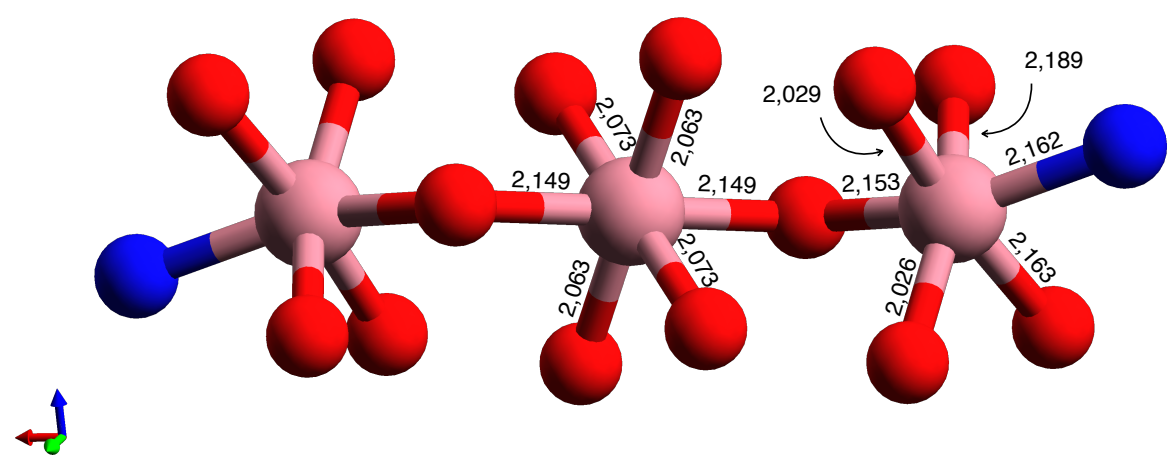

Figura 3.22: Fragmento trinuclear de cobalto do MOF-CoNDI-py-2 pertencente ao grupo de ponto $C_{i}$, com distâncias de ligação.

que utilizam o mesmo ligante NDI-py possuem estruturas bastante diferentes, usualmente empregando Zn(II) como centro metálico. Essas estruturas geralmente assumem a forma de uma roda de pás em que os centros de $Z n(I I)$ ocupam sítios tetraédricos e são unidos por pontes carboxilatos ${ }^{17,18}$; ou, ainda, formam estruturas bidimensionais em forma de rede quadriculada ${ }^{65,67,91}$. Outros MOFs que também usam NDI-py e Co(II) não compartilham da mesma estrutura que o MOF-CoNDI-py-2, retornando estruturas unidimensionais. ${ }^{66}$

Os poros da estrutura cristalina foram investigados usando as rotinas nos softwares Olex2 e Platon. O poros acessíveis por solvente foram calculados com volumes de $2643,4 \AA^{3}$ (33,0\% do volume da cela) usando Olex2 e como $2556,7 \AA^{3}$ (31,9\% do volume da cela) usando Platon. Estes valores são razoavelmente elevados, quando comparado com MOFs similares. ${ }^{62}$

A partir da estrutura de monocristal, simulou-se o padrão de difração de raios-X do pó através programa Mercury ${ }^{\circledR}$ da CCDC (Cambridge Crystallographic Data Centre, University of Cambridge, Reino Unido - versão 3.6), usando uma fonte de cobre $\left(\lambda=1,54056 \AA\right.$ ) com um passo de $0,02^{\circ}$ e largura à meia altura de 0,1 unidades de $2 \Theta$. Este padrão simulado foi comparado com o difratograma do pó experimental, como mostra a Figura 3.23, também obtido com uma fonte de cobre e um passo de $0,02^{\circ} \mathrm{min}^{-1}$.

Como pode ser observado na Figura 3.23, existe uma grande correlação entre os difratogramas simulado e experimental, indicando a validade de estrutura determinada. É importante notar também a diferença que existe nas temperaturas entre os dois difratogramas: enquanto o teórico foi simulado a partir da estrutura de monocristal determinada a $100 \mathrm{~K}$, o experimental foi adquirido em temperatura ambiente, cerca de $300 \mathrm{~K}$. Apesar de existir uma diferença de cerca de $200 \mathrm{~K}$ entre os dois difratogramas, a correlação entre os picos simulados e experimentais é excelente, sugerindo que efeitos de expansão e contração térmicos são inexpressivos. O único efeito térmico proeminente que pode ser observado no difratograma experimental é o alargamento dos picos. Dentre as divergências, além do alargamento pelo efeito térmico, pode ser citada a intensidade relativa entre dos picos que tem origem em duas fontes: 


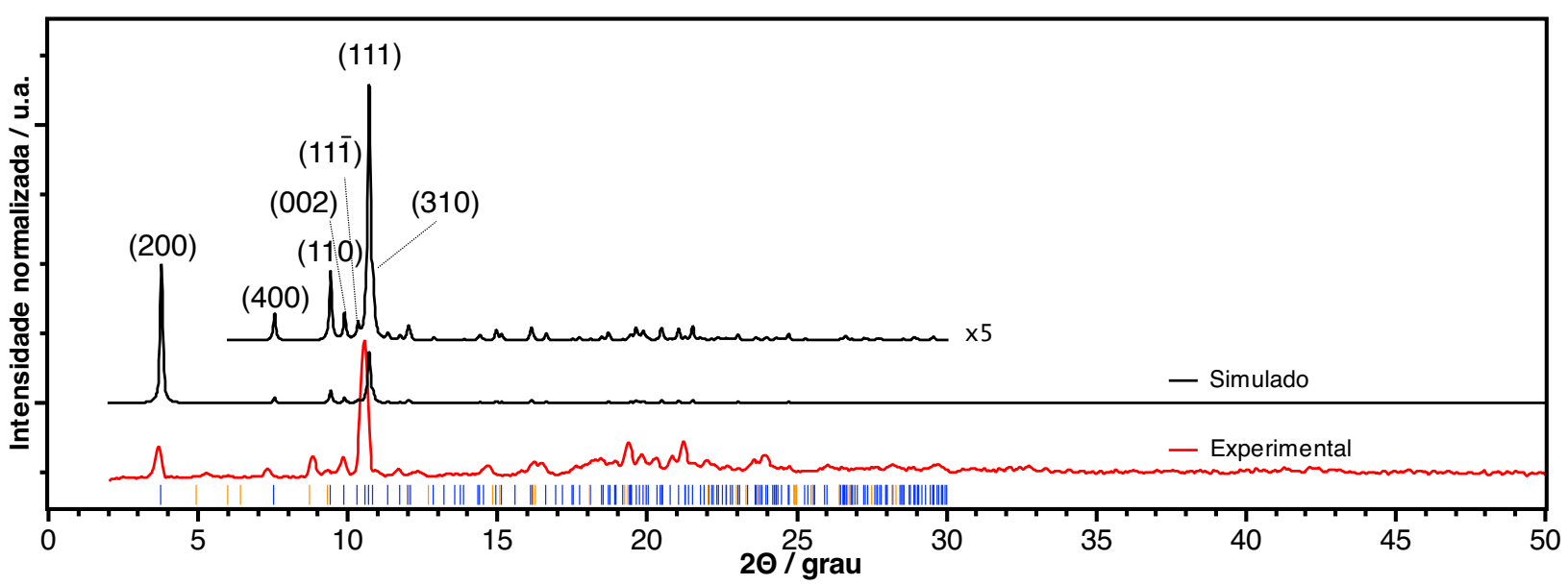

Figura 3.23: Comparação entre os difratogramas de raios-X de pó experimental e simulado do MOF-CoNDI-py-2, usando uma fonte de $\mathrm{Cu}(\lambda=1,54056 \AA$ ) . Traços em azul representam os picos calculados enquanto os traços em laranja representam picos sistematicamente ausentes.

i) de maior importância, o fato de que nem todas as moléculas de solvente possíveis foram incluídas, uma vez que a estrutura porosa pode acomodar uma quantidade significativa de moléculas hospedeiras, que em geral causa divergências de intensidade nos picos, principalmente a baixos ângulos; e ii) o fato de os cristais fisicamente apresentarem planos preferenciais, dada a sua morfologia achatada.

§ 3.3.3. Método de Ligação-Valência - Com a estrutura de monocristal, é possível utilizar o Método de Ligação-Valência ${ }^{(\mathrm{c})}$ para estimar a valência dos centros metálicos. Este método foi desenvolvido a partir do conceito de número de ligação aplicado por PAULING a metais e compostos intermetálicos, em 1947, e posteriormente a óxidos por BYSTRÖM e WILHELMI, em 1951, e ZACHARIASEN, em 1963. Este método consiste na correlação entre valência de ligação $\left(v_{i j}\right)$ e distância de ligação $\left(d_{i j}\right)$ entre os átomos $i$ e $j$, de forma que o somatório de todos os valores de $v_{i j}$ de um centro metálico são iguais a sua valência $\mathrm{V}_{i}$ - Equação 3.3. A expressão utilizada para a estimativa da valência do centro metálico é aquela na Equação 3.4. ${ }^{92}$

$$
\begin{aligned}
\sum v_{i j} & =V_{i} \\
v_{i j} & =e^{\left(R_{i j}-d_{i j}\right) / b}
\end{aligned}
$$

Na Equação 3.4, $v_{i j}$ é a valência de ligação entre os átomos $i$ e $j, R_{i j}$ é conhecido como parâmetro de ligação-valência, um valor tabelado; $d_{i j}$ é a distância da ligação de interesse; e $b$ é uma constante que adota, comumente, o valor de 0,37 Å. Aplicando a Equação 3.4 para o MOF-CoNDI-py-2 com os

\footnotetext{
(c) Não confundir com a Teoria de Ligação de Valência.
} 
Tabela 3.6: Parâmetros e resultados obtidos com o Método de Ligação-Valência aplicado ao MOF-CoNDI-py-2.

\begin{tabular}{cccccc}
\hline${\text { Átomo } i^{a}}^{\prime}$ & Átomo $j$ & $d_{i j}(\mathbf{\AA})$ & $R_{i j}{ }^{b}$ & $v_{i j}$ & $\sum v_{i j}$ \\
\hline $\mathrm{Co}(1)$ & $\mathrm{O}$ & 2,063 & 1,692 & 0,3668 & \\
$\mathrm{Co}(1)$ & $\mathrm{O}$ & 2,073 & 1,692 & 0,3573 & \\
$\mathrm{Co}(1)$ & $\mathrm{O}$ & 2,149 & 1,692 & 0,2909 & $\mathbf{2 , 0 3}$ \\
$\mathrm{Co}(1)$ & $\mathrm{O}$ & 2,063 & 1,692 & 0,3668 & \\
$\mathrm{Co}(1)$ & $\mathrm{O}$ & 2,073 & 1,692 & 0,3573 & \\
$\mathrm{Co}(1)$ & $\mathrm{O}$ & 2,149 & 1,692 & 0,2909 & \\
\hline $\mathrm{Co}(2)$ & $\mathrm{O}$ & 2,026 & 1,692 & 0,4055 & \\
$\mathrm{Co}(2)$ & $\mathrm{O}$ & 2,029 & 1,692 & 0,4018 & \\
$\mathrm{Co}(2)$ & $\mathrm{N}^{c}$ & 2,077 & 1,840 & 0,5273 & $\mathbf{2 , 1 1}$ \\
$\mathrm{Co}(2)$ & $\mathrm{O}$ & 2,153 & 1,692 & 0,2875 & \\
$\mathrm{Co}(2)$ & $\mathrm{N}^{c}$ & 2,162 & 1,840 & 0,4191 & \\
$\mathrm{Co}(2)$ & $\mathrm{O}$ & 2,189 & 1,692 & 0,2800 & \\
$\mathrm{Co}(2)$ & $\mathrm{O}$ & 2,163 & 1,692 & 0,2612 & \\
\hline${ }^{a} \mathrm{Co}(1)=$ central, Co$(2)=$ periférico. \\
${ }^{a}$ Valor tabelado obtido na Ref. 92. \\
${ }^{c}$ Utilizou-se 50\% do valor calculado por conta dos movimentos térmicos.
\end{tabular}

valores de $d_{i j}$ da Figura 3.22, obtemos uma valência média de 2,03 para o átomo de cobalto central, do fragmento trinuclear, e uma média de 2,11 para os dois átomos de cobalto periféricos. A partir deste método, conclui-se tratar de íons cobalto(II) e este resultado é corroborado por análises de EPR, discutidos em seções posteriores. Na Tabela 3.6, são resumidos os valores utilizados e resultados obtidos com o método.

§ 3.3.4. Análise térmica - As análises de TGA e DTG da NDI-py, TpA e MOF-CoNDI-py-2 em atmosfera de oxigênio podem ser encontradas na Figura 3.24. O que se observa da termogravimetria é que NDI-py apresentou algumas moléculas de solvente, indicadas pela perda de massa de $4,9 \%$ em $90{ }^{\circ} \mathrm{C}$, observação ausente para o ácido tereftálico. A NDI-py apresentou outros três processos atribuídos à decomposição dos substituintes piridínicos e do esqueleto central, em $242{ }^{\circ} \mathrm{C}(12 \%), 400{ }^{\circ} \mathrm{C}(36,9 \%)$ e $536{ }^{\circ} \mathrm{C}(45,2 \%)$; enquanto o TpA apresentou apenas uma perda de massa em $343^{\circ} \mathrm{C}$, sendo totalmente consumido. No caso do MOF-CoNDI-py-2, foram observados seis processos: i) em $143{ }^{\circ} \mathrm{C}, 14,8 \%$, atribuído a perda de DMF fracamente adsorvido ao composto; ii) em aproximadamente $190^{\circ} \mathrm{C}$, um processo que ocupa uma longa faixa de temperatura com perda de cerca de 10,5\% de massa, atribuído à lenta e dificultada saída de moléculas de DMF coordenadas aos centros metálicos, dada a estrutura do composto; iii) em $364{ }^{\circ} \mathrm{C}$, com perda de $24,8 \%$; iv) em $375{ }^{\circ} \mathrm{C}$, com perda de $14,4 \%$; e v) em $414{ }^{\circ} \mathrm{C}$, com perda de $16,7 \%$. Os três últimos processos são atribuídos as perdas do íon tereftalato e de NDI-py, porém é difícil distinguí-los nos processos. Também acredita-se que existam perdas de moléculas hóspede e de nitratos, provenientes do sal de cobalto utilizado para a síntese do MOF. O último processo vi) ocorre em $972{ }^{\circ} \mathrm{C}$, com perda de $0,5 \%$ de massa. Esse último processo é atribuído à formação de óxido de cobalto, $\mathrm{Co}_{2} \mathrm{O}_{3}$, que é confirmado pela difração de raios-X do sólido restante ao final da análise de 


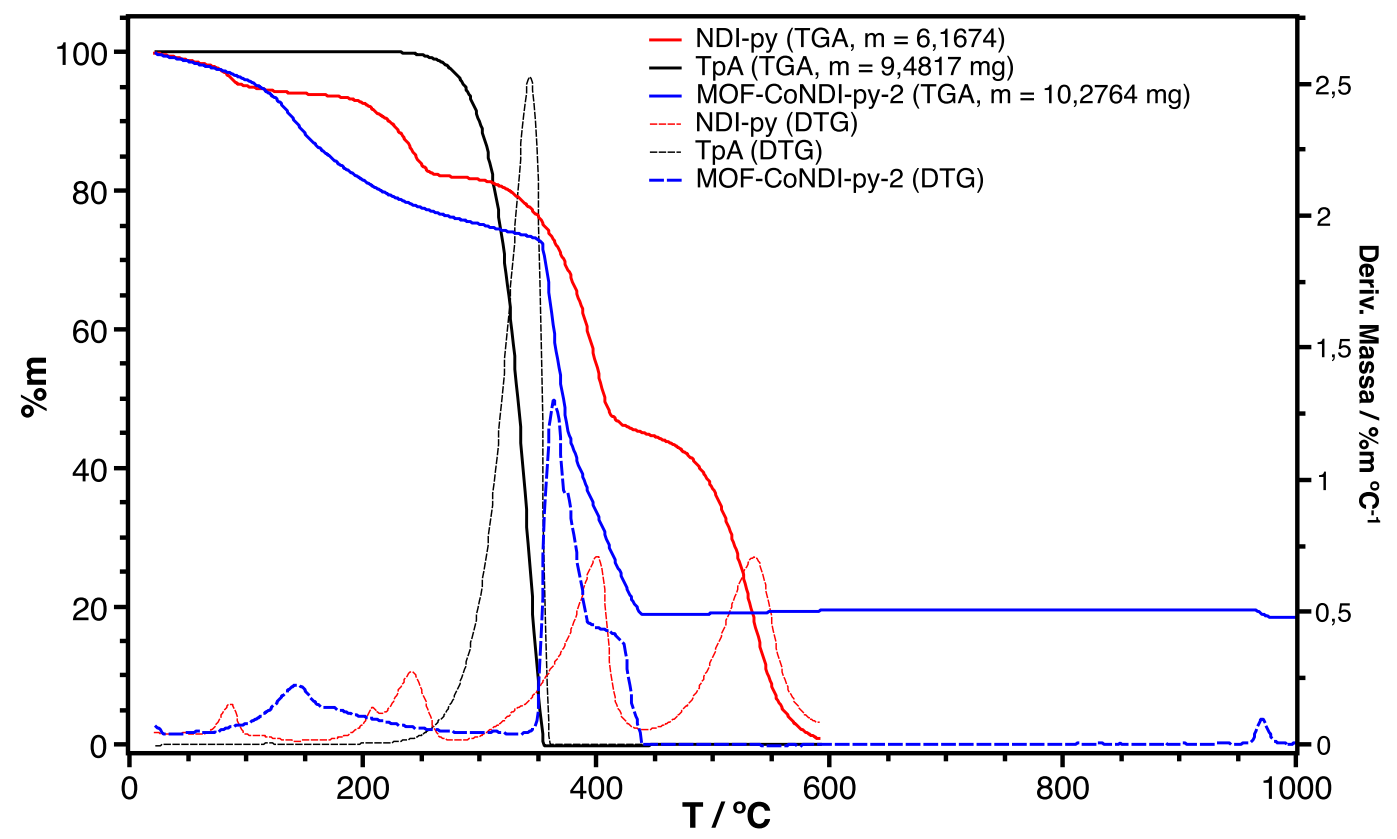

Figura 3.24: Análises de TGA e DTG da NDI-py, TpA e MOF-CoNDI-py-2 em atmosfera de $\mathrm{O}_{2}$.

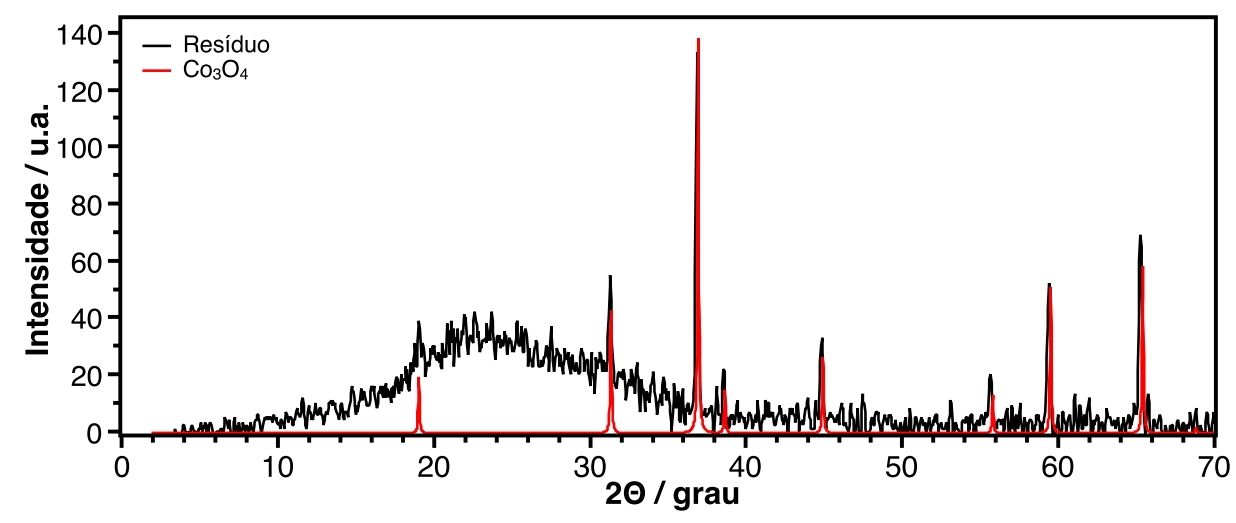

Figura 3.25: Difratograma de raios- $\mathrm{X}$ do sólido restante ao final da análise de TGA do MOF-CoNDI-py-2 em atmosfera de $\mathrm{O}_{2}$.

TGA, como mostra a Figura 3.25.

O difratograma de raios- $\mathrm{X}$ do $\mathrm{Co}_{3} \mathrm{O}_{4}$ apresentado na Figura 3.25 foi simulado no programa Mercury ${ }^{\circledR}$ a partir da estrutura de cristalina publicada ${ }^{93}$ disponível no banco de dados COD, Crystallography Open Database ${ }^{94-96}$, utilizando uma fonte de cobre $\left(\lambda=1,54056 \AA\right.$ ) com um passo de $0,02^{\circ}$ e largura à meia altura de 0,1 unidades de $2 \Theta$.

A partir das massas calculadas, e assumindo que os três processos que ocorrem entre $350{ }^{\circ} \mathrm{C} \mathrm{e}$ $450^{\circ} \mathrm{C}$ sejam provenientes da perda de NDI-py e íons tereftalatos, na proporção de 1:3 NDI-py:TpA, obteve-se a proporção 1:3:2,2:3,7 de NDI-py:TpA:DMF:Co, que está ligeiramente acima do esperado 1:3:2:3. A quantidade de cobalto foi superestimada em relação aos ligantes, observação razoável com a simplificação dos processos de perda de massa entre $350^{\circ} \mathrm{C}$ e $450^{\circ} \mathrm{C}$. 
§ 3.3.5. Espectroscopia vibracional - O espectro de infravermelho do MOF, na Figura 3.26, pode ser interpretado como uma soma das bandas dos componentes individuais com algumas mudanças importantes. O espectro foi comparado com aquele discutido para a NDI-py, e com os do íon tereftalato disponível na literatura ${ }^{97}$ - e disponíveis na Tabela A3.1, página 83 -, DMF ${ }^{98}$, e o ânion nitrato (na forma de $\left.\mathrm{KNO}_{3}\right)^{99}$. Todas essas informações deram origem à Tabela 3.7.

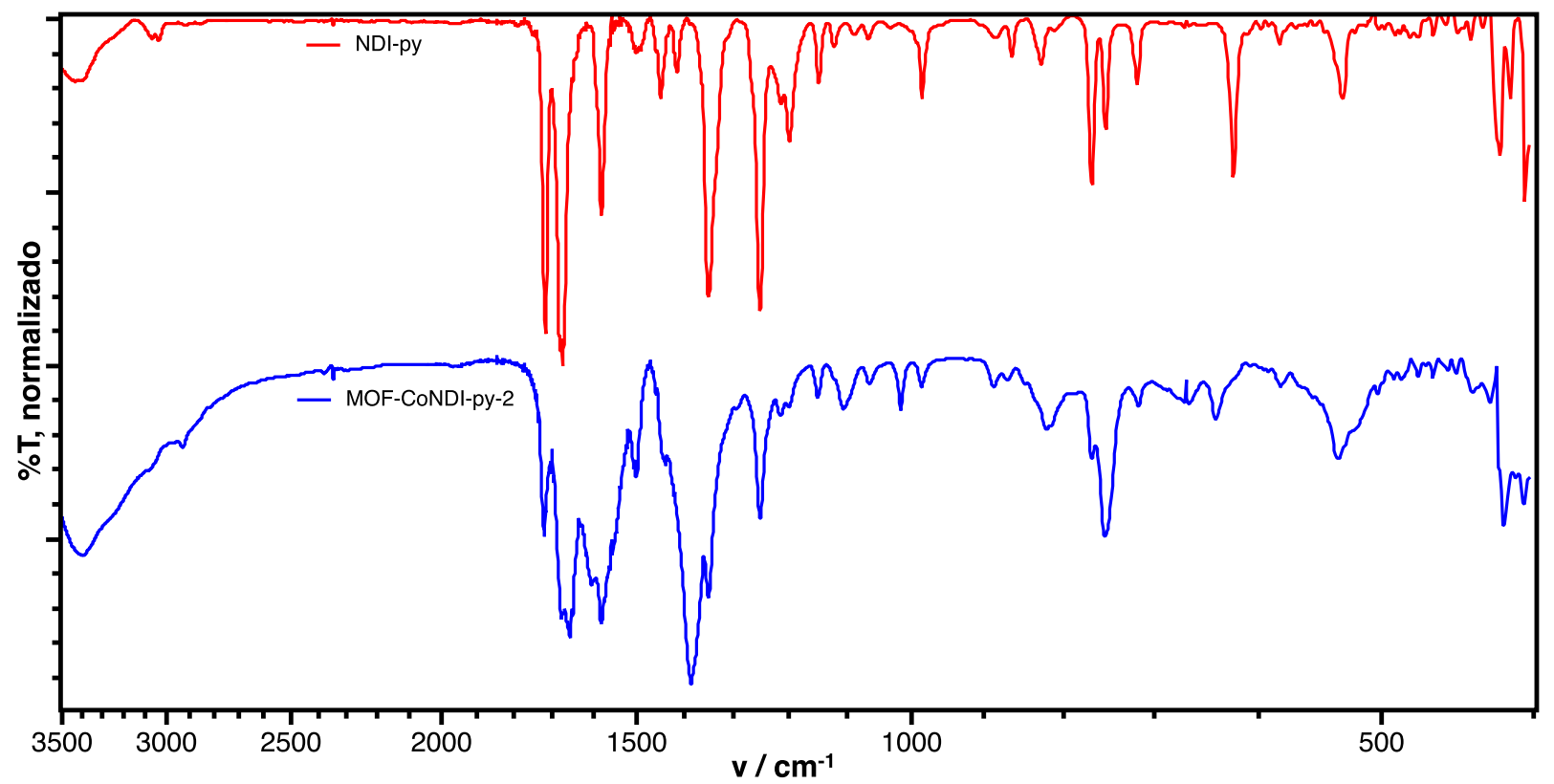

Figura 3.26: Comparação entre os espectros de FTIR do MOF-CoNDI-py-2 e da NDI-py, ambos em pastilha de KBr.

A maior parte dos modos vibracionais sofre pouca ou nenhuma alteração, com exceção apenas das frequências atribuídas aos grupos envolvidos diretamente na coordenação com os centros metálicos. Esses modos vibracionais são identificados como i) os dobramentos simétricos $\mathrm{C}-\mathrm{N}-\mathrm{C}$ no plano da NDIpy (de $623 \mathrm{~cm}^{-1}$ para $639 \mathrm{~cm}^{-1}$ ); ii) o estiramento assimétrico $\mathrm{O}=\mathrm{C}=\mathrm{O}$ do íon tereftalato (de $1617 \mathrm{~cm}^{-1}$ para $1654 \mathrm{~cm}^{-1}$ ); iii) um outro estiramento assimétrico $\mathrm{O}=\mathrm{C}=\mathrm{O}$ do $\operatorname{TpA}\left(\right.$ de $1558 \mathrm{~cm}^{-1}$ para $1606 \mathrm{~cm}^{-1}$ ); iv) o balanço $\mathrm{O}=\mathrm{C}=\mathrm{O}$ do tereftalato $\left(\mathrm{de} 508 \mathrm{~cm}^{-1}\right.$ para $533 \mathrm{~cm}^{-1}$ ); e, possivelmente, v) o estiramento simétrico $\mathrm{O}=\mathrm{C}=\mathrm{O}$ do $\mathrm{TpA}$ (de $1397 \mathrm{~cm}^{-1}$ para $1385 \mathrm{~cm}^{-1}$ ), que está encoberto com o estiramento $\mathrm{N}-\mathrm{O}$ do nitrato.

De maneira geral, a análise completa dos dados de FTIR corrobora com a desprotonação do ácido tereftálico, previamente determinado por cristalografia, e a presença de moléculas hóspede de água, provavelmente originadas da primeira esfera do coordenação do sal de cobalto(II) utilizado. A presença de DMF também foi observada entretanto diversas bandas esperadas $\left(2930 \mathrm{~cm}^{-1}, 1677 \mathrm{~cm}^{-1}, 1502 \mathrm{~cm}^{-1}\right.$ e $1437 \mathrm{~cm}^{-1}$ ) estão superpostas a outras bandas, além de terem intensidade relativa pequena em comparação com os demais grupos funcionais dada sua razão molar na estrutura. Para o DMF, a banda 
Tabela 3.7: Atribuição das bandas de infravermelho do MOF-CoNDI-py-2. ${ }^{a}$

\begin{tabular}{|c|c|}
\hline$v\left(\mathbf{c m}^{-1}\right)$ & Atribuição \\
\hline 3410 & Estiramento $\mathrm{O}-\mathrm{H}$ (moléculas de $\mathrm{H}_{2} \mathrm{O}$ hóspedes) \\
\hline 3260 & Estiramento Ar-H no plano (py, NDI-py) \\
\hline 3080 & Estiramento Ar-H no plano (py, NDI-py e TpA) \\
\hline 2930 & Estiramento $\mathrm{N}-\mathrm{CH}_{3}$ (DMF) \\
\hline 1719 & Estiramento $\mathrm{C}=\mathrm{O}$ (NDI-py) \\
\hline 1677 & Estiramento $\mathrm{C}=\mathrm{O}$ (NDI-py e DMF) \\
\hline 1654 & Estiramento $\mathrm{C}=\mathrm{O}(\mathrm{TpA})$ \\
\hline 1650 & Estiramento $\mathrm{C}=\mathrm{O}$ (NDI-py) \\
\hline 1606 & Estiramento $\mathrm{C}=\mathrm{O}(\mathrm{TpA})$ \\
\hline 1581 & Estiramento $\mathrm{C}=\mathrm{C}(\mathrm{Ar}, \mathrm{NDI}-\mathrm{py}$ e $\mathrm{TpA})$ \\
\hline 1555 & Estiramento $\mathrm{C}=\mathrm{C}(\mathrm{Ar}, \mathrm{TpA})$ \\
\hline 1507 & Estiramento $\mathrm{C}=\mathrm{C}(\mathrm{Ar}$, NDI-py e TpA) \\
\hline 1502 & Estiramento $\mathrm{C}=\mathrm{C}(\mathrm{Ar}, \mathrm{NDI}-\mathrm{py})+$ estiramento $\mathrm{C}-\mathrm{N}(\mathrm{DMF})$ \\
\hline 1437 & Dobramento $\mathrm{N}-\mathrm{CH}_{3}$ (DMF) \\
\hline 1385 & Estiramento $\mathrm{N}-\mathrm{O}\left(\mathrm{NO}_{3}^{-}\right)+$estiramento $\mathrm{O}=\mathrm{C}=\mathrm{O}(\mathrm{TpA}$, simétrico $)$ \\
\hline 1350 & Estiramento Ar-H no plano (core, NDI-py) \\
\hline 1251 & Estiramento Ar-H no plano (core, NDI-py) \\
\hline 1215 & Estiramento Ar-H no plano (core, NDI-py) + estiramento $\mathrm{C}=\mathrm{C}$ (core, respiração, NDI-py) \\
\hline 1199 & Estiramento Ar-H no plano (core, NDI-py) + estiramento C-N-C (core, assimétrico, NDI-py) \\
\hline 1149 & Estiramento Ar-H no plano (core, NDI-py) + estiramento $\mathrm{C}=\mathrm{C}$ (core, NDI-py) \\
\hline 1105 & Estiramento Ar-H no plano (TpA) \\
\hline 1016 & Estiramento Ar-H no plano (TpA) \\
\hline 986 & Dobramento Ar-H no plano (core, NDI-py) + respiração $\mathrm{C}=\mathrm{C}$ (core, NDI-py) \\
\hline 887 & Dobramento Ar-H fora do plano (core, NDI-py e TpA) \\
\hline 836 & Dobramento C-N-C simétrico (core e py, NDI-py) \\
\hline 821 & Dobramento C-N-C simétrico (core e py, NDI-py) + dobramento Ar-H fora do plano (TpA) \\
\hline 767 & Dobramento Ar-H fora do plano (py, NDI-py) \\
\hline 752 & Dobramento $\mathrm{C}-\mathrm{N}-\mathrm{C}$ e Ar-H fora do plano (core, NDI-py) + dobramento $\mathrm{O}=\mathrm{C}=\mathrm{O}$ no plano $(\mathrm{TpA})$ \\
\hline 717 & Dobramento Ar-H fora do plano (py, NDI-py) \\
\hline 639 & Dobramento C-N-C simétrico (core e py, NDI-py) \\
\hline 533 & Balanço $\mathrm{O}=\mathrm{C}=\mathrm{O}(\mathrm{TpA})+$ dobramento Ar-H fora do plano (py, NDI-py) \\
\hline
\end{tabular}

mais proeminente é aquela atribuída ao estiramento $\mathrm{N}-\mathrm{CH}_{3}$ em $2930 \mathrm{~cm}^{-1}$, de pequena intensidade. $\mathrm{O}$ fato de que a maioria dos modos vibracionais da NDI-py se mantém muito próximos do composto isolado indica que a molécula não se encontra distorcida na rede cristalina do MOF, conforme indica a estrutura cristalina obtida. Interpreta-se a diferença como posições médias fruto dos intensos movimentos térmicos. 
§ 3.3.6. Ressonância paramagnética eletrônica - A análise de EPR foi realizada em colaboração com o Prof. Jerome Chauvin, ambos da Université de Grenoble, França. Os espectros foram registrados a diferentes temperaturas -7 K, 25 K, $40 \mathrm{~K} \mathrm{e} 75 \mathrm{~K}$, a saber - e são apresentados na Figura 3.27.

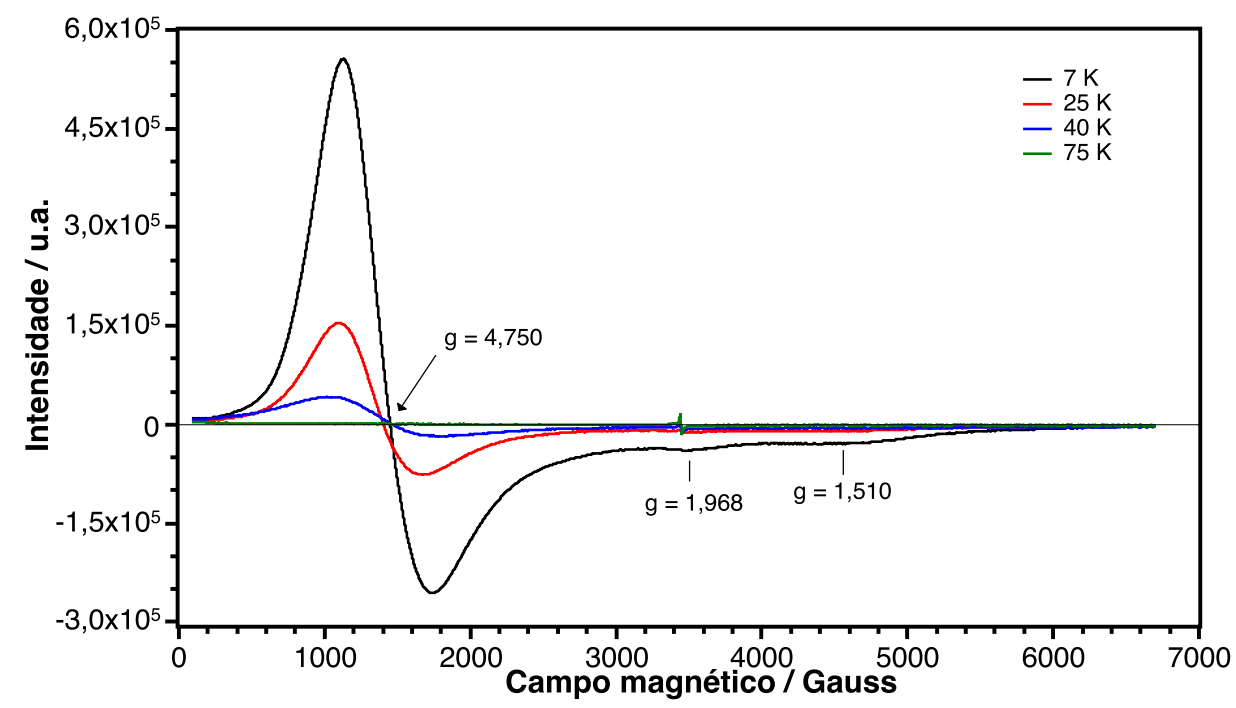

Figura 3.27: Espectros de EPR do MOF-CoNDI-py-2 a $7 \mathrm{~K}, 25 \mathrm{~K}$ e $40 \mathrm{~K}$.

O fator $g$ foi calculado a partir da Equação 3.5, na qual $h$ é a constante de Planck; $v$ é a frequência utilizada, no valor de $9,6399 \mathrm{GHz} ; \mu_{e}$ é o valor do magnéton de Bohr; e $\beta$ é o valor do campo magnético.

$$
h v=g \mu_{e} \beta
$$

A partir do gráfico observa-se que o MOF-CoNDI-py-2 mantém sua atividade paramagnética até $40 \mathrm{~K}$, e em $75 \mathrm{~K}$ a atividade já é completamente suprimida. O valor do fator $\mathrm{g}$ determinado é de $\mathrm{g}=4,750$, sendo que os outros dois valores são estimativas pois as possíveis ressonâncias não estão muito definidas. Os espectros de EPR mostram um espectro típico de Co(II) alto spin, com fator $g$ próximo a 4 e duas possíveis ressonâncias em campos mais elevados. ${ }^{100}$

§ 3.3.7. Eletroquímica - A análise eletroquímica do MOF-CoNDI-py-2 foi realizada em colaboração com o Prof. Jerome Chauvin, da Université de Grenoble, França. Pela limitação física das amostras, que compreendem cristais, os voltamogramas cíclicos foram registrados utilizando microeletrodos de cavidade (CME) como eletrodo de trabalho, um fio de platina como eletrodo auxiliar e o $\mathrm{par} \mathrm{Ag} / \mathrm{AgNO}_{3}$ $10 \mathrm{mmol} \mathrm{dm} \mathrm{m}^{-3}$ em MeCN como referência. Um voltamograma cíclico representativo, a $50 \mathrm{mV} \mathrm{s}^{-1}$, é mostrado na Figura 3.28. 


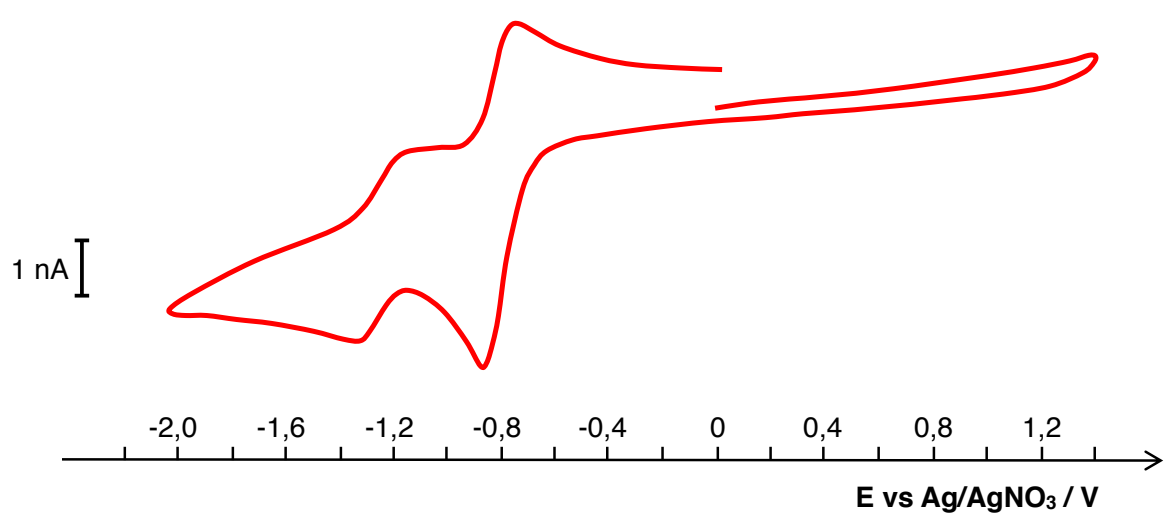

Figura 3.28: Voltametria cíclica do MOF-CoNDI-py-2 a $50 \mathrm{mV} \mathrm{s}^{-1}$ em uma solução $0,1 \mathrm{~mol} \mathrm{dm}^{-3}$ de $\left[\mathrm{N}(\mathrm{n}-\mathrm{Bu})_{4}\right]\left(\mathrm{PF}_{6}\right)$ em $\mathrm{MeCN}$. $\mathrm{WE}=\mathrm{CME}, \mathrm{CE}=\mathrm{Pt}, \mathrm{RE}=\mathrm{Ag} / \mathrm{AgNO}_{3}\left(10 \mathrm{mmol} \mathrm{dm}{ }^{-3}, \mathrm{MeCN}\right)$.

$$
\begin{array}{cl}
\text { MOF-Co"NDI-py-2 }+e^{-} \longrightarrow \text { MOF-Co'NDI-py-2 } & E_{1 / 2} \approx-0,79 \mathrm{~V}, \Delta E=140 \mathrm{mV} \\
\text { MOF-CoNDI-py-2 } \left.+e^{-} \longrightarrow \text { MOF-Co(NDI-py }{ }^{\bullet-}\right)-2 & E_{1 / 2} \approx-0,79 \mathrm{~V}, \Delta E=140 \mathrm{mV} \\
\text { MOF-Co'(NDI-py } \left.\left.^{\bullet-}\right)-2+e^{-} \longrightarrow \text { MOF-Co' }^{\prime} \text { NDI-py }^{2-}\right)-2 & E_{1 / 2}=-1,25 \mathrm{~V}, \Delta E=110 \mathrm{mV}
\end{array}
$$

Foram observados dois pares redox, a princípio eletroquimicamente reversíveis, em $E_{1 / 2}=-0,79 \mathrm{~V}$ $(\Delta \mathrm{E}=110 \mathrm{mV})$ e $\mathrm{E}_{1 / 2}=-1,25 \mathrm{~V}(\Delta \mathrm{E}=140 \mathrm{mV})$, em referência ao par $\mathrm{Ag} / \mathrm{AgNO}_{3}$. Para facilitar a comparação com o voltamograma cíclico da NDI-py, os potenciais observados para o MOF-CoNDI-py-2 foram convertidos para o par $\mathrm{Fc} / \mathrm{Fc}^{+}$como referência, pela simples subtração de $87 \mathrm{mV}^{101}$, e é essa referência utilizada no decorrer desta discussão. Os potenciais do MOF, convertidos, são $E_{1 / 2}=-0,88 \mathrm{~V}$ e $\mathrm{E}_{1 / 2}=-1,34 \mathrm{~V}$, versus $\mathrm{Fc} / \mathrm{Fc}^{+}$, respectivamente. Assim como para a NDI-py, os dois processos redox observados encontram-sem em potenciais negativos, condizente com o que se espera para naftaleno diimidas. Entretanto, as correntes anódicas e catódicas do processo em $E_{1 / 2}=-0,88 \mathrm{~V}$ são cerca de duas vezes maiores que aquelas para o processo em $\mathrm{E}_{1 / 2}=-1,34 \mathrm{~V}$. Acredita-se que este primeiro represente, na verdade, dois pares redox que acontecem em potenciais muito próximos e, portanto, seja composto de duas ondas sobrepostas: i) relativo à redução do centro metálico de $\mathrm{Co}($ (I) para $\mathrm{Co}(\mathrm{I})$ e ii) à redução da NDI-py para NDI-py ${ }^{\bullet-}$. O segundo processo em $E_{1 / 2}=-1,34 \mathrm{~V}$ é atribuído à segunda redução da unidade de NDI-py, de NDI-py•- para NDI-py ${ }^{2-}$. Essas atribuições foram comparadas com os resultados obtidos para a NDI-py e com os dados disponíveis na literatura sobre a redução de um complexo de cobalto(II) ${ }^{102}$, e resumidos na Tabela 3.8. ${ }^{(\mathrm{d})}$

Apesar da grande diferença entre os potenciais de redução do par $\mathrm{Co}(\mathrm{II}) / \mathrm{Co}(\mathrm{I})$ aqui encontrados e os

\footnotetext{
(d) Os potenciais da literatura são referentes ao eletrodo de calomelano saturado (SCE) e as conversões necessárias foram realizadas.
} 
Tabela 3.8: Potenciais de redução versus $\mathrm{Fc} / \mathrm{Fc}^{+}$observados para o MOF-CoNDI-py-2 e NDI-py em comparação com os disponíveis na literatura.

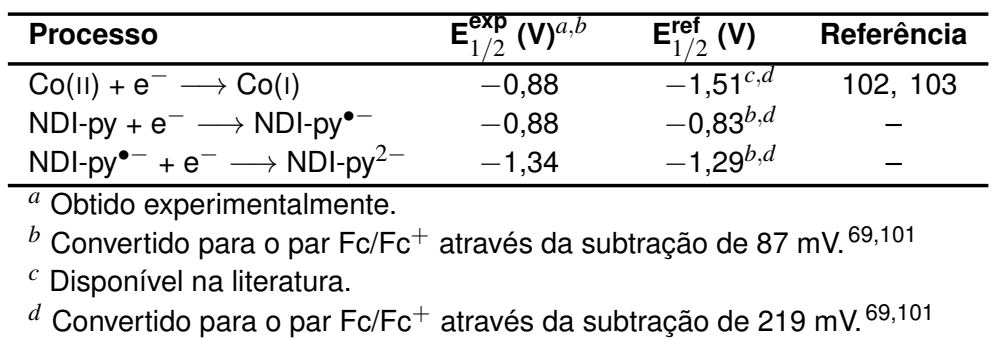

disponíveis na literatura ${ }^{102,103}$, também é necessário notar que outros trabalhos determinaram a grande sensibilidade que este potencial de redução apresenta em relação aos ligantes do complexo, apresentando variações acima de $0,5 \mathrm{~V}^{102}$. Os potenciais de redução da unidade NDI-py no MOF sofreram pequena diminuição - em cerca de $50 \mathrm{mV}$-, isto é, para potenciais mais negativos, para ambos os processos de redução à NDI-py ${ }^{\bullet-}$ e NDI-py ${ }^{2-}$, entendido apenas como uma variação na afinidade eletrônica que o ligante apresenta dada a coordenação com o centro metálico e subsequente doação e retrodoação de densidade eletrônica. Acerca das diferenças entre as variações de potencial anódico e catódico $(\Delta \mathrm{E})$ para a NDI-py livre e no MOF, primeiramente se observa que esses valores não são iguais para os dois processos no MOF, com valores de $\Delta \mathrm{E}_{1}=140 \mathrm{mV}$ e $\Delta \mathrm{E}_{2}=110 \mathrm{mV}$. Essa divergência é atribuída à sobreposição das reduções do ligante e do centro metálico no processo em $\mathrm{E}_{1 / 2}=-0,88 \mathrm{~V}$, sendo portanto um $\Delta \mathrm{E}$ aparente. Acredita-se que a primeira redução da NDI-py apresente o mesmo valor de separação que a segunda, no caso de $110 \mathrm{mV}$. Além disso, este valor de $\Delta \mathrm{E}$ no MOF é cerca de $50 \mathrm{mV}$ menor que para a NDI-py sugere que o processo tenha se tornado mais reversível, entretanto a afirmação deve ser cautelosa pois essas variações podem ser decorrentes unicamente das diferenças que existem entre os experimentos de voltametria cíclica; existem diferenças entre os solventes utilizados (DMF e MeCN), concentrações de eletrólito de suporte $\left(0,1 \mathrm{~mol} \mathrm{dm}^{-3}\right.$ e $\left.0,01 \mathrm{~mol} \mathrm{dm}^{-3}\right)$ e estado físico. Adicionalmente, a separação dos potenciais anódico e catódico do ferroceno em DMF, determinado como $125 \mathrm{mV}$, não está muito abaixo desses valores.

Assim como para a NDI-py em solução, é possível calcular a energia do LUMO do MOF-CoNDI-py-2, através da Equação 3.1. Utilizando o potencial da primeira redução como $\mathrm{E}_{1 / 2}=-0,88 \mathrm{~V} v \mathrm{~F} \mathrm{~F} / \mathrm{Fc}^{+}$, temos que LUMO = -3,92 eV. Este valor é apenas 0,05 eV abaixo do valor de LUMO calculado para NDIpy, $-3,97$ eV, e, levando em conta as aproximações necessárias, é possível considerar que os valores de LUMO para o MOF-CoNDI-py-2 e para a NDI-py sejam os mesmos. 
§ 3.3.8. Espectro eletrônico e níveis de energia - Devido a sua natureza cristalina, o espectro de absorção do MOF-CoNDI-py-2 não pode ser obtido em solução, uma vez que a dissolução deste composto acarreta em sua destruição. Dessa forma, os espectros foram avaliados através de reflectância difusa. Para efeitos de comparação mais acurada, os espectros de reflectância também foram determinados para aqueles compostos que podem ser estudados em solução, como é o caso da NDI-py. Devido a limitações experimentais, os espectros foram divididos entre aqueles nas regiões do ultravioleta e do visível (UV-Vis); e nas regiões do visível e do infravermelho próximo (Vis-NIR). Estes espectros estão na Figura 3.29, normalizados e representados na forma de absorção.

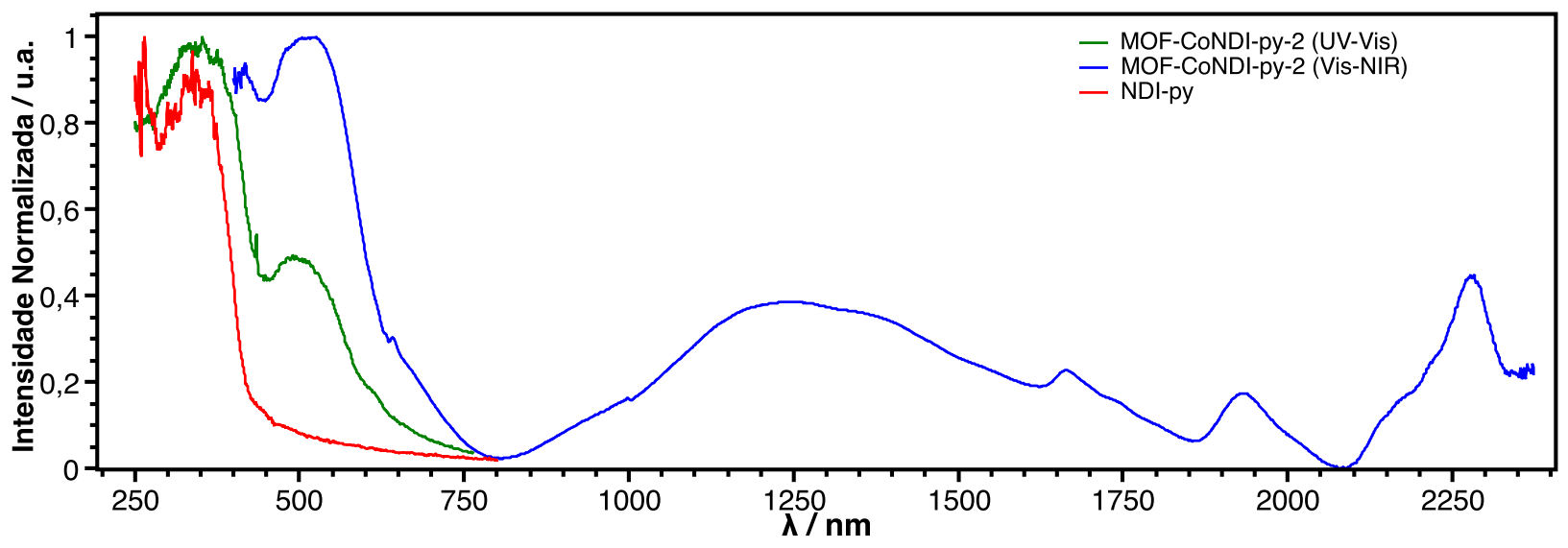

Figura 3.29: Espectros de reflectância difusa do MOF-CoNDI-py-2 e da NDI-py.

No que tange a discussão e atribuição das transições observadas, geralmente as análises de amostras no estado sólido apresentam bandas mais largas que aquelas de moléculas discretas em solução por conta das interações com os modos vibracionais da rede, o que pode dificultar a identificação de algumas transições próximas em energia. No caso específico do MOF-CoNDI-py-2, esta é a única opção dada a sua natureza cristalina. É possível, entretanto, resolver esta limitação através da desconvolução matemática dos espectros utilizando um somatório de funções gaussianas como na equação 2.1.

O espectro de reflectância difusa da NDI-py é bastante simples. Este apresenta apenas uma banda observável de alta intensidade centrada por volta de $340 \mathrm{~nm}$, pouco definida, e nota-se também a ausência das bandas atribuídas à progressão vibrônica, conforme discutido para o espectro de absorção em solução. Além da falta de definição da banda no espectro, esta ausência pode também ser entendida como consequência do estado de agregação do composto que, por se encontrar no estado sólido, apresenta bandas mais largas - quando comparado com espectros em solução - devido a acoplamentos fonônicos e vibrações de rede e, assim, as bandas vibrônicas podem ficar indistinguíveis. No geral, atribui-se esta banda à transição $S_{0}\left(v_{0}\right) \rightarrow S_{1}\left(v_{0}\right)$ e demais transições vibrônicas, $S_{0}\left(v_{0}\right) \rightarrow S_{1}\left(v_{1}\right)$, 
$S_{0}\left(v_{0}\right) \rightarrow S_{1}\left(v_{2}\right)$ e correlatas.

No caso do MOF-CoNDI-py-2, o seu espectro de absorção é muito mais rico e repleto de transições que, exceto pelos vales por volta de $800 \mathrm{~nm}$ e $2080 \mathrm{~nm}$, cobrem toda a região analisada. A descrição completa do espectro, de $250 \mathrm{~nm}$ a $2500 \mathrm{~nm}$ se dá pela comparação entre os espectros na região do UV-Vis e do Vis-NIR. Estes são tratados como complementares e são representados separadamente apenas por uma limitação experimental. O espectro desconvoluído é apresentado na Figura 3.30.

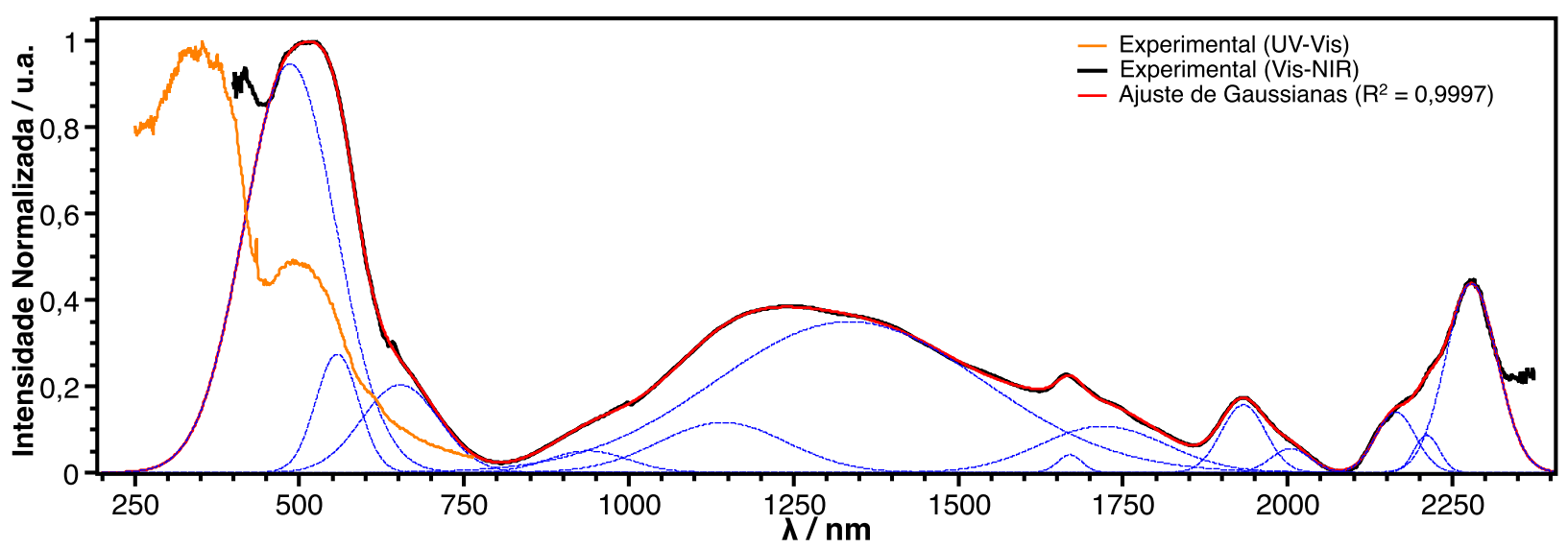

Figura 3.30: Espectros de reflectância difusa do MOF-CoNDI-py-2 na região do UV-Vis e Vis-NIR. A desconvolução é apenas para a região do Vis-NIR.

Resumidamente, o espectro em questão é constituído de transições do ligante NDI-py, transições $d-d$ do metal e uma transição de transferência de carga. A transição observada na região do UV, com máximo em aproximadamente $350 \mathrm{~nm}$, é atribuída às transições da NDI-py, discutidas anteriormente, relativas à transição eletrônica e as suas transições vibrônicas associadas, $S_{0}\left(v_{0}\right) \rightarrow S_{1}\left(v_{n}\right)(n \in \mathbb{N})$. Esta banda, no MOF, é mais larga que aquela da NDI-py livre, e acredita-se que isso seja derivado da combinação dos efeitos de acoplamento fonônico mais acentuado - haja vista uma maior cristalinidade do polímero de coordenação - e pela provável formação de macro-orbitais $\pi$, que geralmente resultam em deslocamentos batocrômicos e bandas mais largas. Um ponto pode ser levantado a respeito da ausência desses macro-orbitais na NDI-py, já que estes resultam de interações $\pi$ - $\pi$ intermoleculares que também são esperadas no ligante livre. Entretanto, considerando a natureza dos sólidos utilizados, analisou-se cristais ordenados e visivelmente grandes para o MOF enquanto a NDI-py consistia de um sólido amorfo. Assim sendo, espera-se efeitos muito mais pronunciados de acoplamentos orbitais intermoleculares de natureza $\pi-\pi$ nos cristais do MOF que para a NDI-py.

A banda mais intensa no espectro desconvoluído, no Vis-NIR, centrada em aproximadamente $490 \mathrm{~nm}$ é atribuída a uma transferência de carga metal-ligante (MLCT), justamente por conta de sua intensidade. Acredita-se que a transferência de carga seja do metal para o ligante ${ }^{104}$, e não no sentido oposto, devido 
à natureza $\pi$-aceptora do ligante, bem como nos seus típicos estados reduzidos estáveis, NDI-py ${ }^{\bullet-} \mathrm{e}$ NDI-py ${ }^{2-}$, conforme discutido nos resultados de eletroquímica.

Com exceção da transição atribuída como MLCT, as demais bandas desconvoluídas nos espectros Vis-NIR são atribuídas a transições $d-d$ do centro metálico de cobalto(II). Este elevado número de bandas é resultado da baixa simetria dos centros metálicos que, apesar de adotarem uma geometria de coordenação octaédrica, possuem simetria muito mais baixa que o grupo de ponto $\mathrm{O}_{h}$. Restringindo-se a estrutura do MOF-CoNDI-py-2 para a estrutura da Figura 3.31, temos um fragmento que corresponde a um complexo trinuclear de simetria $\mathrm{C}_{i}$. O fragmento corresponde a três centros metálicos de cobalto(II) ligados por íons tereftalatos. O íon central adota uma geometria quasi-octaédrica, com quatro tereftalatos coordenados por um único átomo de oxigênio e compartilhando um dos átomos de oxigênio com outros dois tereftalatos que estão bidentados a cada um dos outros dois íons de cobalto(II). Estes últimos, por sua vez, estão coordenados, além dos tereftalatos quelatos, a outros dois tereftalatos monodentados que os conectam ao íon metálico central —, a uma molécula de DMF e a uma molécula de NDI-py.

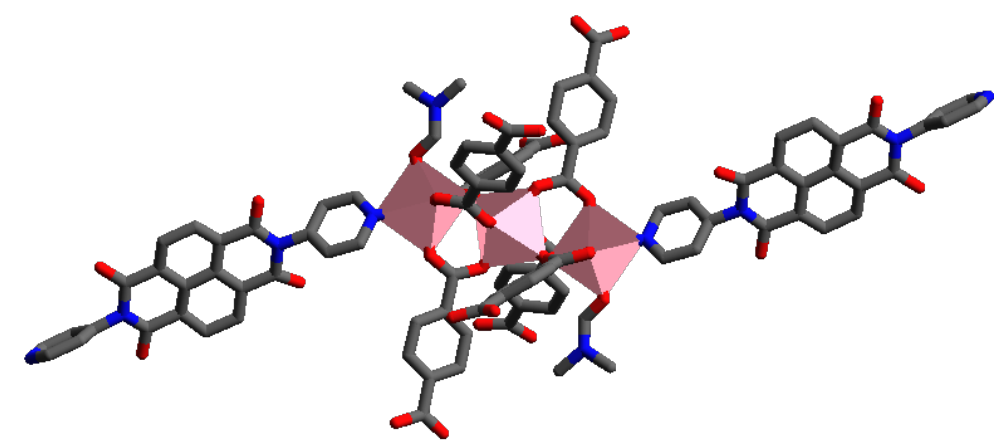

Figura 3.31: Fragmento do MOF-CoNDI-py-2 espectroscopicamente ativo na região do UV-Vis-NIR estudada.

Todos os ligantes estão coordenados aos centros metálicos através de átomos com hibridização sp², o que permite que haja a formação de ligações $\pi$ entre os orbitais $p$ não hibridizados dos átomos ligantes e orbitais $t_{2 g}$ do metal; $d_{x y}, d_{x z}$ e $d_{y z}$, a saber, pois possuem simetria apropriada para tal ${ }^{104}$. A existência de ligações $\pi$ entre os íons metálicos e os demais ligantes leva a uma importante diminuição na repulsão intereletrônica, quando comparado a complexos que não a fazem, e consequente estabilização dos orbitais envolvidos. Isso se deve ao fato de a ligação ser mais difusa no espaço, aumento a comunicação eletrônica entre os metais e os ligantes. Isso acarreta em um aumento no grau de covalência da ligação metal-ligante e, consequentemente, em um efeito nefelauxético - uma diminuição do valor do parâmetro B de Racah, que leva em consideração justamente a repulsão eletrônica. Outro fator importante advindo das ligações $\pi$ formadas é o aumento da intensidade das transições $d-d$ observadas. Esta maior intensidade é atribuída à diminuição do caráter $d$ dos orbitais do metal — justamente pela maior combinação 
com os orbitais dos ligantes, que torna a ligação muito menos localizada - e eventual relaxação da regra de Laporte $(\Delta \ell= \pm 1)$. As intensidades de todas as transições na região do UV-Vis-NIR puderam ser estimadas através da comparação com os coeficientes de absortividade previamente determinados, em solução, para as transições da NDI-py; e considerando que a banda observada em cerca de $490 \mathrm{~nm}$ no espectro de reflectância difusa na região do UV-Vis é a mesma MLCT observada no espectro na região do Vis-NIR. Os coeficientes de absortividade das transições $d-d$ foram estimadas na ordem de $10^{3}$, uma ordem de grandeza acima do esperado, condizente com o que foi discutido.

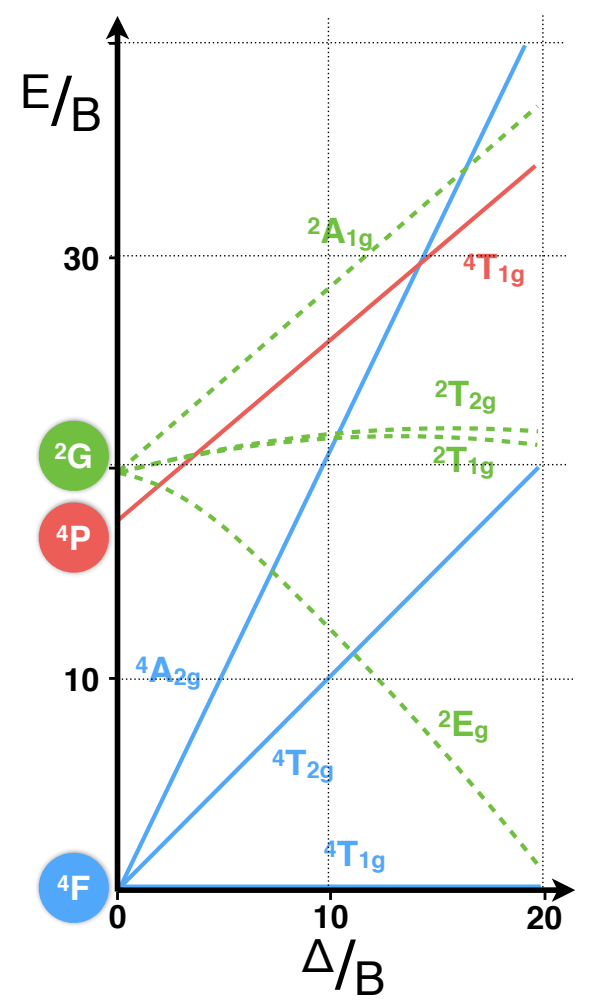

Figura 3.32: Representação qualitativa de um diagrama do tipo Tanabe-Sugano para um íon metálico $\mathrm{d}^{7}$.

Sobre o grande número de transições $d-d$ atribuídas, a razão reside na grande diminuição de simetria dos centros metálicos do MOF-CoNDI-py-2 $\left(C_{i}\right)$ quando comparados a um complexo octaédrico $\left(\mathrm{O}_{h}\right)$ clássico. Na Figura 3.32, temos uma região do diagrama de TanabeSugano ${ }^{104}$ para um metal $d^{7}$, como é o caso do Co(II). O termo fundamental é um ${ }^{4} \mathbf{T}_{1 g}\left({ }^{4} \mathbf{F}\right)$ e em geral as transições observadas são: ${ }^{4} \mathbf{T}_{2 g}\left({ }^{4} \mathbf{F}\right) \leftarrow{ }^{4} \mathbf{T}_{1 g}\left({ }^{4} \mathbf{F}\right),{ }^{4} \mathbf{A}_{2 g}\left({ }^{4} \mathbf{F}\right) \leftarrow{ }^{4} \mathbf{T}_{1 g}\left({ }^{4} \mathbf{F}\right)$ e ${ }^{4} \mathbf{T}_{1 g}\left({ }^{4} \mathbf{P}\right) \leftarrow{ }^{4} \mathbf{T}_{1 g}\left({ }^{4} \mathbf{F}\right)$, em um campo $\mathrm{O}_{h}$. Com a diminuição da simetria, comparativamente, para um campo $C_{i}$, haverá desdobramento dos termos triplamente degenerados ${ }^{4} \mathbf{T}_{1 g} \mathrm{e}$ ${ }^{4} \mathbf{T}_{2 g}$, de acordo com as transformações de simetria que o novo grupo de ponto permitir. $\mathrm{O}$ grupo $\mathrm{C}_{i}$ apresenta apenas a identidade $E$ e um centro de inversão $i$ como elementos de simetria, e apenas $A_{g}$ e $A_{u}$ como representações irredutíveis - ver Tabela A5.4, p. 85. A operação A é uma representação não degenerada e simétrica em relação ao eixo princi-

pal. Atribui-se aqui que os dois termos triplamente degenerados serão desdrobrados em três termos cada, em um total de seis termos ${ }^{4} \mathrm{~A}_{g}$ gerados. O termo ${ }^{4} \mathrm{~A}_{2 g}$ também é não degenerado e foi atribuída a mesma transformação a ele, ${ }^{4} \mathrm{~A}_{g}$, conforme a Figura 3.33. ${ }^{105}$

Além das transições $d-d$ discutidas no parágrafo anterior, também são esperadas transições de baixa energia do ligante NDI-py, uma pouco provável transferência de carga entre os centros metálicos, já que diferem em coordenação e consequentemente na energia dos orbitais $d$, e algumas transições proibidas por spin, como aquelas para termos do tipo ${ }^{2} \mathrm{E}_{g}\left(\mathrm{O}_{h}\right)$, que será desdobrado em outros dois termos em uma simetria $C_{i}$. As transições proibidas foram atribuídas baseadas nos seus coeficientes 

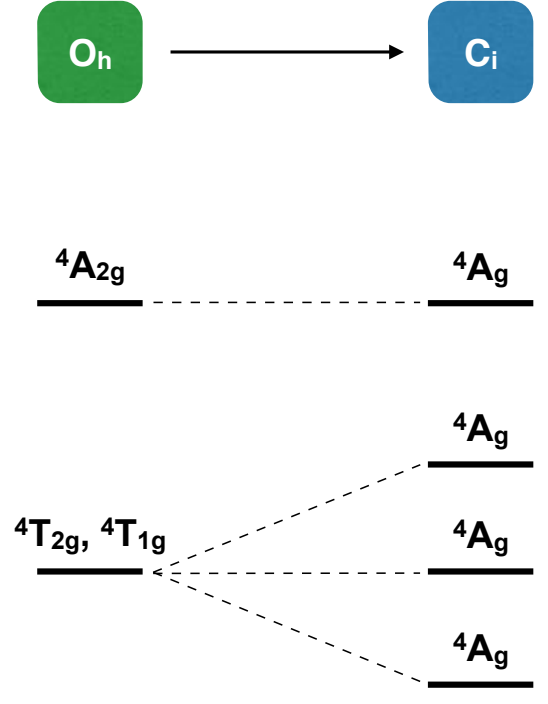

Figura 3.33: Esquema qualitativo de desdobramento dos termos de Russell-Saunders de um campo $\mathrm{O}_{h}$ para um campo $\mathrm{C}_{i}$.

de absorção que são cerca de uma ordem de grandeza menores que as demais transições $d-d$. Um resumo dos parâmetros das bandas desconvoluídas, suas intensidades e atribuições tentativas pode ser encontrado na Tabela 3.9.

Tabela 3.9: Parâmetros da desconvolução gaussiana e atribuições do espectro de reflectância difusa do MOF-CoNDI-py-2.

\begin{tabular}{cccccl}
\hline$\lambda(\mathbf{n m})$ & $\lambda(\mathbf{e V})$ & Área (u.a.) & $\mathbf{w}_{n}(\mathbf{n m})$ & $\varepsilon\left(\times \mathbf{1 0}^{3} \mathbf{\mathbf { ~ } \mathbf { ~ m o l }}{ }^{-1} \mathbf{\mathbf { c m } ^ { - 1 }}\right)^{a}$ & Atribuição \\
\hline 486 & 2,55 & 165 & 139 & 9,9 & Transferência de carga metal-ligante \\
557 & 2,22 & 22,5 & 65,3 & 3,2 & $d-d$, para um ${ }^{4} \mathrm{~A}_{g}$ do termo ${ }^{4} \mathrm{~A}_{2 g}\left({ }^{4} \mathrm{~F}\right)$ \\
653 & 1,90 & 30,0 & 118 & 2,4 & $d-d$, para um ${ }^{4} \mathrm{~A}_{g}$ do termo ${ }^{4} \mathrm{~T}_{1 g}\left({ }^{4} \mathrm{P}\right)$ \\
938 & 1,32 & 7,71 & 122 & 0,59 & $d-d$, para um ${ }^{4} \mathrm{~A}_{g}$ do termo ${ }^{4} \mathrm{~T}_{2 g}\left({ }^{4} \mathrm{~F}\right)$ \\
1142 & 1,09 & 28,3 & 195 & 1,4 & $d-d$, para um ${ }^{4} \mathrm{~A}_{g}$ do termo ${ }^{4} \mathrm{~T}_{1 g}\left({ }^{4} \mathrm{P}\right)$ \\
1335 & 0,93 & 178 & 406 & 4,1 & $d-d$, para um ${ }^{4} \mathrm{~A}_{g}$ do termo ${ }^{4} \mathrm{~T}_{1 g}\left({ }^{4} \mathrm{~F}\right)$ \\
1669 & 0,74 & 1,91 & 36,8 & 0,48 & Proibida por spin $\left(\right.$ de um ${ }^{2} \mathrm{~T}_{1 g}$ ou $\left.{ }^{2} \mathrm{~T}_{2 g}\right)$ \\
1720 & 0,72 & 25,7 & 191 & 1,3 & $d-d$, para um ${ }^{4} \mathrm{~A}_{g}$ do termo ${ }^{4} \mathrm{~T}_{1 g}\left({ }^{4} \mathrm{P}\right)$ \\
1933 & 0,64 & 13,2 & 67,2 & 1,8 & $d-d$, para um ${ }^{4} \mathrm{~A}_{g}$ do termo ${ }^{4} \mathrm{~T}_{2 g}\left({ }^{4} \mathrm{~F}\right)$ \\
2004 & 0,62 & 4,16 & 59,6 & 0,65 & Proibida por spin $\left(\right.$ de um $\left.{ }^{2} \mathrm{E}_{g}\right)$ \\
2164 & 0,57 & 10,6 & 60,5 & 1,6 & $d-d$, para um ${ }^{4} \mathrm{~A}_{g}$ do termo ${ }^{4} \mathrm{~T}_{2 g}\left({ }^{4} \mathrm{~F}\right)$ \\
2211 & 0,56 & 4,14 & 38,2 & 1,0 & Proibida por spin $\left(\right.$ de um $\left.{ }^{2} \mathrm{E}_{g}\right)$ \\
2279 & 0,54 & 42,9 & 78,1 & 5,1 & $d-d$, para um ${ }^{4} \mathrm{~A}_{g}$ do termo termo ${ }^{4} \mathrm{~T}_{1 g}\left({ }^{4} \mathrm{~F}\right)$ \\
$0^{b}$ & 0 & - & - & - & ${ }^{4} \mathrm{~A}_{g}$ do termo ${ }^{4} \mathrm{~T}_{1 g}\left({ }^{4} \mathrm{~F}\right)$ \\
\hline
\end{tabular}

${ }^{a}$ Estimado a partir do valor de $\varepsilon(380 \mathrm{~nm})=2,13 \times 10^{4} \mathrm{~L} \mathrm{~mol}^{-1} \mathrm{~cm}^{-1}$ da NDI-py.

${ }^{b}$ Atribuído como termo fundamental, sua energia é zero por ser a referência.

A partir da discussão anterior, foi possível montar um esquema qualitativo dos desdobramentos dos termos de Russell-Saunders para o MOF-CoNDI-py-2, que se encontra na Figura 3.34. Optou-se por utilizar a escala de energia em elétrons-volt $(\mathrm{eV})$ por ser a escala mais usual para descrever níveis de energia.

Apesar de a construção de um diagrama com os níveis de energia do MOF-CoNDI-py-2 ser muito importante para a caracterização espectroscópica, ainda é delicada a atribuição de um band-gap óptico ou eletrônico pela dificuldade em se determinar a natureza dos orbitais HOMO, se têm maior característica 


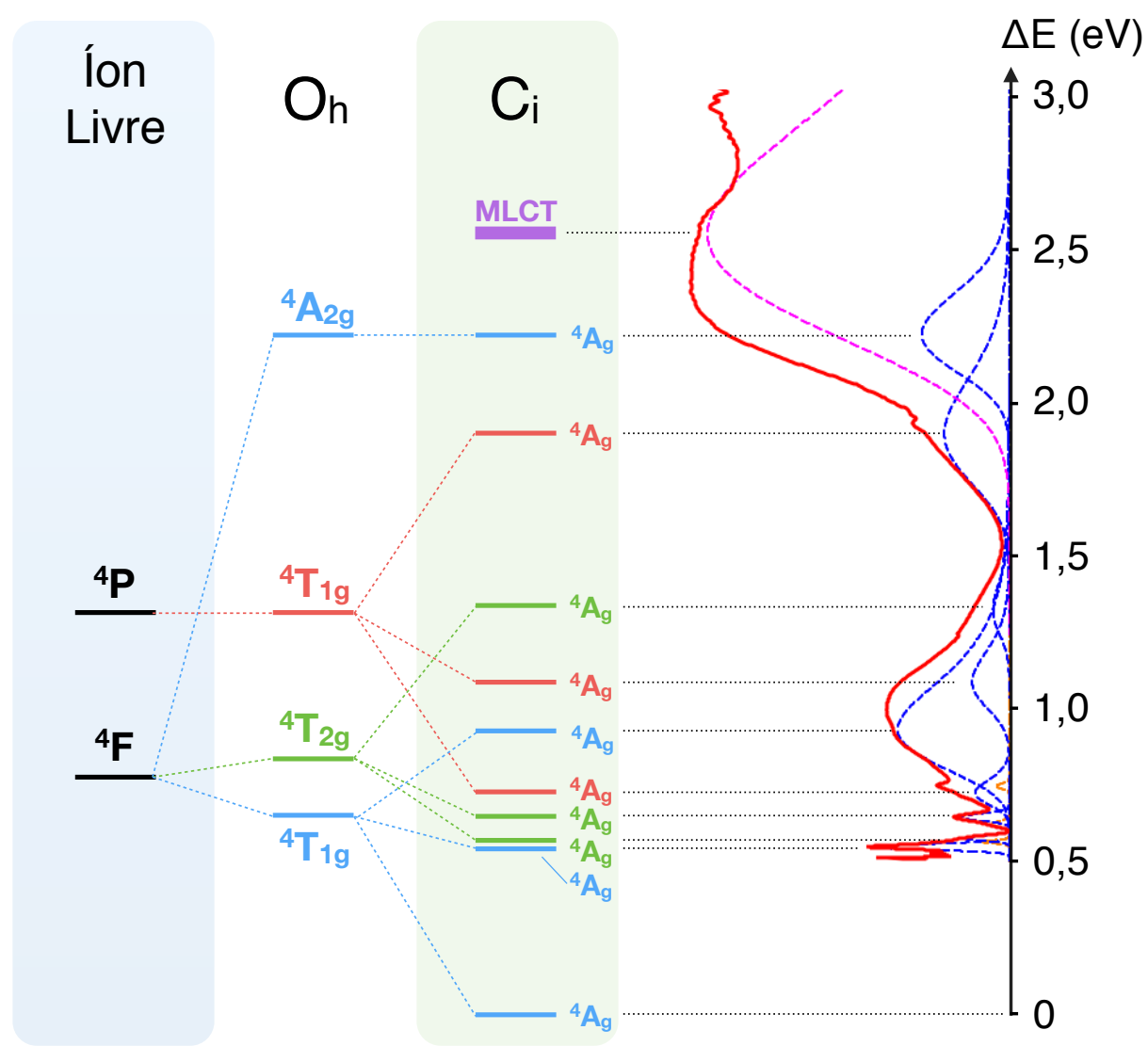

Figura 3.34: Esquema de desdobramento dos termos espectroscópicos do íon Co(II) nas formas (i) livre, (ii) em um campo octaédrico $\left(\mathrm{O}_{h}\right)$ e (iii) em campo de simetria $\mathrm{C}_{i}$ como na estrutura do MOF-CoNDI-py-2; e sua correlação com o espectro experimental de reflectância difusa no Vis-NIR. Os níveis de energia no campo $\mathrm{O}_{h}$ e no íon livre não estão na escala de energia.

dos centros metálicos ou da NDI-py. Se considerarmos que as transições $d-d$ são mais internas, isto é, são de orbitais abaixo do HOMO, e que a transição para os orbitais de fronteira seja a transição da NDI-py, estima-se um band-gap óptico de $\mathrm{E}_{g}=2,6 \mathrm{eV}$, a partir do mesmo tratamento do limite de banda da NDI-py. Dessa forma, inferimos que, com essas considerações, $\mathrm{HOMO}=-6,52 \mathrm{eV}$. O valor do LUMO, determinado previamente, foi de $-3,92 \mathrm{eV}$. 
§ 3.3.9. Fluorescência e tempo de vida emissão - Os cristais do MOF-CoNDI-py-2 são fracamente fluorescentes e apresentam um perfil característico da emissão da NDI-py, com um deslocamento hipsocrômico de cerca de 15 nm. Como pode ser visto na Figura 3.35, as fendas de excitação (FX) e de emissão (FM) do fluorímetro tiveram de ser significativamente ajustadas para que a intensidade da emissão do MOF-CoNDI-py-2 fosse da mesma ordem de grandeza da NDI-py no estado sólido.

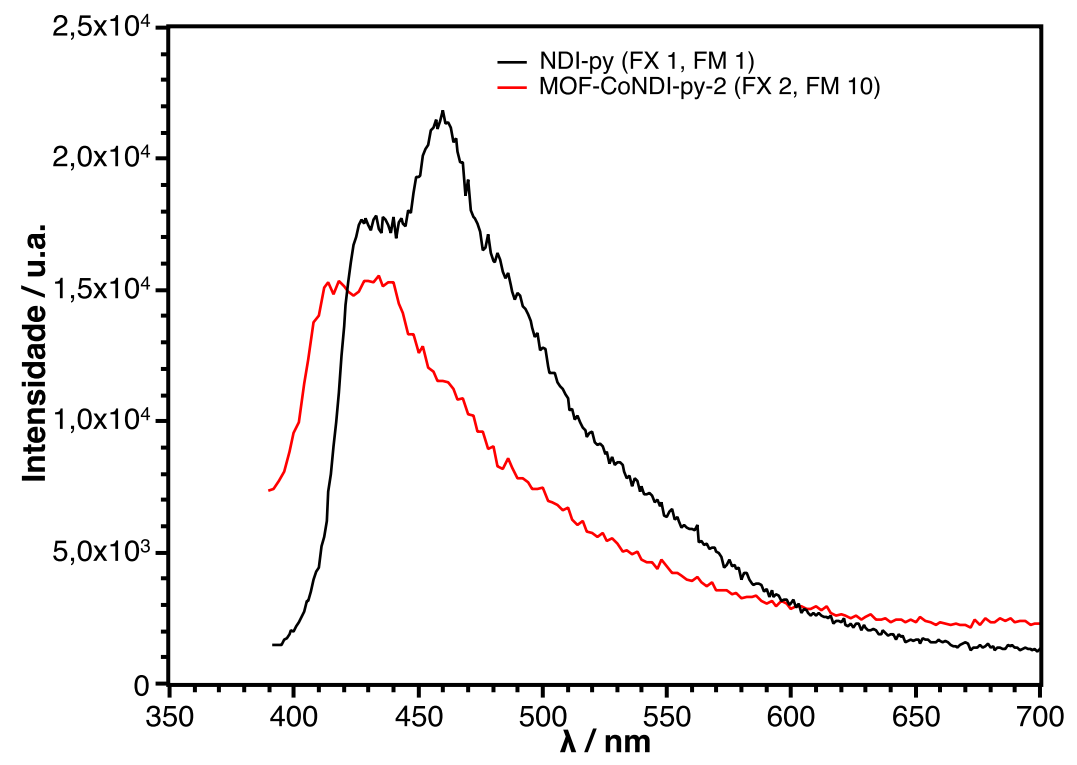

Figura 3.35: Espectros de emissão do MOF-CoNDI-py-2 e da NDI-py no estado sólido com $\lambda_{e x}=360 \mathrm{~nm}$, em temperatura ambiente.

A diferença entre as intensidades de emissão dos dois compostos é atribuída ao efeito do átomo pesado ${ }^{104}$, que consiste na promoção de cruzamento intersistemas através de acoplamentos spin-órbita com o átomo de Co(II) coordenado. Além do deslocamento do máximo de emissão para maiores energias, o espectro do MOF apresenta uma diferença relativa entre as intensidades das componentes. $\mathrm{O}$ espectro de emissão é composto por três ou mais bandas de origem vibrônica e, naturalmente, espera-se que estas intensidades sejam afetadas quando a NDI-py se encontra coordenada na estrutura do MOF. Além disso, o tempo de vida de emissão sofre uma significativa diminuição, como pode ser observado na Figura 3.36.

As curvas foram ajustadas com decaimentos exponenciais de segunda ordem, segundo a Equação 3.6. Os parâmetros matemáticos do ajuste estão resumidos na Tabela 3.10. Os tempos de vida de emissão observados são bastante curtos, como já observado para outras naftaleno diimidas ${ }^{35}$. Isso é atribuído a um rápido cruzamento intersistemas a partir do estado singleto excitado.

$$
y=y_{0}+A_{1} e^{-x / t_{1}}+A_{2} e^{-x / t_{2}}
$$




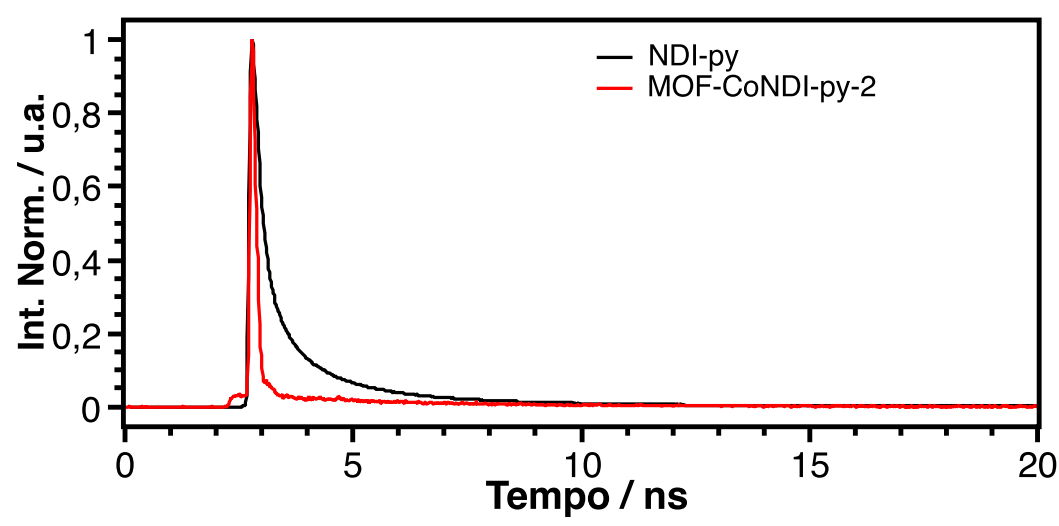

Figura 3.36: Tempos de vida de emissão $(\lambda>405 \mathrm{~nm})$ da NDI-py e MOF-CoNDI-py-2 no estado sólido.

Tabela 3.10: Parâmetros matemáticos do ajuste de decaimento exponencial para os tempos de vida da NDI-py e MOF-CoNDIpy-2 no estado sólido.

\begin{tabular}{ccccccc}
\hline Composto & $\mathbf{A}_{1}$ (u.a.) & $\tau_{1}$ (ns) & $\mathbf{A}_{2}$ (u.a.) & $\tau_{2}$ (ns) & $y_{0}$ (u.a.) & $\mathbf{R}^{2}$ \\
\hline NDI-py & $1,03 \times 10^{6}$ & 0,24 & 1,16 & 1,78 & $9,15 \times 10^{-4}$ & 0,9986 \\
MOF-CoNDI-py-2 & $3,44 \times 10^{14}$ & 0,084 & 0,074 & 3,39 & $6,82 \times 10^{-4}$ & 0,9929 \\
\hline
\end{tabular}

O que se conclui das análises de emissão e tempo de vida é que a emissão da NDI-py sofre um deslocamento hipsocrômico de $15 \mathrm{~nm}$ concomitantemente a uma diminuição tanto na intensidade quanto no tempo de vida de emissão, atribuídos ao efeito da coordenação ao centro metálico de Co(II), que promove um cruzamento intersistemas através de acoplamento spin-órbita. 
§ 3.3.10. Dispositivos eletrônicos - Para determinar as características eletrônicas do MOF-CoNDIpy-2, fabricou-se dispositivos eletrônicos para permitir medidas diretas de corrente versus voltagem (I-V). Como esses dispositivos foram construídos utilizando monocristais do composto, também foi possível analisar o efeito de anisotropia de condução eletrônica, como será discutido a seguir.

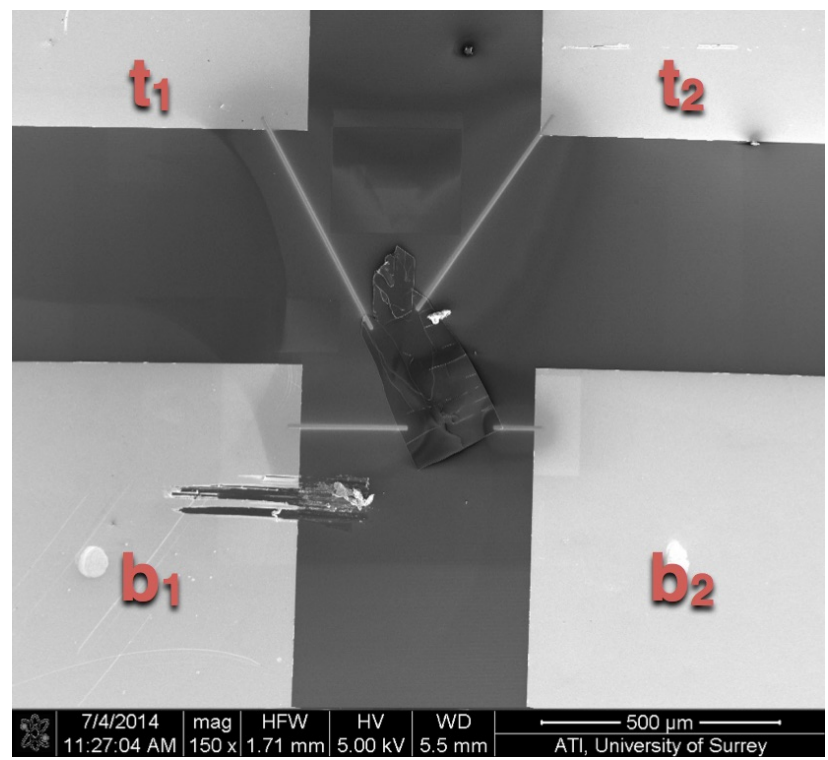

Figura 3.37: Dispositivo eletrônico contendo um cristal do MOF-CoNDI-py-2 conectado a contatos de Au através de eletrodos de $\mathrm{Pt}$, sobre um substrato de $\mathrm{Si} / \mathrm{SiO}_{2}$.

A condutividade elétrica do MOF-CoNDI-py-2 foi determinada utilizando o dispositivo eletrônico mostrado na Figura 3.37. Esse arranjo de quatro pontos foi escolhido pois ele permite a determinação da anisotropia de condutividade elétrica do MOF-CoNDI-py-2, de forma que as medidas foram realizadas em combinações de dois a dois pontos, e as medidas foram normalizadas pela distância entre os dois pontos, como pode ser visto na Figura 3.38.

As curvas de corrente versus voltagem obtidas são sigmoidais, típico de materiais semicondutores. A histerese de condutividade, isto é, a não concordância entre os valores de corrente entre as varreduras nos dois sentidos, é quase imperceptível, o que indica que ocorre pouco aprisionamento de cargas, seja por eventuais defeitos estruturais ou impedimentos energéticos. Além disso, conforme esperado, o cristal apresenta uma significativa anisotropia de condutividade, concluído a partir das diferenças de máximos, mínimos e perfis das curvas I-V para os diferentes pontos de conexão. Para exemplificar, se o cristal fosse isotrópico em termos de condutividade elétrica, isto é, a condutividade fosse independente da direção da medida, todas as curvas I-V para os diferentes pontos de conexão seriam idênticas ou ao menos muito similares. Uma característica importante das curvas medidas é que todas aquelas que envolvem o ponto $\mathbf{b}_{1}$ possuem valores de densidade de corrente $\mathrm{J}$ - equivalente à corrente sobre a distância, $i / d$ - muito inferiores às demais, como se o cristal se comportasse como um isolante nessa direção. 


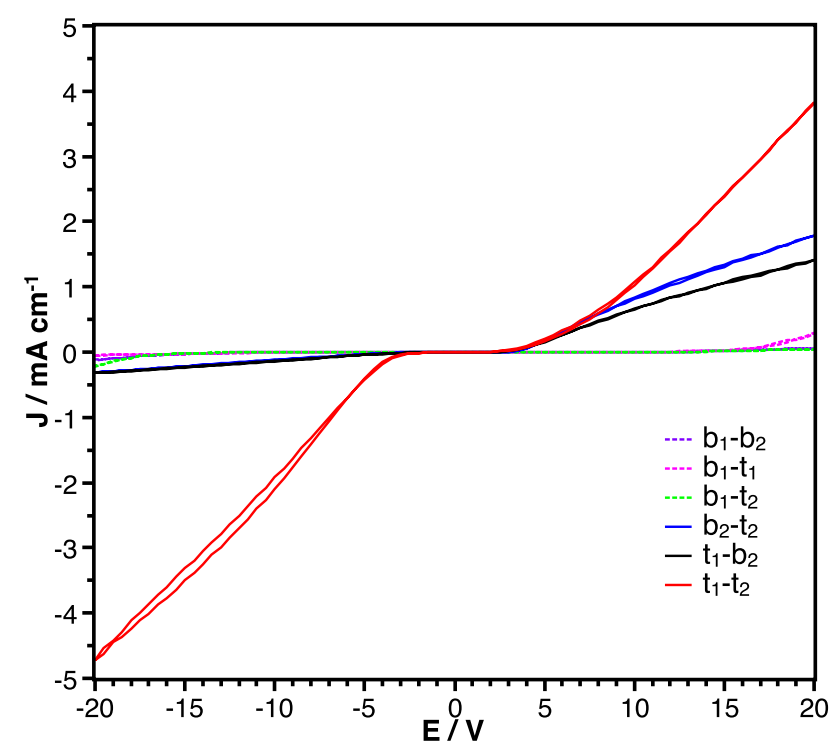

(a) Medidas I-V para o MOF-CoNDI-py-2.

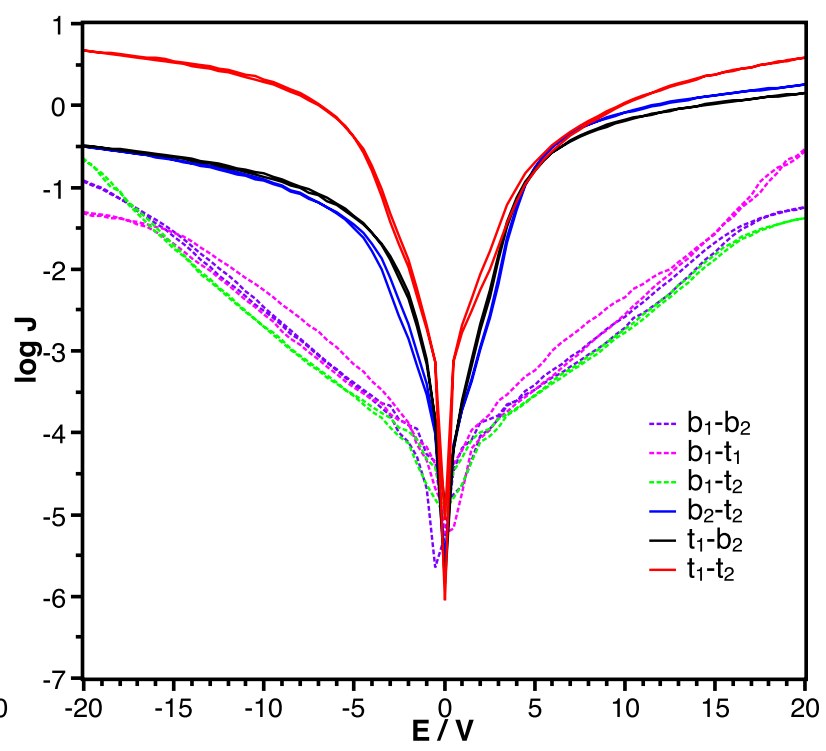

(b) log J, para melhor visualização.

Figura 3.38: Medidas I-V de um cristal de MOF-CoNDI-py-2 conectado a contatos de Au através de eletrodos de Pt sobre um substrato de $\mathrm{Si} / \mathrm{SiO}_{2}$.

Isso não é necessariamente verdade uma vez que o cristal apresenta valores de densidade de corrente consideráveis a partir de $10 \mathrm{~V}$. Interpreta-se esse resultado não como um comportamento isolante e sim como um diferente mecanismo de condução. Por garantia, todos os contatos foram avaliados novamente no microscópio eletrônico e os eletrodos de Pt foram reforçados para garantir que existam bons contatos elétricos entre os eletrodos de platina e o cristal do MOF, principalmente através do contato $\mathbf{b}_{1}$, e as curvas na Figura 3.38 são dos dispositivos com contatos reforçados. Os parâmetros de área de contato e distância entre os diferentes contatos estão resumidos na Tabela 3.11.

Tabela 3.11: Parâmetros obtidos dos dispositivos eletrônicos do MOF-CoNDI-py-2.

\begin{tabular}{ccl}
\hline Contatos & Área $\left(\mu \mathbf{m}^{2}\right)$ & Distância $(\mu \mathrm{m})$ \\
\hline & & $\mathrm{b}_{1}-\mathrm{b}_{2}: 270$ \\
$\mathrm{~b}_{1}$ & 147 & $\mathrm{~b}_{1}-\mathrm{t}_{1}: 314$ \\
& & $\mathrm{~b}_{1}-\mathrm{t}_{2}: 362$ \\
& 137 & $\mathrm{~b}_{2}-\mathrm{t}_{1}: 485$ \\
$\mathrm{~b}_{2}$ & $\mathrm{~b}_{2}-\mathrm{t}_{2}: 430$ \\
$\mathrm{t}_{1}$ & 238 & $\mathrm{t}_{1}-\mathrm{t}_{2}: 148$ \\
$\mathrm{t}_{2}$ & 248 & \\
\hline
\end{tabular}

Para efeitos de comparação, determinou-se a condutividade $(\sigma)$ do MOF-CoNDI-py-2 em uma das direções, $\mathbf{t}_{1}-\mathbf{t}_{2}$. Assumindo uma resistência que segue a Lei de Ohm, $V=R i$, determinou-se a resistividade média através da equação $\rho=\operatorname{RAd}^{-1}-\operatorname{com} \mathrm{R}$ igual à resistência média, $\mathrm{A}$ a área média dos contatos e d a distância entre eles - e, por se tratar de uma curva sigmoidal, descartou-se os valores do platô, entre $-5 \vee$ e $+5 \mathrm{~V}$. A condutividade, $\sigma=\rho^{-1}$, foi de $7,9 \times 10^{-3} \mathrm{~S} \mathrm{~cm}^{-1}$. Este valor é cerca de $10^{3}$ vezes maior que os reportados pelo grupo de DINCĂ. ${ }^{20}$ 
Também foi investigada a fotoatividade do MOF frente a uma fonte de luz branca (LED branco, $2 \mathrm{~mW}$ ) e um laser vermelho (632 nm, $5 \mathrm{~mW}$ ). Para isso, escolheu-se a direção de medida com a maior distância entre os contatos, evitando o contato $\mathbf{b}_{1} \mathbf{e}$, portanto, escolheu-se a direção $\mathbf{b}_{2}-\mathbf{t}_{1}$. Os gráficos de corrente vs voltagem obtidos são mostrados na Figura 3.39.
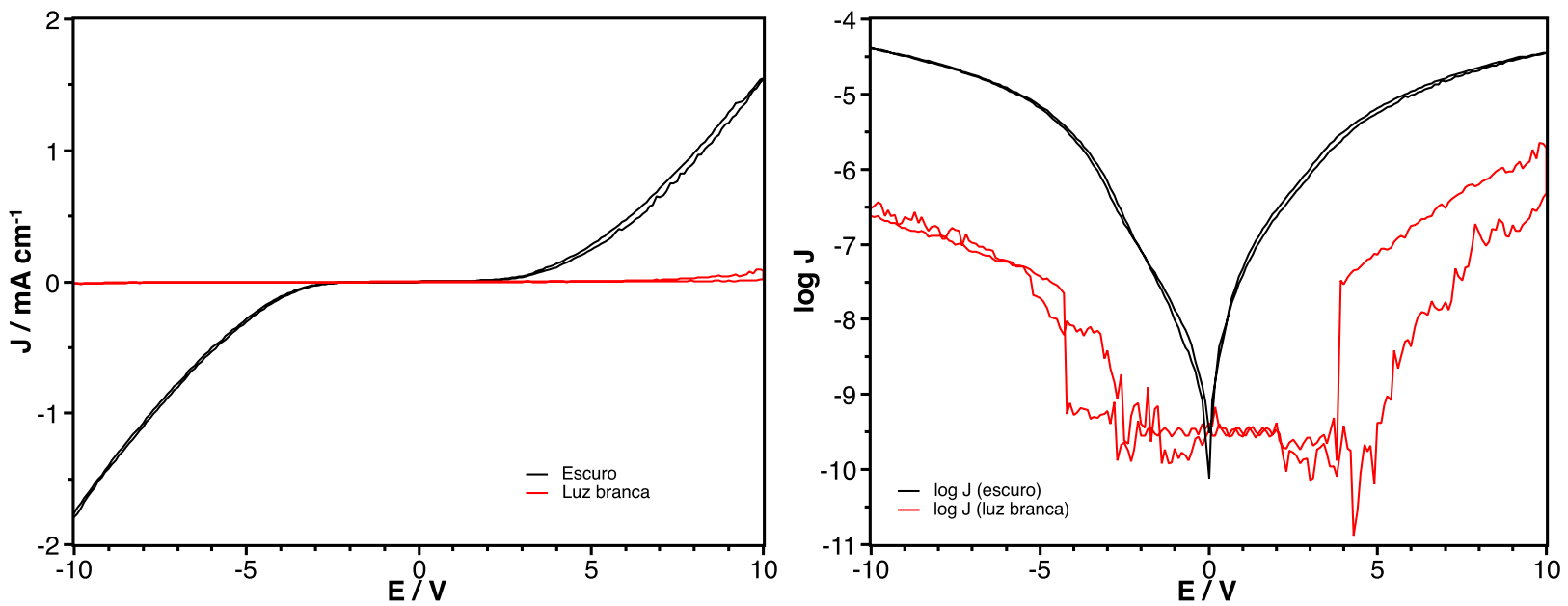

(a) Luz branca.
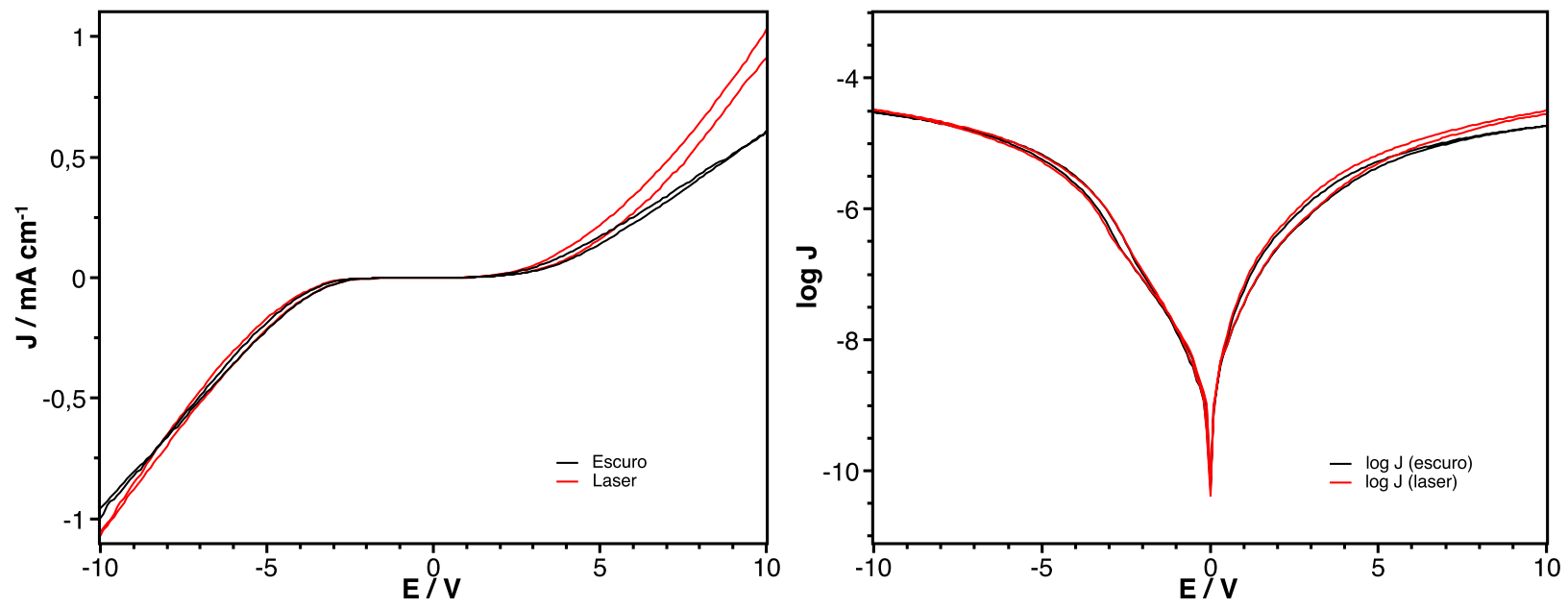

(b) Laser vermelho (632 nm).

Figura 3.39: Medidas I-V do dispositivo contendo um cristal do MOF-CoNDI-py-2 sob diferentes tipos de iluminação.

Como pode ser visto na Figura 3.39a, o cristal do MOF se torna fotorresistivo e sua condutividade diminui para praticamente zero, quando iluminado por uma fonte de luz branca. A origem desse fenômeno é atribuída ao fato de que a fonte de luz branca excita a amostra com fótons dentro de intervalo grande de energias, incluindo a banda atribuída à transferência de carga metal-ligante. Essa atribuição de banda é um contrassenso a esta observação de fotoatividade. Acredita-se que a condutividade elétrica do MOF seja uma característica proveniente do ligante NDI-py, que é um material semicondutor conhecido. Se o material é excitado em uma banda de transferência de carga que são deslocadas do centro metálico ao ligante condutor (MLCT), seria razoável esperar que a condutividade aumentasse. Em contrapartida, 
a observação experimental com a fonte de luz branca sugere que a atribuição da banda seja errônea, e que esta se trata, possivelmente de uma transferência de carga ligante-metal (LMCT), que seria o deslocamento de carga do ligante condutor ao centro metálico. Essa atribuição LMCT é compatível com essa diminuição pois ela leva a uma supressão ou aprisionamento de cargas, resultando em diminuição da condutividade global. A descrição completa da transição seria ${ }^{1} \mathrm{~A}_{u}(\mathrm{HOMO}, \mathrm{NDI}-\mathrm{py}) \rightarrow{ }^{4} \mathrm{~A}_{g}(\mathrm{~d}, \mathrm{Co})$, permitida por paridade.

No caso da excitação com laser vermelho, o comportamento é oposto: apesar de sutil, existe um aumento na condutividade do material. Essa fonte de luz emite fótons de energia significativamente distante da banda de transferência de carga, centrada em $490 \mathrm{~nm}$. É importante salientar, entretanto, que através da desconvolução gaussiana observa-se que essa banda de transferência de carga possui contribuições em $632 \mathrm{~nm}$, porém a absortividade nesse comprimento de onda é de apenas 2,5\% relativo ao máximo desta banda, como pode ser visto na Figura 3.40. Dessa forma, apesar do comportamento competitivo entre as duas transições, o efeito de ativação sobrepuja a desativação da transferência de carga.

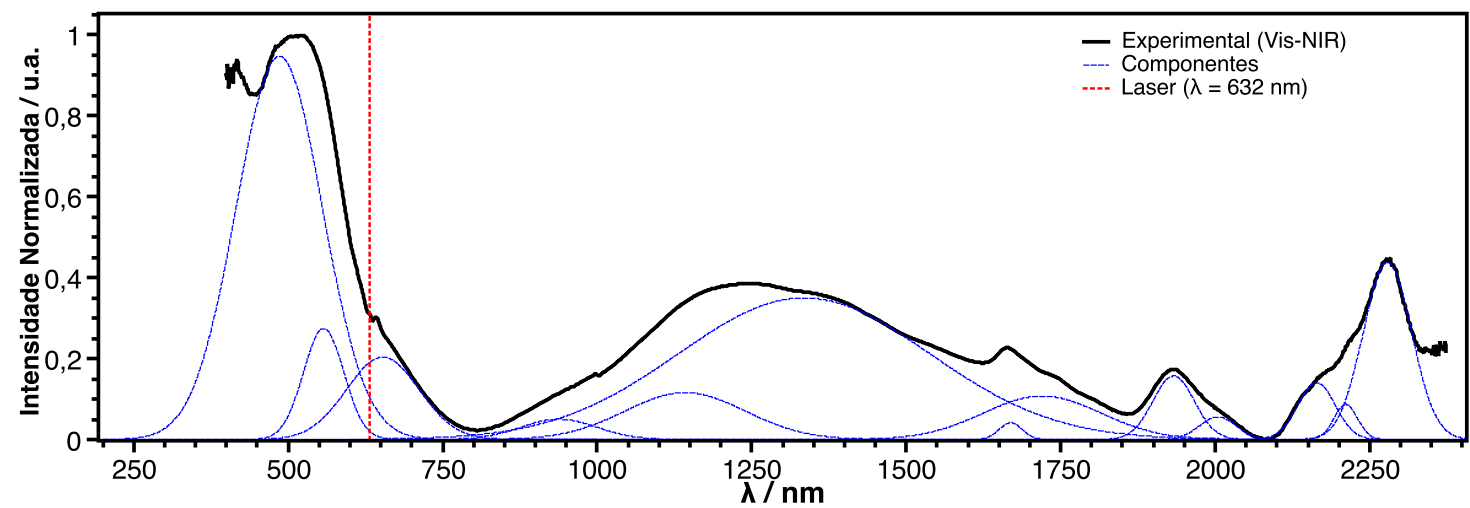

Figura 3.40: Espectro de reflectância difusa na região do Vis-NIR com desconvolução para o MOF-CoNDI-py-2 e posição do laser vermelho utilizado.

Para extrair informações quantitativas das medidas de corrente versus voltagem, as curvas foram ajustadas de acordo com diferentes modelos de mecanismos de condutividade, com mecanismos limitados pelo eletrodo - Schottky e Space-Charge Limited Current (SCLC) - e mecanismos limitados pelo material — Poole-Frenkel (PF) e Fowler-Nordheim (FN $)^{106}$. Os ajustes foram feitos em colaboração com o Dr. Chris Mills, da University of Surrey. É possível eliminar sumariamente os mecanismos de Schottky e PF uma vez que estes requerem campos elétricos muito elevados, da ordem de $10^{5} \mathrm{~V} \mathrm{~cm}^{-1}$. O mecanismo de SCLC acontece quando a mobilidade de um portador de carga (elétrons ou buracos) é muito maior que o outro, causando um desequilíbrio de cargas e limitando a condutividade. O mecanismo FN é essencialmente o tunelamento de elétrons através de uma barreira de potencial favorecida por um 


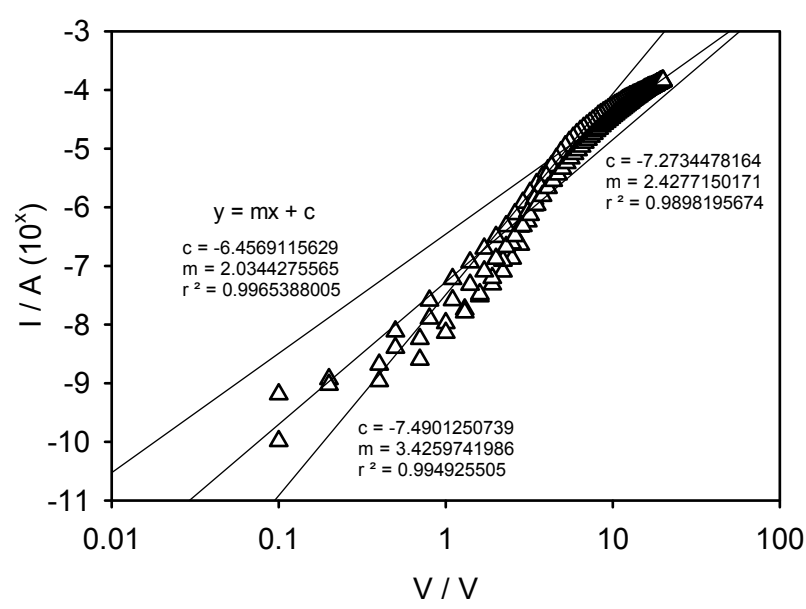

(a) $\mathbf{b}_{2} \mathbf{t}_{1}$, SCLC.

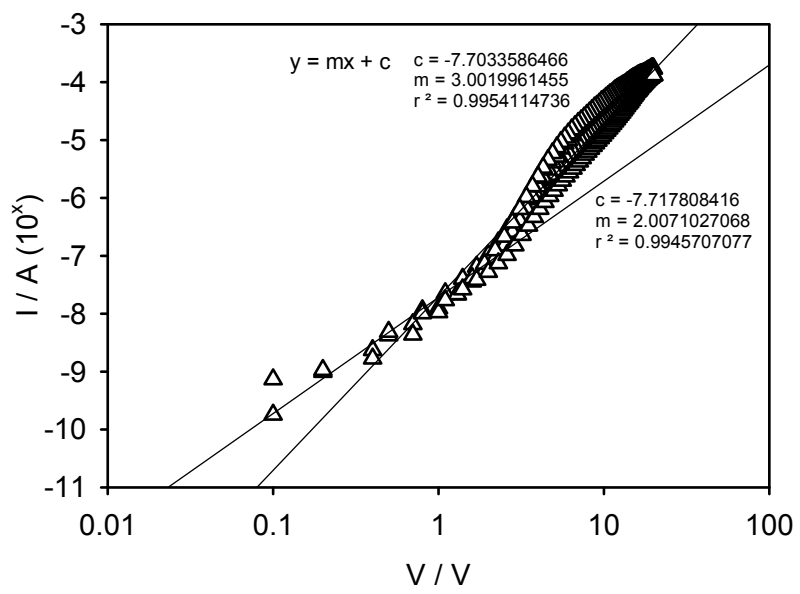

(c) $\mathbf{b}_{2} \mathbf{t}_{2}$, SCLC.

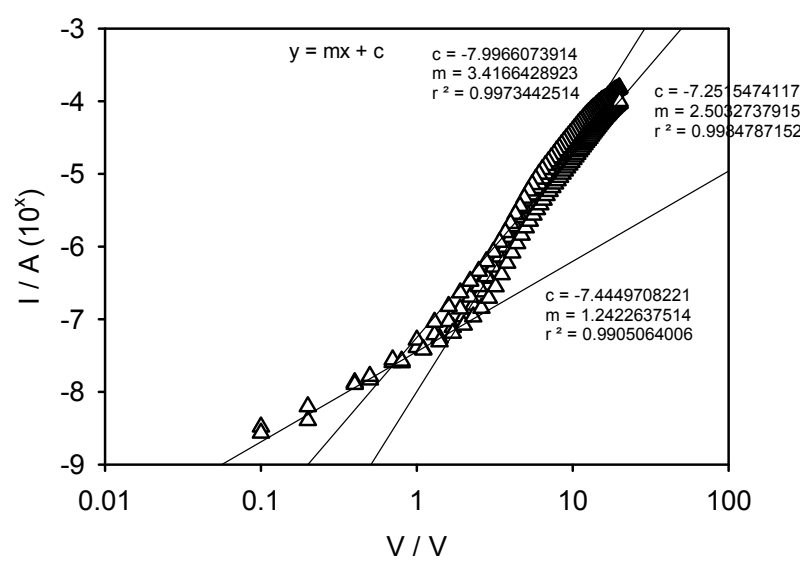

(e) $\mathbf{t}_{1} \mathbf{t}_{2}$, SCLC.

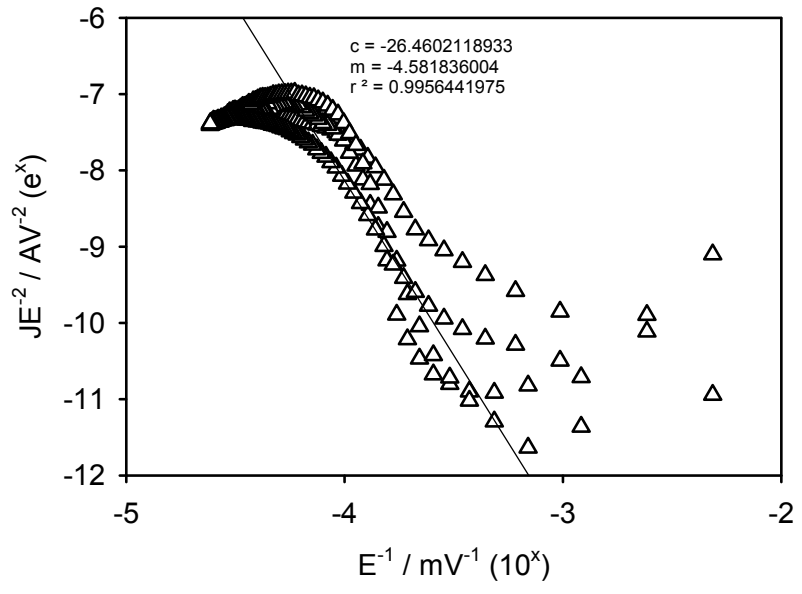

(b) $\mathbf{b}_{2} \mathbf{t}_{1}, \mathrm{FN}$.

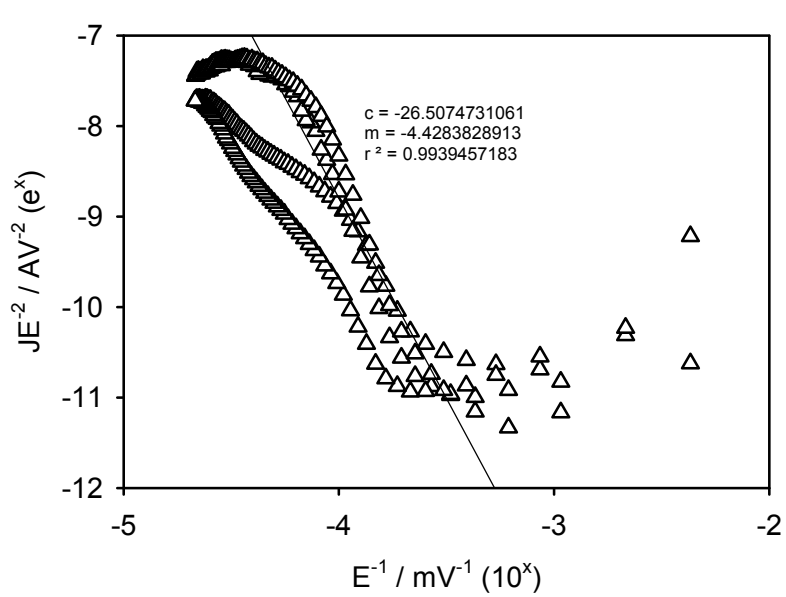

(d) $\mathbf{b}_{2} \mathbf{t}_{2}, \mathrm{FN}$.

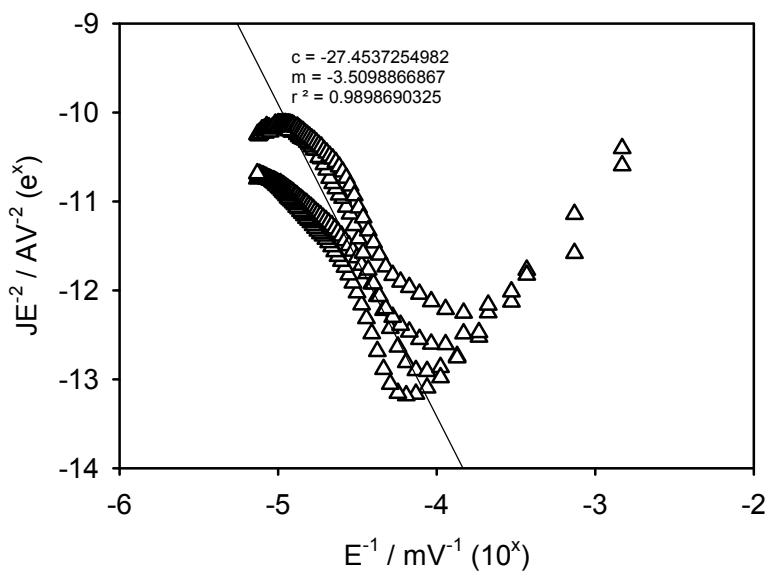

(f) $t_{1} t_{2}, F N$.

Figura 3.41: Ajustes de Space-Charge Limited Current (SCLC) e Fowler-Nordheim (FN) para os contatos $\mathbf{b}_{2}$, $\mathbf{t}_{1}$ e $\mathbf{t}_{2}$. 


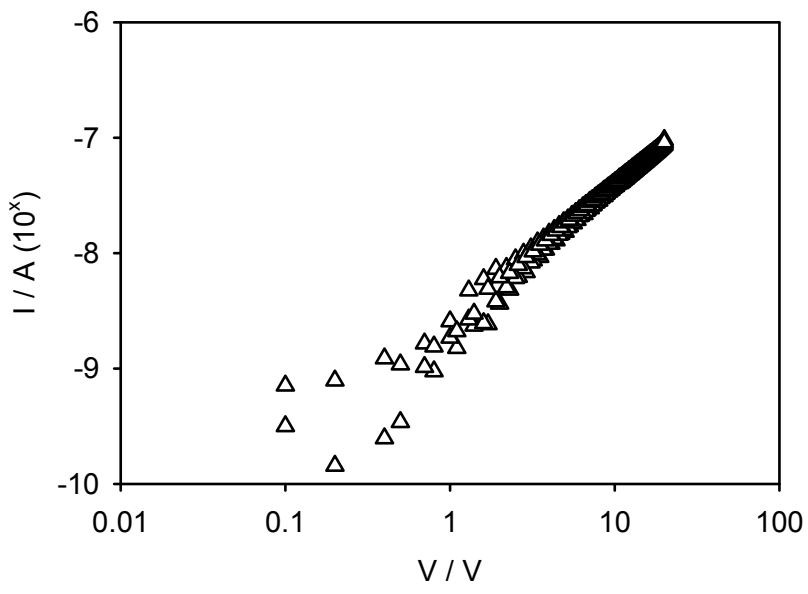

(a) $\mathbf{b}_{1} \mathbf{b}_{2}$, SCLC.

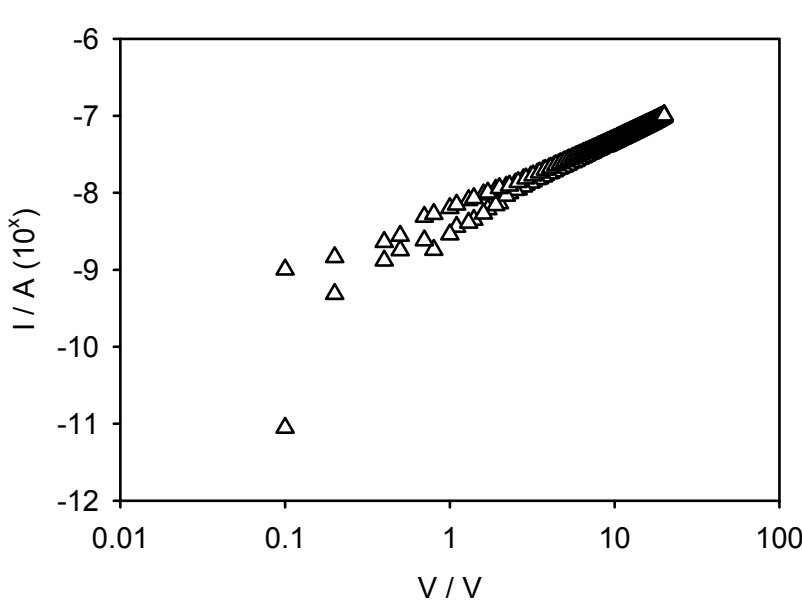

(c) $\mathbf{b}_{1} \mathbf{t}_{1}$, SCLC.

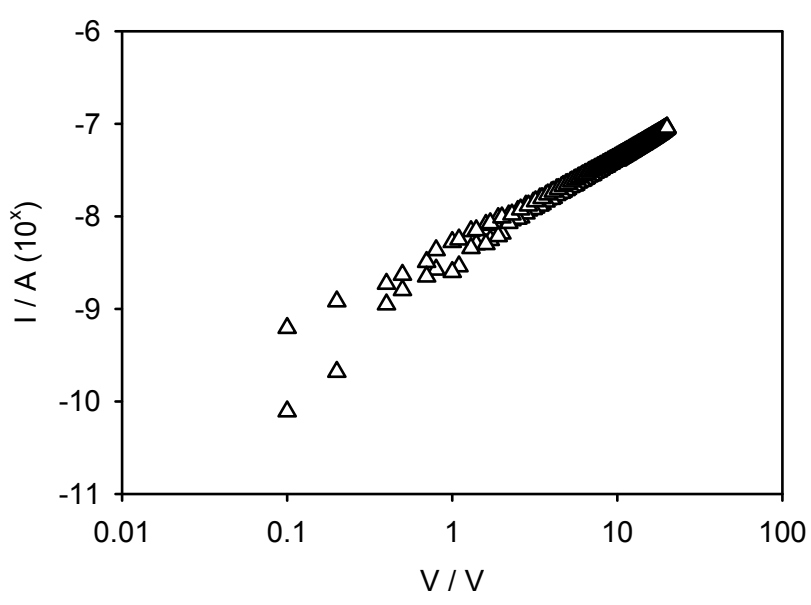

(e) $\mathbf{b}_{1} \mathbf{t}_{2}$, SCLC.

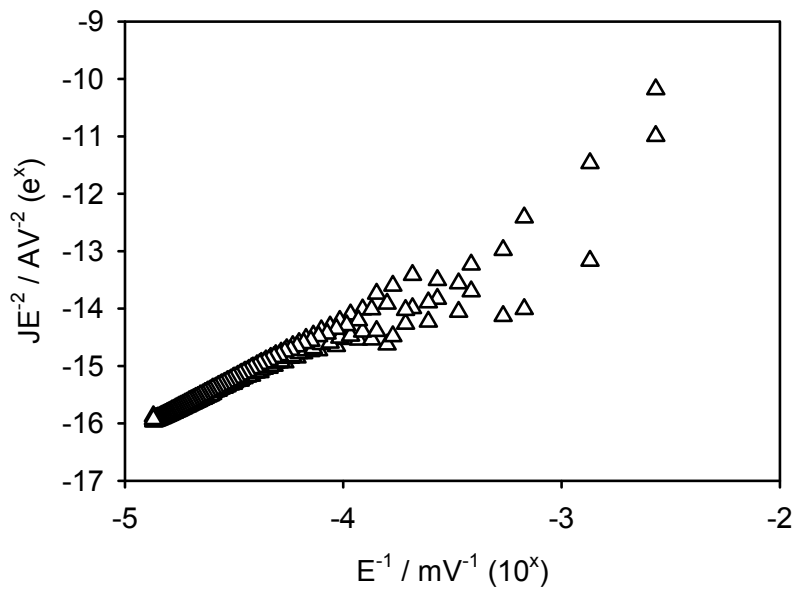

(b) $\mathbf{b}_{1} \mathbf{b}_{2}, \mathrm{FN}$.

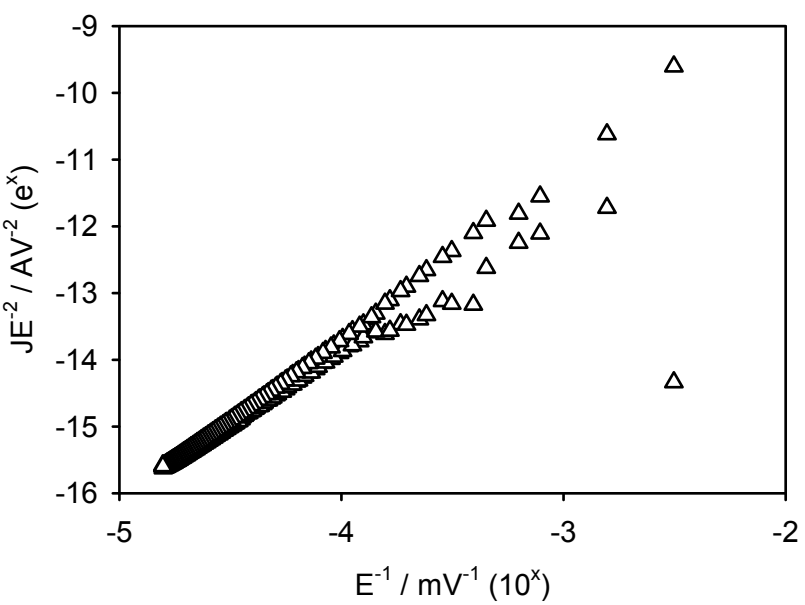

(d) $\mathbf{b}_{1} \mathbf{t}_{1}, \mathrm{FN}$.

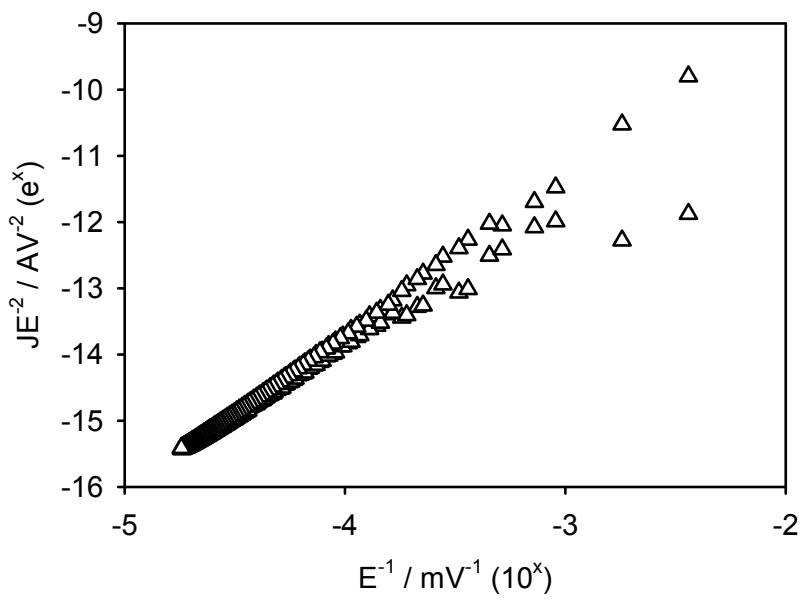

(f) $\mathbf{b}_{1} \mathbf{t}_{2}, \mathrm{FN}$.

Figura 3.42: Ajustes de Space-Charge Limited Current (SCLC) e Fowler-Nordheim (FN) para os contatos $\mathbf{b}_{1}, \mathbf{b}_{2}, \mathbf{t}_{1}$ e $\mathbf{t}_{2}$. 
elevado campo elétrico. Os dados ajustados nesses mecanismos podem ser encontrados na Figura 3.41 e na Figura 3.42.

A partir dos ajustes para o mecanismo de SCLC, o comportamento está dentro do esperado. A inclinação da reta começa em $n \approx 2$, aumenta até $n>2$ e cai novamente a $n \approx 2$. Isso corrobora que ocorra o mecanismo de SCLC e, consequentemente, que a condutividade seja limitada pelo eletrodo e não pelo material. Por outro lado, os ajustes para o mecanismo FN são similarmente bons, com alturas de barreira energética com valores entre $0,64 \mathrm{meV}$ e 0,77 meV. Pela qualidade dos ajustes e pela plausabilidade da ocorrência de ambos mecanismos, é difícil decidir se ocorre um único mecanismo ou uma combinação dos dois. Julgando pelos valores de barreira de energia para o mecanismo de FN, que são razoavelmente pequenas, acredita-se que o mecanismo SCLC seja o que descreve melhor o mecanismo de condutividade do MOF-CoNDI-py-2. Além da melhor adaptação dos parâmetros matemáticos, o mecanismo de SCLC é bastante compatível com a natureza eletrônica do MOF-CoNDI-py-2, tido como um semicondutor do tipo $n$, que possui mobilidade de carga preferencial para elétrons, uma característica proveniente do ligante NDI-py. 


\section{Conclusões e Perspectivas}

finalização desta tese não foi uma tarefa trivial. O design de um MOF que possuísse proprieda-
des de condutividade elétrica e fotossensibilidade, características atualmente raras nesta classe de compostos, necessitou de inúmeras tentativas de rotas sintéticas, com variações sistemáticas de parâmetros como concentração, proporção, temperatura, tempo de síntese e rampas de aquecimento. A solução da estrutura de monocristal, que possui seus próprios desafios, bem como uma completa caracterização estrutural, espectroscópica e eletrônica, com correlações com as propriedades dos elementos individuais - como o ligante isolado ou o centro metálico escolhido - necessitou de um grande número de colaborações, nacionais e internacionais, como demonstrado ao longo do texto.

Para a síntese dos polímeros de coordenação, o ligante escolhido foi a N,N'-bis(4-piridil)-1,4,5,8naftaleno diimida, ou NDI-py, que já foi utilizada para a produção de MOFs que apresentam estrutura porosa e atividade redox. Apesar de não ser um composto inédito, as caracterizações da NDI-py disponíveis na literatura são poucas e superficiais, e, nesta tese, esta diimida foi extensivamente e profundamente estudada com análises estruturais, espectroscópicas e eletroquímicas, além de contar com o suporte de cálculos teóricos em nível de DFT. Este ligante apresentou espectros de absorção, emissão e voltamogramas cíclicos típicos de naftaleno diimidas, e uma atribuição completa das transições eletrônicas e vibracionais foi realizada.

O centro metálico de escolha para a síntese do MOF foi o íon cobalto(II) por conta de suas propriedades magnéticas e espectroscópicas conhecidas. O composto concebido, chamado de MOF-CoNDI-py-2, une os centros de cobalto(II) à NDI-py através de íons tereftalatos, que agem como ligantes suporte, formando uma rede altamente organizada, pertencente ao sistema monoclínico e grupo espacial C2/c, em uma síntese que rende uma extensiva quantidade de cristais grandes. A estrutura de monocristal deste composto foi resolvida em parceria com o Prof. Richard I. Walton e o Dr. Guy Clarkson, da University of Warwick no Reino Unido, e, nesta estrutura inédita, as moléculas de NDI-py se encontram em 
posições e distâncias apropriadas para que haja transferência eletrônica entre as unidades. O estado de oxidação dos centros metálicos foi confirmado como cobalto(II) através do Método de Ligação-Valência e por Ressonância Paramagnética Eletrônica. Os cristais do MOF-CoNDI-py-2 apresentaram atividade redox, como esperado, apresentando processos reversíveis de redução atribuídos ao ligante NDI-py, em potenciais bastante próximos do ligante livre, e reduções dos centros metálicos. O composto também foi analisado por espectroscopia na região do infravermelho e, com a ajuda de cálculos teóricos em nível de DFT, desenvolveu-se uma atribuição detalhada das bandas observadas tanto para o MOF quanto para a NDI-py. Um tratamento semelhante foi feito para as transições eletrônicas observadas no espectro de reflectância difusa, relacionando geometrias e simetrias de coordenação com a distorção do campo ligante $\mathrm{O}_{h}$ para um íon $\mathrm{d}^{7}$ em situações de simetria abaixada, no caso para $C_{i}$. A correlação entre os desdobramentos dos termos de Russell-Saunders neste caso foi bastante satisfatória e permitiu estimar os coeficientes de absortividade molar do MOF a partir das determinações para a NDI-py em solução, que por sua vez possibilitou um maior entendimento das naturezas das ligações Co(II)-NDI-py e Co(II)TpA, que apresentam acentuada deslocalização por conta do maior caráter $p$ dos orbitais moleculares resultantes.

Os dispositivos eletrônicos fabricados para a caracterização da condutividade eletrônica do MOFCoNDI-py-2 é o primeiro do tipo, até onde se sabe, por aferir diretamente a condutividade de um monocristal de um MOF semicondutor. Além disso, o MOF-CoNDI-py-2 é único que se conhece a apresentar este comportamento de semicondutor intrínseco do tipo $n$ com elevada condutividade, similar a outros materiais comumente empregados, como $\mathrm{p}$-Si. A condutividade dos cristais apresentou elevada anisotropia, condizente com a estrutura apresentada onde se atribui a condutividade ao ligante NDI-py. Ademais, os cristais demonstraram fotorrespostas adversas dependendo da fonte de luz empregada, tornando-se levemente mais condutores com um laser vermelho $(632 \mathrm{~nm})$ e fotorresistivos com um LED branco. Além da inédita condutividade, este tipo de comportamento fotorresistivo não é comum em materiais e muito menos em MOFs. As curvas de condutividade obtidas também foram relacionadas à quatro mecanismos majoritários de condutividade: os limitados pelo material, Poole-Frenkel e Fowler-Nordheim; e os limitados pelos contatos, Schottky e Space-Charge Limited Current. Os melhores mecanismos a descrever o sistema são Fowler-Nordheim, que trata essencialmente do tunelamento de cargas, e Space-Charge Limited Current, condizente com o mecanismo de condução preferencial de apenas um portador de cargas.

O material aqui sintetizado e caracterizado apresenta características muito promissoras para aplicações nos campos mais variados, que envolvam materiais que apresentem semicondução, estrutura 
híbrida orgânica-inorgânica, fotorresposta de condução, luminescência, absorção de luz na região do UV, Vis ou NIR. Acredita-se que este trabalho tenha contribuído para o desenvolvimento de novos materiais para dispositivos optoeletrônicos. Estudos futuros para este material envolvem a determinação de um espectro de fotoação completo, através da medida da condutividade elétrica frente a um feixe de luz monocromática e correlação com as transições eletrônicas observadas nos espectros de absorção de luz. Outras caracterizações envolvem a determinação da influência de um campo magnético externo nas propriedades ópticas e elétricas, esperados por conta da conhecida atividade paramagnética dos íons Co(II). Pretende-se estudar e explorar a área superficial deste MOF para aplicações em eletrocatálise. Além disso, pode-se estudar a influência da adsorção seletiva de gases ou inclusão de outras moléculas hospedeiras na rede do MOF-CoNDI-py-2 e as influências nas propriedades optoeletrônicas. 


\section{Bibliografia}

1. S. Kitagawa, R. Kitaura e S. Noro, Angew. Chem. Int. Ed., 2004, 43, 2334-2375.

2. A. N. Khlobystov, A. J. Blake, N. R. Champness, D. A. Lemenovskii, A. G. Majouga, N. V. Zyk e M. Schroder, Coord. Chem. Rev, 2001, 222, 155-192.

3. H. Okamoto e M. Yamashita, Bull. Chem. Soc. Jpn., 1998, 71, 2023-2039.

4. K. Biradha e M. Fujita, J. Am. Chem. Soc. Dalton Trans., 2000, 3805-3810.

5. J. Lu, T. Paliwala, S. C. Lim, C. Yu, T. Niu e A. J. Jacobson, Inorg. Chem., 1997, 36, 923-929.

6. N. G. Pschirer, D. M. Ciurtin, M. D. Smith, U. H. F. Bunz e H.-C. Loye, Angew. Chem. Int. Ed., 2002, 41, 583-585.

7. Y. Cui, H. L. Ngo, P. S. White e W. Lin, Chem. Commun., 2002, 1666-1667.

8. J. S. Seo, D. Whang, H. Lee, S. I. Jun, J. Oh, Y. J. Jeon e K. Kim, Nature, 2000, 404, 982-986.

9. S. R. Batten, N. R. Champness, X.-M. Chen, J. G. Martinez, S. Kitagawa, L. Óhrström, M. O'Keeffe, M. P. Suh e J. Reedijk, Pure Appl. Chem., 2013, 85, 1715-1724.

10. K. A. Wanderley, S. A. Jr e C. O. Paiva-Santos, Quim. Nova, 2011, 34, 434-438.

11. N. Stock e S. Biswas, Chem. Rev., 2012, 112, 933-969.

12. X.-Y. Chen, B. Zhao, W. Shi, J. Xia, P. Cheng, D.-Z. Liao, S.-P. Yan e Z.-H. Jiang, Chem. Mater., 2005, 17, 28662874.

13. U. Mueller, M. Schuber, F. Teich, H. Puetter, K. SchierleArndt e J. Pastré, J. Mater. Chem., 2006, 16, 626-636.

14. J. Kulesza, B. S. Barros, I. M. V. Silva, G. Gentil e S. A. Jr, Cryst. Eng. Comm., 2013, 15, 8881-8882.

15. A. D. Burrows e L. L. Keenan, Cryst. Eng. Comm., 2012, 14, 4112-4114.

16. M. Wriedt, J. P. Sculley, A. A. Yokovenko, Y. Ma, G. J. Halder, P. B. Balbuena e H.-C. Zhou, Angew. Chem. Int. Ed., 2012, 51, 1-6.

17. K. L. Mulfort e J. T. Hupp, J. Am. Chem. Soc., 2007, 129, 9604-9605.

18. B.-Q. Ma, K. L. Mulfort e J. T. Hupp, Inorg. Chem., 2005, 44, 4912-4914.

19. L. Sun, T. Miyakai, S. Seki e M. Dinca, J. Am. Chem. Soc., 2013, 135, 8185-8188.

20. L. Sun, C. H. Hendon, M. A. Minier, A. Walsh e M. Dinca, J. Am. Chem. Soc., 2015, 137, 6164-6167.

21. K. M. Hutchins, T. P. Rupasinghe, L. R. Ditzler, D. C. Swenson, J. R. G. Sander, J. Baltrusaitis, A. V. Tivanski e L. R. MacGillivray, J. Am. Chem. Soc., 2014, 136, 67786781.

22. A. V. Vinogradov, H. Z. Hertling, E. H. Hawkins, A. V. Agafonov, G. A. Seisenbaeva, V. G. Kessler e V. V. Vinogra- dov, Chem. Commun., 2014, 50, 10210-10213.

23. L. L. Luz, B. F. L. Viana, G. C. O. da Silva, C. C. Gatto, A. M. Fontes, M. Malta, I. T. Weber, M. O. Rodrigues e S. A. Jr, Cryst. Eng. Comm., 2014, 16, 6914-6916.

24. S. V. Bhosale, C. H. Jani e S. J. Langford, Chem. Soc. Rev., 2008, 37, 331-342.

25. R. O. Marcon e S. Brochsztain, J. Phys. Chem. A, 2009, 113, 1747-1752.

26. P. K. Sukul, D. Asthana, P. Mukhopadhyay, D. Summa, L. Muccioli, C. Zannoni, D. Beljonne, A. E. Rowan e S. Malik, Chem. Commun., 2011, 47, 11858-11860.

27. S. Bhosale et al., Science, 2006, 313, 84-86.

28. C. Thalacker, C. Röger e F. Würthner, J. Org. Chem., 2006, 71, 8098-8105.

29. G. Andric et al., Aust. J. Chem., 2004, 57, 1011-1019.

30. M. A. Rodrigues, D. B. Tada, M. J. Politi, S. Brochsztain e M. S. Baptista, J. Non-Cryst. Solids, 2002, 304, 116-125.

31. T. C. Barros, S. Brochsztain, V. G. Toscano, P. B. Filho e M. J. Politi, J. Photoch. Photobio. A, 1997, 111, 97-104.

32. M. Sterzel, M. Pilch, M. T. Pawlikowski, P. Skowronek e J. Gawronski, Chem. Phys. Lett., 2002, 362, 243-248.

33. M. Sterzel, M. Andrzejak, M. T. Pawlikowski e J. Gawronski, Chem. Phys., 2004, 300, 93-105.

34. N. S. Kumar, M. D. Gujrati e J. N. Wilson, Chem. Commun., 2010, 46, 5464-5466.

35. S. Alp, S. Erten, C. Kanapire, B. Koz, A. O. Doroshenko e S. Icli, J. Photoch. Photobio. A, 2000, 137, 155-161.

36. D. Gosztola, M. P. Niemczyk, W. Svec, A. S. Lukas e M. R. Wasielewski, J. Phys. Chem. A, 2000, 104, 6545-6551.

37. L. L. Miller, R. G. Duan, Y. Hong e I. Tabakovic, Chem. Mater., 1995, 7, 1552-1557.

38. P. H. Dinolfo, M. E. Williams, C. L. Stern e J. T. Hupp, J. Am. Chem. Soc., 2004, 126, 12989-13001.

39. R. O. Marcon e S. Brochsztain, Thin Solid Films, 2005, 492, 30-34.

40. W. S. Horne, N. Ashkenasy e M. R. Ghadiri, Chem. Eur. J., 2005, 11, 1137-1144.

41. M. Gunaratnam et al., J. Med. Chem., 2009, 52, 37743783.

42. D. A. Vicic, D. C. Odom, M. E. Nunez, D. A. Gianolio, L. W. McLaughlin e J. K. Barton, J. Am. Chem. Soc., 2000, 122 , 8603-8611.

43. T. B. Singh, S. Erten, S. Gunes, C. Zafer, G. Turkmen, B. Kuban, Y. Teoman, N. S. Sariciftci e S. Icli, Org. Electron., 2006, 7, 480-489.

44. H. N. Lee, Z. Xu, S. K. Kim, K. M. K. Swamy, Y. Kim, S.-J. Kim e J. Yoon, J. Am. Chem. Soc., 2007, 129, 38283829 .

45. D. K. Susarova, P. A. Troshin, D. Hoglinger, R. Koeppe, 
S. D. Babenko, R. N. Lyubovskaya, V. F. Razumov e N. S. Sariciftci, Sol. Energ. Mat. Sol. C, 2010, 94, 803-811.

46. W. J. Grzegorczyk, P. Ganesan, T. J. Savenije, S. Bavel, J. Loos, E. J. R. Sudholter, L. D. A. Siebbeles e H. Zuilhof, J. Phys. Chem. C, 2009, 113, 7863-7869.

47. E. Castaldelli, E. R. Triboni e G. J.-F. Demets, Chem. Commun., 2011, 47, 5581-5583.

48. S. Silvi, M. Venturi e A. Credi, Chem. Commun., 2011, 47, 2483-2489.

49. A. M. Brouwer, C. Frochot, F. G. Gatti, D. A. Leigh, L. Mottier, F. Paolucci, S. Roffia e G. W. H. Wurpel, Science, 2001, 291, 2124-2128.

50. S. J. Langford, M. J. Latter e C. P. Woodward, Photochem. Photobiol., 2006, 82, 1530-1540.

51. A. Osuka, R.-P. Zhang, K. Maruyama, T. Ohno e K. Nozaki, Bull. Chem. Soc. Jpn., 1993, 66, 3773-3782.

52. J. H. Alstrum-Acevedo, M. K. Brennaman e T. J. Meyer, Inorg. Chem., 2005, 44, 6802-6827.

53. T. J. Meyer, Acc. Chem. Res., 1989, 22, 163-170.

54. D. Shukla, S. F. Nelson, D. C. Freeman, M. Rajeswaran, W. G. Ahearn, D. M. Meyer e J. T. Carey, Chem. Mater., 2008, 20, 7486-7491.

55. L. J. Rozanski, E. Castaldelli, F. L. M. Sam, C. A. Mills, G. J.-F. Demets e S. R. P. Silva, J. Mater. Chem. C, 2013, 1, 3347-3352.

56. O. Johansson, H. Wolpher, M. Borgstrom, L. Hammarstrom, J. Bergquist, L. Sun e B. Akermark, Chem. Commun., 2004, 194-195.

57. A. Baron, C. Herrero, A. Quaranta, M.-F. Charlot, W. Leibl, B. Vauzeilles e A. Aukauloo, Chem. Commun., 2011, 47, 11011-11013.

58. F. Chaignon, F. Buchet, E. Blart, M. Falkenstrom, L. Hammarstrom e F. Odobel, New J. Chem., 2009, 33, 408-416.

59. K. Qvortrup, A. D. Bond, A. Nielsen, C. J. McKenzie, K. Kilsa e M. B. Nielsen, Chem. Commun., 2008, 19861988.

60. G. Hu, L. Lv, L. Li, Q. Zhang, X. Li, Y. Tian, J. Wu, B. Jin, H. Zhou, J. Yang e S. Zhang, Dyes Pigm., 2011, 89, 105110.

61. D. Kumaresan, K. Lebkowsky e R. H. Schmehl, J. Photoch. Photobio. A, 2009, 207, 86-93.

62. H.-Y. Deng, J.-R. He, M. Pan, L. Li e C.-Y. Su, Cryst. Eng. Comm., 2009, 11, 909-917.

63. G.-B. Li, J.-M. Liu, Y.-P. Cai e C.-Y. Su, Cryst. Growth Des., 2011, 11, 2763-2772.

64. L. Han, L. Qin, L. Xu, Y. Zhou, J. Sun e X. Zou, Chem. Commun., 2013, 49, 406-408.

65. A. Mitra, C. T. Hubley, D. K. Panda, R. J. Clark e S. Saha, Chem. Commun., 2013, 49, 6629-6631.

66. X. Fang, X. Yuan, Y.-B. Song, J.-D. Wang e M.-J. Lin, Cryst. Eng. Comm., 2014, 16, 9090-9095.

67. J.-Z. Liao, X.-J. Dui, H.-L. Zhang, X.-Y. Wu e C.-Z. Lu, Cryst. Eng. Comm., 2014, 16, 10530-10533.

68. J.-J. Liu, Y. Wang, M.-J. Lin, C.-C. Huang e W.-X. Dai, Dalton Trans., 2015, 44, 484-487.

69. A. J. Bard e L. R. Faulkner, Electrochemical Methods Fundamentals and Applications, John Wiley and Sons Inc., 2nd edn, 2001.

70. M. J. Frisch, G. W. Trucks, H. B. Schlegel, G. E. Scuseria, M. A. Robb, J. R. Cheeseman, G. Scalmani, V. Barone, B. Mennucci, G. A. Petersson, H. Nakatsuji, M. Caricato,
X. Li, H. P. Hratchian, A. F. Izmaylov, J. Bloino, G. Zheng, J. L. Sonnenberg, M. Hada, M. Ehara, K. Toyota, R. Fukuda, J. Hasegawa, M. Ishida, T. Nakajima, Y. Honda, O. Kitao, H. Nakai, T. Vreven, J. A. Montgomery, Jr., J. E. Peralta, F. Ogliaro, M. Bearpark, J. J. Heyd, E. Brothers, K. N. Kudin, V. N. Staroverov, R. Kobayashi, J. Normand, K. Raghavachari, A. Rendell, J. C. Burant, S. S. Iyengar, J. Tomasi, M. Cossi, N. Rega, J. M. Millam, M. Klene, J. E. Knox, J. B. Cross, V. Bakken, C. Adamo, J. Jaramillo, R. Gomperts, R. E. Stratmann, O. Yazyev, A. J. Austin, R. Cammi, C. Pomelli, J. W. Ochterski, R. L. Martin, K. Morokuma, V. G. Zakrzewski, G. A. Voth, P. Salvador, J. J. Dannenberg, S. Dapprich, A. D. Daniels, Ö. Farkas, J. B. Foresman, J. V. Ortiz, J. Cioslowski e D. J. Fox, Gaussian 09 Revision A.1, Gaussian Inc. Wallingford CT 2009.

71. A. D. Becke, J. Chem. Phys., 1993, 98, 5648-5652.

72. C. Lee, W. Yang e R. G. Parr, Phys. Rev. B, 1988, 37, 785-789.

73. S. H. Vosko, L. Wilk e M. Nusair, Can. J. Phys., 1980, 58, 1200-1211.

74. P. J. Stephens, F. J. Devlin, C. F. Chabalowski e M. J. Frisch, J. Phys. Chem., 1994, 98, 11623-11627.

75. W. J. Hehre, R. Ditchfield e J. A. Pople, J. Chem. Phys., 1972, 56, 2257-2261.

76. P. C. Hariharan e J. A. Pople, Theoret. Chim. Acta, 1973, 28, 213-222.

77. M. M. Francl, W. J. Pietro, W. J. Hehre, J. S. Binkley, M. S. Gordon, D. J. DeFrees e J. A. Pople, J. Chem. Phys., 1982, 77, 3654-3665.

78. T. H. D. Jr, J. Chem. Phys., 1989, 90, 1007-1023.

79. NIST Computational Chemistry Comparison and Benchmark Database, Release 15b, August 2011, Editor: Russell D. Johnson III, http://cccbdb.nist.gov/, NIST Standard Reference Database Number 101.

80. G. Schreckenbach e T. Ziegler, J. Phys. Chem., 1995, 99, 606-611.

81. M. G. Constantino, Química Orgânica - Curso Básico Universitário, LTC, 2009, vol. 3.

82. M. S. Refat, H. M. A. Killa, I. Grabchev e M. Y. El-Sayed, Spectrochim. Acta, 2007, 68, 123-133.

83. J. Szczepanski, D. Roser, W. Personette, M. Eyring, R. Pellow e M. Vala, J. Phys. Chem., 1992, 96, 78767881.

84. F. Pauzat, D. Talbi, M. D. Miller, D. J. DeFrees e Y. Ellinger, J. Phys. Chem., 1992, 96, 7882-7886.

85. S. Grimme, in Reviews in Computational Chemistry, John Wiley and Sons Inc., 2004, vol. 20, ch. 3. Calculation of the Electronic Spectra of Large Molecules, pp. 153-218.

86. S. Katsuta, K. Tanaka, Y. Maruya, S. Mori, S. Masuo, T. Okujima, H. Uno, K. Nakayama e H. Yamada, Chem. Commun., 2011, 47, 10112-10114.

87. S. Guha, F. S. Goodson, L. J. Corson e S. Saha, J. Am. Chem. Soc., 2012, 134, 13679-13691.

88. O. V. Dolomanov, L. J. Bourhis, R. J. Gildea, J. A. K. Howard e H. Puschmann, J. Appl. Crystallogr., 2009, 42, 339-341.

89. G. M. Sheldrick, Acta Crystallogr. A, 2008, 64, 112-122.

90. A. S. Munn, S. Amabilino, T. W. Stevens, L. M. Stevens, G. J. Clarkson, F. Millange, M. J. Lennox, T. Düren, S. Bourelly, P. L. Llewellyn e R. I. Walton, Cryst. Growth Des., 2015, 15, 891-899. 
91. J.-J. Liu, Y. Wang, M.-J. Lin, C.-C. Huang e W.-X. Dai, Dalton Trans., 2014, 44, 484-487.

92. N. E. Brese e M. O'Keeffe, Acta Cryst., 1991, B47, 192197.

93. I. S. Kotousova e S. M. Polyakov, Kristallografiya, 1972, 17, 661-663.

94. S. Gražulis, A. Daškevič, A. Merkys, D. Chateigner, L. Lutterotti, M. Quirós, N. R. Serebryanaya, P. Moeck, R. T. Downs e A. LeBail, Nucleic Acids Res., 2012, 40, D420-D427.

95. S. Grazulis, D. Chateigner, R. T. Downs, A. T. Yokochi, M. Quiros, L. Lutterotti, E. Manakova, J. Butkus, P. Moeck e A. LeBail, J. Appl. Crystallogr., 2009, 42, 726-729.

96. R. T. Downs e M. Hall-Wallace, Am. Mineral, 2003, 88, 247-250.

97. H. T. Varghese, C. Y. Panicker, D. Philip, K. Sreevalsan e V. Anithakumary, Spectrochim. Acta, 2007, 68, 817-822.

98. R. L. Jones, J. Mol. Spec., 1963, 11, 411-421.
99. http://sdbs.riodb.aist.go.jp, Spectral Database for Organic Compounds of the National Institute of Advanced Industrial Science.

100. G. F. Dionne, Magnetic Oxides, Spinger, 2010.

101. R. Farran, D. Jouvenot, F. Loiseau, J. Chauvin e A. Deronzier, Dalton Trans., 2014, 43, 12156-12159.

02. A. A. Isse, A. Gennaro e E. Vianello, J. Am. Chem. Soc. Dalton Trans., 1993, 14, 2091-2096.

103. M. Cañadas, E. L.-Torres, A. M.-Arias, M. A. Mendiola e M. T. Sevilla, Plyhedron, 2000, 19, 2059-2068.

104. S. F. A. Kettle, Physical Inorganic Chemistry - A Coordination Chemistry Approach, Spektrum Academic Publishers, 1st edn, 1996.

105. F. A. Cotton, Chemical Application of Group Theory, Wiley-Interscience, 3rd edn, 1990.

106. C. T. G. Smith, R. W. Rhodes, M. J. Beliatis, K. D. G. I. Jayawardena, L. J. Rozanski, C. A. Mills e S. R. P. Silva, Appl. Phys. Lett., 2014, 105, 073304. 


\section{A1. Lista de figuras}

1.1 Estruturas básicas representativas para a formação de polímeros de coordenação. . . . . . . . . . 2

1.2 Exemplos de polímeros de coordenação propostos por BIRADHA e LU. . . . . . . . . . . . . . . . . . 4

1.3 Esquema da reação de modificação pós-sintética do MOF produzido por BurRows. ${ }^{15}$. . . . . . 5

1.4 Adsortividade seletiva de $\mathrm{CO}_{2}$ frente $\mathrm{N}_{2}$ do MOF de WRIEDT. ${ }^{16}$. . . . . . . . . . . . . . . 6

1.5 Estruturas dos polímeros de coordenação condutores de J. T. Hupp e HutCHINS. . . . . . . . . . 7

1.6 Principais diimidas aromáticas - naftaleno (NDI, centro), perileno (PDI, direita) e piromelítico (PyDI, esquerda) diimidas. . . . . . . . . . . . . . . . . . . . . . . . . . . . . .

1.7 Espectros de absorção $(A)$, emissão $\left(B, \lambda_{e x}=360 \mathrm{~nm}\right)$ em $\mathrm{CH}_{2} \mathrm{Cl}_{2}$; e de emissão em tolueno $(\mathrm{C})$ de uma NDI dialquil-substituída, retirado da Referência 29. . . . . . . . . . . . . . . . . . . . . . .

1.8 Espectros de absorção de uma naftaleno diimida neutra (5a) e suas formas reduzidas, radical ânion $\left(5 \mathrm{a}^{\bullet-}\right)$ e diânion $\left(5 \mathrm{a}^{2-}\right)$. Adaptado da Referência 36. . . . . . . . . . . . . . . . . . . 10

1.9 Esquemas de síntese de uma naftaleno diimida simétrica e assimétrica. . . . . . . . . . . . . . . 11

1.10 Três abordagens distintas de modelos fotossintéticos artificiais. . . . . . . . . . . . . . . . . . . . 12

1.11 Derivado de $1,4,5,8-n a f t a l e n o$ diimida, DC18. . . . . . . . . . . . . . . . . . . . . . . . . 13

1.12 Ensaios de fotocorrente em um eletrodo de carbono vítreo modificado com um filme de DC18 em um potencial constante de $-0,675 \mathrm{~V}$ vs $\mathrm{Ag} / \mathrm{AgCl}$ em uma solução aquosa de $\mathrm{KCl} 0,1 \mathrm{~mol} \mathrm{dm}^{-3}$ saturada

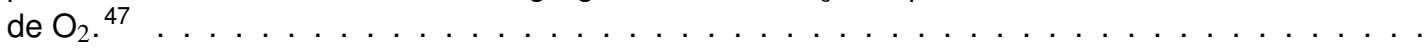

1.13 Polímeros de coordenação contendo $N, N^{\prime}$-bis(4-metilpiridil)-1,4,5,8-naftaleno diimida como ligante com diferentes centros metálicos. ${ }^{62}$

1.14 MOFs contendo NDI como ligante e Zn(II) como centro metálico. O composto 4 utiliza o ácido naftaleno-2,6-dicarboxílico e o composto 5 utiliza o ácido bifenil-1,4-dicarboxílico. ${ }^{18} \ldots$. . . . . . .

2.1 Esquema de síntese da N,N'-bis(4-piridil)-1,4,5,8-naftaleno diimida, ou NDI-py. . . . . . . . . . . .

2.2 Imagem de um dispositivo para a determinação da condutividade elétrica do MOF-CoNDI-py-2. . .

2.3 Imagens de um dispostivo do MOF-CoNDI-py-2 antes e após a deposição dos eletrodos de platina.

2.4 Estrutura do microeletrodo de cavidade (CME) utilizado para as medidas de eletroquímica do MOFCoNDI-py-2. . . . . . . . . . . . . . . . . . . . . . .

3.1 Espectros de RMN de ${ }^{1} \mathrm{H}$ da NDI-py em $\mathrm{CF}_{3}$ COOD a $500 \mathrm{MHz}$, mostrando a região completa (superior) e ampliação dos sinais observados (inferior). . . . . . . . . . . . . . . . . . . . . . . . . 28

3.2 Espectro teórico de RMN de ${ }^{1} \mathrm{H}$ da NDI-py em ácido acético e atribuição de seus sinais. . . . . . . 29

3.3 Espectro teórico de RMN de ${ }^{13} \mathrm{C}$ da NDI-py em ácido acético e atribuição de seus sinais. . . . . . . 30

3.4 Espectros de Dept135 (superior) e de RMN de ${ }^{13} \mathrm{C}$ (inferior) da NDI-py em $\mathrm{CF}_{3} \mathrm{COOD}$ a $500 \mathrm{MHz}$. .

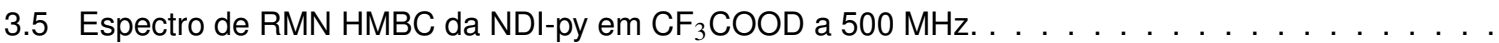

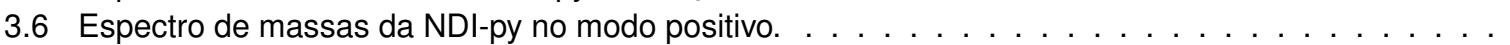

3.7 Espectros de FTIR teórico, no vácuo, e experimental, em KBr, da NDI-py. . . . . . . . . . . . . . . . .

3.8 Distribuição esquemática dos níveis eletrônicos e vibracionais dos estados singletos da NDI-py bem como a correspondência dos níveis no espectro eletrônico de absorção, obtido experimentalmente a paritr de uma solução em DMF. Supõe-se que os estados $\Psi_{0}$ e $\Psi_{1}$ possuam as mesmas coordenadas nucleares $(\mathbf{R})$, diferentemente do estado $\Psi_{2}$

3.9 Orbitais HOMO e LUMO da NDI-py obtidos por B3LYP/cc-pVTZ em solvatação contínua de DMF.

3.10 Desconvolução gaussiana de um espectro de absorção de luz na região do UV-Vis da NDI-py em DMF.

3.11 Espectros de absorção de luz na região do UV-Vis da NDI-py em DMF para a determinação dos coeficientes de absortividade molar.

3.12 Espectros de emissão, excitação e absorção da NDI-py em DMF. . . . . . . . . . . . . . . . . . . . .

3.13 Voltamograma cíclico da NDI-py $\left(1 \mathrm{mmol} \mathrm{dm}{ }^{-3}\right)$ em uma solução $10 \mathrm{mmol} \mathrm{dm}{ }^{-3}$ de $\left[\mathrm{N}(\mathrm{n}-\mathrm{Bu})_{4}\right]\left(\mathrm{PF}_{6}\right)$ em DMF, contendo Fc como referência interna. $\mathrm{WE}=\mathrm{GCE}, \mathrm{CE}=\mathrm{Pt}, \mathrm{RE}=\mathrm{Ag}, v=25 \mathrm{mV} \mathrm{s}^{-1}$. . .

3.14 Determinação do band-gap óptico $\left(E_{g}\right)$ da NDI-py a partir do UV-Vis em solução. . . . . . . . . . . . . (1) 12 3

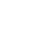

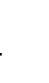

5

(n)
is 
3.15 Comparação entre os difratogramas de raios-X de pó do MOF-CoNDI-py-1 e NDI-py, usando uma fonte de $\mathrm{Cu}(\lambda=1,54056 \AA) . \ldots \ldots \ldots \ldots \ldots \ldots \ldots \ldots$

3.16 Estrutura proposta do MOF-CoNDI-py-1. . . . . . . . . . . . . . . . . . . .

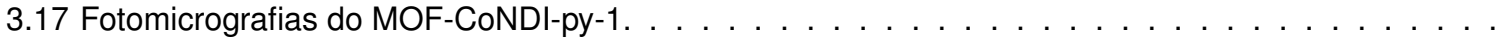

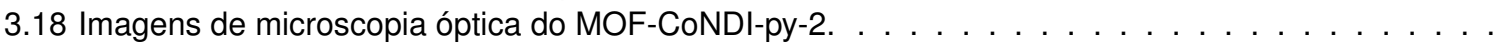

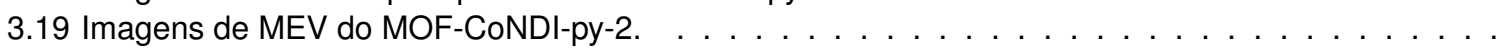

3.20 Estrutura cristalina do MOF-CoNDI-py-2 . . . . . . . . . . . . . . . . . . . . . . . . . . .

3.21 Representação dos centros metálicos e das moléculas de NDI-py no cristal de MOF-CoNDI-py-2. .

3.22 Fragmento trinuclear de cobalto do MOF-CoNDI-py-2 pertencente ao grupo de ponto $\mathrm{C}_{i}$, com distâncias de ligação. . . . . . . . . . . . . . . . . . . . . . . . . . . .

3.23 Comparação entre os difratogramas de raios-X de pó experimental e simulado do MOF-CoNDI-py-2, usando uma fonte de $\mathrm{Cu}(\lambda=1,54056 \AA)$. Traços em azul representam os picos calculados enquanto os traços em laranja representam picos sistematicamente ausentes. . . . . . . . . . . . . . . . . .

3.24 Análises de TGA e DTG da NDI-py, TpA e MOF-CoNDI-py-2 em atmosfera de $\mathrm{O}_{2}$. . . . . . . . . . . .

3.25 Difratograma de raios-X do sólido restante ao final da análise de TGA do MOF-CoNDI-py-2 em

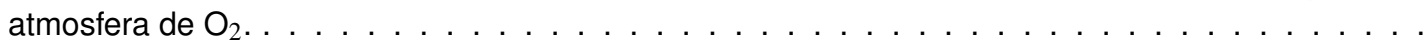

3.26 Comparação entre os espectros de FTIR do MOF-CoNDI-py-2 e da NDI-py, ambos em pastilha de $\mathrm{KBr} \ldots \ldots \ldots \ldots \ldots \ldots \ldots \ldots \ldots \ldots \ldots \ldots \ldots$

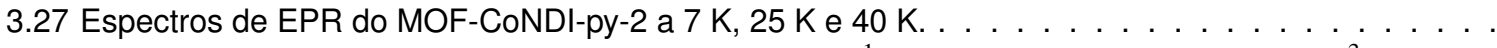

3.28 Voltametria cíclica do MOF-CoNDI-py-2 a $50 \mathrm{mV} \mathrm{s}^{-1}$ em uma solução $0,1 \mathrm{~mol} \mathrm{dm}^{-3} \mathrm{de}[\mathrm{N}(\mathrm{n}$ $\left.\mathrm{Bu})_{4}\right]\left(\mathrm{PF}_{6}\right)$ em $\mathrm{MeCN}$. WE $=\mathrm{CME}, \mathrm{CE}=\mathrm{Pt}, \mathrm{RE}=\mathrm{Ag} / \mathrm{AgNO}_{3}\left(10 \mathrm{mmol} \mathrm{dm}{ }^{-3}, \mathrm{MeCN}\right) . \ldots 56$

3.29 Espectros de reflectância difusa do MOF-CoNDI-py-2 e da NDI-py. . . . . . . . . . . . . . . . . . . . . 58

3.30 Espectros de reflectância difusa do MOF-CoNDI-py-2 na região do UV-Vis e Vis-NIR. A desconvolução é apenas para a região do Vis-NIR.

3.31 Fragmento do MOF-CoNDI-py-2 espectroscopicamente ativo na região do UV-Vis-NIR estudada. .

3.32 Representação qualitativa de um diagrama do tipo Tanabe-Sugano para um íon metálico $\mathrm{d}^{7}$. . . . . .

3.33 Esquema qualitativo de desdobramento dos termos de Russell-Saunders de um campo $\mathrm{O}_{h}$ para um campo $\mathrm{C}_{i} \ldots \ldots \ldots \ldots \ldots \ldots \ldots \ldots \ldots \ldots \ldots \ldots \ldots \ldots$

3.34 Esquema de desdobramento dos termos espectroscópicos do íon Co(II) nas formas (i) livre, (ii) em um campo octaédrico $\left(\mathrm{O}_{h}\right)$ e (iii) em campo de simetria $\mathrm{C}_{i}$ como na estrutura do MOF-CoNDI-py-2; e sua correlação com o espectro experimental de reflectância difusa no Vis-NIR. Os níveis de energia no campo $\mathrm{O}_{h}$ e no íon livre não estão na escala de energia.

3.35 Espectros de emissão do MOF-CoNDI-py-2 e da NDI-py no estado sólido, em temperatura ambiente.

3.36 Tempos de vida de emissão $(\lambda>405 \mathrm{~nm})$ da NDI-py e MOF-CoNDI-py-2 no estado sólido. . . . . . .

3.37 Dispositivo eletrônico contendo um cristal do MOF-CoNDI-py-2 conectado a contatos de Au através de eletrodos de $\mathrm{Pt}$, sobre um substrato de $\mathrm{Si} / \mathrm{SiO}_{2}$.

3.38 Medidas I-V de um cristal de MOF-CoNDI-py-2 conectado a contatos de Au através de eletrodos de Pt sobre um substrato de $\mathrm{Si} / \mathrm{SiO}_{2}$.

3.39 Medidas I-V do dispositivo contendo um cristal do MOF-CoNDI-py-2 sob diferentes tipos de iluminação. 68

3.40 Espectro de reflectância difusa na região do Vis-NIR com desconvolução para o MOF-CoNDI-py-2 e posição do laser vermelho utilizado.

3.41 Ajustes de Space-Charge Limited Current (SCLC) e Fowler-Nordheim (FN) para os contatos $\mathbf{b}_{2}$, $\mathbf{t}_{1}$ e

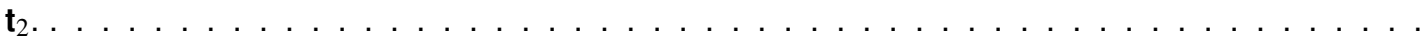

3.42 Ajustes de Space-Charge Limited Current (SCLC) e Fowler-Nordheim (FN) para os contatos $\mathbf{b}_{1}, \mathbf{b}_{2}$,

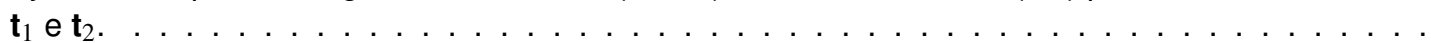




\section{A2. Lista de tabelas}

2.1 Detalhes dos reagentes utilizados neste trabalho. . . . . . . . . . . . . . . . . . . . . . . 17

3.1 Comparação dos dados téorico e experimental para o RMN de ${ }^{1} \mathrm{H}$ da NDI-py. . . . . . . . . . . . . . . 29

3.2 Atribuições das bandas de FTIR da NDI-py baseadas em cálculos DFT e nas referências 82, 62, 83

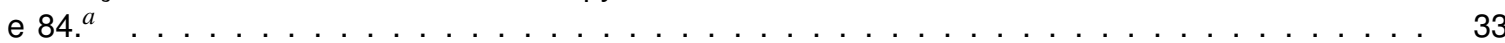

3.3 Transições eletrônicas calculadas para a NDI-py usando B3LYP e cc-pVTZ que possuem $f_{\text {osc }}>0,05$. 36

3.4 Parâmetros da desconvolução gaussiana do espectro UV-Vis e coeficientes de absortividade molar da NDI-py em DMF. . . . . . . . . . . . . . . . . . . . . . . . . . . . . . . . . . . . . . . . . . . . . 37

3.5 Parâmetros cristalográficos do MOF-CoNDI-py-2. . . . . . . . . . . . . . . . . . . . . 46

3.6 Parâmetros e resultados obtidos com o Método de Ligação-Valência aplicado ao MOF-CoNDI-py-2. 51

3.7 Atribuição das bandas de infravermelho do MOF-CoNDI-py-2. ${ }^{a}$. . . . . . . . . . . . . . . . . . . 54

3.8 Potenciais de redução versus Fc/Fc ${ }^{+}$observados para o MOF-CoNDI-py-2 e NDI-py em comparação com os disponíveis na literatura. . . . . . . . . . . . . . . . . . . . . . . . . . . . . . 57

3.9 Parâmetros da desconvolução gaussiana e atribuições do espectro de reflectância difusa do MOFCoNDI-py-2. . . . . . . . . . . . . . . . . . . . . . . . . . . . 62

3.10 Parâmetros matemáticos do ajuste de decaimento exponencial para os tempos de vida da NDI-py e MOF-CoNDI-py-2 no estado sólido. . . . . . . . . . . . . . . . . . . . . . . . . . 65

3.11 Parâmetros obtidos dos dispositivos eletrônicos do MOF-CoNDI-py-2. . . . . . . . . . . . . . . . . 67

A3.1 Atribuições das bandas de infravermelho do íon tereftalato (TpA) baseado na Referência 97. . . . . 83 A4.2 Tabela de caracteres do grupo de ponto $D_{2 h} \ldots \ldots \ldots \ldots$. . . . . . . . . . . . . . . . . . 84

A4.3 Tabela de produtos do grupo de ponto $D_{2 h} \ldots \ldots \ldots \ldots \ldots$. . . . . . . . . . . . . . . . 84

A5.4 Tabela de caracteres do grupo de ponto $C_{i} \ldots \ldots \ldots \ldots \ldots \ldots$

A5.5 Tabela de produtos do grupo de ponto $C_{i} \ldots \ldots \ldots \ldots \ldots$ 


\section{A3. FTIR do íon tereftalato}

Apesar de usarmos a forma ácida (protonada) deste composto como material de partida na síntese do MOF, esta molécula sofre duas desprotonações durante a síntese dando origem ao íon tereftalato. Além da constatação através da estrutura de monocristal, esse fenômeno também é constatado através do espectro de infravermelho uma vez que não é possível observar nenhuma banda referente aos modos vibracionais do grupo O-H no FTIR do MOF-CoNDI-py-2, mais precisamente os modos observados em $3470,2661,2543$ e $1114 \mathrm{~cm}^{-1}$ no espectro do TpA. Além disso, a banda do grupo C-O em $1286 \mathrm{~cm}^{-1}$ também está ausente no espectro do MOF, que é consistente com a estrutura de carboxilato - dupla desprotonação. As diferenças entre as duas formas são advindas da mudança da ordem de ligação do $\mathrm{C}-\mathrm{O}, \mu$, em que na forma ácida apresenta dois valores de $\mu=1$ e $\mu=2$ para o $\mathrm{C}-\mathrm{OH}$ e $\mathrm{C}=\mathrm{O}$, respectivamente; e duas ligações $\mathrm{C}-\mathrm{O}$ ressonantes de mesma ordem de ligação $\mu=1,5$ na forma desprotonada.

Tabela A3.1: Atribuições das bandas de infravermelho do íon tereftalato (TpA) baseado na Referência 97.

\begin{tabular}{ccl}
\hline$v\left(\mathbf{c m}^{-1}\right)$ & Intensidade & Atribuição \\
\hline 3068 & Fraca & Estiramento Ar-H \\
1617 & Média & Estiramento assimétrico $\mathrm{O}=\mathrm{C}=\mathrm{O}$ \\
1558 & Muito forte & Estiramento assimétrico $\mathrm{O}=\mathrm{C}=\mathrm{O}$ \\
1507 & Média & Estiramento $\mathrm{C}=\mathrm{C}(\mathrm{Ar})$ \\
1397 & Muito forte & Estiramento simétrico $\mathrm{O}=\mathrm{C}=\mathrm{O}$ \\
1319 & Média & Estiramento $\mathrm{C}=\mathrm{C}(\mathrm{Ar})$ \\
1150 & Fraca & Dobramento $\mathrm{Ar}-\mathrm{H}$ no plano \\
1100 & Média & Dobramento $\mathrm{Ar}-\mathrm{H}$ no plano \\
1020 & Média & Dobramento $\mathrm{Ar}-\mathrm{H}$ no plano \\
976 & Fraca & Dobramento $\mathrm{Ar}-\mathrm{H}$ fora do plano \\
895 & Média & Dobramento $\mathrm{Ar}-\mathrm{H}$ fora do plano \\
882 & Fraca & Dobramento $\mathrm{Ar}-\mathrm{H}$ fora do plano \\
825 & Forte & Dobramento $\mathrm{Ar}-\mathrm{H}$ fora do plano \\
746 & Muito forte & Dobramento $\mathrm{O}=\mathrm{C}=\mathrm{O}$ no plano \\
508 & Forte & Balanço $\mathrm{O}=\mathrm{C}=\mathrm{O}$ \\
\hline
\end{tabular}




\section{A4. Tabela de caracteres do grupo $D_{2 h}$}

A tabela de caracteres e a tabela de produtos a seguir foram retirados da Referência 105.

Tabela A4.2: Tabela de caracteres do grupo de ponto $D_{2 h}$.

\begin{tabular}{|c|cccccccc|c|c|}
\hline & $\mathbf{E}$ & $\mathbf{C}_{2}(\mathbf{z})$ & $\mathbf{C}_{2}(\mathbf{y})$ & $\mathbf{C}_{2}(\mathbf{x})$ & $\mathbf{i}$ & $\sigma(\mathbf{x y})$ & $\sigma(\mathbf{x z})$ & $\sigma(\mathbf{y z})$ & & \\
\hline $\mathbf{A}_{\mathbf{g}}$ & 1 & 1 & 1 & 1 & 1 & 1 & 1 & 1 & & $\mathrm{x}^{2}, \mathrm{y}^{2}, \mathrm{z}^{2}$ \\
$\mathbf{B}_{\mathbf{1 g}}$ & 1 & 1 & -1 & -1 & 1 & 1 & -1 & -1 & $\mathrm{R}_{\mathrm{z}}$ & $\mathrm{xy}$ \\
$\mathbf{B}_{\mathbf{2 g}}$ & 1 & -1 & 1 & -1 & 1 & -1 & 1 & -1 & $\mathrm{R}_{\mathrm{y}}$ & $\mathrm{xz}$ \\
$\mathbf{B}_{\mathbf{3 g}}$ & 1 & -1 & -1 & 1 & 1 & -1 & -1 & 1 & $\mathrm{R}_{\mathrm{x}}$ & $\mathrm{yz}$ \\
$\mathbf{A}_{\mathbf{u}}$ & 1 & 1 & 1 & 1 & -1 & -1 & -1 & -1 & & \\
$\mathbf{B}_{\mathbf{1 u}}$ & 1 & 1 & -1 & -1 & -1 & -1 & 1 & 1 & $\mathrm{z}$ & \\
$\mathbf{B}_{\mathbf{2 u}}$ & 1 & -1 & 1 & -1 & -1 & 1 & -1 & 1 & $\mathrm{y}$ & \\
$\mathbf{B}_{3 \mathbf{u}}$ & 1 & -1 & -1 & 1 & -1 & 1 & 1 & -1 & $\mathrm{x}$ & \\
\hline
\end{tabular}

Tabela A4.3: Tabela de produtos do grupo de ponto $D_{2 h}$.

\begin{tabular}{|c|cccccccc|}
\hline & $\mathbf{A}_{\mathbf{g}}$ & $\mathbf{B}_{1 \mathrm{~g}}$ & $\mathbf{B}_{2 \mathrm{~g}}$ & $\mathbf{B}_{3 \mathrm{~g}}$ & $\mathbf{A}_{\mathbf{u}}$ & $\mathbf{B}_{1 \mathrm{u}}$ & $\mathbf{B}_{2 \mathrm{u}}$ & $\mathbf{B}_{3 \mathrm{u}}$ \\
\hline $\mathbf{A}_{\mathbf{g}}$ & $\mathrm{A}_{\mathrm{g}}$ & $\mathrm{B}_{1 \mathrm{~g}}$ & $\mathrm{~B}_{2 \mathrm{~g}}$ & $\mathrm{~B}_{3 \mathrm{~g}}$ & $\mathrm{~A}_{\mathrm{u}}$ & $\mathrm{B}_{1 \mathrm{u}}$ & $\mathrm{B}_{2 \mathrm{u}}$ & $\mathrm{B}_{3 \mathrm{u}}$ \\
$\mathbf{B}_{1 \mathrm{~g}}$ & $\mathrm{~B}_{1 \mathrm{~g}}$ & $\mathrm{~A}_{\mathrm{g}}$ & $\mathrm{B}_{3 \mathrm{~g}}$ & $\mathrm{~B}_{2 \mathrm{~g}}$ & $\mathrm{~B}_{1 \mathrm{u}}$ & $\mathrm{A}_{\mathrm{u}}$ & $\mathrm{B}_{3 \mathrm{u}}$ & $\mathrm{B}_{2 \mathrm{u}}$ \\
$\mathbf{B}_{2 \mathrm{~g}}$ & $\mathrm{~B}_{2 \mathrm{~g}}$ & $\mathrm{~B}_{3 \mathrm{~g}}$ & $\mathrm{~A}_{\mathrm{g}}$ & $\mathrm{B}_{1 \mathrm{~g}}$ & $\mathrm{~B}_{2 \mathrm{u}}$ & $\mathrm{B}_{3 \mathrm{u}}$ & $\mathrm{A}_{\mathrm{u}}$ & $\mathrm{B}_{1 \mathrm{u}}$ \\
$\mathbf{B}_{3 \mathrm{~g}}$ & $\mathrm{~B}_{3 \mathrm{~g}}$ & $\mathrm{~B}_{2 \mathrm{~g}}$ & $\mathrm{~B}_{1 \mathrm{~g}}$ & $\mathrm{~A}_{\mathrm{g}}$ & $\mathrm{B}_{3 \mathrm{u}}$ & $\mathrm{B}_{2 \mathrm{u}}$ & $\mathrm{B}_{1 \mathrm{u}}$ & $\mathrm{A}_{\mathrm{u}}$ \\
$\mathbf{A}_{\mathrm{u}}$ & $\mathrm{A}_{\mathrm{u}}$ & $\mathrm{B}_{1 \mathrm{u}}$ & $\mathrm{B}_{2 \mathrm{u}}$ & $\mathrm{B}_{3 \mathrm{u}}$ & $\mathrm{A}_{\mathrm{g}}$ & $\mathrm{B}_{1 \mathrm{~g}}$ & $\mathrm{~B}_{2 \mathrm{~g}}$ & $\mathrm{~B}_{3 \mathrm{~g}}$ \\
$\mathbf{B}_{1 \mathrm{u}}$ & $\mathrm{B}_{1 \mathrm{u}}$ & $\mathrm{A}_{\mathrm{u}}$ & $\mathrm{B}_{3 \mathrm{u}}$ & $\mathrm{B}_{2 \mathrm{u}}$ & $\mathrm{B}_{1 \mathrm{~g}}$ & $\mathrm{~A}_{\mathrm{g}}$ & $\mathrm{B}_{3 \mathrm{~g}}$ & $\mathrm{~B}_{2 \mathrm{~g}}$ \\
$\mathbf{B}_{2 \mathrm{u}}$ & $\mathrm{B}_{2 \mathrm{u}}$ & $\mathrm{B}_{3 \mathrm{u}}$ & $\mathrm{A}_{\mathrm{u}}$ & $\mathrm{B}_{1 \mathrm{u}}$ & $\mathrm{B}_{2 \mathrm{~g}}$ & $\mathrm{~B}_{3 \mathrm{~g}}$ & $\mathrm{~A}_{\mathrm{g}}$ & $\mathrm{B}_{1 \mathrm{~g}}$ \\
$\mathbf{B}_{3 \mathrm{u}}$ & $\mathrm{B}_{3 \mathrm{u}}$ & $\mathrm{B}_{2 \mathrm{u}}$ & $\mathrm{B}_{1 \mathrm{u}}$ & $\mathrm{A}_{\mathrm{u}}$ & $\mathrm{B}_{3 \mathrm{~g}}$ & $\mathrm{~B}_{2 \mathrm{~g}}$ & $\mathrm{~B}_{1 \mathrm{~g}}$ & $\mathrm{~A}_{\mathrm{g}}$ \\
\hline
\end{tabular}




\section{A5. Tabela de caracteres do grupo $\mathrm{C}_{i}$}

A tabela de caracteres e a tabela de produtos a seguir foram retirados da Referência 105.

Tabela A5.4: Tabela de caracteres do grupo de ponto $\mathrm{C}_{i}$.

\begin{tabular}{|c|cc|c|c|}
\hline & $\mathbf{E}$ & $i$ & & \\
\hline $\mathbf{A}_{\mathbf{g}}$ & 1 & 1 & $\mathrm{R}_{\mathrm{x}}, \mathrm{R}_{\mathrm{y}}, \mathrm{R}_{\mathrm{z}}$ & $\mathrm{x}^{2}, \mathrm{y}^{2}, \mathrm{z}^{2}, \mathrm{xy}, \mathrm{xz}, \mathrm{yz}$ \\
$\mathbf{A}_{\mathbf{u}}$ & 1 & -1 & $\mathrm{x}, \mathrm{y}, \mathrm{z}$ & \\
\hline
\end{tabular}

Tabela A5.5: Tabela de produtos do grupo de ponto $\mathrm{C}_{i}$.

\begin{tabular}{|l|ll|}
\hline & $\mathbf{A}_{\mathbf{g}}$ & $\mathbf{A}_{\mathbf{u}}$ \\
\hline $\mathbf{A}_{\mathbf{g}}$ & $\mathrm{A}_{\mathrm{g}}$ & $\mathrm{A}_{\mathrm{u}}$ \\
$\mathbf{A}_{\mathbf{u}}$ & $\mathrm{A}_{\mathrm{u}}$ & $\mathrm{A}_{\mathrm{g}}$ \\
\hline
\end{tabular}


A6. Produção bibliográfica 


\title{
Journal of Materials Chemistry C
}

\section{PAPER View Article Online PAPER View Journal I View Issue \\ Cite this: J. Mater. Chem. C, 2013, 1 \\ Solution processed naphthalene diimide derivative as electron transport layers for enhanced brightness and efficient polymer light emitting diodest} 3347

\author{
L. J. Rozanski, ${ }^{a}$ Evandro Castaldelli, ${ }^{\text {b }}$ F. L. M. Sam, ${ }^{a}$ Christopher A. Mills, ${ }^{a}$ \\ Grégoire Jean-François Demets ${ }^{\mathrm{b}}$ and S. R. P. Silva*a
}

\begin{abstract}
Increasing the efficiency and lifetime of polymer light emitting diodes (PLEDs) requires a balanced injection and flow of charges through the device, driving demand for cheap and effective electron transport/hole blocking layers. Some materials, such as conjugated polyelectrolytes, have been identified as potential candidates but the production of these materials requires complex, and hence costly, synthesis routes. We have utilized a soluble small molecule naphthalene diimide derivative (DC18) as a novel electron transport/hole blocking layer in common PLED architectures, and compared its electronic properties to those of the electron transport/hole blocking small molecule bathocuproine (BCP). PLEDs incorporating DC18 as the electron transport layer reduce turn on voltage by $25 \%$; increase brightness over three and a half times; and provide a full five-fold enhancement in efficiencies compared to reference devices. While DC18 has similar properties to the effective conjugated polyelectrolytes used as electron transport layers, it is simpler to synthesise, reducing cost while retaining favourable electron transport properties, and producing a greater degree of efficiency enhancement. The impact on device lifetime is hypothesized to be significant as well, due to the air-stability seen in many naphthalene diimide derivatives.
\end{abstract}

Received 28th January 2013

Accepted 8th April 2013

DOI: $10.1039 / \mathrm{c} 3 \mathrm{tc} 30175$

www.rsc.org/MaterialsC

\section{Introduction}

Polymer light emitting diodes (PLEDs) offer a cheap, flexible alternative to existing lighting display technologies, as they can be fabricated using solution processing techniques for large area devices. ${ }^{1}$ While advances in PLED technology have been numerous, they remain hindered by low efficiencies and limited lifetime stability. Since PLEDs require injection of both electrons and holes into the active material, balancing charge flow is essential to increase device efficiency. ${ }^{2}$ The majority of electroluminescent polymers used as active materials have highe hole mobilities than electron mobilities, in addition to an incompatibility between their low LUMO levels and the high work function metallic cathodes used., ${ }^{3,4}$ Thus significan interest towards increasing charge flow balance has focused on improving electron injection at the cathode-polymer interface. Early modifications involved inserting a thin layer of low work function reactive metals such as calcium ${ }^{5,6}$ beneath the metal electrode, requiring encapsulation to prevent degradation.

${ }^{a}$ Advanced Technology Institute, University of Surrey, Guildford, GU2 7XH, UK. E-mail s.silva@surrey.ac.uk; Tel: +44 (0)1483689825

${ }^{b}$ Departamento de Quimica, Faculdade de Filosofia Ciências e Letras de Ribeirão Preto, Universidade de São Paulo, Av. Bandeirantes 3900 CEP 14040-901, Ribeirão Preto, SP, Brazil

† Electronic supplementary information (ESI) available: Cyclic voltammetry data, calculations of HOMO/LUMO levels, UV-Vis and PLED characterization for MEH PPV devices. See DOI: 10.1039/c3tc30175c
However, these metals require high vacuum and temperatures for evaporation, hindering the translation of PLEDs to complete solution fabrication.

Recently, focus has shifted towards the use of solution processed electron injection layers made of self-assembled monolayers (SAMs), ${ }^{7}$ conjugated polyelectrolytes (CPEs) or conjugated surfactants. ${ }^{8-10}$ These novel organics have excellent solubility in alcohol-based solvents, allowing them to be applied to the active polymer layer for good electrical contact without interfacial mixing. The charged CPE electron transport layers (ETLS) are believed to lower the charge injection barrier between the high work function electrode and the active layer by creating a permanent dipole between the metal and the CPE, in addition to a migration of charged ions into the film. ${ }^{11-14}$ Although enhanced efficiency in PLEDs has been demonstrated using CPEs, ${ }^{8,15}$ these polymers require complicated synthesis routes. The most effective polymers have used a hole-transporting polyfluorene backbone, which could hinder their hole-blocking properties. ${ }^{\mathbf{8 1 0 , 1 6 - 1 8}}$ An inexpensive alternative to these CPEs would be to replace them with soluble small molecules displaying similar electron-transporting capabilities. Unlike polymers, small molecules are not limited by low product yields or adversely affected by an extensive molecular weight range. Furthermore, delayed response times have been seen in devices incorporating CPEs,${ }^{17}$ a problem not observed in devices containing their short chain oligomer counterparts. ${ }^{19}$ 
Naphthalene diimides (NDIs) are a class of compounds with high electron mobilities, and have primarily been used to produce air-stable n-type organic field effect transistors. ${ }^{20-22}$ In addition, polymers developed from NDIs have shown promise as novel acceptors in organic solar cells, providing in excess of $1.5 \%$ device efficiencies, one of the highest for non-fullerene cells, with potential for extending device lifetimes. ${ }^{23-25}$ The high electron mobilities of naphthalene diimides, coupled with thei excellent air stability, give them considerable potential as air stable electron injection layers. It is facile to chemically tune the electrical characteristics of naphthalene diimides using simple organic chemistry to modify either the conjugated backbone or the nitrogen atoms to introduce solubilizing side chains for easy solution processing. ${ }^{26}$ For this work we have utilized a noncore modified NDI derivative, $N, N^{\prime}$-bis(ethyl- $N^{\prime \prime}, N^{\prime \prime}, N^{\prime \prime}$-dimethyloctadecyl ammonium)-1,4,5,8-naphthalene diimide (DC18, Fig. 1A), as a novel small molecule electron transport material. To our knowledge, this is the first time a NDI derivative has been utilized as such, and illustrates the ease with which n-type active layer materials can be employed as interfacial layers to further enhance organic electronics. We have reported on the synthesis and electroactivity of the DC18 molecule previously. ${ }^{27}$ DC18 is expected to be an excellent electron injection layer due to its inherent properties, being a charged cationic species with the high electron transport known to NDIs. From cyclic voltammetry measurements (ESI $\dagger$ ), the LUMO value for DC18 was calculated ${ }^{28}$ to be $-4.2 \mathrm{eV}$, with the HOMO calculated using the optical bandgap to be $-7.5 \mathrm{eV}$. These values are in good agreement with similarly structured NDI materials..$^{\mathbf{2 1 , 2 9}}$ The deep HOMO value for DC18 ensures it will be an excellent holeblocking material for many PLED polymers while facilitating electron injection.
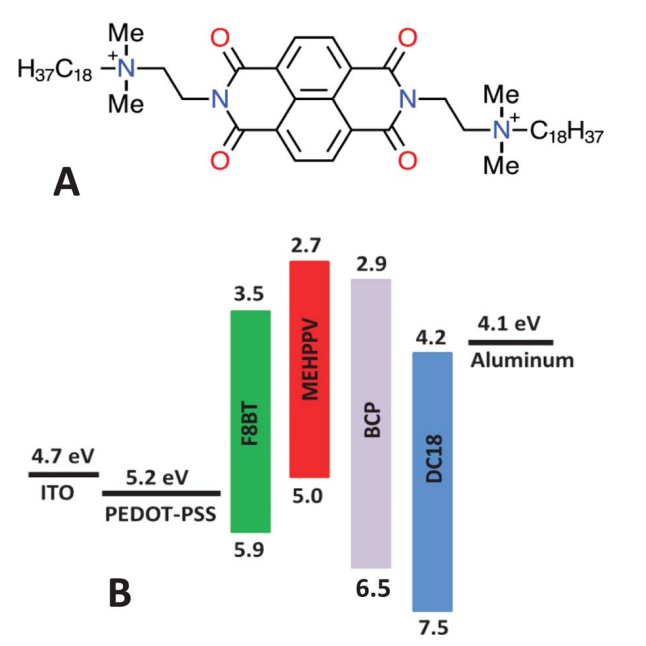

Fig. 1 (A) DC18 chemical structure and (B) energy levels (in eV) of the different layered materials used in the PLED structure studied here. Two types of emissive layers, F8BT and MEHPPV were used, with the novel electron transport layer of DC18 compared to the standard BCP reference.

\section{Results and discussion}

To test DC18's effectiveness as an electron injection/hole blocking layer, PLEDs using a conventional three layer structure (hole-transport layer (HTL)/active layer/electron-transport layer (ETL)) were fabricated to ascertain changes caused by a single layer substitution. Poly(3,4-ethylenedioxythiophene) poly(styrenesulfonate) (PEDOT-PSS) was used as the hole transport layer for all devices, while two active layer polymers were chosen with different HOMO/LUMO levels to compare ETL charge injection abilities. The structure of the PLEDs was: indium tin oxide (ITO)/PEDOT-PSS (40 nm)/active layer (100 nm)/ETL/ aluminum (80 nm). Poly[2-methoxy-5-(2-ethylhexyloxy)-1,4phenylene vinylene] (MEH PPV) and poly[(9,9-di- $n$-octylfluorenyl-2,7-diyl)-alt-(benzo[2,1,3]thiadiazol-4,8-diyl)] (F8BT) were used as the emissive active layer for orange and green (respectively) PLEDs. These polymers were chosen as the wellstudied, inexpensive polymers facilitate a selection route for the best ETL to subsequently be transferred to costly and more complex, higher-efficiency devices. Likewise, the straightforward three layer structure (HTL/active layer/ETL) contributes to accurate measurement of the impact seen by changing an individual layer.

The different polymers were chosen to see if the deep lower unoccupied molecular orbital (LUMO) of DC18 at $-4.2 \mathrm{eV}$ (shown in Fig. 1B) would hinder its effectiveness as an electron injection layer, as MEH PPV has a higher LUMO value in comparison to F8BT $(-2.7 \mathrm{eV}$ compared to $-3.5 \mathrm{eV})$. For comparison as a dual-purpose electron-transporting and hole blocking layer, DC18 was compared to a commonly used ${ }^{30,31}$ air-stable, evaporated small molecule, 2,9-dimethyl-4,7diphenyl-1,10-phenanthroline, known as bathocuproine (BCP). BCP was chosen as a reference ETL due to its airstability and excellent hole-blocking ability in place of an unstable low work function metal. With a LUMO of $-2.9 \mathrm{eV}$, $\mathrm{BCP}$ is well matched for electron injection to the chosen active layer polymers, and its fairly high HOMO of $-6.5 \mathrm{eV}$ makes it a good hole blocking material, making the comparison with DC18 a confirmation of its usefulness as a novel, solution processed interfacial layer.

Table 1 summarizes typical results for our measured PLEDs, illustrating the enhancement seen in different parameters when switching to DC18. For the F8BT devices, the maximum brightness increased 3.5 times (Fig. 2A) when comparing PLEDs with a $5 \mathrm{~nm}$ BCP electron transport layer to

Table 1 Summary of the enhanced output parameters observed in the PLED structures when the ETL of the novel DC18 is compared to the standard BCP laye devices

\begin{tabular}{llllll}
\hline Active & $\begin{array}{l}\text { ETL } \\
\text { layer }\end{array}$ & $\begin{array}{l}\text { Turn on } \\
\text { voltage }(\mathrm{V})\end{array}$ & $\begin{array}{l}\text { Max } \\
\text { luminance } \\
\left(\mathrm{cd} \mathrm{m}^{-2}\right)\end{array}$ & $\begin{array}{l}\text { Max EQE } \\
(\%)\end{array}$ & $\begin{array}{l}\text { Max luminance } \\
\text { efficiency } \\
\left(\mathrm{cd} \mathrm{A}^{-1}\right)\end{array}$ \\
\hline MEH PPV & BCP & 4.0 & 89.7 & 0.012 & 0.048 \\
MEH PPV & DC18 & 3.0 & 970.7 & 0.036 & 0.142 \\
F8BT & BCP & 4.1 & 981.7 & 0.137 & 1.337 \\
F8BT & DC18 & 2.9 & 3395.1 & 0.709 & 6.899
\end{tabular}



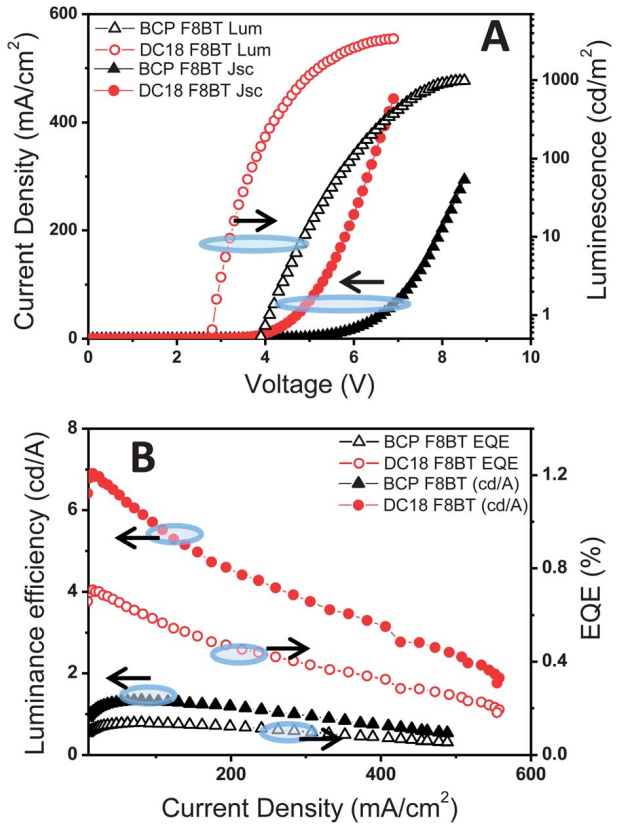

Fig. 2 (A) Current density and luminescence intensity for a F8BT PLED incorporating the reference $B C P$ and $D C 18$. (B) Luminance efficiency and EQE (\%) for the active F8BT material with the reference BCP in comparison to $D C 18$.

devices with a $20 \mathrm{~nm}$ thick DC18 layer. These devices also see full volt enhancement in their turn on voltage, defined as the voltage where luminance is $1 \mathrm{~cd} \mathrm{~m}^{-2}$, dropping from $4.1 \mathrm{~V}$ to $2.9 \mathrm{~V}$, decreasing by $25 \%$. The efficiencies for the F8BT device improved significantly with the addition of DC18, providing a five-fold improvement in both luminescence efficiency and EQE (Fig. 2B). In comparison, the MEH PPV devices have a tenfold increase in maximum brightness when switching from BCP to DC18, with an identical turn on voltage decrease (ESI $\dagger$ ). When compared to the reference, both external quantum efficiency (EQE) and luminescence efficiency for MEH PPV devices increased 3.5 times with the switch to DC18 (ESI + ). While there is no comparable literature data for NDIs as ETLs, the more than tripled improvement seen in maximum brightness and up to five-fold improvement in device efficiencies seen with DC18 are a greater improvement than previously reported for charged oligomers ${ }^{19}$ and conjugated polyelectrolytes as ETLs. ${ }^{\mathbf{8} 13}$ Indeed, our device efficiency enhancements improve on those for recently reported noncharged small molecule ETLs. ${ }^{32,33}$ All of the measured DC18 inclusive devices maintain this significant efficiency increase over BCP devices across the entire current range.

The overall brightness and efficiency of the reference devices, while not the highest reported, remain consistent with reported results using MEH PPV and F8BT in similar device structures, ${ }^{34-36}$ providing evidence that they are a reproducible testing platform for novel injection layers. The brightness and turn on voltages are improved for both active layer polymers with the inclusion of DC18, but the F8BT devices see a larger efficiency improvement compared to the MEH PPV devices. Considering this difference in enhancement, it is possible that even with the improved charge injection due to the dipole effect ${ }^{11-14}$ created by the DC18 transport layer, its efficacy with electron injection remains somewhat limited by its deep LUMO value, as the greater energy level difference for the MEHPPV/ DC18 junction $(1.5 \mathrm{eV})$, to that of the F8BT/DC18 junction $(0.7 \mathrm{eV})$ is represented by a lower device efficiency enhancement for the former. Thus it can be inferred that the large energy barrier between LUMO levels does limit electron injection, but this could be offset by an increased hole-blocking ability of DC18, with its deeper HOMO level in comparison to BCP, as well as DC18 having a higher conductivity, allowing for a thicker layer $(20 \mathrm{~nm})$ that protects the underlying active layer polymer from thermal damage during the aluminum electrode deposition. Further investigation into this charge injection barrier was examined by running the PLEDs under solar illumination.

When operated as a solar cell, the open-circuit voltage $\left(V_{\text {oc }}\right)$ of the PLED reflects the built in potential across the device. ${ }^{37}$ As only the ETL was varied in the device structures, it would be solely responsible for any measured $V_{\text {oc }}$ shift. The cells' photovoltaic response (Fig. 3) makes it clear that DC18 increases the $V_{\mathrm{oc}}$ for both polymers, from $0.38 \mathrm{~V}$ to $0.82 \mathrm{~V}$ for F8BT and from $0.92 \mathrm{~V}$ to $1.13 \mathrm{~V}$ for MEH PPV. A correlation between increased $V_{\mathrm{oc}}$ and improved PLED characteristics has been demonstrated by others, relating a higher open circuit voltage with a reduced charge injection barrier into the device. ${ }^{9}$ Additionally, other novel electron transport layers using charged materials similar to our DC18 have been shown to increase the $V_{\text {oc }}$ in solar cells. ${ }^{38}$ This is believed to be a shift of the device's built-in field as it aligns with the interfacial dipole created in the presence of the charged layer at the aluminum interface. ${ }^{39} \mathrm{~A}$ greater $V_{\mathrm{oc}}$ shift was observed for the F8BT devices compared to MEH PPV, evidence that there is a lower electron barrier for DC18 with F8BT than when combined with MEH PPV. This is further evidence that a large difference in the LUMO levels can affect

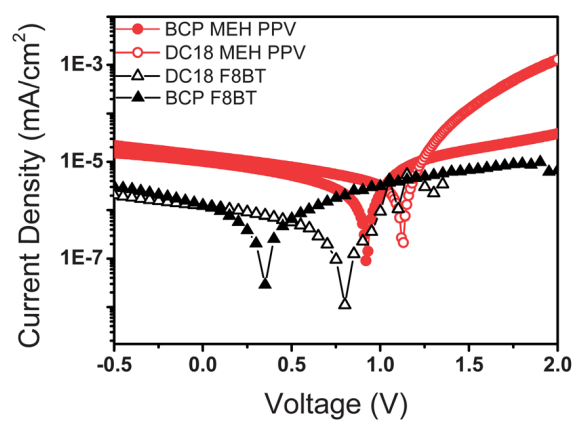

Fig. 3 Photovoltaic response curves of MEH PPV devices incorporating reference $B C P$ and DC18 (circles), and F8BT devices with reference BCP and DC18 (triangles), electron transport layers. 
DC18's function as an electron injection layer, thus a double ETL using a second material with a better matched energy level to polymers with low LUMOs would enhance efficiency even further. Double ETLs have been used to address energy level mismatch before with excellent results, ${ }^{40}$ and we are currently investigating similar methods for our material.

Tapping mode AFM was used for further examination of PLEDs with DC18 to probe if there were any surface morphology effects that could contribute to the differences between the ETLs (Fig. 4, shown for MEH PPV). The polymer surface alone has a RMS value of $0.512 \mathrm{~nm}$ and a $R_{\max }$ of $4.62 \mathrm{~nm}$, indicating a smooth surface in both topography (Fig. $4 \mathrm{~A}$ ) and phase contrast mode (Fig. 4C). In contrast, the spin cast DC18 film $(20 \mathrm{~nm})$ on top of the same polymer presents a rougher surface (Fig. 4B) with a RMS value of $0.818 \mathrm{~nm}$ and $R_{\max }$ of $10.9 \mathrm{~nm}$. While overal the DC18 film is rougher in comparison, the higher $R_{\max }$ value indicates distinct 'grains' of DC18 are the main contributor towards this roughness. These grains become more evident in the phase contrast image (Fig. 4D) with clear crystallized regions most likely of well aligned stacks of DC18. ${ }^{27}$ This order could facilitate charge transport paths through the film, and contribute to the higher device efficiencies seen for both types of PLEDs. The rougher DC18 surface could foster closer interaction with the evaporated aluminum layer as a means of further enhancing charge injection. Additionally, it is possible that there are bonds being formed between the nitrogen atoms on DC18 and the aluminum further enhancing electrical contact. $^{41}$

A visual comparison of light emission from PLEDs (Fig. 5, inset), illustrates the increased brightness when switching to DC18 as the ETL. The electroluminescence spectra (Fig. 5)
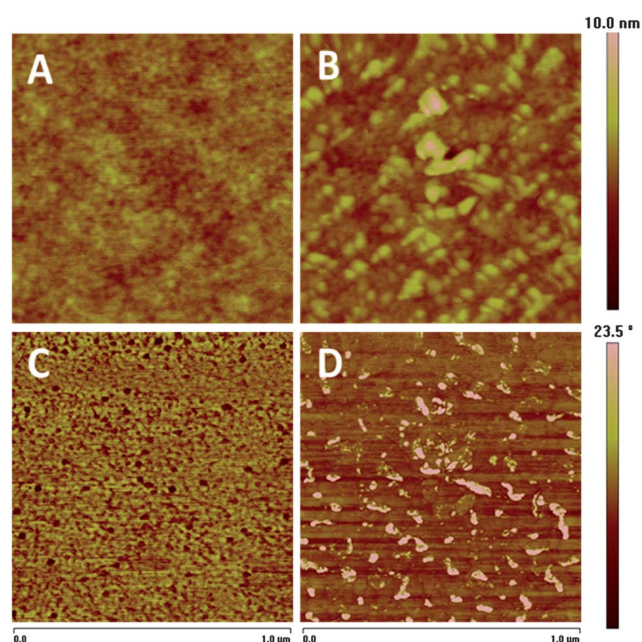

Fig. 4 AFM topography images $\left(1 \mu \mathrm{m}^{2}\right)$ of (A) a MEH PPV film, and (B) $0.5 \mathrm{mg}$ $\mathrm{mL}^{-1}$ DC18 on top of a MEH PPV film. The corresponding phase contrast images for (C) MEH PPV and (D) DC18 show the high degree of crystallization found in the DC18 film

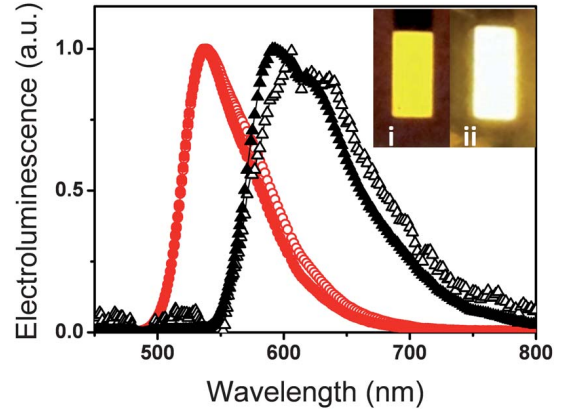

Fig. 5 Normalized EL spectra for F8BT with BCP (open red circle) and DC18 (closed red circle), and MEH PPV with BCP (open black triangle) and DC18 (closed black triangle). Inset: photos of PLEDs with BCP (i) and DC18 (ii).

remain essentially unchanged for F8BT devices (leftmost two red spectra), while MEH PPV devices (rightmost two black spectra) produce a modest hypsochromic (blue) shift with the switch to DC18. This shift seen for MEH PPV indicates that quenching of the red-edge of polymer luminescence is occurring with DC18, as hypsochromic shifts have been observed for MEH PPV films with zinc oxide nanoparticles having a similar LUMO level to DC18. ${ }^{42}$ With the large LUMO difference between MEH PPV and DC18, a greater degree of quenching is more likely, creating a larger blue shift for the MEH PPV electroluminescence. While this creates potential towards combining the materials in a solar cell, it does explain the lower efficiency enhancement seen for the MEH PPV devices, and this effect could be suppressed by a double layer ETL with better energy level matching. Work is on-going to pinpoint the exact origin of this blue shift.

\section{Experimental section}

Patterned ITO substrates (15 $\Omega \mathrm{sq}^{-1}$ ) were purchased from Luminescence Technology Corporation, and cleaned using a series of acetone and isopropanol sonications, followed by an oxygen plasma treatment ( $5 \mathrm{~min}, 100 \mathrm{~W}, 20 \mathrm{mbar}_{2}$, Emitech K1050X plasma cleaner). Poly(3,4-ethylenedioxythiophene) poly(styrenesulfonate) (PEDOT-PSS, Heraeus Clevios P VP AI 4083) was filtered $(45 \mu \mathrm{m})$, mixed in a $5: 1$ ratio with ethanol, and the $45 \mathrm{~nm}$ film was annealed for 10 minutes at $160^{\circ} \mathrm{C} .100 \mathrm{~nm}$ thick active layers were of either poly[2-methoxy-5-(2-ethylhexyloxy)1,4-phenylene vinylene] (MEH PPV, ADS100RE) in chlorobenzene, or poly[(9,9-di- $n$-octylfluorenyl-2,7-diyl)-alt-(benzo[2,1,3]thiadiazol-4,8-diyl)] (F8BT, ADS133YE) in chloroform, from American Dye Source Inc. Both solutions were filtered $(0.2 \mu \mathrm{m})$ prior to use. 2,9-Dimethyl-4,7-diphenyl-1,10-phenanthroline (BCP) from Luminescence Technology Corporation was evaporated to form a $5 \mathrm{~nm}$ thick layer. $N, N^{\prime}$-Bis(ethyl- $N^{\prime \prime}, N^{\prime \prime}, N^{\prime \prime}$ dimethyloctadecyl ammonium)-1,4,5,8-naphthalene diimide (DC18) was synthesised according to a previously described method, ${ }^{27}$ dissolved in ethanol at a $0.5 \mathrm{mg} \mathrm{mL}^{-1}$ concentration, and filtered $(0.2 \mu \mathrm{m})$ prior to spincasting to form a $20 \mathrm{~nm}$ thick 
layer. This solution was optimized from a range of concentrations, where more dilute solutions produced uneven luminescence with higher turn on voltages, and more concentrated solutions produced electrically shorted devices. All devices had $80 \mathrm{~nm}$ of aluminum evaporated through a shadow mask for pixel areas of $8 \mathrm{~mm}^{2}$. All device fabrication was performed inside a glovebox, with the exception of the HTL and DC18. PLEDs were encapsulated prior to removal from the glovebox for testing in air. Current-voltage measurements were taken using a Keithley 2400 source meter, with simultaneous luminescence data collected using a calibrated silicon photodiode. An Ocean Optics USB4000 UV-VIS fiber optic spectrometer was used fo electroluminescence spectra. AFM measurements were taken using a Veeco Dimension 3100. Solar measurements were taken using an Abet Technologies 10500 solar simulator, at AM 1.5G solar irradiation.

\section{Conclusions}

We have demonstrated the effectiveness of using an inexpensive, highly soluble charged small molecule with high electron mobility typical of naphthalene diimides, DC18, as an electron transport hole blocking layer in a well-studied polymer light emitting diode platform. In spite of the energy level differences between DC18 and the active layer materials, the inclusion of this novel ETL resulted in increased brightness, significantly higher device efficiencies and reduced turn on voltages. These enhancements are attributed to a combination of an interfacial dipole created from the charged DC18, its deep HOMO ensuring it is an improved hole-blocking layer, and effective charge injection from the aluminum cathode. The inclusion of DC18 provides up to a fivefold efficiency enhancement and has considerable potential for long term device stability. Additional research is on-going to produce double layer ETL devices to address the energy leve mismatch in the active layer material, and to combine DC18 in devices with higher stability hole transport layers as a means of further extending device lifetimes. ${ }^{43-45}$

\section{Acknowledgements}

The Advanced Technology Institute would like to acknowledge RCUK research funding and that from E-On AG. Evandro Castaldelli acknowledges support from Santander's University Global Partnership Network. The authors wish to thank Dr Eduardo R. Triboni for the synthesis of the DC18 used in this study.

\section{Notes and references}

1 A. W. Hwang, G. Xin, M. Cho, S. Cho and H. Chae, Nanoscale Res. Lett., 2012, 7, 1.

2 D. Obrien, A. Bleyer, D. Lidzey, D. Bradley and T. Tsutsui, J. Appl. Phys., 1997, 82, 2662.

3 X. Zheng, Y. Wu, R. Sun, W. Zhu, X. Jiang, Z. Zhang and S. Xu, Thin Solid Films, 2005, 478, 252.

4 Y. Cao, G. Yu, I. D. Parker and A. J. Heeger, J. Appl. Phys., $2000,88,3618$.
5 A. Inigo, S. Henley and S. Silva, Nanotechnology, 2011, 22, 265711.

6 I. Parker, Y. Cao and C. Yang, J. Appl. Phys., 1999, 85, 2441. 7 G. Heimel, L. Romaner, E. Zojer and J. L. Brédas, Nano Lett. 2007, 7, 932.

8 A. Garcia, R. C. Bakus II, P. Zalar, C. V. Hoven, J. Z. Brzezinski and T. Q. Nguyen, J. Am. Chem. Soc., 2011, 133, 2492.

9 F. Huang, Y. Zhang, M. S. Liu and A. K. Y. Jen, Adv. Funct. Mater., 2009, 19, 2457.

10 F. Huang, Y. H. Niu, Y. Zhang, J. W. Ka, M. S. Liu and A. K. Y. Jen, Adv. Mater., 2007, 19, 2010

11 J. H. Seo, R. Yang, J. Z. Brzezinski, B. Walker, G. C. Bazan and T. Q. Nguyen, Adv. Mater., 2009, 21, 1006.

12 L. Wang, B. Liang, F. Huang, J. Peng and Y. Cao, Appl. Phys. Lett., 2006, 89, 151115.

13 C. Hoven, R. Yang, A. Garcia, A. J. Heeger, T. Q. Nguyen and G. C. Bazan, J. Am. Chem. Soc., 2007, 129, 10976.

14 C. V. Hoven, J. Peet, A. Mikhailovsky and T. Q. Nguyen, Appl. Phys. Lett., 2009, 94, 033301.

15 G. Latini, L. W. Tan, F. Cacialli and S. R. P. Silva, Org. Electron., 2012, 13, 992.

16 B. W. D'Andrade, S. Datta, S. R. Forrest, P. Djurovich, E. Polikarpov and M. E. Thompson, Org. Electron., 2005, 6, 11.

17 J. Fang, B. H. Wallikewitz, F. Gao, G. Tu, C. Müller, G. Pace, R. H. Friend and W. T. S. Huck, J. Am. Chem. Soc., 2010, 133 683.

8 Y. Zhang, F. Huang, Y. Chi and A. K. Y. Jen, Adv. Mater., 2008 , 20, 1565

19 R. Yang, Y. Xu, X.-D. Dang, T.-Q. Nguyen, Y. Cao and G. C. Bazan, J. Am. Chem. Soc., 2008, 130, 3282.

20 K. C. See, C. Landis, A. Sarjeant and H. E. Katz, Chem. Mater., 2008, 20, 3609

21 L. E. Polander, S. P. Tiwari, L. Pandey, B. M. Seifried, Q. Zhang, S. Barlow, C. Risko, J. L. Brédas, B. Kippelen and S. R. Marder, Chem. Mater., 2011, 23, 3408.

22 X. Zhan, A. Facchetti, S. Barlow, T. J. Marks, M. A. Ratner, M. R. Wasielewski and S. R. Marder, Adv. Mater., 2011, 23, 268

23 R. Steyrleuthner, M. Schubert, F. Jaiser, J. C. Blakesley, Z. Chen, A. Facchetti and D. Neher, Adv. Mater., 2010, 22, 2799.

24 E. Ahmed, G. Ren, F. S. Kim, E. C. Hollenbeck and S. A. Jenekhe, Chem. Mater., 2011, 23, 4563.

25 G. Ren, E. Ahmed and S. A. Jenekhe, J. Mater. Chem., 2012, 22, 24373

26 S. V. Bhosale, C. H. Jani and S. J. Langford, Chem. Soc. Rev., 2008, 37, 331.

27 E. Castaldelli, E. R. Triboni and G. J. F. Demets, Chem. Commun., 2011, 47, 5581.

28 A. P. Kulkarni, C. J. Tonzola, A. Babel and S. A. Jenekhe, Chem. Mater., 2004, 16, 4556.

29 B. A. Jones, A. Facchetti, M. R. Wasielewski and T. J. Marks, J. Am. Chem. Soc., 2007, 129, 15259.

30 M. Misaki, Y. Ueda, S. Nagamatsu, M. Chikamatsu, Y. Yoshida, N. Tanigaki and K. Yase, Appl. Phys. Lett., 2005, 87, 243503. 
31 J. Yu, X. Tang, L. Li and Y. Jiang, J. Lumin., 2009, 129, 820. 32 Z.-Y. Liu, S.-R. Tseng, Y.-C. Chao, C.-Y. Chen, H.-F. Meng, S.-F. Horng, Y.-H. Wu and S.-H. Chen, Synth. Met., 2011, 161, 426.

33 T. Earmme, E. Ahmed and S. A. Jenekhe, Adv. Mater., 2010 22, 4744 .

34 J. S. Kim, R. H. Friend, I. Grizzi and J. H. Burroughes, Appl. Phys. Lett., 2005, 87, 023506.

35 H. Yan, B. J. Scott, Q. Huang and T. J. Marks, Adv. Mater., 2004, 16, 1948.

36 R. Singh and M. Katiyar, J. Encapsulation Adsorpt. Sci., 2012 2, 11.

37 C. J. Brabec, A. Cravino, D. Meissner, N. S. Sariciftci, T. Fromherz, M. T. Rispens, L. Sanchez and J. C. Hummelen, Adv. Funct. Mater., 2001, 11, 374.
38 C. He, C. Zhong, H. Wu, R. Yang, W. Yang, F. Huang, G. C. Bazan and Y. Cao, J. Mater. Chem., 2010, 20, 2617.

39 Z. He, C. Zhong, X. Huang, W. Y. Wong, H. Wu, L. Chen, S. Su and Y. Cao, Adv. Mater., 2011, 23, 4636.

40 J. H. Lee, P. S. Wang, H. D. Park, C. I. Wu and J. J. Kim, Org. Electron., 2011, 12, 1763.

41 X. Zhang, A. S. Shetty and S. A. Jenekhe, Macromolecules, 1999, 32, 7422

42 C. Ton-That, M. R. Phillips and T.-P. Nguyen, J. Lumin., 2008, 128, 2031.

43 S. Shi and S. R. P. Silva, Carbon, 2012, 50, 4163.

44 A. Inigo, J. Underwood and S. R. P. Silva, Carbon, 2011, 49, 4211.

45 S. Shi, V. Sadhu, R. Moubah, G. Schmerber, Q. Bao and S. R. P. Silva, J. Mater. Chem. C, 2013, 1, 1708. 


\title{
Self-assembled naphthalenediimide derivative films for light-assisted electrochemical reduction of oxygen $\dagger$
}

\author{
Evandro Castaldelli, ${ }^{a}$ Eduardo Rezende Triboni ${ }^{b}$ and Grégoire Jean-François Demets ${ }^{* a}$
}

Received 7th January 2011, Accepted 18th March 2011

DOI: $10.1039 / \mathrm{c} 1 \mathrm{cc10139k}$

This naphthalene diimide derivative, DC18, forms highly conjugated semiconducting stacked assemblies over electrodes after electrochemical conditioning. These molecular materials are very efficient towards electrochemical photoreduction of oxygen under visible light.

Naphthalimide and diimide derivatives are very promising compounds for the design of molecular materials and devices such as organic field-effect transistors, ${ }^{1}$ sensors, ${ }^{2}$ molecular junctions ${ }^{3}$ and models for photosynthesis. ${ }^{4}$ Their photophysical and electrochemical properties as well as their thermal and chemical stabilities make them suitable for the assembly of atmosphere-resistant solid state devices, which is not the case for most of the so-called "synthetic metals" and organic devices. As they form stable radical-anion species after reduction, it is possible to use them as electron acceptors in complex supramolecular structures such as photochemical diads and triads or as bulk n-type organic semiconductors. ${ }^{5-8}$ It is quite easy to change and even tune their physical and chemical properties using several functional groups. These can be bonded to their nitrogen atoms or directly to the aromatic system affecting their photophysical properties. These groups also exert a strong influence on the way these molecules aggregate, to form a variety of molecular stacks. ${ }^{9}$ In this context, 1,4,5,8-naphthalene diimides (NDIs) may be regarded as efficient and stable building blocks for photosensitive molecular materials. Their photophysical properties have been extensively investigated during the last decades, but there is still a lot to be done to understand better their electrochemistry especially under the influence of visible light, since few papers deal with this subject. ${ }^{10}$

In this work we have studied the electrochemical and photoelectrochemical behavior of a NDI derivative, $N, N^{\prime}$-(ethyl$N^{\prime \prime}, N^{\prime \prime}, N^{\prime \prime}$-dimethyloctadecane ammonium)-1,4,5,8-naphthalene

${ }^{a}$ Departamento de Quimica, Faculdade de Filosofia Ciências e Letras de Ribeirão Preto, Universidade de São Paulo,

Av. Bandeirantes 3900 CEP 14040-901, Ribeirão Preto, SP

Brazil.E-mail: greg@usp.br; Fax: +55 163602 4838;

Tel: +551636024860

${ }^{b}$ Instituto de Química, Universidade de São Paulo,

Av. Lineu Prestes 748, CEP 05508-900, São Paulo, SP, Brazil

$\dagger$ Electronic supplementary information (ESI) available: Experimental $\dagger$ Electronic supplementary information (ESI) available: Experimental
data for the synthesis and characterization of $N, N^{\prime}$-(ethyl- $N^{\prime \prime}, N^{\prime \prime}, N^{\prime \prime}$ data for the synthesis and characterization of $N, N^{\prime}$-(ethyl- $N^{\prime \prime}, N^{\prime \prime}, N^{\prime \prime}$ -
dimethyloctadecane ammonium)-1,4,5,8-naphthalene diimide bromide. See DOI: $10.1039 /$ clcc $10139 \mathrm{k}$

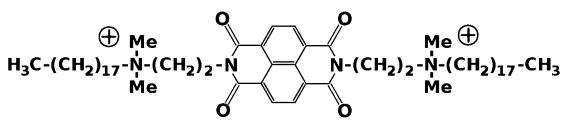

Fig. 1 Molecular structure of DC18.

diimide bromide or DC18 (Fig. 1): a nitrogen-functionalized derivative with long aliphatic chains, aiming highly selforganized structures over electrodes held together by strong solvophobic and electronic interactions. These are crucial to preserve the whole structure of the molecular material even during electrochemical swelling as well as to ensure highly reproducible electrochemical responses. DC18 films have shown high sensitivity to visible light, which was used in this work to promote biased photoreduction of oxygen.

DC18 was synthesized as a bromide and it is a cationic species. All the details of its preparation and characterization may be found in the ESI. $\dagger$ DC18 films were prepared over fluorine-doped tin oxide glass electrodes (FTO) and glassy carbon electrodes (GCEs) from $n$-heptane suspensions $\left(0.3 \mu \mathrm{L} \mathrm{cm}^{-2} ; 1 \times 10^{-3} \mathrm{~mol} \mathrm{dm}^{-3}\right)$ leading to thin, white and homogeneous films (calc. $4 \times 10^{-9} \mathrm{~mol} \mathrm{~cm}^{-2}$ ). Initial potential cycles of voltammetry for these films on GCE $(\varnothing=2 \mathrm{~mm})$ or FTO electrodes $\left(0.25 \mathrm{~cm}^{2}\right)$ revealed ill-defined voltammograms that change gradually during the cycling process (Fig. 2). Successive potential cycles (100 cycles from 0.2 to $-0.85 \mathrm{~V}$ vs. $\mathrm{Ag} / \mathrm{AgCl}$ ) lead to well-defined and intense voltammograms showing that the films suffer a conformational rearrangement. After this electrochemical conditioning, two reversible peaks become clearly visible $\left(E_{1 / 2}^{1}=-0.19 \mathrm{~V}\right.$ and $E_{1 / 2}^{2}=-0.61 \mathrm{~V} v$ s. $\mathrm{Ag} / \mathrm{AgCl}$ ) that can be assigned to the DC18 $\leftrightarrow$ DC18 $^{--}$and DC18 ${ }^{-} \leftrightarrow$ DC18 $^{2-}$ pairs, in agreement with other diimides data from the literature. ${ }^{11}$

The color of the film changes from white to red after this process which is expected from highly conjugated electron systems such as $\pi$-stacked assemblies (Fig. 3). The formation of molecular wire-type structures enhances the global bulk electrical conductivity of these materials which behave as organic semi-conductors. ${ }^{1}$ Surface AFM images reveal a turbostratic structure that was not observed before the electrochemical rearrangement (see ESI + ). The rearrangement is due to negative charge injection in the film, expelling bromine ions and neutralizing the positive charge of the sidechains, promoting a more compact film structure in which 

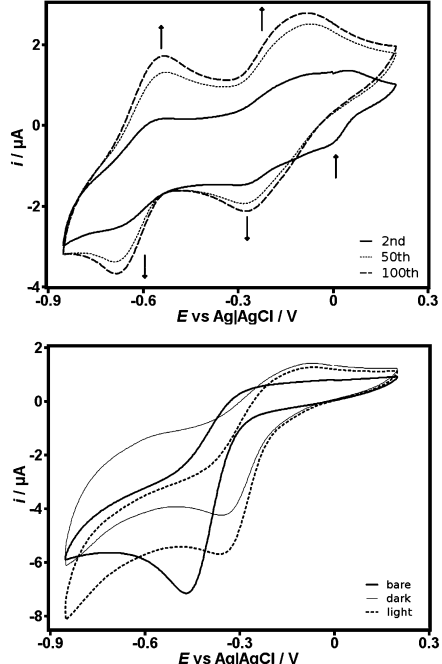

Fig. 2 Cyclic voltammograms $\left(10 \mathrm{mV} \mathrm{s}^{-1} ; 0.1 \mathrm{~mol} \mathrm{dm}^{-3} \mathrm{KCl}\right)$ recorded for a DC18 film $\left(4 \times 10^{-9} \mathrm{~mol} \mathrm{~cm}^{-2}\right)$ casted onto GCE during electrochemical conditioning in the absence of oxygen. Top: 2nd cycle (black line), 50th cycle (grey dots) and 100th cycle (black dots). Bottom: after conditioning and in the presence of $\mathrm{O}_{2}$ (sat.), in the dark (gray), under white light (dotted). The black solid line voltammogram stands for the naked electrode in the same conditions.

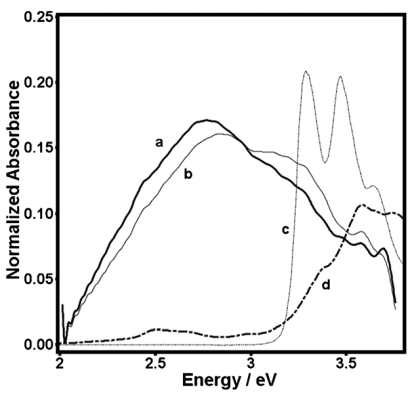

Fig. 3 Absorption spectra of (a): DC18 film at $-0.579 \mathrm{~V} v s$. $\mathrm{Ag} / \mathrm{AgCl}$, (b): $\mathbf{D C 1 8}$ film at $0.200 \mathrm{~V} v s . \mathrm{Ag} / \mathrm{AgCl}$, (c): $\mathbf{D C 1 8}^{\circ-}$ and (d): $\mathbf{D C 1 8}$ in ethanol.

aromatic cores get closer and the sidechains can maximize their interaction. ${ }^{9}$ This aggregation is confirmed by reflectance spectra, which reveal broad bands (Fig. 3a and b) and low-energy absorption edges when compared to DC18 in solution (Fig. 3c and d).

The presence of oxygen induces important changes in the electrode's behavior: the second DC18 reduction step is completely suppressed and the remaining wave becomes irreversible, indicating a quantitative electron transfer to the solution interface below $-0.3 \mathrm{~V}$. White tungsten/halogen lamp light intensifies this effect, increasing the reduction current by about $40 \%$. This fact can be explained essentially in terms of photoconduction, once no significant potential shifts are

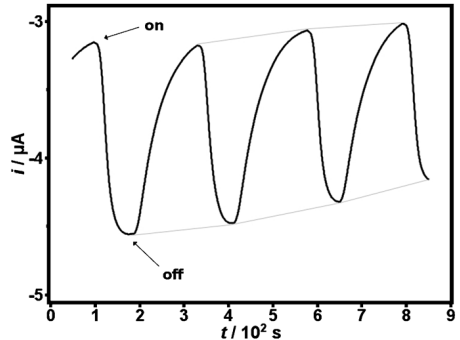

Fig. 4 Successive photochronoamperometric curves at $E=-0.67 \mathrm{~V}$ for the DC18 film (under white lamp illumination (on), and in the dark (off)) recorded in oxygen saturated water, $0.1 \mathrm{~mol} \mathrm{dm}^{-3} \mathrm{KCl}$, naked GC electrode area $A=0.031 \mathrm{~cm}^{2}$.

observed, causing only an increase in the faradaic current, which means a better electronic conduction of the film and more effective electron transfer at the interface, since interfacial oxygen concentrations are kept constant. Photochronoamperometric measurements at the reduction potential, switching the light source on and off (Fig. 4), demonstrate that the current intensity may be modulated by it with $i_{\text {on }} / i_{\text {off }}=41 \%$, and the maxima-minima behavior of such successive curves (gray lines) are a clear indication that the reduction yield is limited by oxygen interfacial concentration.

Electrochemical impedance spectroscopy (EIS) data $(\Delta E=80 \mathrm{mV} ; E=-0.23 \mathrm{~V} ; 0.1 \mathrm{~Hz}-1 \mathrm{MHz})$ can be fitted in a classic Randles circuit since the spectra are marked by depressed circles in high frequency domains followed by Warburg regions, which are diffusion controlled regions (Fig. 5). In all cases the constant phase element (CPE), which impedance is given by $Z_{\mathrm{CPE}}(\omega)=Z_{0}(j \omega)^{-\alpha}$, ranged from 4.3 to $5.6 \times 10^{-7} \mathrm{~F}$ and their exponents $(\alpha)$ were always around 0.8 , which indicates a capacitive behavior. ${ }^{12}$ In this case it is the double layer capacitance (Table 1).

The apparent electron-transfer rates may be obtained from eqn (1) below. ${ }^{13}$

$$
k_{\mathrm{et}}^{\mathrm{app}}=\frac{R T}{(n \mathrm{~F})^{2} A R_{\mathrm{ct}} C_{\infty}}
$$

where $n$ is the number of electrons involved, $A$ is the area, $C_{\infty}$ is the oxygen concentration (we have considered $1.9 \times 10^{-4} \mathrm{~mol} \mathrm{dm}^{-3}$ ) and the other symbols have their usual

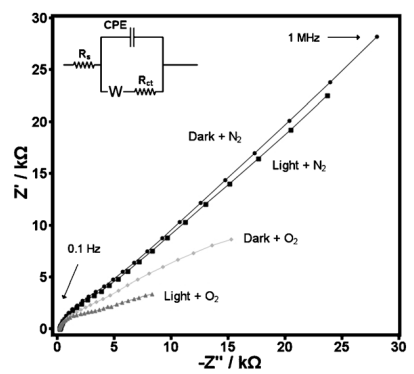

Fig. 5 EIS Nyquist plots for the films in different conditions $(\Delta E=80 \mathrm{mV}, E=-0.23 \mathrm{~V})$. Inset: the Randles circuit. 
Table 1 EIS equivalent circuit parameters

\begin{tabular}{lllcll}
\hline Condition & $R_{\mathrm{s}} / \Omega$ & $R_{\mathrm{ct}} / \mathrm{k} \Omega$ & $\omega / 10^{-5}$ & $Z_{\mathrm{CPE}} / 10^{-7}$ & $\alpha$ \\
\hline Dark $/ \mathrm{N}_{2}$ & 282 & 4.81 & 3.19 & 5.60 & 0.85 \\
Light $/ \mathrm{N}_{2}$ & 272 & 4.42 & 3.87 & 5.60 & 0.85 \\
Dark $/ \mathrm{O}_{2}$ & 283 & 5.40 & 8.55 & 5.07 & 0.78 \\
Light $/ \mathrm{O}_{2}$ & 275 & 3.83 & 19.9 & 4.36 & 0.80 \\
\hline
\end{tabular}

meanings. Using this expression for the oxygen reduction reaction one finds $8.5 \times 10^{-3} \mathrm{~cm} \mathrm{~s}^{-1}$ in the dark and $1.2 \times 10^{-3} \mathrm{~cm} \mathrm{~s}^{-1}$ under illumination. These rates are very reasonable and they increase by $41 \%$ upon illumination. The driving force of this kind of photo-induced electron transfer can be roughly modelled in terms of the Rehm-Weller expression (eqn (2)), in which $E_{00}$ is the energy of the singlet $(0,0)$ transition observed (Fig. 3b) and the last term is the solvent effect, and this influence is negligible in polar solvents like water. $^{14-16}$

$$
\Delta G_{\mathrm{et}}^{0}=E^{0}\left(\mathrm{DC} 18^{\bullet-} / \mathrm{DC} 18\right)-E^{0}\left(\mathrm{O}_{2} / \mathrm{O}_{2}^{-}\right)-E_{00}-\frac{Z e^{2}}{\varepsilon_{\mathrm{s}}}
$$

The Gibbs free energy calculated for this process is $\Delta G_{\mathrm{et}}^{0}=-2.8 \mathrm{eV}$, a very strongly favored reaction.

In summary, we were able to chemically modify FTO and glassy carbon electrodes with a 1,4,5,8-naphthalene diimide derivative producing air-stable, conductive and photosensitive electrodes which can electrocatalyse the oxygen reduction reaction upon irradiation of visible light. AFM and SEM images indicate a homogeneous lamellar structure and spectra data indicate the formation of a $\pi$ extended system. The creation of $\mathbf{D C}^{-\mathbf{0}^{-}}$radicals, after the first reduction potential, lowers the optical absorption edge of the solid, due to the creation of SOMO levels in the band gap, corresponding to the formation of a n-type semiconductor. This energy reduction makes exciton formation upon illumination easier.
These excitons are driven to the interfacial region where electrons are readily captured by $\mathrm{O}_{2}$ molecules. Charge compensation forces electrons to flow from the electrode to the bulk material. In spite of the strongly favored electron-transfer process, DC18 films are still somehow resistive and this, allied to bulky bromine anions, limits the whole process. Monolayers and small counter-anions should enhance even more the photo-induced electron transfer reaction for this system.

The authors warmly thank Prof. Mario José Politi, for his precious help and CAPES for financial support.

\section{Notes and references}

1 D. Shukla, S. Nelson, D. Freeman, M. Rajeswaran, W. Ahearn, D. Meyer and J. Carey, Chem. Mater., 2008, 20, 7486-7491.

2 G.-F. Demets, E. Triboni, E. Alvarez, G. Arantes, P. Berci Fo and M. Politi, Spectrochim. Acta, Part A, 2006, 63, 220-226.

3 N. Sakai, J. Mareda, E. Vauthey and S. Matile, Chem. Commun. 2010, 46, 4225-4237.

4 S. Langford, M. Latter and C. Woodward, Photochem. Photobiol., 2006, 82, 1530-1540

5 B. A. Jones, M. R. Wasielewski and T. J. Marks, J. Am. Chem. Soc., 2007, 129, 15259-15278.

6 S. Freilich, Macromolecules, 1987, 20, 973-978.

7 Y. Che, A. Datar, K. Balakrishnan and L. Zang, J. Am. Chem. Soc., 2007, 129, 7234-7235.

8 T. Kudo, M. Kimura, K. Hanabusa and H. Shirai, J. Porphyrins Phthalocyanines, 1998, 2, 231-235.

9 C. J. Zhong, W. S. V. Kwan and L. L. Miller, Chem. Mater., 1992, 4, 1423-1428

10 J. Danziger, J.-P. Dodelet and N. Armstrong, Chem. Mater., 1991, 3, $812-820$

11 D. Gosztola, M. Niemczyk, W. Svec, A. Lukas and M. Wasielewski, J. Phys. Chem. A, 2000, 104, 6545-6551.

12 Z. Gao, Y. Zhang and G. Wang, Anal. Sci., 1998, 14, 1053-1058. 13 A. M. Oliveira-Brett, L. A. da Silva and C. M. A. Brett, Langmuir, 2002, 18, 2326-2330

14 Y. Kureishi, H. Shiraishi and H. Tamiaki, J. Electroanal. Chem. 2001, 496, 13-20.

15 N. Oda, K. Tsuji and A. Ichimura, Anal. Sci., 2001, 17, i375-i377.

16 W. Zhang, Y. Shi, L. Gan, C. Huang, H. Luo, D. Wu and N. Li,

J. Phys. Chem. B, 1999, 103, 675-681. 


\section{A7. Súmula curricular}

\section{Evandro Castaldelli}

Graduado em Bacharelado em Química com Atribuições Tecnológicas pela Universidade de São Paulo (2008). Possui Mestrado também pela USP-RP e é doutorando na área de Química na mesma instituição. Tem interesse em estudos fotofísicos e fotoeletroquímicos de compostos orgânicos e redes de coordenação híbridas, principalmente as naftaleno diimidas e os MOFs que as contém, bem como dispositivos do estado sólido, como células solares e sensores.

\section{Formação}

2014-2015 Estágio do tipo BEPE, durante o Doutorado, na University of Surrey. Título: "Electronic devices based on metal-organic frameworks bearing aromatic diimides as ligands". Orientador: S. Ravi P. Silva. Bolsa FAPESP 2012/09719-5.

2011-atual Doutorado em Química pela FFCLRP/Universidade de São Paulo. Título: "Polímeros de coordenação à base de cobalto(II) e $N, N^{\prime}$-bis(4-piridil)-1,4,5,8-naftaleno diimida como ligante e suas propriedades estruturais, espectroscópicas e fotoelétricas". Orientador: Grégoire Jean-François Demets. Bolsa FAPESP 2011/22379-6.

2011 Estágio, durante o Mestrado, na University of Surrey, orientado por S. Ravi P. Silva. Bolsa de estudos Prêmio de Mobilidade Santander.

2009-2011 Mestrado em Química pela FFCLRP/Universidade de São Paulo. Dissertação: "Fotoeletroquímica de naftaleno diimidas - eletrocatálise fotoassistida e dispositivos eletrônicos". Orientador: Grégoire Jean-François Demets. Bolsista CAPES.

2005-2008 Graduação em Química com Atribuições Tecnológicas pela FFCLRP/Universidade de São Paulo. 


\section{Atividades}

2007 Monitoria voluntária de Química Geral para o curso de Bacharelado em Química da FFCLRP/USP. Professor responsável: Glaico Chiericato Júnior.

2008 Monitoria voluntária de Química Geral para o curso de Bacharelado em Química da FFCLRP/USP. Professor responsável: Glaico Chiericato Júnior.

2010 Monitoria através do Programa PAE de Química Analítica I para o curso de Bacharelado em Química da FFCLRP/USP. Professora responsável: Marilda das Dores Assis

2011 Monitoria através do Programa PAE de Química Inorgânica Experimental I para o curso de Bacharelado em Química da FFCLRP/USP. Professor responsável: Elia Tfouni

2012 Monitoria através do Programa PAE de Química Analítica II para o curso de Bacharelado em Química da FFCLRP/USP. Professora responsável: Marilda das Dores Assis

\section{Produção bibliográfica}

- L. J. Rozanski, E. Castaldelli, F. L. M. Sam, C. A. Mills, G. J.-F. Demets e S. R. P. Silva, J. Mater. Chem. C, 2013, 1, 3347-3352.

- E. Castaldelli, E. R. Triboni e G. J.-F. Demets, Chem. Commun., 2011, 47, 5581-5583.

\section{Participação em eventos e reuniões científicas}

- XIV Encontro da Sociedade Brasileira de Pesquisa em Materiais, 2015, "MOF for light-harvesting devices: a spectroscopic investigation". Rio de Janeiro, Brasil.

- IV International Conference on Multifunctional, Hybrid and Nanomaterials, 2015, "Semiconducting metal-organic framework for optoelectronic devices". Sitges, Barcelona, Espanha.

- $35^{a}$ Reunião Anual da Sociedade Brasileira de Química, 2012, "Aprimoramento de PLEDs utilizando 1,4,5,8-naftaleno diimidas". Águas de Lindóia, Brasil.

- XVI Brazilian Meeting on Inorganic Chemistry, 2012, "Metal-Organic Framework Bearing Naphthalene Diimides". Florianópolis, Brasil.

- IX Encontro da Sociedade Brasileira de Pesquisa em Materiais, 2010, "Photoconduction and Electrocatalysis in a Naphthalene Diimide Derivative Film Towards Oxygen Reduction". Ouro Preto, Brasil. 


\section{Supervisões}

- Camila Parizzi, "Estudo de junções orgânicas semicondutoras", 2015. Trabalho de Conclusão de Curso. Graduação em Química - Universidade de São Paulo.

- Victor Chadud Costacurta, "Síntese e aplicação de nanopartículas de carbono luminescentes e de ferritas magnéticas", 2013. Iniciação científica (Graduando em Química) - Universidade de São Paulo, bolsista FAPESP.

- Ayla Robera Borges da Silva Galaço, "Síntese e aplicação de nanopartículas de azul da Prússia", 2012. Iniciação científica (Graduanda em Química) - Universidade de São Paulo, bolsista CNPq.

- Jérémy Lelong, "Nanoparticules de carbone, d'argent et de magnétite", 2012. Trabalho de Conclusão de Curso, Universidade de São Paulo.

- Diego Teixeira Baptista, "Nanopartículas luminescentes de carbono e magnéticas de ferro", 2011. Trabalho de Conclusão de Curso. Graduação em Química com Atribuições em Biotecnologia Universidade de São Paulo. 


\section{A8. Índice remissivo}

Acoplamento

fonônico, 58, 59

orbital, 59

spin-órbita, 64, 65

spin-spin, 27, 29

vibrônico, 35, 37, 39

Agregado, 9, 38, 58

Band-gap, 41, 62

Catálise, 3, 6

Coeficiente de absortividade molar, 35, 37, 61

Condutividade

anisotropia de, 66

aumento de, 68, 69

diminuição de, 68, 69

elétrica, 66, 67

histerese de, 66

limitação de, 69, 72

mecanismo de, 69, 72

Cruzamento intersistema, 64, 65

Dobramento simétrico, 53

Eletrocatálise, 11

Eletrodo

arranjo de, 5, 40

auxiliar, 55

de trabalho, 55

modificado, 12

pseudo-referência, 40

Enantiosseletivo, 3

Estiramento

assimétrico, 53

simétrico, 53

Excímero, 9, 39

Fotorresistividade, 68

Hipsocrômico, 64, 65

Isolante, 6, 66

Laporte, 35, 61

Lei de Ohm, 67
LMCT, veja Transferência LMCT

Microeletrodo de cavidade, 55

MLCT, veja Transferência MLCT

MOF-CoNDI-py-1, 42

MOF-CoNDI-py-2, 43, 44, 46, 49, 51, 55-62, 64, 66, 72

NDI-py, 27, 31, 32, 34-38, 40, 42, 46, 49, 51-54, 56, 58-61, 63-65, 68

Nefelauxético, 60

Quiralidade, 3

Racah, parâmetro de, 60

Redox

atividade, 6, 15

par, 56

processo, 56

Representação simétrica, 61

Resistência, 67

Resistividade, 67

Russell-Saunders, 62

SCE, 56

Semicondutor, 66, 68, 72

Sigmoidal, 66, 67

Stokes, deslocamento de, 38, 39

Transferência

de carga, 9, 59, 61, 68, 69

eletrônica, 12

fotoinduzida, 9

LMCT, 69

MLCT, 59-61, 68

Transição

$\pi-\pi, 35,37$

$d-d, 59-63$

eletrônica, 37, 59

HOMO-LUMO, 35, 36, 58

proibida, 35, 61

vibrônica, 58, 59

Unidade assimétrica, 46 


\section{A9. Propriedades dos reagentes utilizados}

Aqui são apresentadas algumas propriedades dos reagentes utilizados. As informações foram retiradas do site da Sigma-Aldrich (www.sigmaaldrich.com) em 08/11/2015.

\section{Acetonitrila}

Estado Físico $\left(25^{\circ} \mathrm{C}\right)$ : Líquido

Cor: Incolor

$\mathrm{MM}=41,05 \mathrm{~g} \mathrm{~mol}^{-1}$
Densidade: $0,786 \mathrm{~g} \mathrm{~cm}^{-3}$ a $25^{\circ} \mathrm{C}$

Ponto de Fusão: $-48^{\circ} \mathrm{C}$

Ponto de Ebulição: $81^{\circ} \mathrm{C}$

Altamente inflamável. Irritante. Tóxico. Produtos de combustão ou decomposição podem gerar cianeto. Irritante. Extremamente tóxico a organismos aquáticos.

\begin{tabular}{|c|c|}
\hline \multicolumn{2}{|c|}{ Ácido Nítrico } \\
\hline $\begin{array}{l}\text { Estado Físico }\left(25^{\circ} \mathrm{C}\right) \text { : Líquido } \\
\text { Cor: Incolor } \\
\mathrm{MM}=63,01 \mathrm{~g} \mathrm{~mol}^{-1}\end{array}$ & $\begin{array}{l}\text { Densidade: } 1,413 \mathrm{~g} \mathrm{~cm}^{-3} \text { a } 20{ }^{\circ} \mathrm{C} \\
\text { Ponto de Fusão: não disponível } \\
\text { Ponto de Ebulição: } 120,5^{\circ} \mathrm{C}\end{array}$ \\
\hline \multicolumn{2}{|c|}{ Irritante. Comburente. Pode causar sérios danos à saúde. } \\
\hline
\end{tabular}

\section{Ácido Trifluoroacético}

Estado Físico $\left(25^{\circ} \mathrm{C}\right)$ : Líquido

Cor: Incolor

$\mathrm{MM}=114,02 \mathrm{~g} \mathrm{~mol}^{-1}$
Densidade: $1,489 \mathrm{~g} \mathrm{~cm}^{-3}$ a $20{ }^{\circ} \mathrm{C}$

Ponto de Fusão: $-15,4^{\circ} \mathrm{C}$

Ponto de Ebulição: $72,4^{\circ} \mathrm{C}$

Altamente Irritante. Tóxico por inalação. Tóxico para o ambiente aquático. Pode causar sérios danos à saúde.

\section{Ácido Tereftálico}

Estado Físico $\left(25^{\circ} \mathrm{C}\right)$ : Sólido

Cor: Branco

$\mathrm{MM}=166,13 \mathrm{~g} \mathrm{~mol}^{-1}$
Densidade: $1,58 \mathrm{~g} \mathrm{~cm}^{-3}$ a $25{ }^{\circ} \mathrm{C}$

Ponto de Fusão: $>300^{\circ} \mathrm{C}$

Ponto de Ebulição: não disponível

Toxicidade aguda por contato com a pele. 


\section{4-Aminopiridina}

Estado Físico $\left(25^{\circ} \mathrm{C}\right)$ : Sólido

Cor: Bege

$\mathrm{MM}=94,11 \mathrm{~g} \mathrm{~mol}^{-1}$
Densidade: não disponível Ponto de Fusão: $155-158{ }^{\circ} \mathrm{C}$

Ponto de Ebulição: $273^{\circ} \mathrm{C}$

Toxicidade aguda por ingestão. Irritante. Tóxico para o ambiente aquático. Toxicidade aguda para órgãos específicos.

\section{Dianidrido 1,4,5,8-naftálico}

Estado Físico $\left(25^{\circ} \mathrm{C}\right)$ : Sólido

Cor: Bege

$\mathrm{MM}=268,18 \mathrm{~g} \mathrm{~mol}^{-1}$
Densidade: não disponível

Ponto de Fusão: $>300^{\circ} \mathrm{C}$

Ponto de Ebulição: não disponível

Irritante para pele, olhos e sistema respiratório.

\section{$N, N$-Dimetilformamida}

Estado Físico $\left(25^{\circ} \mathrm{C}\right)$ : Líquido

Cor: Incolor

$\mathrm{MM}=73,09 \mathrm{~g} \mathrm{~mol}^{-1}$
Densidade: $0,948 \mathrm{~g} \mathrm{~cm}^{-3}$ a $25^{\circ} \mathrm{C}$

Ponto de Fusão: $-61^{\circ} \mathrm{C}$

Ponto de Ebulição: $153^{\circ} \mathrm{C}$

Inflamável. Irritante. Altamente tóxico por via aérea, cutânea e ingestão. Toxicidade reprodutiva.

\begin{tabular}{|ll|}
\hline & \multicolumn{1}{c}{ Etanol } \\
\hline Estado Físico $\left(25^{\circ} \mathrm{C}\right)$ : Líquido & Densidade: $0,79 \mathrm{~g} \mathrm{~cm}^{-3}$ a $25{ }^{\circ} \mathrm{C}$ \\
Cor: Incolor & Ponto de Fusão: $-144^{\circ} \mathrm{C}$ \\
$\mathrm{MM}=46,07 \mathrm{~g} \mathrm{~mol}^{-1}$ & Ponto de Ebulição: $78{ }^{\circ} \mathrm{C}$ \\
& \\
& Tóxico ao sistema nervoso central. \\
\hline
\end{tabular}

\section{Éter Etílico}

Estado Físico $\left(25^{\circ} \mathrm{C}\right)$ : Líquido

Cor: Incolor

$\mathrm{MM}=74,12 \mathrm{~g} \mathrm{~mol}^{-1}$
Densidade: $0,71 \mathrm{~g} \mathrm{~cm}^{-3}$ a $20{ }^{\circ} \mathrm{C}$

Ponto de Fusão: $-116^{\circ} \mathrm{C}$

Ponto de Ebulição: $34,6^{\circ} \mathrm{C}$

Altamente inflamável. Toxicidade aguda por inalação e ingestão. Toxicidade aguda para órgãos específicos.

\section{Ferroceno}

Estado Físico $\left(25^{\circ} \mathrm{C}\right)$ : Sólido

Cor: Laranja

$\mathrm{MM}=186,03 \mathrm{~g} \mathrm{~mol}^{-1}$
Densidade: não disponível

Ponto de Fusão: $172-174^{\circ} \mathrm{C}$

Ponto de Ebulição: $249^{\circ} \mathrm{C}$ 
Hexafluorofosfato de Tetrabutilamônio

Estado Físico $\left(25^{\circ} \mathrm{C}\right)$ : Sólido

Cor: Branco

$\mathrm{MM}=387,43 \mathrm{~g} \mathrm{~mol}^{-1}$
Densidade: não disponível Ponto de Fusão: $244-246{ }^{\circ} \mathrm{C}$

Ponto de Ebulição: não disponível

Irritante. Toxicidade aguda para órgãos específicos.

Imidazol

Estado Físico $\left(25^{\circ} \mathrm{C}\right)$ : Sólido

Cor: Branco

$\mathrm{MM}=68,08 \mathrm{~g} \mathrm{~mol}^{-1}$
Densidade: $1,03 \mathrm{~g} \mathrm{~cm}^{-3}$ a $20^{\circ} \mathrm{C}$

Ponto de Fusão: $88-91^{\circ} \mathrm{C}$

Ponto de Ebulição: $256{ }^{\circ} \mathrm{C}$

Toxicidade aguda por ingestão. Corrosivo em contato com a pele. Lesões oculares graves. Toxicidade reprodutiva.

\section{Nitrato de Cobalto(II) Hexahidratado}

Estado Físico $\left(25^{\circ} \mathrm{C}\right)$ : Sólido

Cor: Vermelho

$\mathrm{MM}=291,03 \mathrm{~g} \mathrm{~mol}^{-1}$
Densidade: $1,88 \mathrm{~g} \mathrm{~cm}^{-3}$ a $20^{\circ} \mathrm{C}$

Ponto de Fusão: $55^{\circ} \mathrm{C}$

Ponto de Ebulição: não disponível

Sólido comburente. Toxicidade aguda por ingestão. Mutagênico. Carcinogênico. Toxicidade reprodutiva. Tóxico para o ambiente aquático. 